William T. Ziemba

University of British Columbia and Oxford University

\title{
The Stochastic \\ Programming Approach \\ to Asset, Liability, and \\ Wealth Management
}

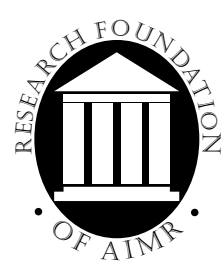

The Research Foundation of AIMR ${ }^{\mathrm{TM}}$ 


\section{Research Foundation Publications}

Anomalies and Efficient Portfolio Formation by S.P. Kothari and Jay Shanken

Benchmarks and Investment Management by Laurence B. Siegel

The Closed-End Fund Discount

by Elroy Dimson and Carolina Minio-Paluello

Common Determinants of Liquidity and Trading

by Tarun Chordia, Richard Roll, and Avanidhar Subrahmanyam

Company Performance and Measures of Value Added

by Pamela P. Peterson, CFA, and David R. Peterson

Controlling Misfit Risk in Multiple-Manager Investment Programs

by Jeffery V. Bailey, CFA, and David E. Tierney

Country Risk in Global Financial Management

by Claude B. Erb, CFA, Campbell R. Harvey, and Tadas E. Viskanta

Country, Sector, and Company Factors in Global Equity Portfolios

by Peter J.B. Hopkins and C. Hayes Miller, CFA

Currency Management: Concepts and Practices

by Roger G. Clarke and Mark P. Kritzman, CFA

Earnings: Measurement, Disclosure, and the Impact on Equity Valuation

by D. Eric Hirst and Patrick E. Hopkins

Economic Foundations of Capital Market Returns by Brian D. Singer, CFA, and

Kevin Terhaar, CFA

Emerging Stock Markets: Risk, Return, and Performance

by Christopher B. Barry, John W. Peavy III, CFA, and Mauricio Rodriguez

Franchise Value and the Price/Earnings Ratio by Martin L. Leibowitz and Stanley Kogelman

The Franchise Value Approach to the Leveraged Company

by Martin L. Leibowitz

Global Asset Management and Performance Attribution

by Denis S. Karnosky and Brian D. Singer, CFA
Interest Rate and Currency Swaps: A Tutorial by Keith C. Brown, CFA, and Donald J. Smith

Interest Rate Modeling and the Risk Premiums in Interest Rate Swaps

by Robert Brooks, CFA

The International Equity Commitment

by Stephen A. Gorman, CFA

Investment Styles, Market Anomalies, and Global Stock Selection

by Richard O. Michaud

Long-Range Forecasting

by William S. Gray, CFA

Managed Futures and Their Role in Investment Portfolios

by Don M. Chance, CFA

Options and Futures: A Tutorial

by Roger G. Clarke

Real Options and Investment Valuation

by Don M. Chance, CFA, and

Pamela P. Peterson, CFA

Risk Management, Derivatives, and Financial Analysis under SFAS No. 133

by Gary L. Gastineau, Donald J. Smith, and Rebecca Todd, CFA

The Role of Monetary Policy in Investment Management

by Gerald R. Jensen, Robert R. Johnson, CFA, and Jeffrey M. Mercer

Sales-Driven Franchise Value

by Martin L. Leibowitz

Term-Structure Models Using Binomial Trees

by Gerald W. Buetow, Jr., CFA, and

James Sochacki

Time Diversification Revisited

by William Reichenstein, CFA, and

Dovalee Dorsett

The Welfare Effects of Soft Dollar Brokerage:

Law and Ecomonics

by Stephen M. Horan, CFA, and

D. Bruce Johnsen 


\section{The Stochastic}

Programming Approach

to Asset, Liability, and

Wealth Management 
The Research Foundation of The Association for Investment Management and Research ${ }^{\mathrm{TM}}$, the Research Foundation of $\mathrm{AIMR}^{\mathrm{TM}}$, and the Research Foundation logo are trademarks owned by the Research Foundation of the Association for Investment Management and Research. CFA ${ }^{\circledR}$, Chartered Financial Analyst ${ }^{\circledR}$, AIMR-PPS $^{\circledR}$, and GIPS ${ }^{\circledR}$ are just a few of the trademarks owned by the Association for Investment Management and Research. To view a list of the Association for Investment Management and Research's trademarks and a Guide for the Use of AIMR's Marks, please visit our website at www.aimr.org.

(C) 2003 The Research Foundation of the Association for Investment Management and Research

All rights reserved. No part of this publication may be reproduced, stored in a retrieval system, or transmitted, in any form or by any means, electronic, mechanical, photocopying, recording, or otherwise, without the prior written permission of the copyright holder.

This publication is designed to provide accurate and authoritative information in regard to the subject matter covered. It is sold with the understanding that the publisher is not engaged in rendering legal, accounting, or other professional service. If legal advice or other expert assistance is required, the services of a competent professional should be sought.

ISBN 0-943205-65-4

Printed in the United States of America

December 5, 2003

\section{Editorial Staff}

Rebecca L. Bowman

Book Editor

Sophia E. Battaglia

Assistant Editor
Kara H. Morris

Production Manager

Kelly T. Bruton/Lois A. Carrier

Composition and Production 


\section{Mission}

The Research Foundation's mission is to encourage education for investment practitioners worldwide and to fund, publish, and distribute relevant research. 


\section{Biography}

William T. Ziemba is Alumni Professor of Financial Modeling and Stochastic Optimization at the Sauder School of Business, University of British Columbia, where he has taught since 1968, and Nomura Visiting Senior Research Fellow in Financial Mathematics at Oxford University. He has been a visiting professor at the University of Chicago, Stanford University, the University of California at Berkeley, the University of California at Los Angeles, the London School of Economics, Cambridge University, the National University of Singapore, University of Bergamo, and University of Zurich and a consultant to a number of leading financial institutions, including the Frank Russell Company and Morgan Stanley. Professor Ziemba has also worked as a futures and equity trader and a hedge fund and investment manager since 1983 . His research has focused on asset/liability management, portfolio theory and practice, security market imperfections, Japanese and Asian financial markets, hedge funds, sports and lottery investments, and applied stochastic programming.

Professor Ziemba is the author or co-author of many articles and books, including Stochastic Programming: State of the Art 1998, Worldwide Asset and Liability Modeling, and Research in Stochastic Programming. Other recent books are Security Market Imperfections in Worldwide Equity Markets and Applications of Stochastic Programming. His articles have been published in journals such as Operations Research, Management Science, American Economic Review, Journal of Economic Perspectives, Economics Letters, Journal of Finance, Mathematical Finance, Financial Analysts Journal, Journal of Portfolio Management, Journal of Economic Dynamics and Control, and Interfaces. (For details of his publications, see his website, homepage.mac.com/wtzimi/index.htm.) He is the series editor for North Holland's Handbooks in Finance (see www.elsevier.com/homepage/sae/ $\mathrm{hf} / \mathrm{menu} . \mathrm{htm}$ ) and a regular columnist for Wilmott, a London-based institutional investor magazine. From 1982 to 1992, he was the department of finance editor of Management Science. Professor Ziemba's co-written practitioner paper on the Russell-Yasuda Kasai model won second prize in the 1993 Edelman Practice of Management Science Competition. He earned a $\mathrm{PhD}$ from the University of California at Berkeley. 


\section{Contents}

Dedication $\ldots \ldots \ldots \ldots \ldots \ldots \ldots \ldots \ldots \ldots \ldots \ldots \ldots$, viii

Acknowledgements........................ ix

Foreword $\ldots \ldots \ldots \ldots \ldots \ldots \ldots \ldots \ldots \ldots \ldots \ldots \ldots \ldots \ldots \ldots, \quad$ xi

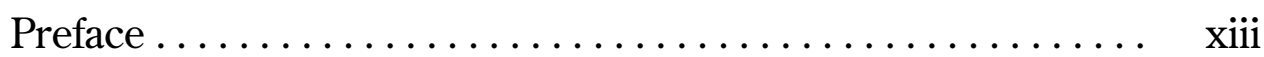

Chapter 1. The Fundamentals of Asset Allocation......... 1

Chapter 2. The Stochastic Programming Approach to Asset/Liability Management.............. 23

Chapter 3. Insurance Company Applications . . . . . . . . . 73

Chapter 4. Pension Fund Applications .............. 94

Chapter 5. Individual Asset/Liability Planning Models...... 130

Chapter 6. Hedge Fund Applications................ 142

Chapter 7. The Top 10 Points to Remember........... 177

References............................... 180 


\section{Dedication}

This Research Foundation monograph is dedicated to the memory of my two most admired purists whose work has stood the test of time against the critics-Theodore Samuel Williams, baseball player and fisherman, and Merton H. Miller, finance theorist, financial market colleague, and professional keynote speaker; to Chris Hensel, my late Frank Russell colleague, and Teppo Martikainen, my late University of Helsinki colleague, both of whom were most supportive of our joint work on anomalies and portfolio management and the stochastic programming work discussed in this monograph; and to my late UBC colleague Shelby Brumelle, who was always supportive of my work in financial markets and stochastic programming. 


\section{Acknowledgments}

Special thanks go to the Research Foundation of AIMR for financial support for the research and writing of this monograph, which combines many of the institutional investor lectures that I have presented over the past 10+ years. Thanks also go to the organizers and participants of the Frank Russell Consulting Client Conference; Decision Analysis Investment Systems (DAIS) Group, New York; Berkeley Program in Finance; Pacific Investment Management Company; Yamaichi Securities; San Francisco Institute of Chartered Financial Analysts Quantitative Investment Program; Swiss Institute of Banking, St. Gallen; Mexican Bolza; Chicago Board of Trade; University of Bergamo Financier Association, Turin; Isaac Newton Institute, Cambridge University; Den Norske Dataforening, Oslo; University of British Columbia (UBC) Faculty Association; Charles University; UBC Global Investment Conference, Lake Louise; UNICOM, London; Bendheim Center for Finance, Princeton University; Portfolioakatemia Investment Management Seminar Helsinki; Euro Plus, Dublin; Uni Credit, Milan; Centre for Financial Engineering, National University of Singapore; Helsinki School of Economics; Hermes Centre of Excellence in Computational Finance, University of Cyprus; International Institute for Applied Systems Analysis, Austria; Nomura Centre for Quantitative Finance at the Mathematical Institute, Oxford University; Arrowstreet Capital Client Conference; and many other academic conferences and universities around the world for help in encouraging and developing my ideas.

The ideas in this monograph are the intersection of my theoretical and applied work on stochastic programming and portfolio theory, my consulting and money management activities, and my interest in various types of investments and gambling. My stochastic programming colleagues Roger Wets, Chanaka Edirisinghe, Markus Rudolf, Stavros Zenios, John Mulvey, Stein Wallace, Michael Dempster, Karl Frauendorfer, Alan King, Jitka Dupačovà, John Birge, Marida Bertocchi, Rita D'Eclessia, Alexei Gavaronski, Julie Higle, Suvrajeet Sen, Georg Pflug, Hercules Vladimirou, Leonard MacLean, Roy Kouwenberg, Andrea Consiglio, Gautam Mitra, Yonggan Zhao and Horand Gassmann have all made contributions to asset/liability management and have encouraged me in my work. My nine years as a consultant to the Frank Russell Company gave me an applied setting at the highest level to develop and expand my ideas. Thanks go to my former colleagues there, Chris Hensel, Andy Turner, David Cariño, David Myers, and Doug Stone. Thanks also go to the members of my 1974 course on stochastic programming at UBC, where this monograph started to develop in a serious way, especially Martin Kusy 
and Jerry Kallberg, who co-wrote key papers with me. My intellectual debt to asset/liability management pioneers Kenneth Arrow, Harry Markowitz, Robert Merton, Bill Sharpe, Paul Samuelson, John Campbell, Robert Shiller, and others is evident throughout the text. Thanks also go to colleagues Kaifeng Chen, Stewart Hodges, Daniel Jones, Joachim Loebb, and Robert Tompkins for comments on an earlier version of the manuscript. Special thanks also go to my NumerikaALM and Operational Research Systems colleagues Pier Riva, Reno Oberto, $\mathrm{Al}$ Hynd and Giorgio Consigli. The manuscript was completed at the Nomura Centre for Quantitative Finance at the Mathematical Institute, Oxford University. Thanks are due to Dr. Sam Howison, the director, for his generous hospitality and to Keith Gillow, Sara Jolliffe, and Angela Howard for their help with this project. Thanks also go to Master Roger Ainsworth, John Ockendon, and the other fellows, staff, and friends of St. Catherine's College for their gracious hospitality during my stay as a Christensen visiting fellow. Finally, special thanks go to my wife Sandra Schwartz for encouragement, many discussions, and the production of the manuscript.

W.T.Z.

Vancouver, British Columbia, Canada Oxford, United Kingdom May 2003 


\section{Foreword}

The recent confluence of low interest rates and substandard capital market performance has strained institutions that manage assets for the purpose of funding liabilities, namely, pension funds, endowment funds, and charitable foundations. Individuals as well have found the recent investment climate especially challenging as they strive to meet ongoing financial obligations while accumulating sufficient capital to ensure a comfortable retirement. These trying times have led many financial analysts to question several timehonored beliefs, including the reliability of the equity risk premium and the suitability of policy portfolios. William Ziemba's excellent monograph is, therefore, a timely and welcome contribution to the literature on asset, liability, and wealth management.

Ziemba begins with a concise and accessible explication of mean-variance analysis, utility maximization, and capital asset pricing. This chapter provides the theoretical foundation for the standard tools used by most financial analysts to form portfolios. The remainder of the monograph departs from the static world of mean-variance analysis and introduces us to the dynamic world of stochastic programming.

Ziemba motivates this transition to dynamic programming by first demonstrating that the real world is far different from the theoretical world of mean-variance analysis. For example, he recounts many of the extreme events that have recently plagued the capital markets as evidence that return distributions tend not toward normality but rather toward fat tails. He also shows that correlations seem to be scenario dependent; hence, they offer less diversification during stressful markets than typically assumed. In addition, he discusses certain time-series dynamics of returns, such as mean reversion, as well as certain time-series dynamics of volatility, such as clustering. He then introduces stochastic programming and shows why it is more suitable than static approaches for tackling these real-world complexities.

In the next few chapters, Ziemba presents applications of stochastic programming models for various types of investors, including insurance companies, pension funds, individuals, and hedge funds. These applications illustrate the benefits of stochastic programming in addressing such important but often neglected investment considerations as human capital in the case of pension funds and taxes in the case of individual investors.

Although some readers may find parts of the material mathematically daunting, Ziemba has a knack for distilling the essential insights into straightforward rules of thumb, as evidenced by his closing list of 10 points to remember. Feel free to skip the math if is not to your taste, but I encourage 
you to pay close attention to the essential insights of this important monograph. The complexities of the real world demand a new set of tools, many of which are contained herein.

The Research Foundation is especially pleased to present The Stochastic Programming Approach to Asset, Liability, and Wealth Management.

Mark Kritzman, CFA Research Director The Research Foundation of the Association for Investment Management and Research 


\section{Preface}

All individuals and institutions face asset/liability management problems on a continuous basis. The assets must be invested over time to achieve sufficient returns to cover liabilities and achieve goals subject to various uncertainties, policy and legal constraints, taxes, and other requirements. Investors, whether individuals or institutions, typically do not properly diversify their asset holdings across markets and time, especially in relation to their certain and uncertain liability commitments.

This Research Foundation of AIMR monograph presents an easily readable, up-to-date treatment of asset and wealth management in the presence of liabilities and other portfolio complexities, such as transaction costs, liquidity, taxes, investor preferences (including downside risk control, policy constraints, and other constraints), uncertain returns, and the timing of returns and commitments. The monograph addresses the issues involved in the management of investment portfolios for both large financial institutions (such as pension funds, insurance companies, and hedge funds) and individuals concerned with life-cycle planning.

The approach discussed and recommended here is discrete-time, multiperiod stochastic programming. For most practical purposes, such models provide a superior alternative to other approaches, such as mean-variance, simulation, control theory, and continuous-time finance. Stochastic programming leads to models that take into account investor preferences in a simple, understandable way.

The use of scenario-based, stochastic programming optimization models in discrete time provides an approach to asset/liability modeling over time. The models provide a way to think about, organize, and do calculations based on how one should choose asset mixes over time to achieve goals and cover liabilities. Risk and return are balanced to achieve period-by-period goals and targets and long-run objectives. The models force diversification and the consideration of extreme scenarios to protect investors from the effects of extreme outcomes and also do well in normal times. They simply will not let individuals or institutions get into situations in which extreme, but plausible, scenarios would lead to truly disastrous consequences, such as losing half or more of one's assets. Because these models force consideration of all relevant scenarios, the common practice of assuming that low-probability scenarios will not occur is avoided. Hence, the disasters that frequently follow from this error can be avoided.

In discrete-time, multiperiod stochastic programming models, one typically maximizes a concave, risk-averse utility function composed of the 
discounted expected wealth in the final period less a risk measure composed of a risk-aversion index times the sum of convex penalties for target violations relating to investor goals of various types in various periods. The convexity means that the larger the target violation, the larger the penalty cost. Hence, risk is measured as the nonattainment of investor goals, and this risk is traded off against expected returns. This approach is similar to a mean-variance preference structure, except it is based on final wealth and the risks are downside risks that are measured across several periods and by several investor goals. Discrete scenarios that represent the possible returns and other random parameter outcomes in various periods are generated from econometric and other models, such as those related to market dangers with increasing risk and from expert modeling. Mean-return estimation and inclusion of extreme events are important for model success. The scenario approach has a number of advantages:

- Normality or lognormality, which is used in other approaches but is not an accurate representation of actual asset prices, especially for losses, need not be assumed.

- Tail events can be easily included; studies show that downside probabilities estimated from actual option prices are 10 to 100 to 1,000 times fatter than lognormal.

- Scenario-dependent correlations between assets can be modeled and used in the decision-making process so that "normal" and "crisis" economic times (with higher and differing signed correlations) can be considered separately.

- The exact scenario that will occur and the probabilities and values of all the scenarios do not need to be accurately determined to provide model performance that is superior to that of other models and strategies, such as mean-variance or portfolio insurance.

- The best decisions are determined in light of relevant constraints, uncertainties, and preferences of the decision maker.

- Most of the natural, practical aspects of asset/liability applications can be modeled well in the multiperiod stochastic programming approach. Methods to solve such models are now highly developed and can be implemented on high-performance personal computers. Model output is easy to understand and interpret if good graphical interfaces are used that are user friendly and easily understood by such nonoptimization experts as pension fund trustees. The models can be tested via simulation and statistical methods and considerable independent evidence demonstrates their superiority to other standard approaches and strategies. 
- The approach tends to protect investors from large market losses by considering the effects of extreme scenarios while accounting for other key aspects of the problem. The world today is very dangerous with many extreme scenarios. For example, the use of derivatives worldwide has grown into a US\$142 trillion industry. Although much of this trade is for hedging and reduces risk, the sheer volume adds new risks.

- Determining whether investment positions are truly diversified and of the right size across time is crucial to protect against extreme scenarios and ensure that the results will be good in normal times and avoid disasters.

Chapter 1 of this monograph reviews static mean-variance and expectedutility-based portfolio theory and provides the principles of utility theory and measurement, preferences, risk measurement, and the effect of estimation errors used later in the multiperiod models.

Chapter 2 discusses extreme events, scenario estimation, and a stockbond return crash danger model that would have been useful in predicting the 1987 (U.S. and worldwide), 1990 (Japanese), and 2000 (U.S. and worldwide) stock market crashes. In this chapter, stochastic programming models are introduced and compared with fixed-mix portfolio models; also, the main points regarding their use are discussed.

Chapter 3 deals with insurance industry models, namely, the RussellYasuda Kasai model and models for the management of policies with guarantees.

Chapter 4 discusses pension plans, as well as the increased risk of investing heavily in one's own-company stock. I develop a case study for an Austrian pension fund and compare a continuous-time approach with the discrete-time, scenario-based stochastic programming approach.

Chapter 5 discusses individual asset/liability management for wealthy individuals and institutions, particularly for retirement and endowments of universities and other foundations for which spending never decreases.

Chapter 6 discusses hedge fund strategies-including typical trades, performance, risk control, and the Kelly or capital growth theory of investment over time.

Although the basic ideas are fairly simple and, I hope, explained well here, some of the technical complexities I do not cover are available online at my website, homepage.mac.com/wtzimi/index.htm, and can be downloaded without cost. Those interested in making stochastic programming models can e-mail me at wtzimi@mac.com or check my website or www.numerikaalm.com. 
In this monograph, I have tried to explain my ideas at a graduate level, as I have in institutional lectures around the world and in MBA classes at the universities of British Columbia, Chicago, Cambridge, Oxford, Warwick, Reading, Helsinki, Tsukuba, and Zurich, Imperial College, London, and the London School of Economics.

\author{
W.T.Z. \\ Vancouver, British Columbia, Canada \\ Oxford, United Kingdom \\ May 2003
}




\section{The Fundamentals of Asset Allocation}

This chapter provides an introduction to mean-variance analysis, utility theory and practice, and other aspects of static portfolio allocation. The concepts presented here will be useful in later chapters on multiperiod models with liabilities.

\section{Mean-Variance Analysis and Its Limitations}

The Markowitz (1952) mean-variance model is a useful paradigm that ushered in the modern approach to quantitative asset management. The idea is to trade off mean return, which is desirable, with variance, which is a measure of risk and is undesirable. Other useful sources of information related to material in this chapter are Michaud (1998) and Ziemba and Mulvey (1998).

Suppose there are $n$ assets, $i=1, \cdots, n$, with random returns $\xi_{1}, \ldots, \xi_{n}$. The return on asset $i$, namely $\xi_{i}$, is the capital appreciation plus dividends in the next investment period, which could be monthly, quarterly, yearly, or some other time period. The $n$ assets have the distribution $F\left(\xi_{1}, \ldots, \xi_{n}\right)$, with mean vector $\bar{\xi}=\left(\bar{\xi}_{1}, \ldots, \bar{\xi}_{n}\right)$, and $n x n$ variance-covariance matrix $\sum$, with typical covariance $\sigma_{i j}$ for $i \neq j$ and variance $\sigma_{i}^{2}$ for $i=j$.

A mean-variance model is

$$
\begin{aligned}
& \phi(\delta)=\max \bar{\xi}^{\prime} x, \\
& \text { subject to } x^{\prime} \Sigma x \leq \delta \\
& e^{\prime} x=w_{0} \\
& x \geq o \text {, }
\end{aligned}
$$

where $\phi$ represents maximum expected wealth for a given variance level $\delta, x$ $=\left(x_{1}, \ldots, x_{n}\right)$ are the asset weights, $e$ is a vector of 1 's, and $w_{0}$ is the investor's initial wealth.

When variance is parameterized, it yields a concave curve, as shown in Panel A of Figure 1.1. This curve is a Markowitz mean-variance-efficient frontier that optimally trades off mean, which is desirable, with variance, which is undesirable. Tobin (1958) extended the Markowitz model to include a riskfree asset with mean, $r_{f}$, and no variance, in which case the efficient frontier curve becomes the straight line shown in Panel B of Figure 1.1. To make the line straight, the standard deviation, rather than the variance, is plotted. 
Figure 1.1. Two Efficient Frontiers

A. Markowitz Mean-Variance-Efficient Frontier

Expected Return

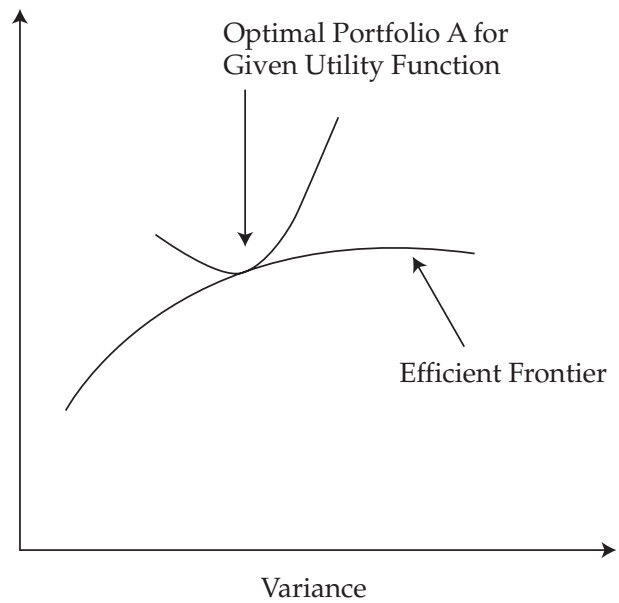

B. Tobin's Risk-Free Asset and Separation Theorem

Expected Return

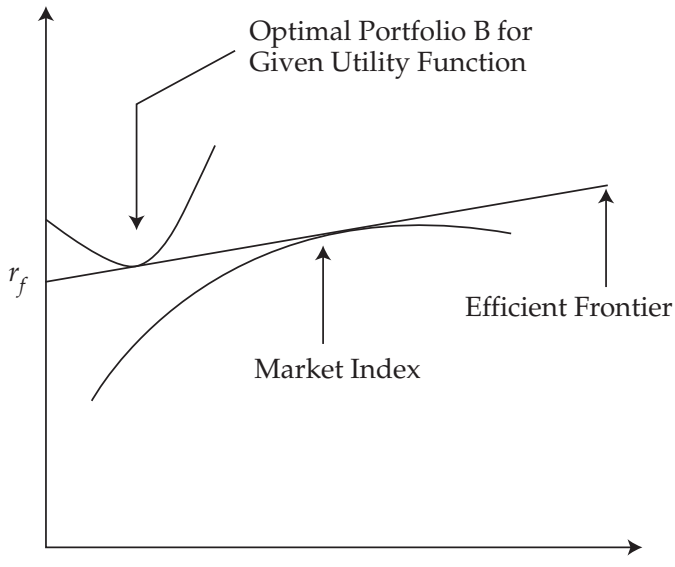

Standard Deviation

An investor selects an optimal portfolio in the Markowitz model using a utility function that trades off mean for variance, or, equivalently, standard deviation, to yield portfolio A, as shown in Panel A of Figure 1.1. For the Tobin model, a simpler calculation can be used to find the optimal portfolio-the line in Panel B of Figure 1.1 between the risk-free asset and the market index. Here, the investor picks a portfolio B that is about half cash/risk-free asset 
and half market index. The market index may be proxied by the S\&P 500 or Wilshire 5000 value-weighted indexes. Because all investors choose between cash and the market index, this separation of the investor's problem into finding the market index and then figuring out where to be on the line is called "Tobin's separation theorem." Ziemba, Parkan, and Brooks-Hill (1974) discussed how to compute the market index and optimal weights of cash and the market index for various utility functions and constraints.

I will now investigate the effect of errors in the estimates of the mean returns, variances, and covariances $\bar{\xi}_{i}, \sigma_{i}^{2}$, and $\sigma_{i j}$, respectively, on the optimal asset weights $x_{i}^{*}$ and overall portfolio mean and variance. This analysis will be easier using the general expected utility model:

$$
\begin{aligned}
\max _{x \geq 0} z(x)=E_{\xi} u\left(w_{0} \xi^{\prime} x\right), & \\
\text { subject to } e^{\prime} x & =1 \\
x & \geq 0 \\
x & \in K,
\end{aligned}
$$

where $z(x)$ is the expected utility for a given $x, u$ is a concave risk-averse utility function, the convex set $K$ is additional constraints, and the $w_{0}$ is put into the objective so the $x$ 's are asset weight fractions or percentages that sum to 1 . By risk averse, I mean that the investor would not prefer a fair gamble to the status quo. Hence risk aversion is identical to the definition of concavity $u\left(w_{0}\right) \geq \lambda u\left(w_{u}\right)+(1-\lambda) u\left(w_{l}\right)$, where $\lambda$ is a number between zero and 1 and $w_{0}=\lambda w_{u}+(1-\lambda) w_{l}$.

Consider two risk-aversion indexes:

1) The Arrow (1965)-Pratt (1964) absolute risk-aversion index

$$
R_{A}(w)=\frac{-u^{\prime \prime}(w)}{u^{\prime}(w)},
$$

whose average value

$$
\bar{R}_{A}=E_{w} \frac{-u^{\prime \prime}(w)}{u^{\prime}(w)},
$$

allows for an accurate approximation of any concave $u$ with the quadratic $\bar{\xi}^{\prime} x-\left(\bar{R}_{A} / 2\right) x^{\prime} \Sigma x$. The key is the choice of $\bar{R}_{A}$. For relative investments, I use $w R_{A}(w)$, the Arrow-Pratt relative risk-aversion index; and

2) the very useful, from a theoretical point of view, Rubinstein (1973) relative risk-aversion measure

$$
R_{R}=-\frac{E_{W}\left[w u^{\prime \prime}(w)\right]}{E_{W}\left[u^{\prime}(w)\right]},
$$


which completely characterizes optimal portfolio behavior if the asset returns are normally or symmetrically distributed.

If two investors have the same Rubinstein risk-aversion measure, then they have the same optimal portfolio weights, even if they have different concave utility functions and initial wealth. ${ }^{1}$

Under the normality assumptions, $R_{R}$ is exact, but how to estimate it is not obvious. Also, Samuelson (1970) showed that in the choice between a risky and a risk-free asset, as $\sigma^{2} \rightarrow 0$, then $R_{R} \rightarrow R_{A}$ and

$$
\lim _{\sigma^{2} \rightarrow 0} x_{r i s k y}^{*}=\frac{\text { Constant }}{R_{A}} \text {. }
$$

Hence, the amount invested in the risky asset is inversely proportional to the investor's risk aversion.

Several interesting questions arise:

- How accurate is $R_{A}$ when $\sigma^{2}>0$ ?

- What are some guidelines for its use?

- How robust is $R_{A}$ ?

- Is a change in $R_{A}$ from $1 \rightarrow 2$ different from a change from $10 \rightarrow 11$ or $10 \rightarrow 20$ ?

As I will now discuss, Kallberg and Ziemba (1983) provided answers to these questions.

In Figure 1.2, Panel A and Panel B show typical monthly output for the quadratic and exponential utility functions. The asset weights sum to 1 . More interesting are Panel $\mathrm{C}$ and Panel D of Figure 1.2. Special exponential and negative power have different functional forms, but with similar risk-aversion indexes, they have similar asset weights versus parameter values. Negative power is a useful utility function for many applications.

The errors are usually less than $10^{-4}$ percent, and the largest is less than 1 percent, which is below the accuracy of the data. Actual portfolio weights, means, and variances are close. In general, these values are closer for monthly data and lower $R_{A}$ because one then has lower variance and less curvature of $U$. Table 1.1, Table 1.2, and Table 1.3 show a sample calculation for yearly data with 10 securities for $R_{A}=4$. The cash-equivalent errors are always less than 1 percent, and for the quadratic function, which is the most convenient utility function to use in practice, the errors are less than $10^{-4}$ percent.

Figure 1.3 shows that changes in $R_{A}$ from 1 to 2 are much more important than those from 4 to 5,4 to 8 , or 10 to 20 . This finding and the related results

1For further discussion, see Theorem 1 in Appendix A (p. 1), which is available online in the Supplementary Material area at www.aimrpubs.org/rf/issues/v2003n6/pdf/AppendixA.pdf. 


\section{Figure 1.2. Functional Form Asset Weights}

A. Quadratic Monthly $U_{1}(w)=w-\beta_{1} w^{2}$ Percent in Each Stock

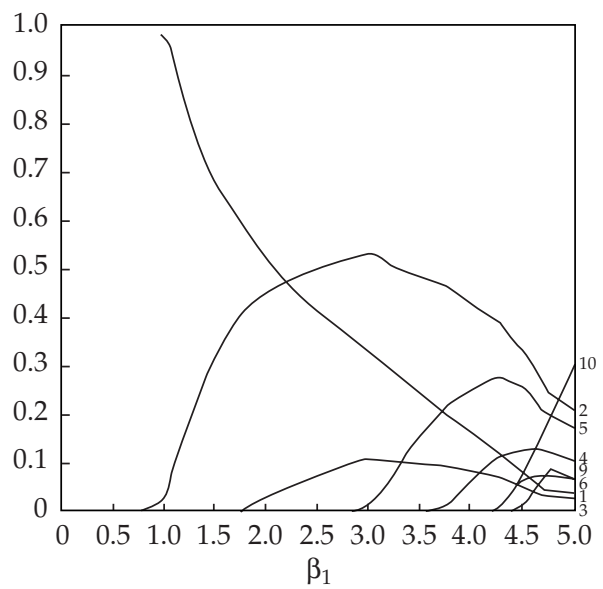

C. Special Exponential Monthly $U_{4}(w)=-e^{\beta_{4} / w}$ Percent in Each Stock

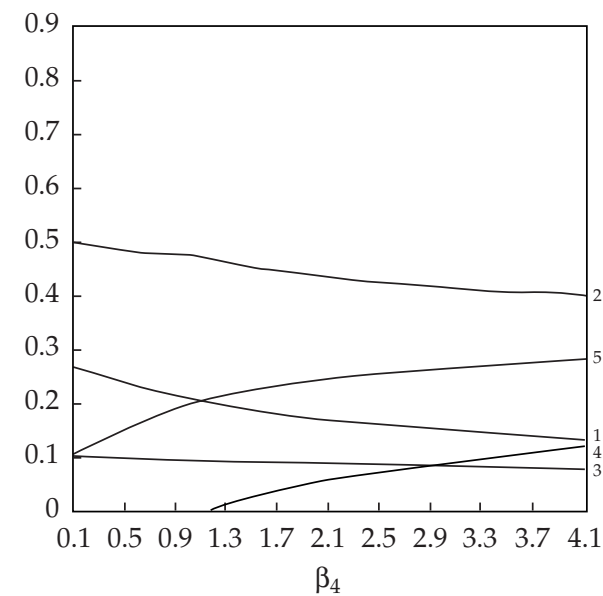

B. Exponential Monthly $U_{2}(w)=1-e^{-\beta_{2} w}$ Percent in Each Stock

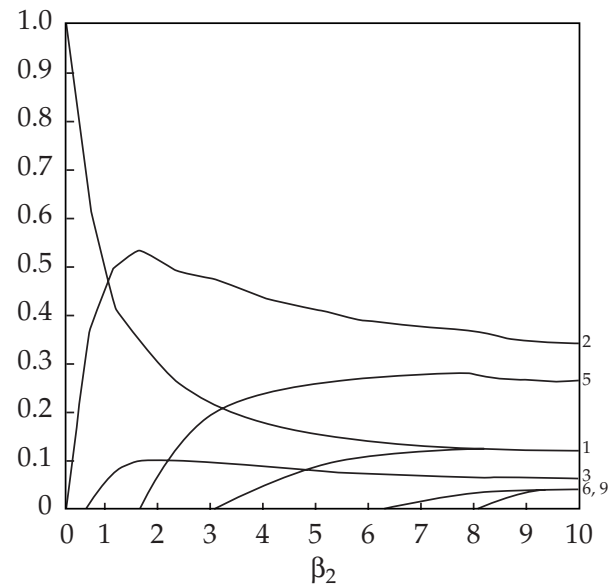

D. Negative Power Monthly $U_{6}(w)=\left(w-w_{0}\right)-\beta_{6}$ Percent in Each Stock

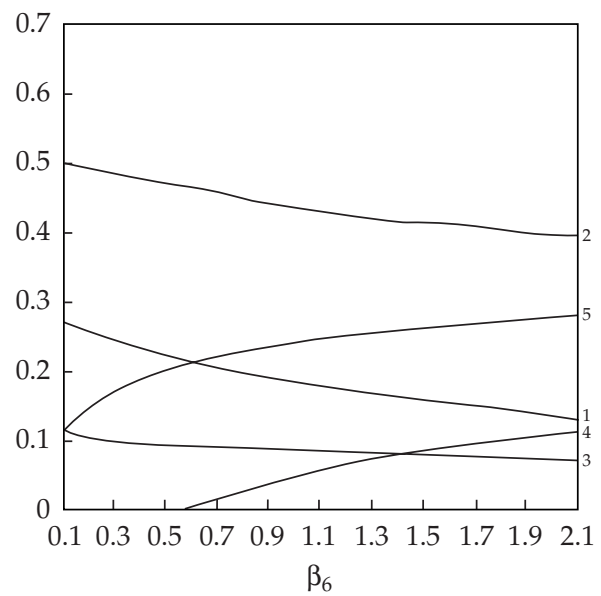

Note: Numbers beside lines are the numbers of the individual stocks.

of Kallberg and Ziemba (1983) provide another simple, but extremely powerful and useful, method to estimate individual utility functions. We can simply assess a person's aversion to risk through interviews and then assign numerical values to that person's risk-aversion index. Because these results imply 
Table 1.1. Security Means and Variances

\begin{tabular}{rlcc}
\hline Security & Mean & Variance \\
\hline 1 & Cunningham Drug Stores & 1.2852 & 0.3276 \\
2 & National Cash Register & 1.2549 & 0.2152 \\
3 & Metro-Goldwyn-Mayer & 1.1819 & 0.7111 \\
4 & Gillette Co. & 1.1694 & 0.0666 \\
5 & Household Finance Corp. & 1.1484 & 0.0517 \\
6 & H.J. Heinz Co. & 1.1608 & 0.1413 \\
7 & Anaconda Co. & 1.1711 & 0.1865 \\
8 & Kaiser Aluminum \& Chemical & 1.0861 & 0.0324 \\
9 & Maytag Co. & 1.1292 & 0.1676 \\
10 & Firestone Tire and Rubber & 1.0626 & 0.0155 \\
\hline
\end{tabular}

Table 1.2. Correlation Matrix

\begin{tabular}{r|cccccccccc}
\hline & 1 & 2 & 3 & 4 & 5 & 6 & 7 & 8 & 9 & 10 \\
\hline 1 & 0.3276 & 0.0755 & 0.0311 & 0.0451 & 0.0226 & 0.0746 & 0.1126 & 0.0313 & 0.0991 & 0.0201 \\
2 & & 0.2152 & 0.0256 & 0.0462 & -0.0011 & 0.0407 & 0.0361 & 0.0347 & 0.0509 & 0.0077 \\
3 & & & 0.1711 & 0.0318 & 0.0118 & 0.0504 & 0.0531 & 0.0150 & 0.0298 & 0.0066 \\
4 & & & & 0.0666 & 0.0121 & 0.0267 & 0.0458 & 0.0165 & 0.0221 & 0.0084 \\
5 & & & & & 0.0517 & 0.0243 & 0.0271 & 0.0109 & 0.0235 & 0.0090 \\
6 & & & & & & 0.1413 & 0.0492 & 0.0085 & 0.0489 & 0.0117 \\
7 & & & & & & & 0.1865 & 0.0354 & 0.0609 & 0.0162 \\
8 & & & & & & & & 0.0324 & 0.0245 & 0.0044 \\
9 & & & & & & & & & 0.1674 & 0.0097 \\
10 & & & & & & & & & & 0.0135 \\
\hline
\end{tabular}

that any concave utility function can be estimated well with any other concave utility function, we can use as our approximating function the quadratic

$$
u(w)=w-\frac{R_{A}}{2} w^{2} .
$$

Then, we simply supply $R_{A}$ values. For example, $R_{A}=4$, which corresponds approximately to the risk of a portfolio with 60 percent in stocks and 40 percent in bonds, represents a moderately conservative investment style, similar to many pension plans; $R_{A}=6$ to 8 represents a very conservative style, and $R_{A}=1$ to 2 represents a much more aggressive style.

Comments on Utility Functions. Special exponential and negative power yield very risk-averse portfolios. Negative power has many attractive properties for conservative investors. Positive power (usually) yields highly risky portfolios and moderately risk-averse portfolios for different parameter 
Table 1.3. Optimal Portfolio Weights for Alternative Utility Functions and $\overline{\boldsymbol{R}}_{\boldsymbol{A}}$ Values

\begin{tabular}{lccccc}
\hline $\begin{array}{l}\text { Security/ } \\
\text { Statistic }\end{array}$ & Exponential (4.0) & $\begin{array}{c}\text { Quadratic } \\
(0.351447)\end{array}$ & $\begin{array}{c}\text { Log } \\
(-0.832954)\end{array}$ & $\begin{array}{c}\text { Special } \\
\text { Exponential } \\
(2.884400)\end{array}$ & $\begin{array}{c}\text { Negative } \\
\text { Power } \\
(1.443557)\end{array}$ \\
\hline 1 & 0.088239 & 0.082991 & 0.046975 & 0.021224 & 0.047611 \\
2 & 0.169455 & 0.165982 & 0.116220 & 0.185274 & 0.112794 \\
3 & 0.106894 & 0.106663 & 0.080160 & 0.104064 & 0.079600 \\
4 & 0.194026 & 0.198830 & 0.161247 & 0.048522 & 0.154474 \\
5 & 0.441385 & 0.445533 & 0.343318 & 0.441182 & 0.328958 \\
6 & & & & & \\
7 & & & & & \\
8 & & & & & \\
9 & & & & & \\
10 & & & & & \\
Mean & 1.186170 & 1.185175 & 1.151634 & 1.158397 & 1.149527 \\
Variance & 0.037743 & 0.037247 & 0.024382 & 0.027802 & 0.023756 \\
Expected utility & 0.988236 & 0.988236 & 0.987863 & 0.987589 & 0.987821 \\
Percent error & - & 0 & 0.703000 & 0.709900 & 0.782700 \\
\hline
\end{tabular}

Note: Parameter values are in parentheses. Zeros and blanks indicate values less than $10^{-4}$.

Figure 1.3. Riskiness as a Percentage of Maximum Variance vs. $\boldsymbol{R}_{\boldsymbol{A}}$

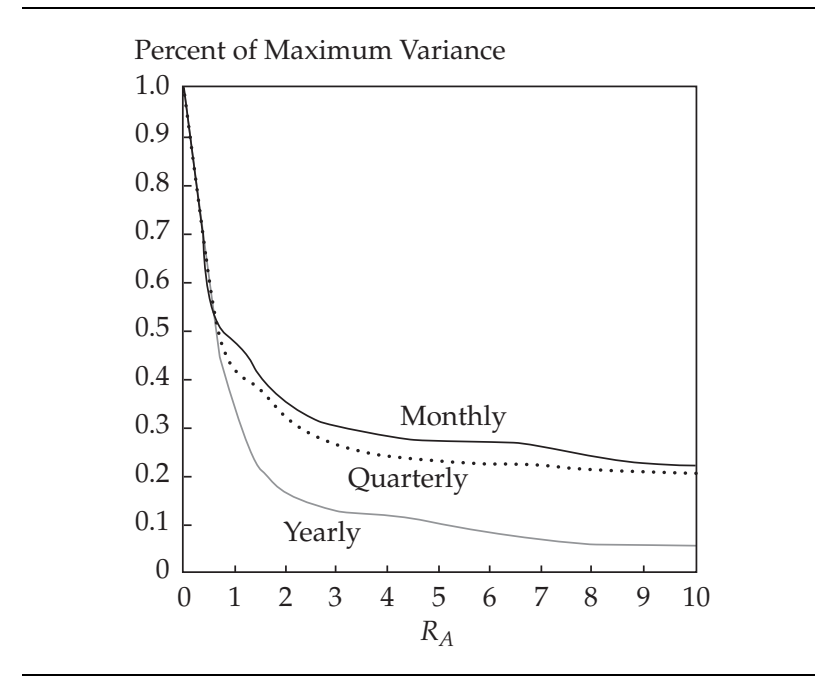


values. Arctan (usually) yields highly risky portfolios and has $R_{A} \leq 1$. Quadratic, exponential, and log span the whole range of absolute risk aversion from zero to infinity. Other useful utility functions are the double exponential and that proposed by Bell (1995) $-u(w)=w-a e^{-b w}$, for constants $a$ and $b$, where $e$ refers to exponentiation (see also papers in Ziemba and Vickson 1975).

\section{Estimation of Utility Functions}

Figure 1.4 and Figure 1.5 show the utility of wealth function and the absolute and relative risk-aversion functions for Donald Hausch. These functions were estimated using the double exponential utility function

$$
u(w)=-e^{-a w}-b e^{-c w},
$$

where $a, b$, and $c$ are constants. This function is strictly concave and strictly increases with decreasing absolute risk aversion when one uses the certainty-

Figure 1.4. Utility of Wealth Function for Donald Hausch

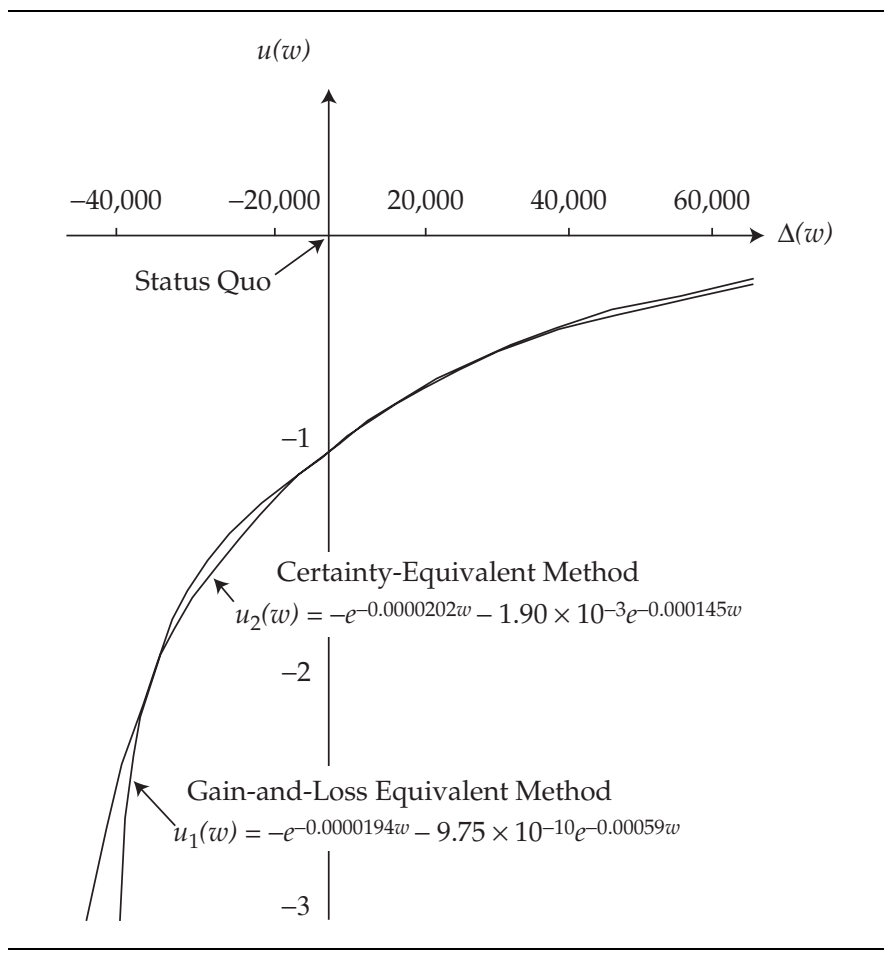


Figure 1.5. Risk-Aversion Functions for Donald Hausch

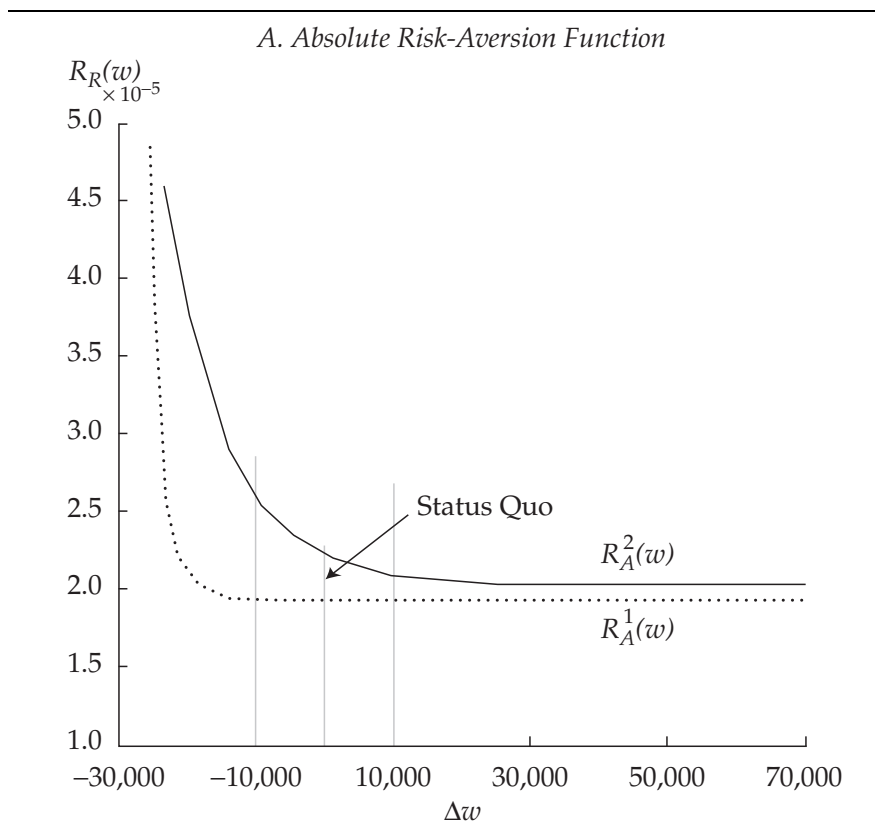

B. Relative Risk-Aversion Function

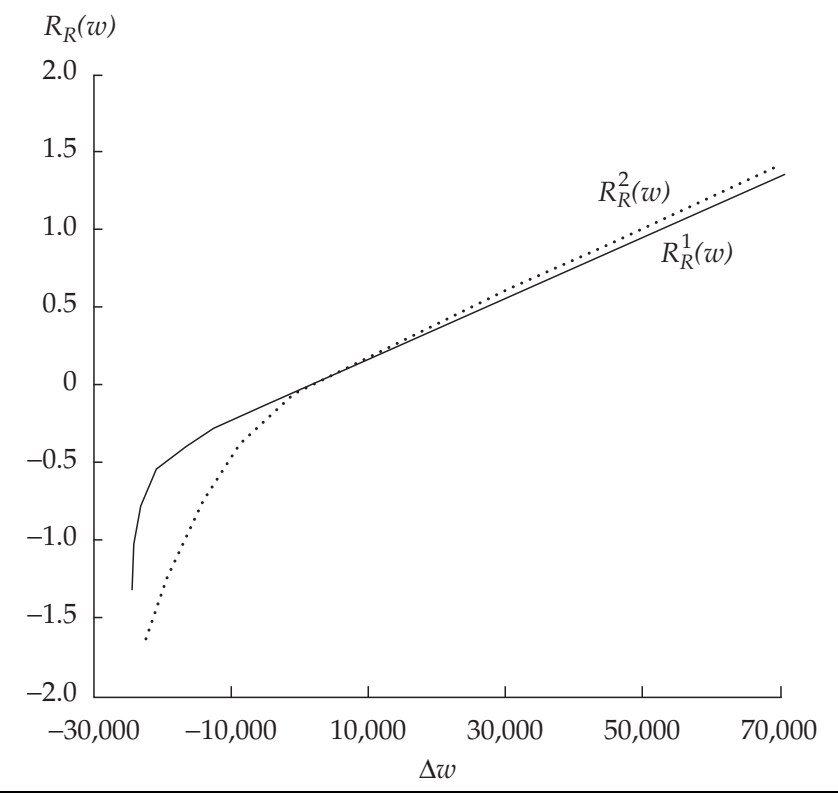

Note: Both risk-aversion functions are estimated by the certainty-equivalent method (1) and the gain-and-loss equivalent method (2). 
equivalent and gain-and-loss equivalent methods. ${ }^{2}$ Hausch's utility function was fit by least squares, and both methods provide similar curves. His absolute risk aversion is decreasing and roughly constant in his investment range when initial wealth $w_{0}$ changes by $\pm 10,000$, corresponding to $R_{A}$ between 2.0 and 2.5. His relative risk aversion, $-w\left[u^{\prime \prime}(w) / u^{\prime}(w)\right]$, is increasing and linear in his investment range.

\section{The Importance of Means}

Means are by far the most important part of any return distribution for actual portfolio results. To have good results with any portfolio problem, good mean estimates for future returns are necessary, as Hanoch and Levy (1969) discuss:

If asset $X$ has cumulative distribution $F(\cdot)$ and asset $Y$ has $G(\cdot)$ and these cumulative distribution functions cross only once, then asset $X$ dominates asset $Y$ for all increasing concave utility functions, that is, has higher expected utility, if and only if the mean of $X$ exceeds the mean of $Y$.

This means that the variance and other moments are unimportant for singlecrossing distributions. Only the means count. With normal distributions, $X$ and $Y$ will cross only once if and only if the standard deviation of asset $X$ is less then the standard deviation of asset $Y$. This is the basic equivalence of mean-variance analysis and expected utility analysis via second order (concave, nondecreasing) stochastic dominance, as shown in Figure 1.6; Panel A depicts the second degree and mean-variance dominance, but no dominance exists in Panel B because there are two crosses. This $F$ has a higher mean but also higher variance than $G$. The densities $f$ and $g$ are plotted for convenience and yield the same results as those for the cumulative distribution functions $F$ and $G$. There is a similar theory for infinite variance stable distributions; see Ziemba (1974) and Rachev (2003).

Errors in inputs can lead to significant losses (Figure 1.7) and high turnover (Figure 1.8). Additional calculations appear in Kallberg and Ziemba $(1981,1984)$ and in Michaud (1989).

The error depends on the risk tolerance. Errors in means, variances, and covariances, however, are roughly 20:2:1 times as important, respectively (see Table 1.4). Therefore, good estimates are by far the most crucial aspect of successfully applying a mean-variance analysis, and we will see that in all other stochastic modeling approaches.

Conclusion: Spend your money getting good mean estimates and use historical variances and covariances.

2These methods are described in Appendix A (p. 2), which is available online in the Supplementary Material area at www.aimrpubs.org/rf/issues/v2003n6/pdf/AppendixA.pdf. 
Figure 1.6. Mean-Variance and Second-Order Stochastic Dominance

A. Dominance Does Not Exist

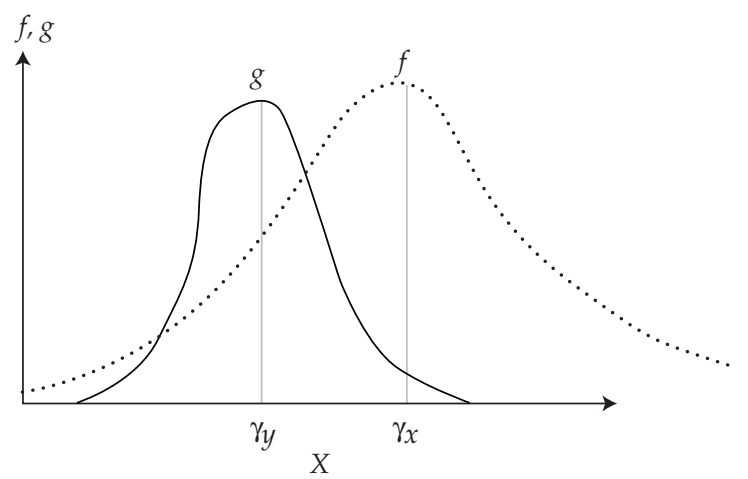

$F$ Does Not Dominate $G \quad \gamma_{x}>\gamma_{y}$

$G$ Does Not Dominate $F \quad$ but $\sigma_{x}^{2}>\sigma_{y}^{2}$

B. Dominance Exists

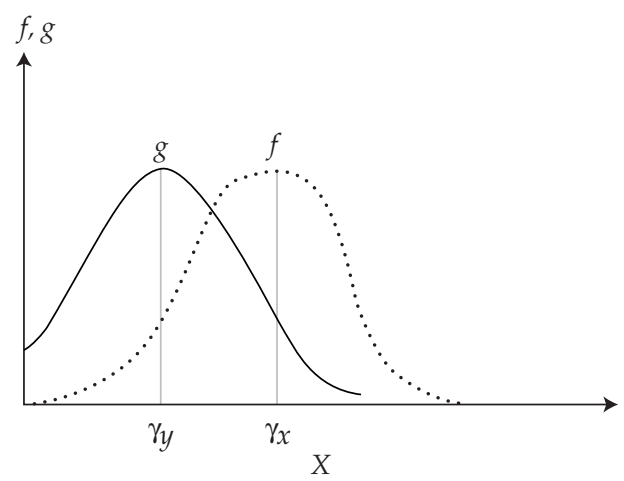

F Dominates $G$

\section{Capital-Asset-Pricing-Based Performance Analysis}

The 1964 Sharpe-Lintner-Mossin capital asset pricing model (CAPM) implies that the mean return, $\bar{R}_{j}$, of an individual asset, $j$, is related to the mean of the market index, $\bar{R}_{M}$, through the covariance of asset $j$ with the market. The expected return is

$$
\bar{R}_{j}=r_{f}+\beta_{j}\left(\bar{R}_{M}-r_{f}\right),
$$

where 
Figure 1.7. Mean Percentage Cash-Equivalent Loss because of Errors in Inputs

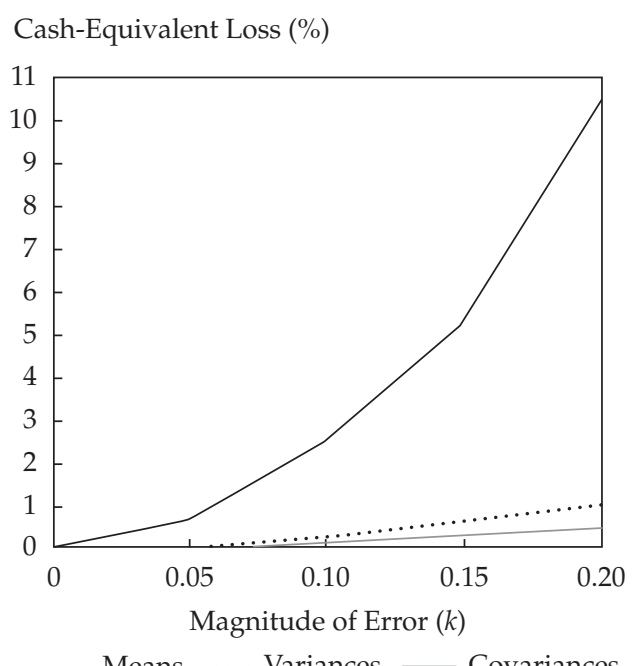

Source: Based on data from Chopra and Ziemba (1993).

Figure 1.8. Average Turnover for Different Percentage Changes in Means, Variances, and Covariances

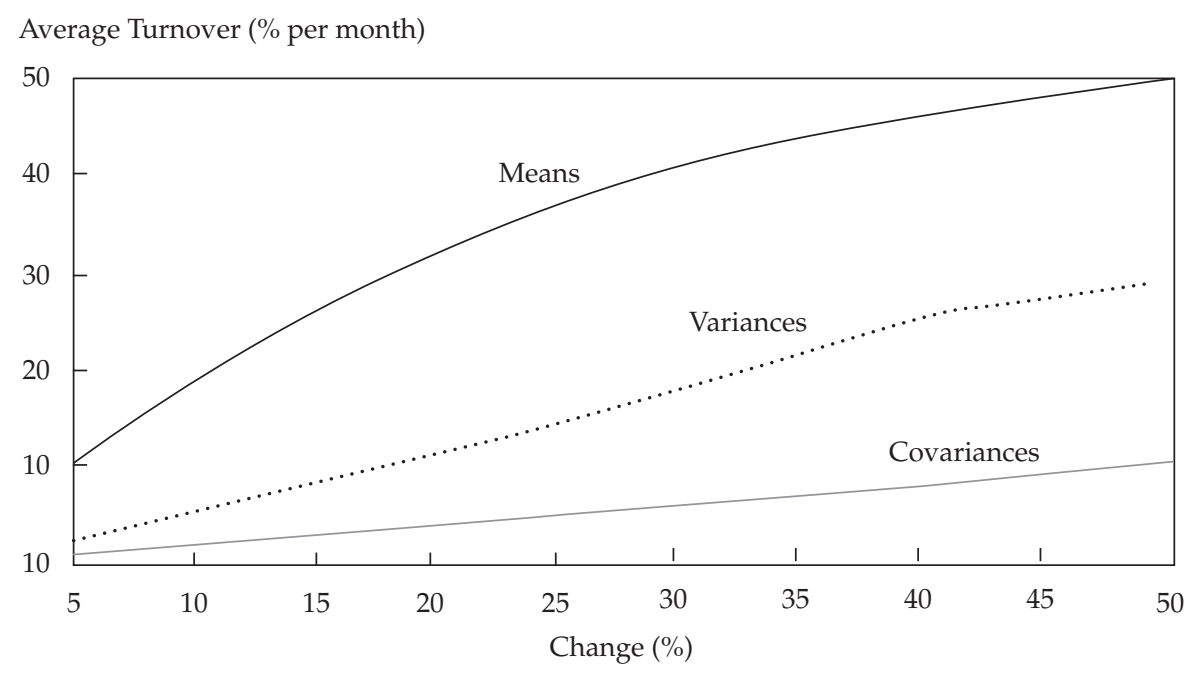

Source: Based on data from Chopra (1993). 
Table 1.4. Average Ratio of Certainty Equivalent Loss for Errors in Means, Variances, and Covariances

\begin{tabular}{lccc}
\hline$t$-Risk Tolerance & $\begin{array}{c}\text { Errors in Means vs. } \\
\text { Covariances }\end{array}$ & $\begin{array}{c}\text { Errors in Means vs. } \\
\text { Variances }\end{array}$ & $\begin{array}{c}\text { Errors in Variances vs. } \\
\text { Covariances }\end{array}$ \\
\hline 25 & 5.38 & 3.22 & 1.67 \\
50 & 22.50 & 10.98 & 2.05 \\
75 & 56.84 & 21.42 & 2.68 \\
& $\downarrow$ & $\downarrow$ & $\downarrow$ \\
& 20 & 10 & 2
\end{tabular}

Error mean

20

Error variance

2

Error covariance

1

$$
\beta_{j}=\frac{\operatorname{cov}\left(R_{j}, \bar{R}_{M}\right)}{\sigma_{M}^{2}}
$$

and $r_{f}$ is the risk-free return.

Superior investment performance (i.e., the search for alpha) is

$$
\alpha_{j}=\bar{R}_{j}-r_{f}-\beta_{j}\left(\bar{R}_{M}-r_{f}\right)
$$

This analysis is all derived in a mean-variance normal distribution or quadratic utility world. As the theory behind the explosive growth in index funds and various aspects of portfolio management, the CAPM has been useful in many diverse settings, such as regulatory hearings. But we live in a fat-tailed investment world, especially over short periods of time, such as a week, month, or quarter. For yearly time horizons, normality is usually a reasonable assumption for many equity and other investment markets, but a serious problem with normality and mean-variance analyses arises when investment portfolios contain options. For example, the two distributions in Figure 1.9 have the same mean and variance.

How do we deal with a CAPM-type analysis if the tails are fatter than normal? Also, we know that, empirically, investors prefer positive skewness and distinguish between downside and upside risk.

The CAPM analysis penalizes strategies that buy options and biases them toward negative alphas. Conversely, the CAPM analysis rewards strategies that sell options and biases them toward positive alphas. In both cases, the alpha is incorrectly measured.

Leland (1999) shows how to correct for these biases in a simple way: Instead of using beta, one can use a modified beta, $B$. Theoretical studies by Rubinstein, Constantinides (1982), and He and Leland (1993) argued that if 


\section{Figure 1.9. Two Distributions with Identical Means and Variances but Different Skewness}

\section{A. Equities, Bonds, and Cash}

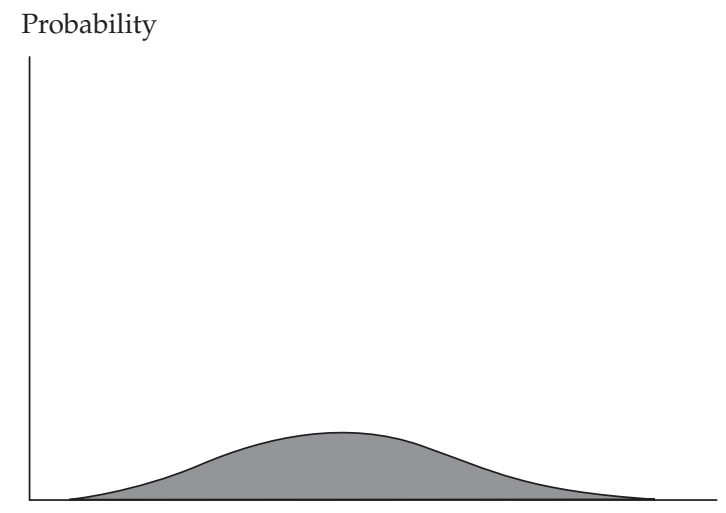

Return (\%)

B. Equities, Bonds, Cash, and Options

Probability

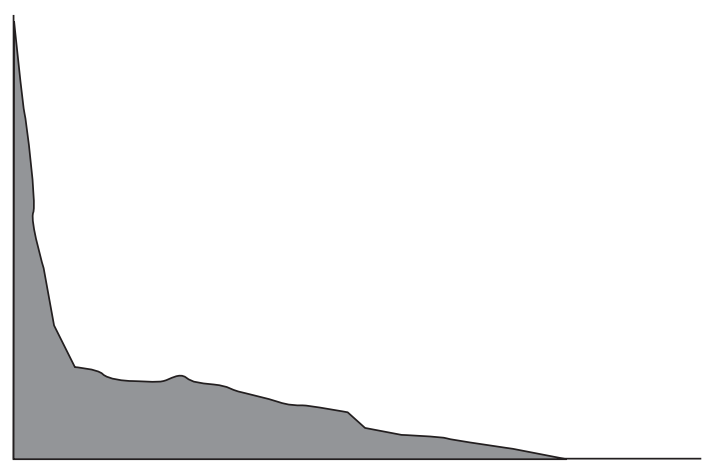

Return (\%)

the market rate of return is independent and identically distributed, then by the central limit theorem, returns are lognormally distributed. If markets are dynamically complete, Harrison and Kreps (1979) showed that an aggregate investor exists with a negative power utility function:

$$
u(w)=\frac{w^{1-\gamma}}{1-\gamma},
$$

where 


$$
\gamma=\frac{\left(\bar{R}_{M}-r_{f}\right)}{\sigma_{M}^{2}}>0,
$$

and absolute risk aversion, $\gamma / w$, and constant relative risk aversion $\gamma$. This $u$ is positively skewed because its third derivative is positive with respect to wealth $w$. Then, instead of using

$$
\beta_{j}=\frac{\operatorname{cov}\left(r_{j}, r_{m}\right)}{\operatorname{cov}\left(r_{m}, r_{m}\right)},
$$

use

$$
\beta_{j}=\frac{\operatorname{cov}\left[r_{j}\left(1+r_{M}\right)^{-\gamma}\right]}{\operatorname{cov}\left[r_{m}\left(1+r_{M}\right)^{-\gamma}\right]} .
$$

Table 1.5 illustrates the idea for rebalancing (or value) strategies that are long the market and short one call and momentum (or portfolio insurance) strategies that are long the market and long one put or follow a dynamic tactical asset allocation strategy. The use of $B$ corrects the bias in the third column to the correct zero value in the last column. Then, one can compute the mean, $\mu_{j}$ and $\beta_{j}$, of a portfolio; if it lies above the market line (that is, $A$ is

Table 1.5. CAPM-Based $\beta$ and $\alpha$ versus $B$ and $A$

\begin{tabular}{rrrrrr}
\hline Strike Price & $E(r)$ & $\beta$ & $\alpha$ & $\mathrm{B}$ & $\mathrm{A}$ \\
\hline \multicolumn{7}{c}{ A. Long the } \\
$\quad$ market, short & one call at & $S=100$ \\
90 & $5.51 \%$ & 0.038 & $0.24 \%$ & 0.073 & 0 \\
100 & 6.76 & 0.163 & 0.62 & 0.251 & 0 \\
110 & 8.61 & 0.394 & 0.85 & 0.515 & 0 \\
120 & 10.27 & 0.650 & 0.72 & 0.753 & 0 \\
130 & 11.30 & 0.838 & 0.57 & 0.900 & 0 \\
140 & 11.77 & 0.939 & 0.20 & 0.967 & 0 \\
B. Long the market, long & one call at $S=100$ & & \\
90 & $11.60 \%$ & 0.962 & $-0.24 \%$ & 0.927 & 0 \\
100 & 10.24 & 0.832 & -0.62 & 0.749 & 0 \\
110 & 8.40 & 0.606 & -0.84 & 0.485 & 0 \\
120 & 6.73 & 0.351 & -0.72 & 0.247 & 0 \\
130 & 5.70 & 0.163 & -0.44 & 0.101 & 0 \\
140 & 5.24 & 0.062 & -0.19 & 0.034 & 0 \\
\hline
\end{tabular}


positive), then it has a true positive alpha, which implies superior performance.

This example assumes a lognormal market portfolio with $\bar{R}_{M}=12$ percent, with $\sigma_{M}^{2}=15$ percent, and $\gamma$ is computed to be 3.63 . This result corresponds to a portfolio blend of

$$
\frac{1}{\gamma}=28 \%
$$

in the log optimal portfolio, and

$$
\frac{\gamma-1}{\gamma}=72 \%
$$

in cash.

This analysis is for the case with lognormally distributed asset returns. Studies at Barra show minor differences in stock $\beta$ 's and $B$ 's over one-month to one-year time horizons. Table $\mathbf{1 . 6}$ shows these differences for various portfolio standard deviations and covariances with the market. Of course, with options, the differences will be much greater.

\begin{tabular}{lccc} 
Table 1.6. & \multicolumn{2}{c}{$\begin{array}{l}\text { Values of } \boldsymbol{\beta}_{\boldsymbol{j}} \text { (for } \boldsymbol{B}_{\boldsymbol{j}} \text { in parentheses) for } \\
\text { Lognormally Distributed Assets }\end{array}$} \\
\hline$\rho_{j M}$ & 0.25 & 0.50 & 0.75 \\
\hline 0.15 & 0.256 & 0.508 & 0.756 \\
& $(0.248)$ & $(0.498)$ & $(0.748)$ \\
0.25 & 0.415 & 0.819 & 1.213 \\
& $(0.405)$ & $(0.813)$ & $(1.224)$ \\
0.35 & 0.561 & 1.103 & 1.625 \\
& $(0.551)$ & $(1.108)$ & $(1.670)$ \\
\hline
\end{tabular}

\section{Sharpe and Generalized Sharpe Ratios}

The Sharpe (1994) ratio

$$
S=\frac{\bar{R}-r_{F}}{\sigma_{R}},
$$

where $\bar{R}$ is the mean portfolio return with standard deviation $\sigma_{R}$ and risk-free asset return $r_{F}$, is a useful measure of portfolio performance. For example, based on 101 yearly observations in Dimson, Marsh, and Staunton (2002) from 1900 to 2000, U.S. stocks had a geometric mean return of 10.1 percent with a 
yearly standard deviation of 19.9 percent, with T-bills returning 4.1 percent, giving $S=(10.1-4.1 / 19.9)=0.30$. U.S. bonds returned 4.8 percent with a standard deviation of 8.3 percent, so $S=0.08$. Outstanding hedge funds have $S$ at 3 or higher.

The Sharpe ratio is based on normal distribution mean-variance analysis. When distributions are nonnormal or have fat tails, the performance rankings are not accurate. ${ }^{3}$ Consider Asset $A$ and Asset B, which are identical, except that Asset A has a 1 percent chance of returning 35 percent and Asset $B$ has a 1 percent chance of returning 45 percent (see Table 1.7). Clearly, Asset B is preferred to Asset $\mathrm{A}$ by first-degree stochastic dominance, so it will have higher expected utility for any monotone increasing utility function. Asset A, however, has a larger Sharpe ratio.

Table 1.7. Sharpe Ratios for Two Investment

Strategies (corrected)

\begin{tabular}{ccccc}
\hline \multicolumn{2}{c}{ Distribution A } & & \multicolumn{2}{c}{ Distribution B } \\
\cline { 1 - 2 } \cline { 5 - 5 } Return & Probability & & Return & Probability \\
\hline-25 & 0.01 & & -25 & 0.01 \\
-15 & 0.04 & & -15 & 0.04 \\
-5 & 0.25 & & -5 & 0.25 \\
+5 & 0.40 & & +5 & 0.40 \\
+15 & 0.25 & & +15 & 0.25 \\
+25 & 0.04 & & +25 & 0.04 \\
+35 & 0.01 & & +45 & 0.01 \\
Mean & 5.00 & & & 5.10 \\
Standard & 10.00 & & & 10.34 \\
deviation & 0.50 & & & 0.49 \\
Sharpe ratio & & &
\end{tabular}

Source: Based on data from Hodges (1998).

\footnotetext{
${ }^{3}$ Sharpe ratios can also be manipulated to obtain funds under management based on consistently high Sharpe values using option positions that smooth returns (with option-selling strategies) and minimize tail effects (with option-buying strategies); see Bernardo and Ledoit (2000), Goetzmann, Ingersoll, Spiegel, and Welch (2002), and Spurgin (2000). Dugan, Burton, and Mollenkamp (2002) discussed how such manipulation led to a US\$43 million loss for the Chicago Art Institute because the real risk of selling puts in a Dallas-based hedge fund run by Conrad Seghers was neither measured nor investigated properly. Put selling can be a dangerous strategy that can lead to many disasters for those who overbet. Properly controlled, with a very small number of positions, such strategies can yield good, steady, and not very risky returns.
} 
The shift from 35 to 45 percent for the 1 percent outlier increases the standard deviation by a larger percentage than the mean, so the Sharpe ratio falls from 0.500 with Asset A to 0.493 with Asset B. Hodges (1998) introduced and resolved this paradox by using an exponential utility function $u(w)=$ $-e^{-\lambda w}$ for $\lambda>0$, the Arrow-Pratt risk-aversion index, which is constant for exponential utility independent of wealth.

When returns are normally or symmetrically distributed, Hodges' generalized Sharpe ratio measure

$$
G S=\sqrt{\frac{-2}{T} \ln U^{*}},
$$

where $T$ is the investment horizon in years and $U^{*}$ is the optimal expected utility, reduces to the Sharpe ratio. 4 Using this generalized Sharpe ratio resolves the paradox because $G S_{A}=0.498<0.500=G S_{B}$.

One of Hodges' reasons for choosing exponential utility is that having exponential utility along with a normal distribution is equivalent to quadratic utility and mean-variance analysis. He is also able to work with distributions on the whole real line (such as normal distributions or others that may have losses), not simply those with positive returns (such as the lognormal). The risk-aversion parameter is of no significance because the $G S$ measure does not depend on it. Exponential utility may be less well suited to other applications, such as when wealth levels are bounded below because of option positions or other investment strategies.

Because ex post return distributions differ from ex ante returns, no single formula will provide a fully satisfactory performance measure. This generalized Sharpe ratio resolves some paradoxes, as with Assets A and B above. Exponential utility with constant risk aversion is not a good theoretical utility function.

The family of negative power utility functions, also called constant relative risk aversion, which is theoretically more desirable, is

$$
U_{\gamma}(w)=\frac{w^{1-\gamma}}{1-\gamma} \text { for } \gamma>0 .
$$

When $\gamma$ approaches $1, U_{\gamma}(w)=\log w$.

Janacek (1998) showed that if wealth follows standard Brownian motion with instantaneous mean $\mu$ and variance $\sigma^{2}$, then the optimal betting fraction for given $\gamma$ is 4The derivation is in Appendix A (p. 3), which is available online in the Supplementary Material
area at www.aimrpubs.org/rf/issues/v2003n6/pdf/AppendixA.pdf. 


$$
F_{\gamma}^{*}=\frac{1}{\gamma} \frac{\mu}{\sigma^{2}},
$$

and the optimal expected utility at time $T$ is

$$
U_{\gamma}^{*}= \begin{cases}\frac{1}{1-\gamma} \exp \left(\frac{1}{2} \frac{1-\gamma}{\gamma} \frac{\mu^{2}}{\sigma^{2}} T^{2}\right) & \text { for } \gamma>0 \\ \frac{1}{2} \frac{\mu^{2}}{\sigma^{2}} T & \text { for } \gamma=1 .\end{cases}
$$

Then, solving for $\mu / \sigma$ gives the generalized Sharpe ratio for negative power or $\log$ utility, namely,

$$
\begin{array}{ll}
G S_{\gamma}=\sqrt{\frac{2}{T} \frac{\gamma}{1-\gamma} \log (1-\gamma) U^{*}} & \text { for } \gamma>0, \text { and } \\
G S_{\gamma}=\sqrt{\frac{2}{T} U_{0}^{*}} & \text { for } \gamma=1,
\end{array}
$$

where the $\log$ utility case 2.2 is 2.1 when $\gamma$ approaches 1 . This generalized Sharpe ratio is a strictly increasing function of utility $U_{\gamma}$, so paradoxes such as those associated with Asset A and Asset B will be avoided. Nonetheless, $G S_{\gamma}$ depends on the risk-aversion parameter $\gamma$ and the initial wealth, so it does not have a unique value, as does the Sharpe ratio or Hodges' generalized Sharpe ratio. It reduces to the ordinary Sharpe ratio when assets follow geometric Brownian motion.

Another performance measure, which I call the symmetric downside risk Sharpe measure, is

$$
S=\frac{\bar{R}-r_{F}}{\sigma_{S D}},
$$

where $\sigma_{S D}=\sqrt{2} \sigma_{D}$,

and $\sigma_{D}=\sum_{i=1}^{n} \frac{\left(X_{i}-\bar{X}\right)^{2}}{n-1}$,

where only $X_{i} \leq \bar{X}$ are counted in the summation, is the downside risk (Ziemba and Schwartz 1991). This measure makes the returns symmetric so that a superior investor, such as Warren Buffett, is not penalized for good performance. The idea is to find the downside standard deviation and forget about the upside variation and then create a symmetric total variation by multiplying 
$\sigma_{D}$ by $\sqrt{2}$; the total variance is twice the downside variance and the standard deviation is the square root of the variance. If one thinks of a mirror, both sides are the same.

\section{Mean-Variance in Practice}

I close this chapter with some practical tips regarding the use of meanvariance analysis for real portfolio management. My colleagues at the Frank Russell Company and I devised these ideas and have used them in portfolio applications.

Figures 1.3, 1.7, 1.8, and 1.9 provide insight into the practical use of meanvariance analysis. To minimize the impact of forecast errors and improve portfolio performance, we should do as follows:

1. Modify the output and put minimum and maximum constraints on asset weights to prevent the optimization from jumping on estimation errors;

2. Modify the input to adjust for short-term momentum (over the next year) and long-term (over the past 5-10 years) mean reversion of asset mean returns. Adjustments that have worked well are (a) to shrink individual country estimates toward global estimates using James-Stein, BayesStein, or truncated estimators (see MacLean, Foster, and Ziemba 2002; Hensel and Turner 1998; and Jorion 1985) and (b) to assume that assets that are similar should have similar mean returns over long-term horizons. The latter comes from Turner and Hensel (1993), who found no statistical differences in the returns of major countries in the 1980s; and

3. Use transaction costs for a more accurate representation of reality. Moving to or staying at a near-optimal portfolio may be preferable to incurring the transaction costs of moving to the optimal portfolio. High-turnover strategies are justified only by dramatically different forecasts. There will be a large number of near-optimal portfolios. Portfolios with similar risk and return characteristics can differ in composition.

Using data from 1980-1990 on stocks (S\&P 500 Index), bonds (Lehman Brothers Long-Term Government Bond Index), and cash (Ibbotson Associates' Index), Turner and Hensel obtained the results shown in Table 1.8 for performance over time of constrained and unconstrained optimal portfolios. They used 60-month rolling windows to estimate inputs and compute optimal portfolios. The new portfolio was formed and held for the 61st month. Then, they rolled the data forward one month, dropping the earliest month and adding the latest month, and computed portfolio return for each month for an out-of-sample test. The results indicate that constrained portfolios dominated unconstrained portfolios with higher mean returns, lower standard deviation 
Table 1.8. Constrained and Unconstrained Portfolio Performance, 1985-90

\begin{tabular}{lccccc}
\hline Portfolio Type & $\begin{array}{c}\text { Mean } \\
\text { Return }\end{array}$ & $\begin{array}{c}\text { Standard } \\
\text { Deviation }\end{array}$ & $\begin{array}{c}\text { Minimum } \\
\text { Return }\end{array}$ & $\begin{array}{c}\text { Maximum } \\
\text { Return }\end{array}$ & $\begin{array}{c}\text { Average } \\
\text { Turnover }\end{array}$ \\
\hline Constrained & & & & & \\
10 percent & $1.21 \%$ & $3.78 \%$ & $-13.2 \%$ & $9.5 \%$ & $2.2 \%$ \\
20 percent & 1.14 & 3.86 & -16.0 & 9.9 & 4.3 \\
30 percent & 1.08 & 3.99 & -18.8 & 10.0 & 6.2 \\
Unconstrained & 0.97 & 4.18 & -21.5 & 10.0 & 9.6 \\
$60 / 40$ Benchmark & 1.29 & 3.76 & -10.4 & 9.2 & \\
\hline
\end{tabular}

Source: Based on data from Turner and Hensel.

risk, and lower turnover. The fixed-mix $60 / 40$ stock/bond portfolio dominated in this period of low stock returns.

Table 1.9 depicts six near-optimal portfolios reported in Chopra (1993). Although they have quite different weights, they all have a risk tolerance of 50 (risk-aversion index of 4), which is typical for pension plans.

As an example of the equal future parameter estimates for similar asset classes, consider three levels of shrinkage:

1) assume that the mean returns for all stocks (or stock classes or countries) are equal and the same for bonds;

2) as in 1 but with all stock-stock and bond-bond correlations equal to the within group averages; and

3) equal expected returns, correlations, and variances within asset classes; thus, stock is stock, bonds are bonds, and cash is cash, independent of the country.

Table 1.9. Six Near-Optimal Portfolios, 1985-90

\begin{tabular}{|c|c|c|c|c|c|c|}
\hline \multirow[b]{2}{*}{ Portfolio No. } & \multicolumn{3}{|c|}{ Weight } & \multirow[b]{2}{*}{ Return } & \multirow[b]{2}{*}{ Risk } & \multirow[b]{2}{*}{ Turnover } \\
\hline & Stocks & Bonds & Cash & & & \\
\hline 1 & $9 \%$ & $83 \%$ & $8 \%$ & $1.03 \%$ & $3.48 \%$ & $60 \%$ \\
\hline 2 & 73 & 2 & 25 & 1.17 & 3.52 & 21 \\
\hline 3 & 73 & 0 & 27 & 1.16 & 3.50 & 23 \\
\hline 4 & 9 & 84 & 7 & 1.03 & 3.52 & 61 \\
\hline 5 & 27 & 72 & 1 & 1.10 & 3.53 & 49 \\
\hline 6 & 61 & 0 & 39 & 1.09 & 2.92 & 23 \\
\hline Base & 58 & 23 & 19 & 1.14 & 3.21 & - \\
\hline
\end{tabular}

Source: Based on data from Chopra. 
In this experiment, Chopra used 16 international asset classes (six equities, five bonds, and five cash) during the 1980-90 period. He used 60-month rolling windows to estimate parameters and make subsequent allocations. The tests are out of sample for 1985-1990, with a risk tolerance of 50, and the benchmark portfolio is the mean-variance optimal portfolio based on unadjusted historical inputs. As Table $\mathbf{1 . 1 0}$ shows, the portfolios with adjusted inputs dominated portfolios based on historical inputs in terms of higher mean returns and lower standard deviations. The passive 60/40 fixedmix portfolio also dominated the active portfolio benchmark.

The conclusions are that despite its shortcomings, mean-variance analysis is still widely used for asset-only portfolio management, when options are not part of the asset mix. Simple techniques, such as using appropriate constraints on asset weights and/or adjusting the inputs, can improve the performance of mean-variance portfolios. Experience, judgment, and past behavior of asset classes determine the appropriate constraints.

The results in this chapter will be useful in the models developed in Chapters 3-6. In Chapter 2, I will compare fixed-mix and multiperiod stochastic programming models with scenarios. In addition to handling scenarios, fat tails, and more realistic constraints, the stochastic programming approach can handle uncertain parameters, as opposed to fixed parameters, in meanvariance models.

Table 1.10. Portfolio with Different Inputs, 1980-90

\begin{tabular}{lccccc}
\hline Type of Input & $\begin{array}{c}\text { MonthlyMean } \\
\text { Return }\end{array}$ & $\begin{array}{c}\text { Standard } \\
\text { Deviation }\end{array}$ & $\begin{array}{c}\text { Minimum } \\
\text { Return }\end{array}$ & $\begin{array}{c}\text { Maximum } \\
\text { Return }\end{array}$ & Turnover \\
\hline Active benchmark & $0.82 \%$ & $5.93 \%$ & $-20.6 \%$ & $14.5 \%$ & $10.1 \%$ \\
Equal expected returns & 1.04 & 4.46 & -23.3 & 9.1 & 9.3 \\
Equal returns and correlations & 1.05 & 4.35 & -23.3 & 9.3 & 9.3 \\
Stock/bond/cash & 1.01 & 4.25 & -24.5 & 8.3 & 8.1 \\
Passive benchmark & 0.99 & 3.05 & -12.3 & 7.4 & 1.4 \\
\hline
\end{tabular}




\section{The Stochastic Programming Approach to Asset/Liability Management}

A banker is a fellow who lends you his umbrella when the sun is shining and wants it back the minute it begins to rain.

Mark Twain

What investors want is true diversification and protection from extreme scenarios when it is needed and to be able to plan in advance what they need to do in such situations.

\section{Discrete Scenarios/Fat Tails}

The basic theory of modern finance uses normality as the key assumption in static or discrete-time models and lognormality in continuous-time models.

Sums of random variables converge to normal distributions by the central limit theorem, and sums of normal distributions are normal. Similarly, products of lognormal random variables are lognormal. Hence, these two assumptions are versions of a similar view of the world. These assumptions allow for a clean, elegant theory that is useful as a benchmark and to derive qualitative results. Real asset prices, however, have much fatter tails, especially for short intervals.

Table 2.1 provides insight into how market participants who buy and sell put and call options view the probability distribution of returns for the S\&P 500 Index. The column of standard deviations corresponds to returns below the mean, and the standardized lognormal distribution values reflect this distribution. The next three columns represent implied probability distributions from bid-ask prices of traded put and call options on the S\&P 500 during one period before and two periods after the October 1987 stock market crash. These probabilities are not the true chances of these events occurring (which is unknown) but, rather, reflect the probabilities that the options market prices indicate. Before the crash, the 1-3 standard deviation tail event probabilities from the options were about the same as those from the lognormal model underlying the Black-Scholes options' fair prices. The implied probabilities were 10 to 100 or more times fatter for $4-6$ standard deviation moves. This 
Table 2.1. Cumulative Probabilities of S\&P 500 Returns Computed from Daily Bid-Ask Prices of Puts and Calls

\begin{tabular}{cllll}
\hline \multirow{2}{*}{$\begin{array}{c}\text { Standard } \\
\text { Deviation }\end{array}$} & Standard Lognormal Distribution & $4 / 86-10 / 87$ & $11 / 87-12 / 88$ & $1 / 91-12 / 91$ \\
\cline { 3 - 5 } & 0.000000000000000000000000078 & & 0.0000083 & 0.0000018 \\
9 & 0.000000000000000000011 & & 0.000021 & 0.0000056 \\
8 & 0.00000000000000063 & & 0.000049 & 0.000017 \\
7 & 0.0000000000013 & & 0.00011 & 0.000049 \\
6 & 0.000000001 & 0.00000016 & 0.00026 & 0.00015 \\
5 & 0.00000029 & 0.000014 & 0.00076 & 0.00055 \\
4 & 0.000032 & 0.00025 & 0.0029 & 0.0029 \\
3 & 0.0013 & 0.0014 & 0.011 & 0.015 \\
2 & 0.023 & 0.026 & 0.045 & 0.051 \\
1 & 0.16 & 0.19 & 0.16 & 0.15 \\
0 & 0.50 & 0.52 & 0.47 & 0.45 \\
\hline
\end{tabular}

Source: Based on data from Jackwerth and Rubinstein (1996).

finding is consistent with the behavioral economics finding that small probabilities are overestimated (see Kahneman and Tversky 1979). After the 1987 crash, the effect was even stronger because investors were willing to pay much more for deep out-of-the-money puts for portfolio insurance or other types of protection. The last two columns show tail probabilities 10 to 100 times fatter than the precrash levels.

An interesting question is: What is the return, on average, to investors who buy puts and calls at different strike prices on the S\&P 500? Tompkins, Ziemba, and Hodges (2003) have studied this question. Ali (1979), Snyder (1978) and others going back to the 1940s have documented a favorite longshot bias in racetrack betting. The data show that bets on high-probability, low-payoff gambles have high expected value and those on low-probability, high-payoff gambles have low expected value. For example, a 1-10 horse, having more than a 90 percent chance of winning, has an expected value of about US\$1.03 (for every US\$1 bet), whereas a 100-1 horse has an expected value of only about 14 cents for each dollar invested. Hence, for this bet, the fair odds are about 700-1. The favorite long-shot bias exists in other sportsbetting markets. (See Hausch, Lo, and Ziemba 1994, and for a survey of results and references, see Hausch and Ziemba forthcoming 2004.)

Ziemba and Hausch (1986) studied the expected return per dollar bet versus the odds levels for more than 300,000 horse races. The North American public underbets favorites and overbets long shots. This bias has appeared in 
many years and in all sizes of racetrack betting pools. ${ }^{1}$ The expected return varies with the odds level (see Figure 2.1). The expected return is positive for bets on extreme favorites, but for all other bets, the expected return is negative. The favorite long-shot bias is monotone across odds, and the drop in expected value is very large for the lower-probability horses. The effect of differing track take-transaction costs-can be seen in the California versus New York lines, which show expected returns versus odds or probabilities for pari-mutuel pooled bets; for fixed-odds bookie wagers, the result is about the same. ${ }^{2}$ The bookies create odds to clear the market and equilibrate bettor demand knowing bettor biases.

Thaler and Ziemba (1988) suggested some reasons for this bias; bettors, for example, might overestimate the chances that long-shot bets will win, or, as shown in Kahneman and Tversky, bettors might overweight small probabilities of winning when the potential payout is large (in calculating their utility). Bettors may also derive utility simply from the hope associated with holding a ticket on a long shot; not only is it more fun to pick a long shot to win over a favorite, it has more bragging rights. I have used this idea in consulting on the design of lotteries for the British Columbia Lottery Corporation, Singapore Pools, and British Lotto. Transaction costs related to the time cost of cashing tickets also play a role because bettors prefer collecting large payoffs rather than small payoffs. Also, some bettors may choose horses for irrational reasons, such as the name of the horse or its number. This behavior occurs in Hong Kong and the Kentucky Derby (see Ziemba and Hausch 1987) and tends to flatten the favorite long-shot bias curve.

Are the buyers of puts and calls on the S\&P 500 futures similar in behavior to the racetrack bettors? The demand for options comes from hedging and speculative investing. The primary use of put options is for hedging. Some demand also exists for speculative investing. The hedging demand for puts implies that the expected return is negative, and more so for deep out-of-themoney options. The main hedging demand for call options is for those selling them in covered-call strategies, which depresses their price. If this strategy were the sole mechanism for dealing in call options, it should result in an increase in the expected return for out-of-the-money call options, which Tompkins, Ziemba, and Hodges did not observe. The expected loss from the purchase of deep out-of-the-money call options more likely results from speculative activity similar to that for the favorite long-shot bias.

1While the horseracing favorite long-shot bias is quite stable and pervasive, exceptions exist in Asian racetrack markets (see Busche and Hall 1988 and Busche 1994, reprinted in Hausch, Lo, and Ziemba).

2 Figgis (1974), Lord Rothschild (1978), and Ziemba and Hausch (1986) provide British data. 

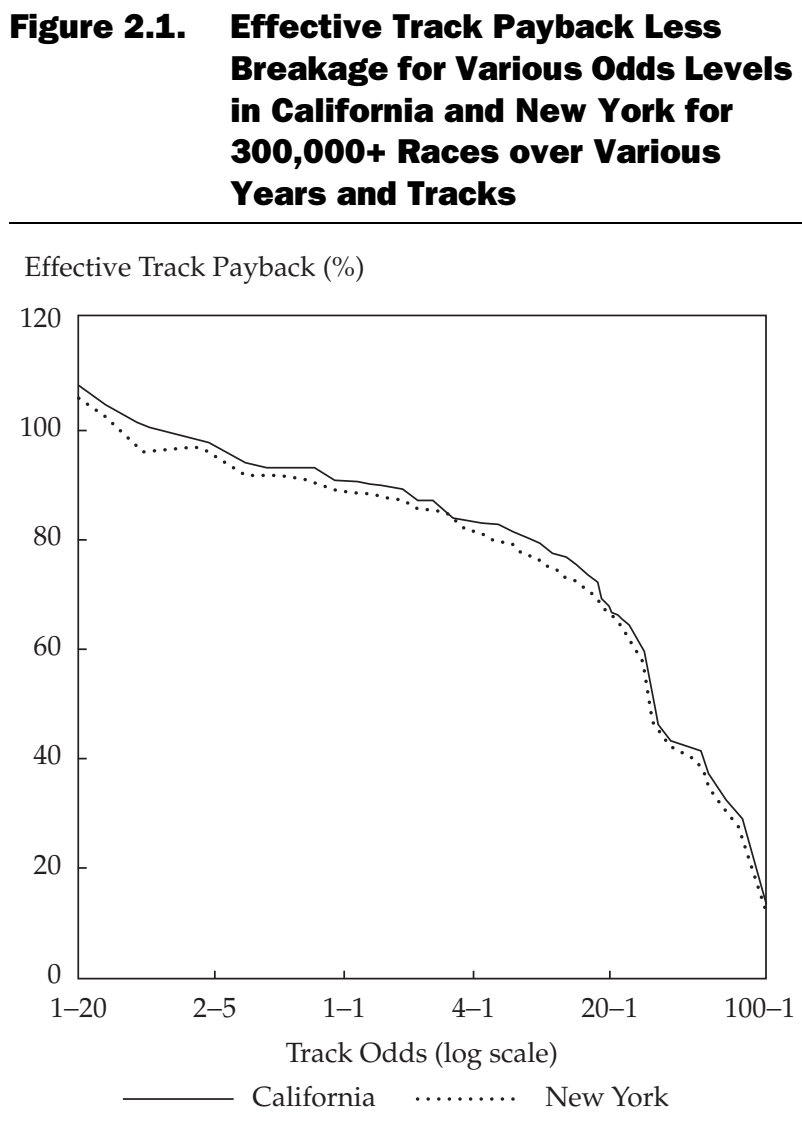

Note: Breakage is the rounding down of payoffs to round numbers (e.g., 6.87 to 6.80 ).

Source: Based on data from Ziemba and Hausch (1986).

Tompkins, Ziemba, and Hodges collected a large sample of independent events, namely, the prices of the put and call options on S\&P 500 futures from the Chicago Mercantile Exchange from March 1985 to September 2002. Table 2.2 and Figure 2.2 show their results for three-month options. They also investigated the Financial Times Stock Exchange (FTSE) 100 and onemonth options for the S\&P 500 and FTSE. With some minor changes, the results are broadly similar to those of the three-month options. A comparison of the racing and S\&P 500 results shows that the probabilities equal the reciprocal of the odds +1 . 
Table 2.2. Expected Return per $\$ 1$ Bet vs. Odds Levels: Three-Month Options on S\&P 500 Futures, March 1985-September 2002

\begin{tabular}{|c|c|c|c|c|c|c|c|c|c|}
\hline \multicolumn{5}{|c|}{ Call Options } & \multicolumn{5}{|c|}{ Put Options } \\
\hline $\begin{array}{l}\text { Odds } \\
\text { (\%) }\end{array}$ & $\begin{array}{c}\# \\
\text { Obs. }\end{array}$ & $\begin{array}{c}\text { Average } \\
\text { Payoff }\end{array}$ & $\begin{array}{l}\text { Std. Dev. } \\
\text { of Payoff }\end{array}$ & $\begin{array}{l}t \text {-Test } \\
\text { vs. } \$ 1\end{array}$ & $\begin{array}{l}\text { Odds } \\
(\%)\end{array}$ & $\begin{array}{c}\# \\
\text { Obs. }\end{array}$ & $\begin{array}{l}\text { Average } \\
\text { Payoff }\end{array}$ & $\begin{array}{l}\text { Std. Dev. } \\
\text { of Payoff }\end{array}$ & $\begin{array}{l}t \text {-Test } \\
\text { vs. } \$ 1\end{array}$ \\
\hline $0.95-1.00$ & 47 & 1.0010 & 0.3204 & 0.02 & $0.95-1.00$ & 37 & 0.8998 & 0.4493 & $-1.35^{\star}$ \\
\hline $0.90-0.95$ & 60 & 1.0561 & 0.4605 & 0.95 & $0.90-0.95$ & 44 & 0.8662 & 0.5872 & $-1.50^{*}$ \\
\hline $0.85-0.90$ & 66 & 1.1231 & 0.5704 & $1.76^{\star *}$ & $0.85-0.90$ & 50 & 0.8426 & 0.7265 & $-1.53^{\star}$ \\
\hline $0.80-0.85$ & 67 & 1.1407 & 0.6990 & $1.66^{\star \star *}$ & $0.80-0.85$ & 54 & 0.7937 & 0.8120 & $-1.86^{\star *}$ \\
\hline $0.75-0.80$ & 63 & 1.0938 & 0.5953 & 1.25 & $0.75-0.80$ & 53 & 0.8137 & 0.8950 & $-1.51^{*}$ \\
\hline $0.70-0.75$ & 64 & 1.1366 & 0.7732 & $1.41^{*}$ & $0.70-0.75$ & 51 & 0.7879 & 0.9979 & $-1.51^{*}$ \\
\hline $0.65-0.70$ & 62 & 1.1461 & 0.8648 & $1.33^{\star}$ & $0.65-0.70$ & 53 & 0.7702 & 0.9648 & $-1.73^{\star *}$ \\
\hline $0.60-0.65$ & 59 & 1.1311 & 0.9972 & 1.01 & $0.60-0.65$ & 54 & 0.6215 & 1.0258 & $-2.70^{* * *}$ \\
\hline $0.55-0.60$ & 58 & 1.1727 & 1.1154 & 1.18 & $0.55-0.60$ & 50 & 0.8225 & 1.2458 & -1.01 \\
\hline $0.50-0.55$ & 54 & 0.9890 & 1.0410 & -0.08 & $0.50-0.55$ & 56 & 0.5807 & 1.1377 & $-2.76^{\star * *}$ \\
\hline $0.45-0.50$ & 56 & 1.1365 & 1.3925 & 0.73 & $0.45-0.50$ & 51 & 0.7344 & 1.4487 & $-1.31^{*}$ \\
\hline $0.40-0.45$ & 58 & 1.2063 & 1.6012 & 0.98 & $0.40-0.45$ & 56 & 0.6785 & 1.5367 & $-1.57^{\star}$ \\
\hline $0.35-0.40$ & 51 & 0.9770 & 1.7015 & -0.10 & $0.35-0.40$ & 56 & 0.4744 & 1.2383 & $-3.19^{\star \star \star}$ \\
\hline $0.30-0.35$ & 54 & 0.9559 & 1.6041 & -0.20 & $0.30-0.35$ & 62 & 0.6257 & 1.6791 & $-1.76^{\star \star}$ \\
\hline $0.25-0.30$ & 59 & 1.2923 & 2.7539 & 0.81 & $0.25-0.30$ & 64 & 0.6316 & 1.8231 & $-1.62^{\star}$ \\
\hline $0.20-0.25$ & 53 & 1.1261 & 2.5378 & 0.36 & $0.20-0.25$ & 65 & 0.6426 & 1.9854 & $-1.45^{\star}$ \\
\hline $0.15-0.20$ & 55 & 0.8651 & 2.0742 & -0.48 & $0.15-0.20$ & 64 & 0.6696 & 2.2441 & -1.18 \\
\hline $0.10-0.15$ & 56 & 1.2262 & 3.6982 & 0.46 & $0.10-0.15$ & 66 & 0.6602 & 2.6359 & -1.05 \\
\hline $0.05-0.10$ & 53 & 1.5085 & 5.3370 & 0.69 & $0.05-0.10$ & 66 & 0.6432 & 3.4256 & -0.85 \\
\hline $0.00-0.05$ & 39 & 0.0123 & 0.1345 & $-44.89^{\star \star *}$ & $0.00-0.05$ & 57 & 0.7525 & 5.6025 & -0.33 \\
\hline All options & 69 & 1.1935 & 2.4124 & 0.67 & All options & 69 & 0.6212 & 2.5247 & -1.25 \\
\hline
\end{tabular}

Note: When the hypothesis is rejected at a 90 percent level or above, the $t$-statistic appears in bold. \# Obs. $=$ number of observations; std. dev. $=$ standard deviation.

* Significant at the 10 percent level.

**Significant at the 5 percent level.

$* * *$ Significant at the 1 percent level.

Source: Based on data from Tompkins, Ziemba, and Hodges.

In Table 2.2, the first column is the odds of finishing in the money, as measured by $N\left(d_{2}\right)$ or $N\left(-d_{2}\right)$ from the Black-Scholes (1973) formula. The next column is the number of options that fall into various 5 percent bands. The average payoff for a US\$1 investment in that option band appears next, followed by the standard deviation of the option payoffs in that band. The final column is a one-sided $t$-test of the hypothesis that the mean return is equal to the initial investment of US\$1. 
Figure 2.2. Expected Return per $\$ 1$ Bet vs. Odds Levels: Three-Month Calls and Puts on S\&P 500 Futures, March 1985-September 2002

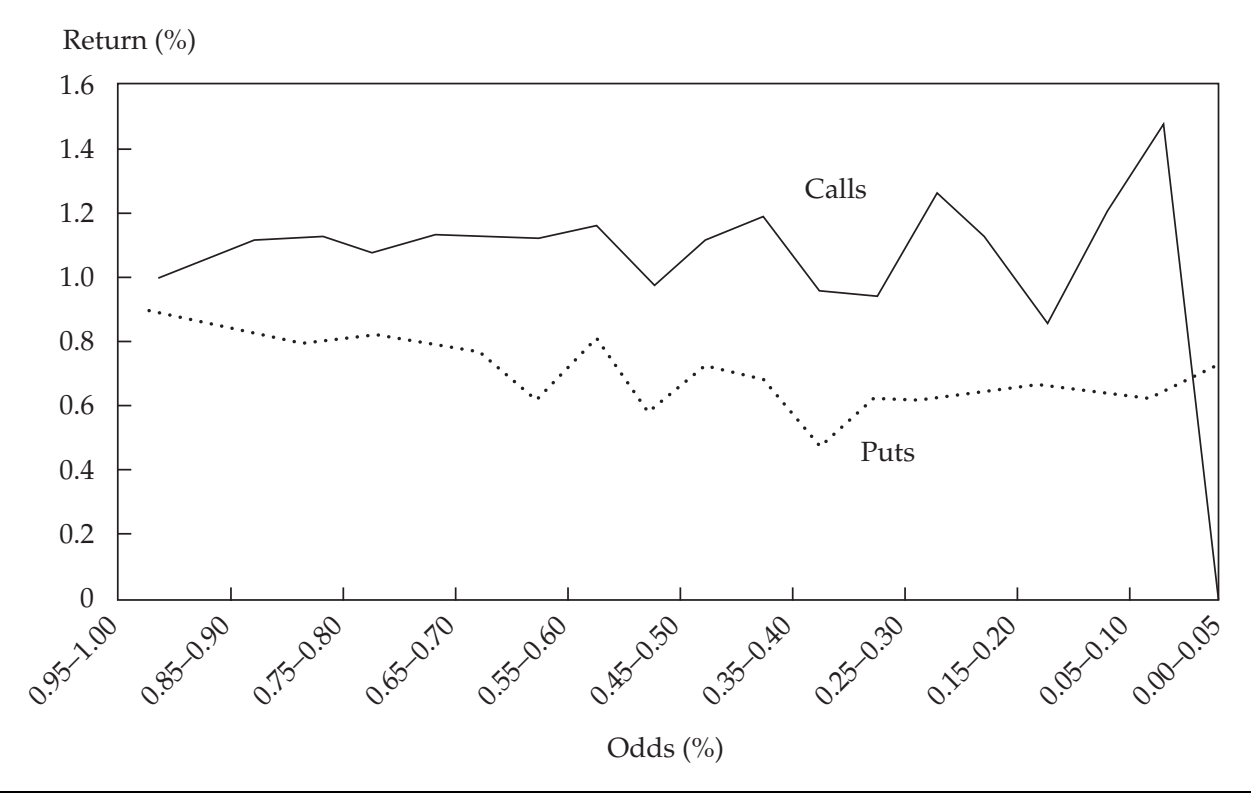

Source: Based on data from Tompkins, Ziemba, and Hodges.

For the three-month call options on S\&P 500 futures, there is a favorite long-shot bias, as in horseracing. The in-the-money call options return more than the US\$1 investment, on average. The at-the-money and out-of-the-money calls return about the US\$1 investment. At the lowest level of $0-5$ percent, a $t$-statistic could not be estimated because no call option in this range paid off during the March 1985-September 2002 period. This result confirms the hypothesis of Figlewski (1989) that investors see out-of-the-money call options in the same way they see lottery tickets; they overpay for deep out-of-themoney call options on S\&P 500 futures.

No put options (on average) pay more than the US\$1 initial investment. The average payoff decreases as the probabilities decrease, which is analogous to the horseracing favorite long-shot bias. This result is consistent with the contention of Jackwerth and Rubinstein (1996) and Dumas, Fleming, and Whaley (1998) that investors view put options as insurance policies and are willing to accept an expected loss to protect their stockholdings. 


\section{Extreme Scenario Examples}

Here is a short little quiz. The damage from earthquakes in California from 1971 to 1993 is shown in Table 2.3 and Figure 2.3. In these data, some years have zero damage, some have 5 , and so on. The highest loss ratio is 129 . The question is: How much earthquake damage occurred in California in the next year? Can we forecast the 1994 value? When I present this question in lectures, most people answer 10 or less. The 1989 peak of 129 and the 47 in 1990 are not considered in most observers' calculations. They look like outliers because the main probability mass is from 1972-1986, when the maximum damage was less than 10 .

Table 2.3. Earthquake Loss Ratios per Year

\begin{tabular}{cc|cc|cc}
\hline Year & Loss Ratio & Year & Loss Ratio & Year & Loss Ratio \\
\hline 1971 & 17.4 & 1979 & 2.2 & 1987 & 22.8 \\
1972 & 0.0 & 1980 & 9.2 & 1988 & 11.5 \\
1973 & 0.6 & 1981 & 0.9 & 1989 & 129.0 \\
1974 & 3.4 & 1982 & 0.0 & 1990 & 47.0 \\
1975 & 0.0 & 1983 & 2.9 & 1991 & 17.2 \\
1976 & 0.0 & 1984 & 5.0 & 1992 & 3.2 \\
1977 & 0.7 & 1985 & 1.3 & 1993 & 3.2 \\
1978 & 1.5 & 1986 & 9.3 & 1994 & - \\
\hline
\end{tabular}

Source: Based on data from Embrechts, Resnick, and Samovodmitsky (1998).

The answer for 1994 is 2,272.7. And the peak shown in Panel A of Figure 2.3 that was so high became relatively small in the next year. Hence, as shown in Panel B of Figure 2.3, extreme events can occur that are beyond the range of all previous events. There may have been earthquakes in California 400 years ago that were bigger than Northridge's (greater Los Angeles) in 1994, but few people and buildings were around then and the earthquakes could not destroy much. In Figure 2.3, the years 1989 and 1990 appear as similar to the 1972-86 years, and all the 1971-93 years appear to have similar values. What we have is an outcome way beyond the range of all past data. Thirty-two insurance companies in the United States declared bankruptcy in 1998, and 2001 (post-9/11), 2002, and 2003 (through May) were also difficult years.

The number of such extreme events is increasing. Below is a list of events that occurred in 1998 that were beyond the range of the previous data. These rare, beyond-previous-data events are not so rare. Highly levered speculative investing has occurred for hundreds of years. But recently, more and more 
Figure 2.3. Earthquake Losses per Year in California

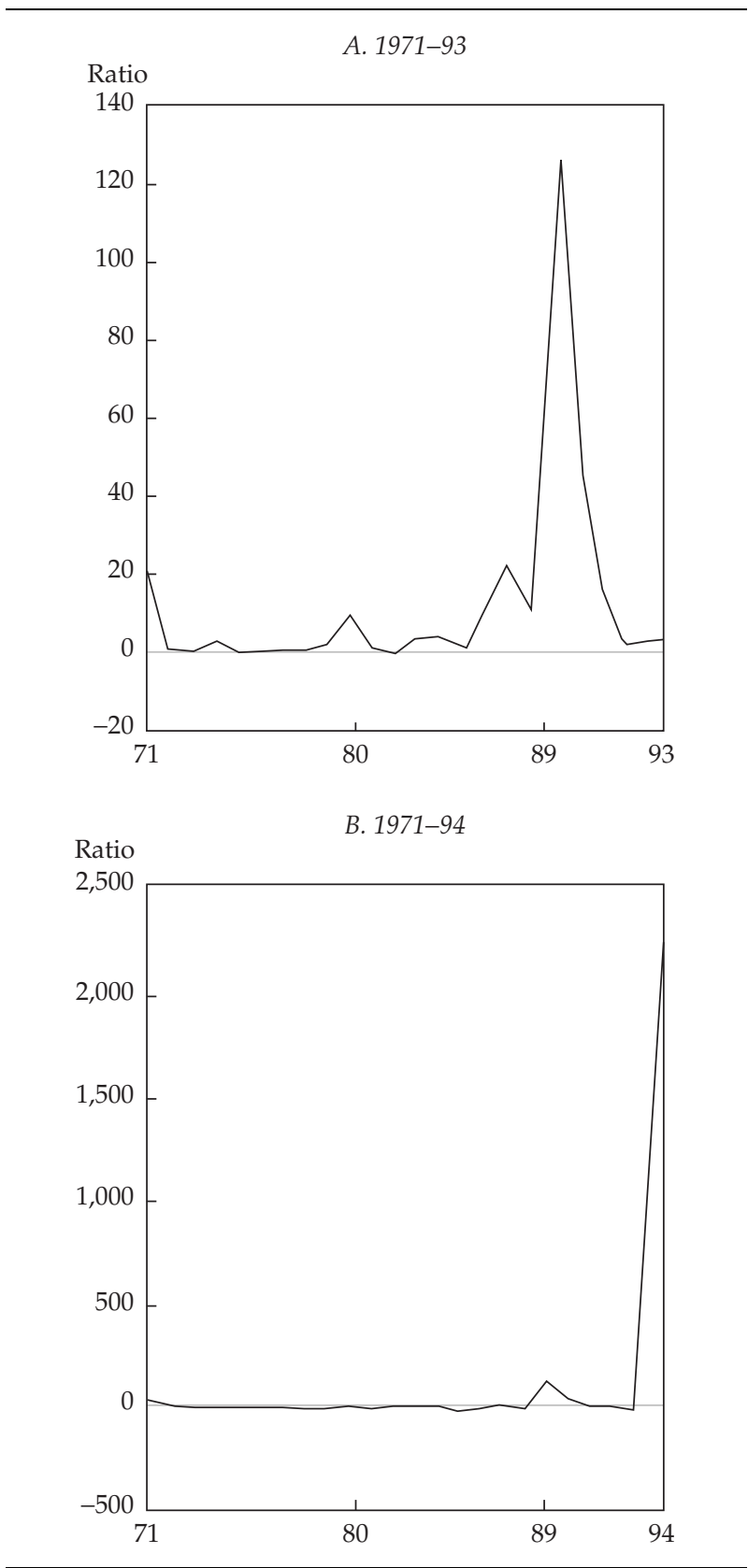


complex derivative instruments have become available, helping to cause the growth of these rare events. The New York risk management consultants at Capital Markets Risk have a list of "first-time" market events-events that conventional (not stochastic programming) risk-control models cannot foresee because the events have occurrences way beyond the range of previous historical occurrences. Normally, 4 or 5 such events occur each year; 77 occurred in 1998! Here are 17 of them:

- 18 May: Indonesia's rupiah collapsed to 17,000 to the U.S. dollar.

- 17 Aug: Russia defaulted on ruble-denominated debt; the ruble collapsed by two-thirds.

- 31 Aug: The DJIA plunged 512.61 points or 6.37 percent (on -1 day, the strongest trading day of the month).

- Jul/Sep: U.S. banks suffered the worst derivatives losses ever-US\$445 million.

- 24 Sep: Hedge fund Long-Term Capital Management was bailed out with US\$3.6 billion.

- 27 Sep: Japan Leasing Association filed for bankruptcy with US\$17.9 billion in liabilities, the biggest financial failure since World War II.

- 5 Oct: 30-year U.S. Treasury yields hit a record 4.74 percent low.

- 7 Oct: The U.S. dollar plunged 7.8 percent against the yen, the largest one-day loss in 12 years.

- 8 Oct: China's yuan soared to an all-time high of 8.2777 to the U.S. dollar.

- 9 Oct: Japan's Nikkei Index sank to 11,542, the lowest since 1984.

- 13 Oct: London's FTSE 100 soared a record 214.2 points.

- 2 Nov: The U.S. savings rate sank to 0.2 percent.

- 5 Nov: Some leading western banks cut yen deposit rates to negative values.

- 11 Nov: Shares of theglobe.com skyrocketed more than tenfold in the first day of trading.

- 30 Nov: U.S. mortgage rates fell to 6.64 percent, the lowest since 1967.

- 3 Dec: Eleven European countries cut interest rates simultaneously.

- 10 Dec: World oil prices slid below US\$10 a barrel, the lowest since 1986.

\section{A Bond-Stock Return Crash Danger Model}

In May 1988, I was invited by Yamaichi Securities to interview to be the first Yamaichi visiting professor of finance at the University of Tsukuba, a Japanese national university. Yamaichi wished to try to establish the study of finance, especially investments, in Japanese universities, which was not generally taught. They established a five-year program with five such visiting professors in succession. The teaching at the university (I taught investments, security 
market anomalies, futures, and options) was supplemented with a two-day-aweek consulting position in Tokyo, around 60 kilometers southwest of Tsukuba, at the Yamaichi Research Institute associated with Yamaichi Securities, then the fourth largest securities firm in Japan and one of the 10 largest in the world.

In my interview, I asked whether I could study market imperfections (anomalies) and stock-market crashes in two study groups with some of the young Yamaichi Research Institute employees who also came up to Tsukuba for my classes. My proposal was accepted, and each study group (with about 10 eager young students in each group) proceeded with my lectures on the U.S. experience and their helping me to investigate the Japanese situation. We focused on the postwar $1948-88$ period. ${ }^{3}$ We had a good idea right away that the Japanese policies that had led to astronomically high land and stock prices and massive trade surpluses would lead to disaster and Japan would eventually lose most of the money it had received from selling cars, stereos, and the like. We made a list of prestigious buildings that the Japanese had overpaid for in the 1987-89 era; even at the height of Japan's economic power in 1989, only 3 percent of Japanese assets were invested abroad (see Ziemba and Schwartz 1992).

My study groups started in August 1988 and ended a year later. I was asked to remain as a consultant for the fall of 1988 to complete a factor model, which is discussed in Schwartz and Ziemba (2000) and was originally presented at a Berkeley Program in Finance meeting in Santa Barbara in September 1990. The factor model used anomaly ideas, such as mean reversion, momentum, and value, embedded in 30 variables to separate and rank stocks by their future mean performance from best to worst for all the stocks on the Tokyo Stock Exchange (TSE) first section, which was about 86 percent of the total capitalization. The model performed well out of sample and hence was useful for hedge fund long-short trading as well as long-only investing. The hedge fund Buchanan Partners in London discovered the model and hired me to help them in their warrant trading, which was largely long underpriced warrants and short overpriced stocks. The firm's trading was successful, and the model, which was estimated using data during a stock market rise, still worked when the decline came because variables, such as earnings, were the key drivers of the returns. 4

In the study group, I came up with a simple model in 1988 with only a single variable-the difference between stock and bond rates of return. The idea was that stocks and bonds compete for investment dollars, and when

${ }^{3}$ Much of what I learned appears in Ziemba and Schwartz $(1991,1992)$ and Stone and Ziemba (1993).

4An update of Japanese anomalies to 1994 appears in Comolli and Ziemba (2000). 
interest rates are low, stocks are favored, and when interest rates are high, bonds are favored. The main thing that I wished to focus on was that when the measure-the difference between these two rates, the long bond yield minus the earnings yield (the reciprocal of the $\mathrm{P} / \mathrm{E}$ ratio) - was very large, then there was a high chance of a stock market crash. A crash is a 10 percent fall in the index within one year. The model explains the October $1987 \mathrm{crash}$. That application is how this idea came to me. Table 2.4 shows this relationship for the U.S. market. The bold numbers in Table 2.4 indicate the existence of extreme danger in the stock market; 30-year government bond yields were much higher than usual stock market yields, as measured by the reciprocal of the last year's reported $\mathrm{P} / \mathrm{E}$. These high interest rates invariably lead to a stock market crash. Here, the danger indicator moved across a statistical 95 percent confidence line in April. The market ignored this signal and eventually crashed in October 1987. Most investors ignored a similar signal in the S\&P 500 in 1999, and then a crash began in August 2000 and a weak stock market ensued in 2001-2002, which is discussed below. 5

In 1988-1989, I asked one of my colleagues in the study group, Sugheri Iishi, to check this measure for Japan, as shown in Figure 2.4 from 1980 to mid-1990. Twenty 10+ percent crashes occurred during the 1949-89 period. We found that whenever this measure was in the danger zone (that is, outside a 95 percent confidence band), within one year, a crash of 10 percent or more from the current level would occur. Not all crashes had the measure in the danger zone, but whenever it was, there was a crash with no misses.

So, the measure was successful at predicting future crashes-but there was no precise way to know when they would occur or how deep they would be. Long-run mean reversion, however, suggests that the longer the bull run and the more overpriced the measure, the longer and deeper the decline. Thus, one can use the measure as part of an econometric system to estimate future scenarios.

Each time the spread exceeded the 4.23 percent cutoff (which was higher than 95 percent confidence), a crash would occur. The measure was way in the danger zone in late 1989, and the decline (the 21st crash) began on the first trading day of 1990, with the Nikkei Stock Average (NSA) peaking at 38,916 (see Figure 2.4). Unfortunately, Yamaichi's top management did not listen to Iishi when I sent him up to explain our results in Japanese; there was much greater danger in the market than they thought in 1989. By 1995, Yamaichi Securities had declared bankruptcy and ceased to exist.

5 For a study of this measure from 1970 to 2003 in five major markets, see Berge and Ziemba (2003). 
Table 2.4. S\&P 500, P/E, Government Bond Yield, and the Yield Premium over Stocks, January 1984-August 1988

\begin{tabular}{|c|c|c|c|c|c|}
\hline Month & S\&P 500 & $\mathrm{P} / \mathrm{E}$ & $\begin{array}{l}\text { 30-Year } \\
\text { Govt. Bond } \\
\text { (a) }\end{array}$ & $\begin{array}{c}1 /(\mathrm{P} / \mathrm{E}) \\
\text { (b) }\end{array}$ & (a) $-(b)$ \\
\hline \multicolumn{6}{|l|}{1986} \\
\hline Jan & 208.19 & 14.63 & 9.32 & $6.84 \%$ & 2.48 \\
\hline Feb & 219.37 & 15.67 & 8.28 & 6.38 & 1.90 \\
\hline Mar & 232.33 & 16.50 & 7.59 & 6.06 & 1.53 \\
\hline Apr & 237.98 & 16.27 & 7.58 & 6.15 & 1.43 \\
\hline May & 238.46 & 17.03 & 7.76 & 5.87 & 1.89 \\
\hline Jun & 245.30 & 17.32 & 7.27 & 5.77 & 1.50 \\
\hline Jul & 240.18 & 16.31 & 7.42 & 6.13 & 1.29 \\
\hline Aug & 245.00 & 17.47 & 7.26 & 5.72 & 1.54 \\
\hline Sep & 238.27 & 15.98 & 7.64 & 6.26 & 1.38 \\
\hline Oct & 237.36 & 16.85 & 7.61 & 5.93 & 1.68 \\
\hline Nov & 245.09 & 16.99 & 7.40 & 5.89 & 1.51 \\
\hline Dec & 248.60 & 16.72 & 7.33 & 5.98 & 1.35 \\
\hline \multicolumn{6}{|l|}{1987} \\
\hline Jan & 264.51 & 15.42 & 7.47 & 6.49 & 0.98 \\
\hline $\mathrm{Feb}$ & 280.93 & 15.98 & 7.46 & 6.26 & 1.20 \\
\hline Mar & 292.47 & 16.41 & 7.65 & 6.09 & 1.56 \\
\hline Apr & 289.32 & 16.22 & 9.56 & 6.17 & 3.39 \\
\hline May & 289.12 & 16.32 & 8.63 & 6.13 & 2.50 \\
\hline Jun & 301.38 & 17.10 & 8.40 & 5.85 & 2.55 \\
\hline Jul & 310.09 & 17.92 & 8.89 & 5.58 & 3.31 \\
\hline Aug & 329.36 & 18.55 & 9.17 & 5.39 & 3.78 \\
\hline Sep & 318.66 & 18.10 & 9.66 & 5.52 & 4.14 \\
\hline Oct & 280.16 & 14.16 & 9.03 & 7.06 & 1.97 \\
\hline Nov & 245.01 & 13.78 & 8.90 & 7.26 & 1.64 \\
\hline Dec & 240.96 & 13.55 & 9.10 & 7.38 & 1.72 \\
\hline \multicolumn{6}{|l|}{1988} \\
\hline Jan & 250.48 & 12.81 & 8.40 & 7.81 & 0.59 \\
\hline Feb & 258.10 & 13.02 & 8.33 & 7.68 & 0.65 \\
\hline Mar & 265.74 & 13.42 & 8.74 & 7.45 & 1.29 \\
\hline Apr & 262.61 & 13.24 & 9.10 & 7.55 & 1.55 \\
\hline May & 256.20 & 12.92 & 9.24 & 7.74 & 1.50 \\
\hline Jun & 270.68 & 13.65 & 8.85 & 7.33 & 1.52 \\
\hline Jul & 269.44 & 13.59 & 9.18 & 7.36 & 1.82 \\
\hline Aug & 263.73 & 13.30 & 9.30 & 7.52 & 1.78 \\
\hline
\end{tabular}

Source: Based on data from Ziemba and Schwartz (1991). 


\section{Figure 2.4. Bond-Stock Yield Differential Model for the Nikkei Stock Average, 1980-90}

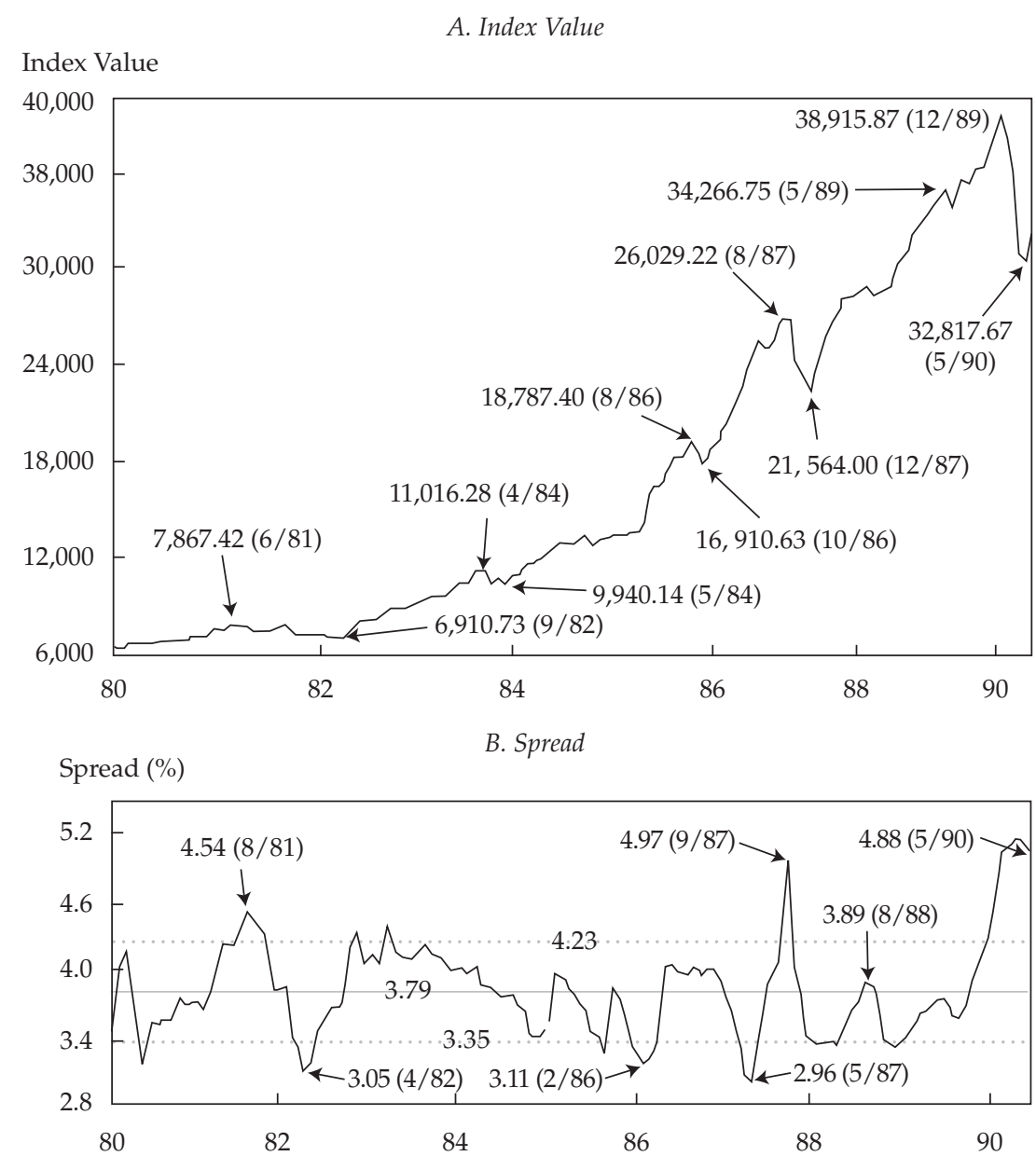

Note: Data through 29 May 1990. Shaded lines in Panel B denote upper limit, mean, and lower limit. Source: Based on data from Ziemba and Schwartz (1991).

The model also indicates that the valuation was still high as of 29 May 1990 , at 4.88 percent. Not much later, the 22 nd crash began. Interestingly, at the bottom of the 22nd crash on 1 October 1990, the NSA was at 20,222, which was almost exactly the mean. Meanwhile, the same calculation on 29 May 1990 for the S\&P 500, as shown in Figure 2.5, shows that the U.S. market was cheap-that is, below the mean-following the September 1987 peak of 4.42 
Figure 2.5. Bond-Stock Yield Differential Model for the S\&P 500, 1980-90

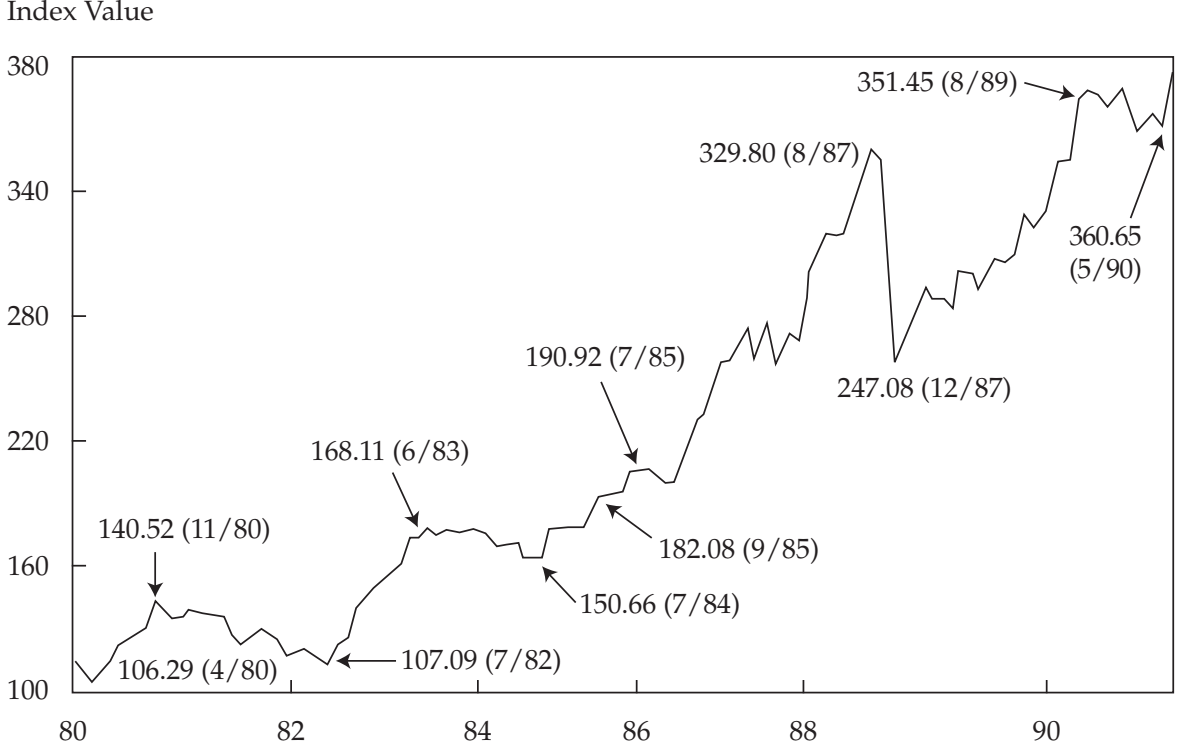

Spread (\%)

B. Spread

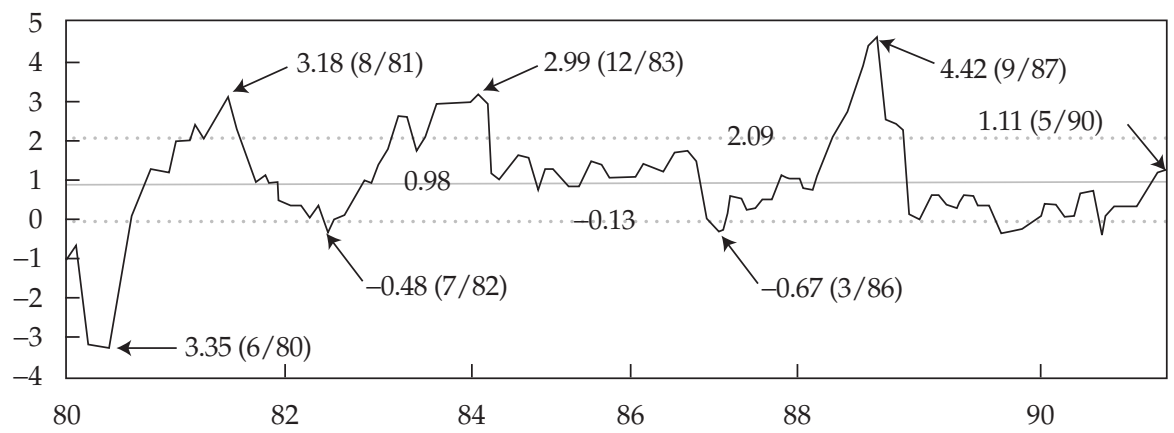

Note: Data through 29 May 1990. Shaded lines in Panel B denote upper limit, mean, and lower limit. Source: Based on data from Ziemba and Schwartz (1991).

percent. The 29 May 1990 value of 1.11 percent, however, was slightly above the mean level and the highest since the late fall of 1987.

Japan has had weak stock and land markets since the beginning of 1990, but the future looks better in May 2003. This situation has been caused by many factors, political as well as economic. But rising interest rates for eight 
full months leading up to August 1990 (see Figure 2.6) were a major factor. The extreme tightening of an overlevered economy was too much. Cheap and easily available money, which caused the big run-up in asset prices in the 1980s, turned into expensive and unavailable money in the 1990s.

\section{Figure 2.6. Short-Term Interest Rates in Japan, June 1984-June 1995}

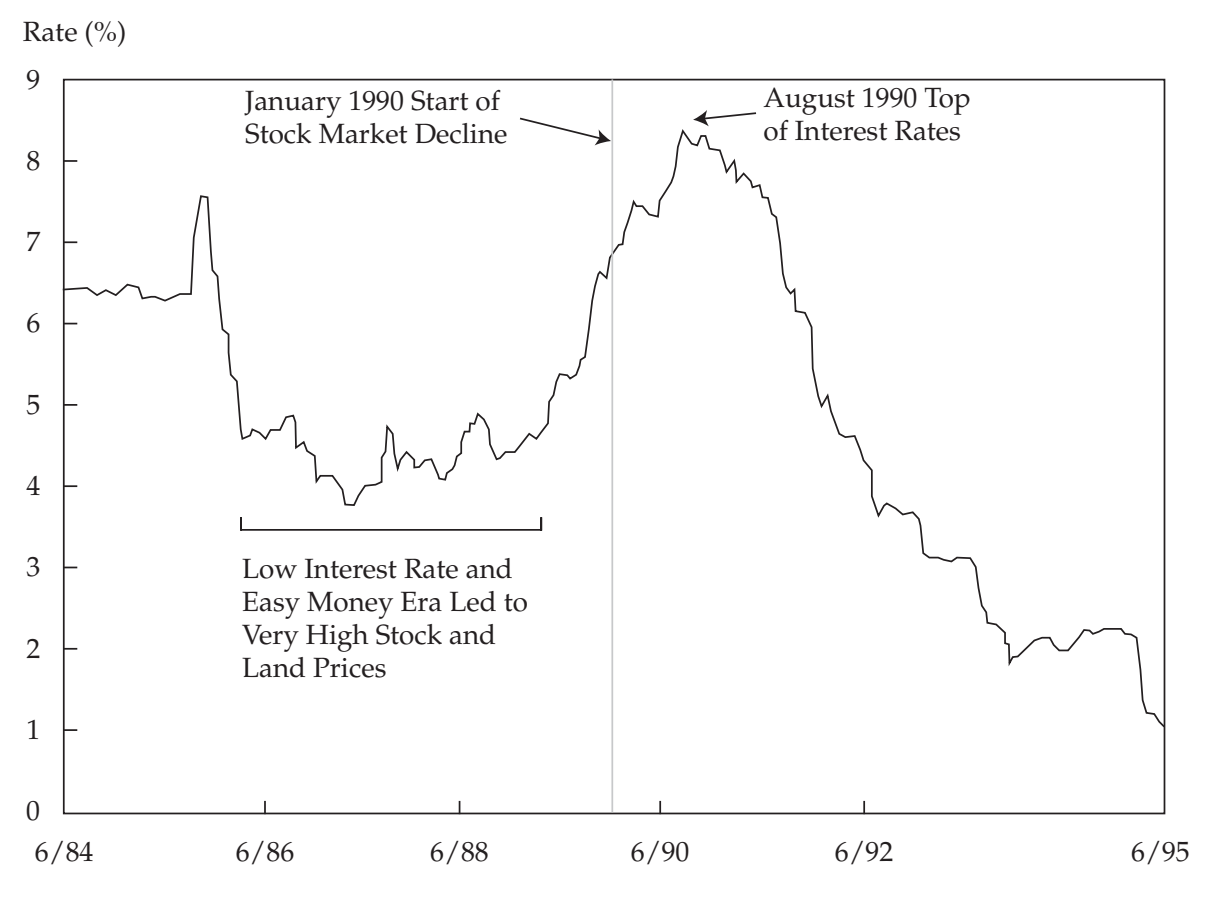

\section{The 2002-03 Crash in the S\&P 500}

The S\&P 500 was at 470.42 at the end of January 1995. It was at about 750 in late 1996, at the time of Alan Greenspan's famous speech on irrational exuberance in the U.S. stock market. It peaked at 1,527.46 on 24 March 2000, fell to 1,356.56 on 4 April 2000, and then rose close to its peak, reaching 1,520 on 1 September 2000, the Friday before Labor Day. The bond-stock return crash danger model was in the danger zone for much of 1999, and it got deeper in danger as the year progressed and the S\&P 500 rose from 1,229.23 at the end of December 1998 to $1,469.25$ at the end of December 1999. Meanwhile, the 
$\mathrm{P} / \mathrm{E}$ ratio was flat, increasing only from 32.34 to 33.29 , and long-bond yields rose from 5.47 to 6.69 percent. 6

Table 2.5 and Figure 2.7 detail this progression from January 1995 to December 1999. The spread reached 3 percent, which was well in the 95 percent confidence danger band in April, and rose to 3.69 percent in December 1999. The stage was set for a crash, which did occur, as shown in Panel A of Figure 2.8.7 Meanwhile, Hong Kong's Hang Seng Index, as shown in Figure 2.9, was also in the danger zone. The model for Japan was hard to interpret because of high $\mathrm{P} / \mathrm{E}$ ratios and interest rates that were close to zero. One had a close to 0-0 situation, so the model did not seem to apply to Japan in 1999. With return differences close to zero, the model was not in the danger zone (see Figure 2.10).

We witnessed a dramatic fall in the S\&P 500 from its peak of 1,527 in March 2000 to its September 2000 low of 1,085. Further declines occurred in 2001 and 2002 (see Panel A and Panel B of Figure 2.8). The lowest close as of May 2003 was 768.63 , on 10 October 2002. This decline was similar to previous crashes. There were other signals, as noted by Bagnell (1999):

History shows that a period of shrinking breadth is usually followed by a sharp decline in stock values of the small group of leaders. Then the broader market takes a more modest tumble. (Business, p. 1)

Figure 2.11 shows the rise in Canada's Toronto Stock Exchange (TSE300) during 1999 and 2000 and the subsequent fall in 2001 and 2002. During 1999, the TSE300 gained 31 percent, but the gain was only 3 percent without three very high $\mathrm{P} / \mathrm{E}$, large-cap stocks. The largest gainer in market value, Nortel Networks, peaked at US\$120 and was at about US\$1.70 at the end of 2002 and US\$3 at the end of May 2003.8

The concentration of stock market gains into very few stocks, with momentum and size being the key variables predicting performance, had increased before 1997 in Europe and North America. Table 2.6 shows that in 1998, the largest-cap stocks had the highest return in North America and Europe, but small-cap stocks outperformed in Asia and Japan. The situation was similar in 1995-1999, particularly in 1998 and 1999.

6The S\&P 500 fell to 1,085 on 17 September 2000, prior to 9/11. Panel B of Figure 2.8 shows the decline following $9 / 11$.

7Long-term mean reversion indicates that the 1996-2000 S\&P 500 values were too high relative to 1991-1995, and a linear interpolation of the latter period gives a value close to that in May 2003.

8This occurrence is shown in Figure 1 in Appendix B (p. 5), which is available online in the Supplementary Material area at www.aimrpubs.org/rf/issues/v2003n6/pdf/AppendixB.pdf. 
Table 2.5. Bond-Stock Yield Differential Model for the S\&P 500, 1995-99

\begin{tabular}{|c|c|c|c|c|c|}
\hline Year/Month & S\&P 500 & $\begin{array}{l}\mathrm{P} / \mathrm{E} \\
\text { (a) }\end{array}$ & $\begin{array}{l}\text { 30-Yr. Govt. Bond } \\
\text { (b) }\end{array}$ & $\begin{array}{l}\text { Return on Stocks } \\
\qquad(\mathrm{c}=1 / \mathrm{a})\end{array}$ & $\begin{array}{l}\text { Crash Signal } \\
\quad(b-c)\end{array}$ \\
\hline \multicolumn{6}{|l|}{1995} \\
\hline Jan & 470.42 & 17.10 & $8.02 \%$ & $5.85 \%$ & 2.17 \\
\hline Feb & 487.39 & 17.75 & 7.81 & 5.63 & 2.18 \\
\hline Mar & 500.71 & 16.42 & 7.68 & 6.09 & 1.59 \\
\hline Apr & 514.71 & 16.73 & 7.48 & 5.98 & 1.50 \\
\hline May & 533.40 & 16.39 & 7.29 & 6.10 & 1.19 \\
\hline Jun & 544.75 & 16.68 & 6.66 & 6.00 & 0.66 \\
\hline Jul & 562.06 & 17.23 & 6.90 & 5.80 & 1.10 \\
\hline Aug & 561.88 & 16.20 & 7.00 & 6.17 & 0.83 \\
\hline Sep & 584.41 & 16.88 & 6.74 & 5.92 & 0.82 \\
\hline Oct & 581.50 & 16.92 & 6.55 & 5.91 & 0.64 \\
\hline Nov & 605.37 & 17.29 & 6.36 & 5.78 & 0.58 \\
\hline Dec & 615.93 & 17.47 & 6.25 & 5.72 & 0.53 \\
\hline \multicolumn{6}{|l|}{1996} \\
\hline Jan & 636.02 & 18.09 & $6.18 \%$ & $5.53 \%$ & 0.65 \\
\hline Feb & 640.43 & 18.86 & 6.46 & 5.30 & 1.16 \\
\hline Mar & 645.50 & 19.09 & 6.82 & 5.24 & 1.58 \\
\hline Apr & 654.17 & 19.15 & 7.07 & 5.22 & 1.85 \\
\hline May & 669.12 & 19.62 & 7.21 & 5.10 & 2.11 \\
\hline Jun & 670.63 & 19.52 & 7.30 & 5.12 & 2.18 \\
\hline Jul & 639.96 & 18.80 & 7.23 & 5.32 & 1.91 \\
\hline Aug & 651.99 & 19.08 & 7.17 & 5.24 & 1.93 \\
\hline Sep & 687.31 & 19.65 & 7.26 & 5.09 & 2.17 \\
\hline Oct & 705.27 & 20.08 & 6.95 & 4.98 & 1.97 \\
\hline Nov & 757.02 & 20.92 & 6.79 & 4.78 & 2.01 \\
\hline Dec & 740.74 & 20.86 & 6.73 & 4.79 & 1.94 \\
\hline \multicolumn{6}{|l|}{1997} \\
\hline Jan & 786.16 & 21.46 & $6.95 \%$ & $4.66 \%$ & 2.29 \\
\hline Feb & 790.82 & 20.51 & 6.85 & 4.88 & 1.97 \\
\hline Mar & 757.12 & 20.45 & 7.11 & 4.89 & 2.22 \\
\hline Apr & 801.34 & 20.69 & 7.23 & 4.83 & 2.40 \\
\hline May & 848.28 & 21.25 & 7.08 & 4.71 & 2.37 \\
\hline Jun & 885.14 & 22.09 & 6.93 & 4.53 & 2.40 \\
\hline Jul & 954.29 & 23.67 & 6.78 & 4.22 & 2.56 \\
\hline Aug & 899.47 & 22.53 & 6.71 & 4.44 & 2.27 \\
\hline Sep & 947.28 & 23.29 & 6.70 & 4.29 & 2.41 \\
\hline Oct & 914.62 & 22.67 & 6.46 & 4.41 & 2.05 \\
\hline Nov & 955.40 & 23.45 & 6.27 & 4.26 & 2.01 \\
\hline Dec & 970.43 & 23.88 & 6.15 & 4.19 & 1.96 \\
\hline
\end{tabular}


Table 2.5. Bond-Stock Yield Differential Model for the S\&P 500, 1995-99 (continued)

\begin{tabular}{|c|c|c|c|c|c|}
\hline Year/Month & S\&P 500 & $\begin{array}{l}\mathrm{P} / \mathrm{E} \\
\text { (a) }\end{array}$ & $\begin{array}{l}\text { 30-Yr. Govt. Bond } \\
\text { (b) }\end{array}$ & $\begin{array}{l}\text { Return on Stocks } \\
\qquad(\mathrm{c}=1 / \mathrm{a})\end{array}$ & $\begin{array}{l}\text { Crash Signal } \\
\quad(b-c)\end{array}$ \\
\hline \multicolumn{6}{|l|}{1998} \\
\hline Jan & 980.28 & 24.05 & $6.01 \%$ & $4.16 \%$ & 1.85 \\
\hline Feb & $1,049.34$ & 25.09 & 6.00 & 3.99 & 2.01 \\
\hline Mar & $1,101.75$ & 27.71 & 6.11 & 3.61 & 2.50 \\
\hline Apr & $1,111.75$ & 27.56 & 6.03 & 3.63 & 2.40 \\
\hline May & $1,090.82$ & 27.62 & 6.10 & 3.62 & 2.48 \\
\hline Jun & $1,133.84$ & 28.65 & 5.89 & 3.49 & 2.40 \\
\hline Jul & $1,120.67$ & 28.46 & 5.83 & 3.51 & 2.32 \\
\hline Aug & 97.28 & 27.42 & 5.74 & 3.65 & 2.09 \\
\hline Sep & $1,017.01$ & 26.10 & 5.47 & 3.83 & 1.64 \\
\hline Oct & $1,098.67$ & 27.41 & 5.42 & 3.65 & 1.77 \\
\hline Nov & $1,163.63$ & 31.15 & 5.54 & 3.21 & 2.33 \\
\hline Dec & $1,229.23$ & 32.34 & 5.47 & 3.09 & 2.38 \\
\hline \multicolumn{6}{|l|}{1999} \\
\hline Jan & $1,279.64$ & 32.64 & $5.49 \%$ & $3.06 \%$ & 2.43 \\
\hline $\mathrm{Feb}$ & $1,238.33$ & 32.91 & 5.66 & 3.04 & 2.62 \\
\hline Mar & $1,286.37$ & 34.11 & 5.87 & 2.93 & 2.94 \\
\hline Apr & $1,335.18$ & 35.82 & 5.82 & 2.79 & 3.03 \\
\hline May & $1,301.84$ & 34.60 & 6.08 & 2.89 & 3.19 \\
\hline Jun & $1,372.71$ & 35.77 & 6.36 & 2.80 & 3.56 \\
\hline Jul & $1,328.72$ & 35.58 & 6.34 & 2.81 & 3.53 \\
\hline Aug & $1,320.41$ & 36.00 & 6.35 & 2.78 & 3.57 \\
\hline Sep & $1,282.70$ & 30.92 & 6.50 & 3.23 & 3.27 \\
\hline Oct & $1,362.92$ & 31.61 & 6.66 & 3.16 & 3.50 \\
\hline Nov & $1,388.91$ & 32.24 & 6.48 & 3.10 & 3.38 \\
\hline Dec & $1,469.25$ & 33.29 & 6.69 & 3.00 & 3.69 \\
\hline
\end{tabular}

Source: Based on data from Berge and Ziemba (2003).

The influential book Irrational Exuberance by Robert Shiller (2000), a behavioral finance economist at Yale University, hit the market in April 2000. It was a monumental success in market timing, with an especially bearish view that is consistent with Figure 2.7 and Table 2.5. Shiller's data, as shown in Figure 2.12, document very high P/Es in relation to earnings in 2000, with most of the rise occurring in the 1995-2000 period, which is similar to the data shown in Table 2.5 for the S\&P 500. Clearly, in 1996-2000, the stock market was overpriced relative to historical norms. 


\section{Figure 2.7. Bond-Stock Yield Differential Model for the S\&P 500,} January 1990-December 1999

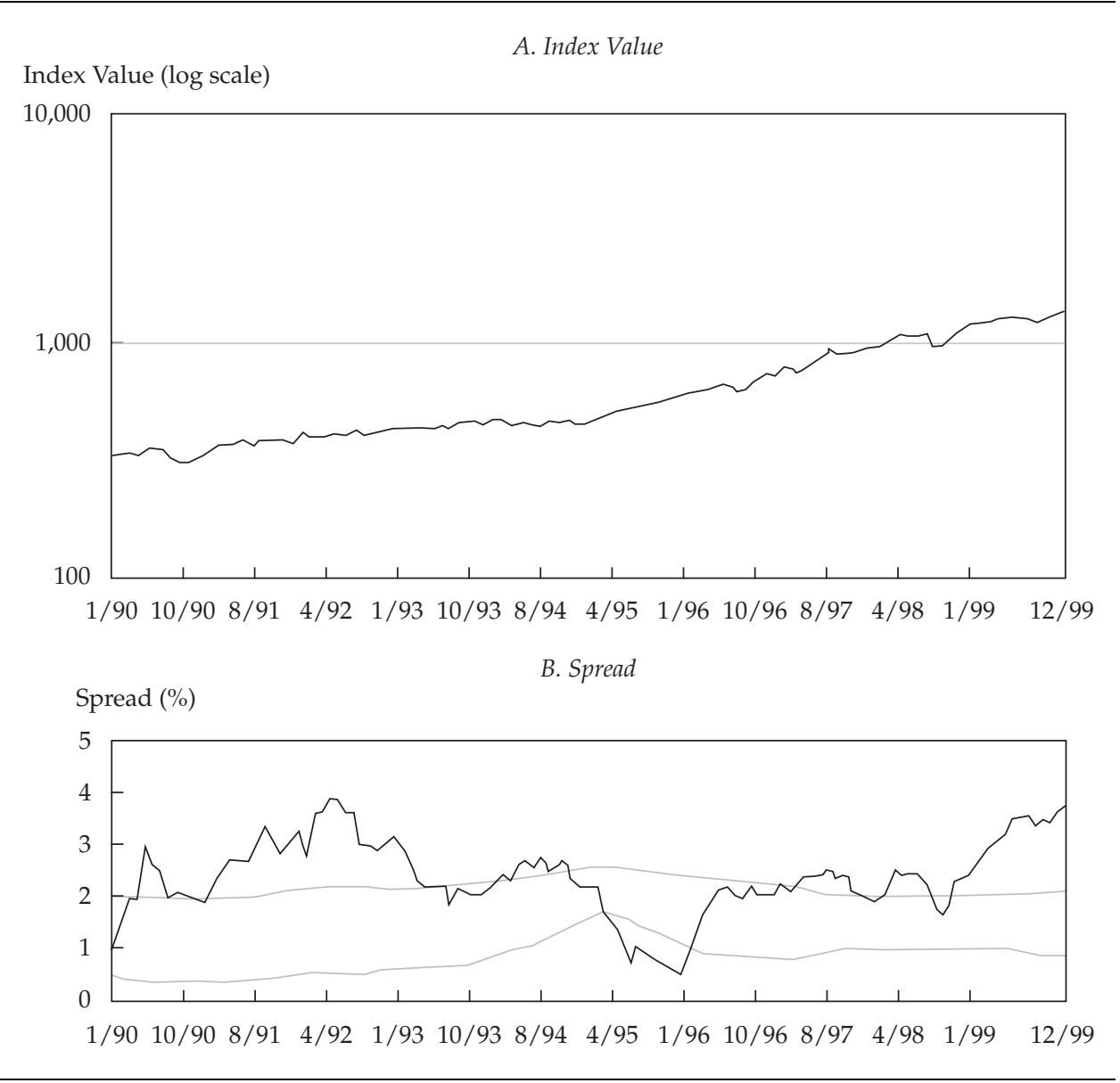

Note: Shaded lines in Panel B denote upper and lower limit.

Source: Based on data from Berge and Ziemba (2003).

Shiller had been predicting a crash since 1996, as reported by Campbell and Shiller (1998). He has remained defiantly bearish, as in Campbell and Shiller (2001), which is an update of the 1998 paper, and in recent interviews (up to May 2003). His case has been helped by three largely unpredictable bad scenarios: the 9/11 attacks on the United States, the June/July 2002 crises of accounting confidence in the United States, and the 2003 U.S./British war with Iraq. One could argue that the second bad scenario was a direct 


\section{Figure 2.8. The S\&P 500}

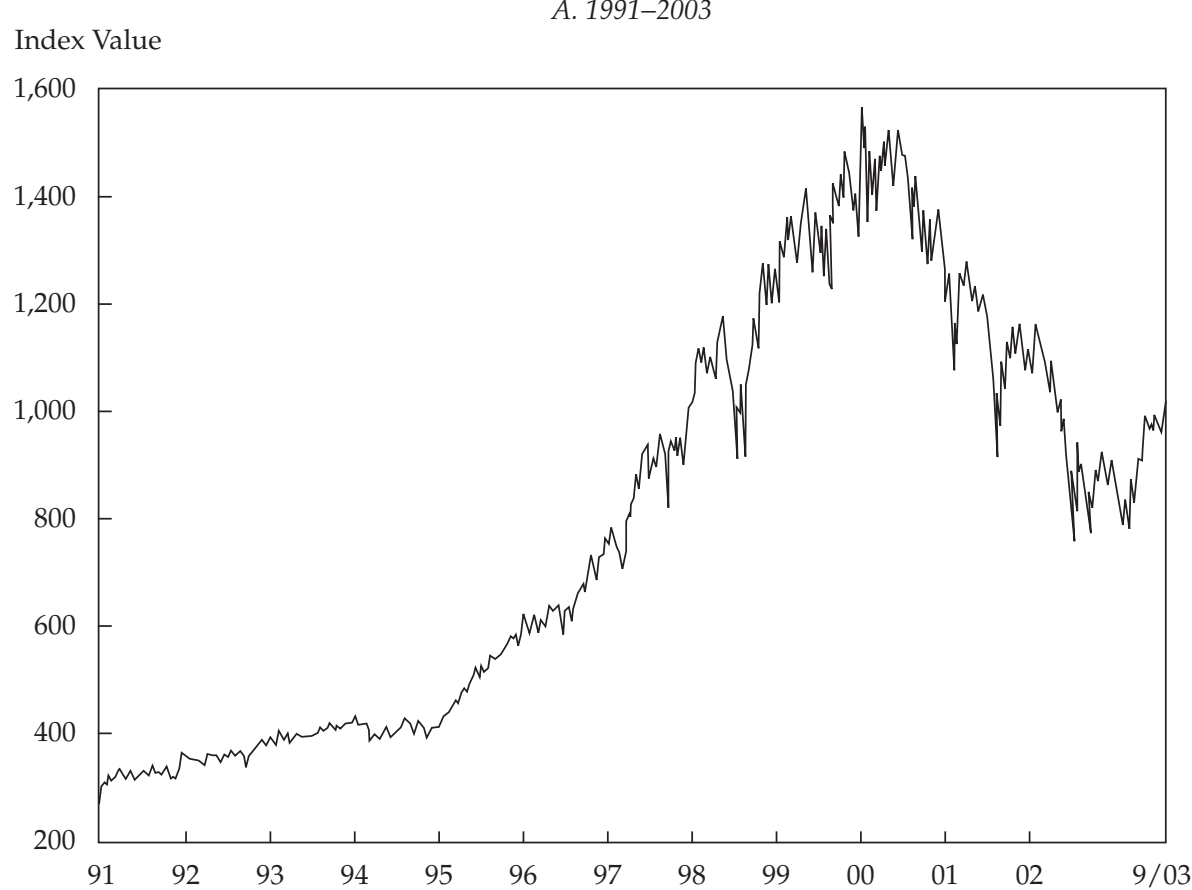

Index Value

B. Around 9/11

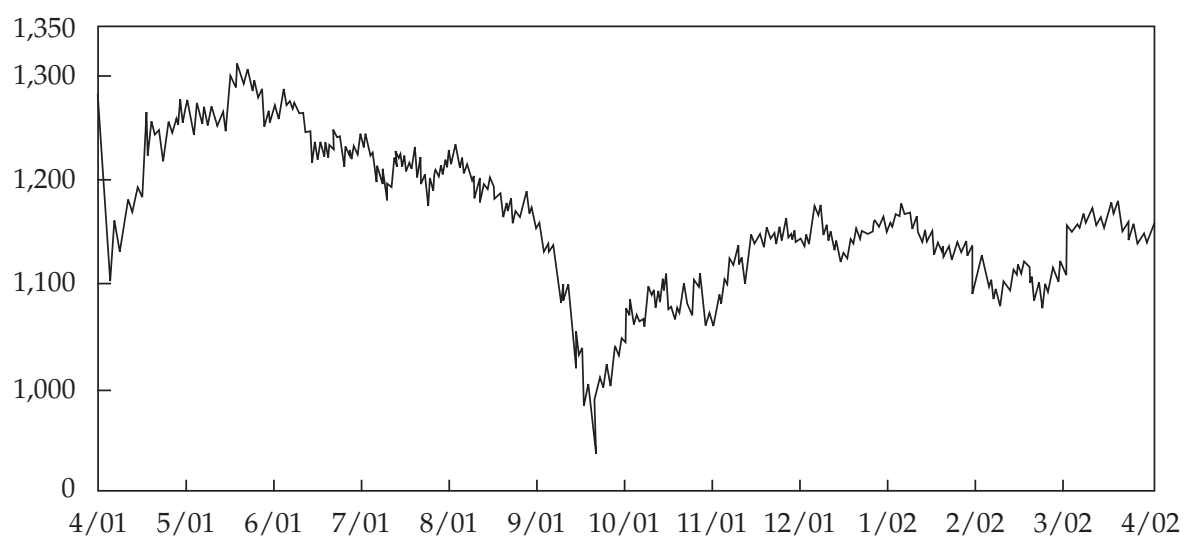

Source: Based on data from Bloomberg. 


\section{Figure 2.9. Hang Seng Bond-Stock Yield Differential Model Using Five- Year Government Bonds, January 1995-December 1999}
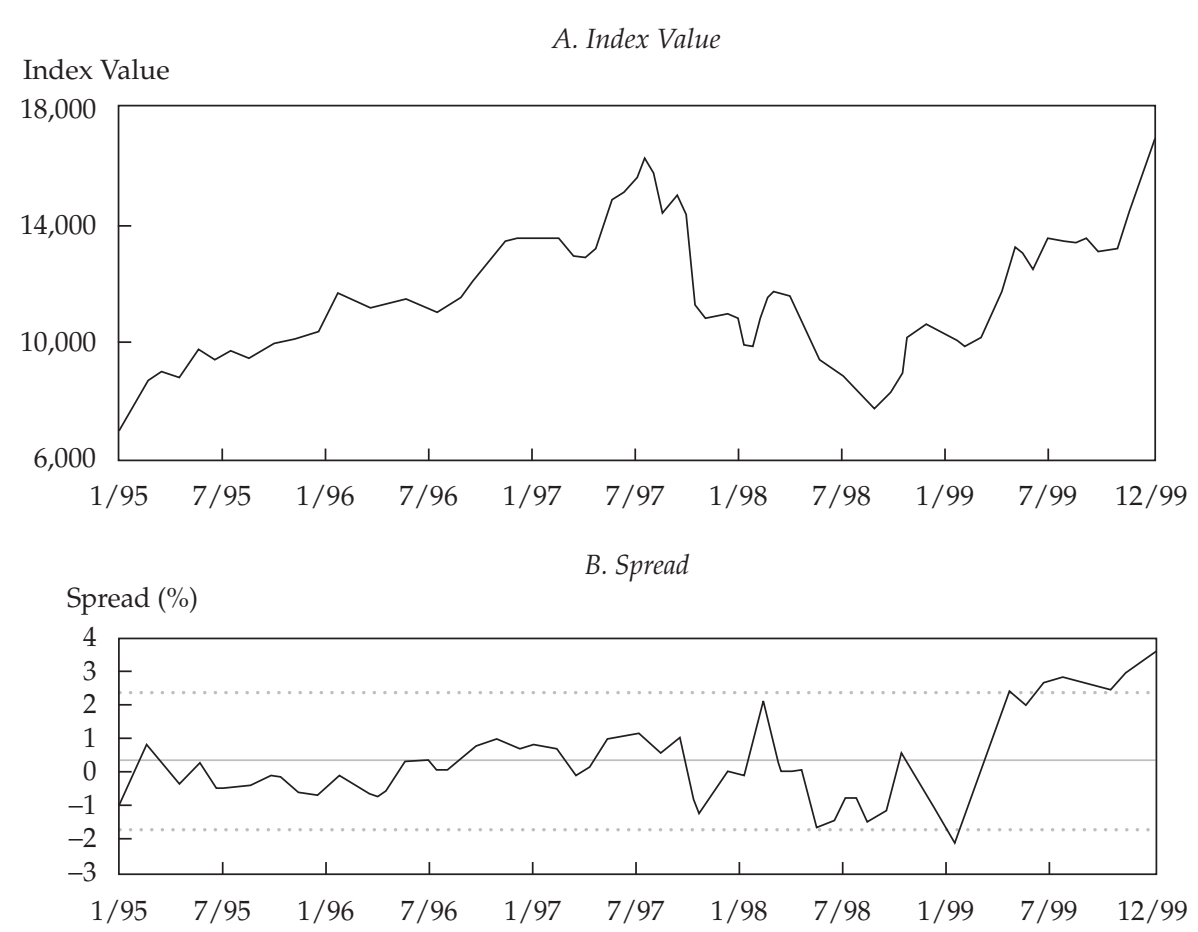

Note: Shaded lines in Panel B denote upper limit, mean, and lower limit. Bond-stock yield differential mean and standard deviation calculated for October 1994-December 1999.

Source: Based on data from Berge and Ziemba (2003).

consequence of the 1996-99 bubble period, as did the Economist (2002) and Warren Buffett and Peter Drucker in interviews in 2002. The latter two sages saw this scenario coming a long time ago. Also, the third bad scenario was a consequence of the first.

This monograph is about the stochastic programming approach to asset, liability, and wealth management, so the main points most relevant for my analysis are:

1. We should be able to use such measures as the bond-stock yield differential and such data as those provided by Shiller to create better scenarios. In this monograph, I argue that the mean is by far the most important aspect of return distributions. Figure 2.13, depicting the S\&P 500 in 2000-2002, serves as a reminder of this finding. 
Figure 2.10. Nikkei Stock Average and Bond-Stock Yield Differential Model for 10-Year Government Bonds, January 1990-April 1998

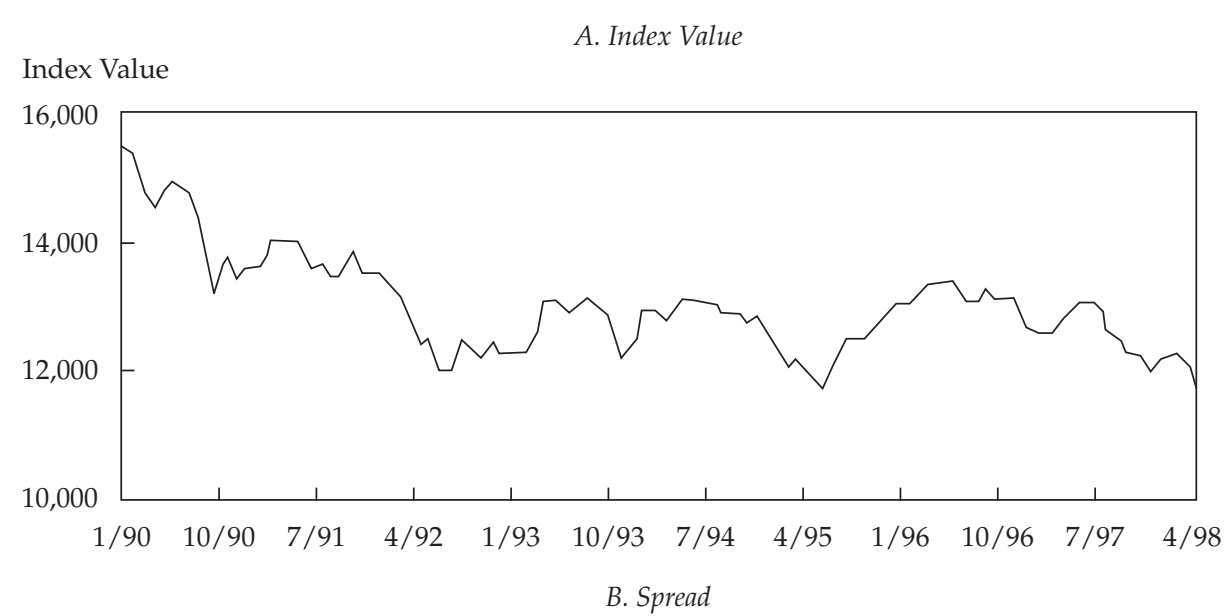

Spread (\%)

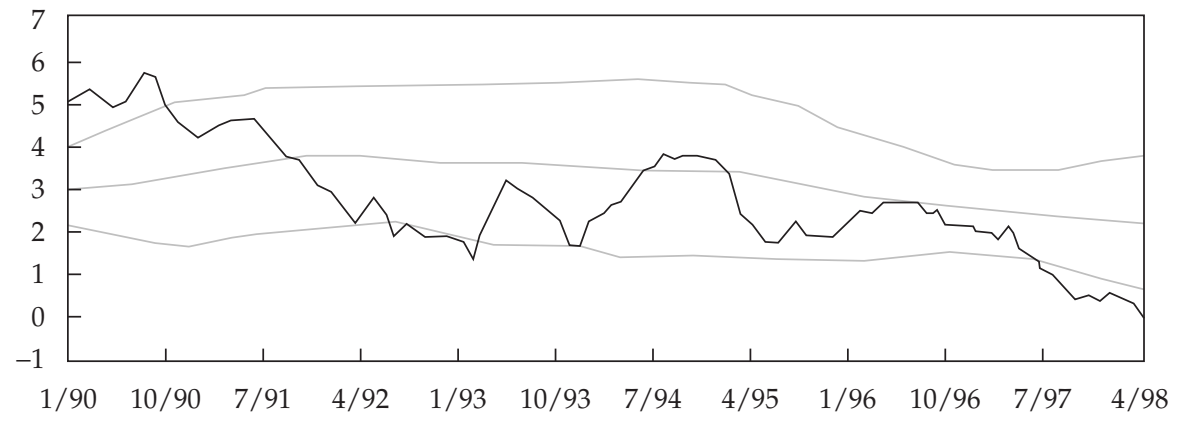

Note: Shaded lines in Panel B denote upper limit, mean, and lower limit. Bond-stock yield differential mean and standard deviation calculated for October 1994-August 1998.

Source: Based on data from Berge and Ziemba (2003).

2. The extent of such danger measures also suggests that the entire distribution from which scenarios are drawn should be shifted left toward lower and more volatile returns. We know that volatility increases as markets decline. Koivu, Pennanan, and Ziemba (2003) showed one way to create better scenarios.

3. The evidence is high that stocks outperform bonds, T-bills, and most other financial assets in the long run (see Siegel 2002; Dimson, Marsh, and Staunton 2002; and Table 2.7, Figure 2.14, and Figure 2.15). Stocks generally outperform in times of inflation and bonds outperform in times 


\section{Figure 2.11. The Toronto Stock Exchange,} February 1998-January 2003

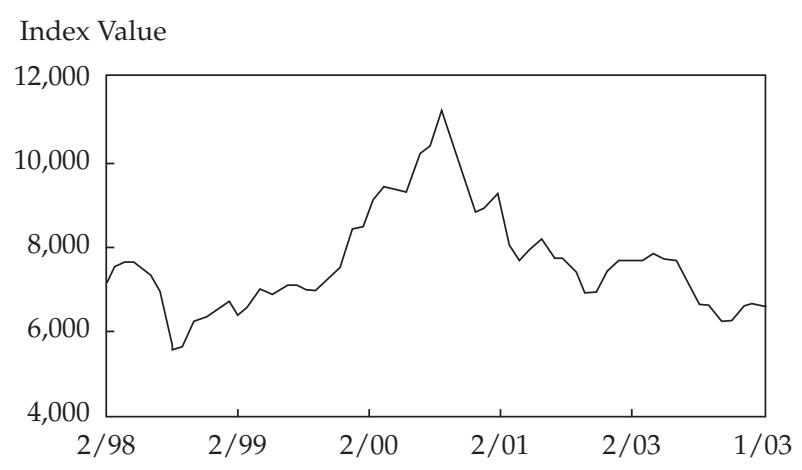

of deflation (see, for example, Smith 1924). Why do stocks generally outperform bonds? As has been said, a major reason is that businesses retain earnings, which go on to create more earnings and dividends too. 9 In times of growth, firms borrow at fixed cost with the expectation of earning positive economic profit, so in the long term, equities, as a reflection of this positive income creation, should grow at the rate of productivity.

4. Occasionally, stocks underperform alternative asset classes for long periods. Figure 2.15 shows this phenomenon for the DJIA from 1885 to 2001 in 2001 dollars, and Figure 2.13 shows the $2000-02$ period for the S\&P 500 and U.S. Government bonds. When bonds outperform stocks, as in this latter period, they are usually negatively correlated with stocks as well; see Figure 2.16, which has rolling correlations. Between 1982 and 1999, the return of equities over bonds was more than 10 percent a year in European Union countries. The question is whether we are moving back to a period during which the two asset classes move against each other or whether the phenomenon will prove to be temporary. Moreover, the historical evidence, since 1802 for the United States and since 1700 for the United Kingdom, indicates that the longer the period, the more likely this dominance. Siegel showed that in all 20-year periods from 1926 to 2001, U.S. equities outperformed bonds, and for 30-year horizons, based on the past data, it is optimal (with a mean-variance model) to be more than 100 percent in stocks and have a short position in bonds. Siegel used various risk tolerance measures, such as ultraconservative and risk taking. These

${ }^{9}$ From the review of Smith by J.M. Keynes in 1925, quoted in Buffett (2001). 
Figure 2.12. Stock Prices, Earnings. and PE, January 1871-January 2000

A. Real SEP 500 Composite Price Index, Monthly (upper series) and Real SEP 500 Composite Earnings (lower series)

Index Value

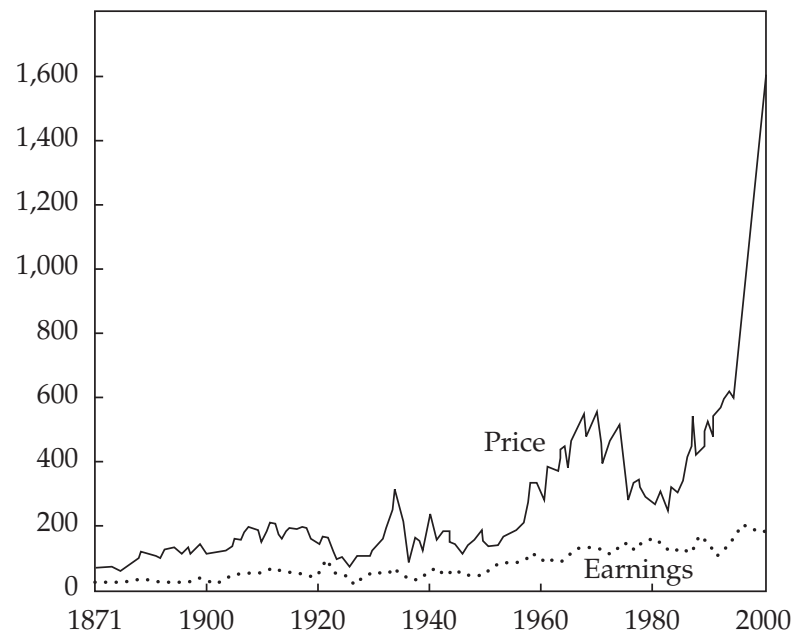

B. Inflation Corrected P/E, Moving Average over Preceding 10 Years of Real SEP 500 Earnings

$\mathrm{P} / \mathrm{E}$

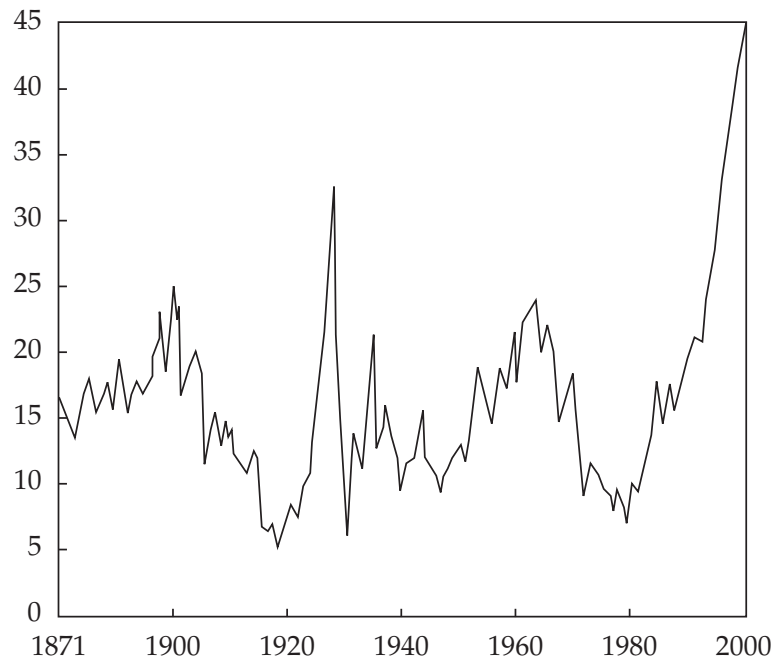

Source: Based on data from Shiller. 
Figure 2.13. S\&P 500 and U.S. Government Bonds, 2000-02

J.P. Morgan U.S. T-Bond Price Index

120

1,600

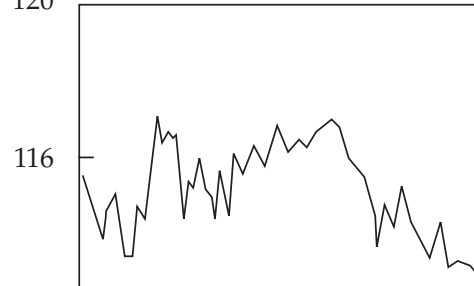

112

104

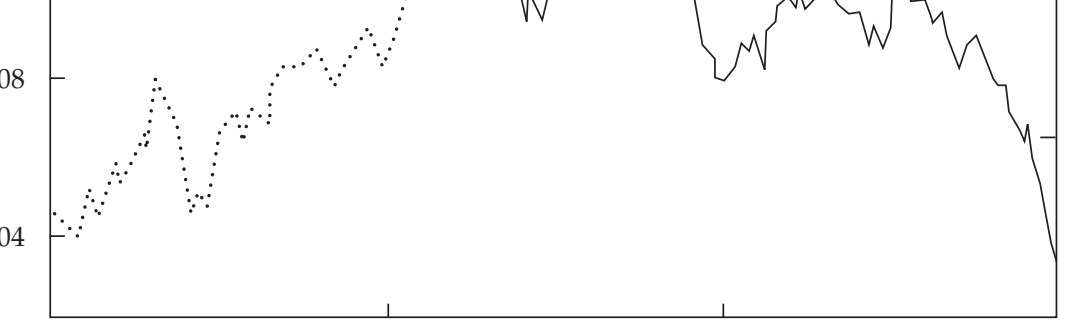

1,400

1,000

00

01

02

S\&P 500 Price Index

J.P. Morgan U.S. T-Bond Price Index

Source: Based on data from Schroder Investment Management Ltd.

Table 2.7. Equities' Superior Returns, December 1925-December 1998

\begin{tabular}{ll}
\hline \multicolumn{1}{c}{ Asset Class } & Multiple \\
\hline Inflation & 9 times \\
T-bills & 15 times \\
T-bonds & 44 times \\
Corporate bonds & 61 times \\
Large-cap stocks & 2,351 times \\
Small-cap stocks & 5,117 times \\
\hline
\end{tabular}

Source: Based on data from Ibbotson (1999), in Swenson (2000). 


\section{Figure 2.14. Total Nominal Return Indexes, 1801-2001}

Total Return Index $(\$)$

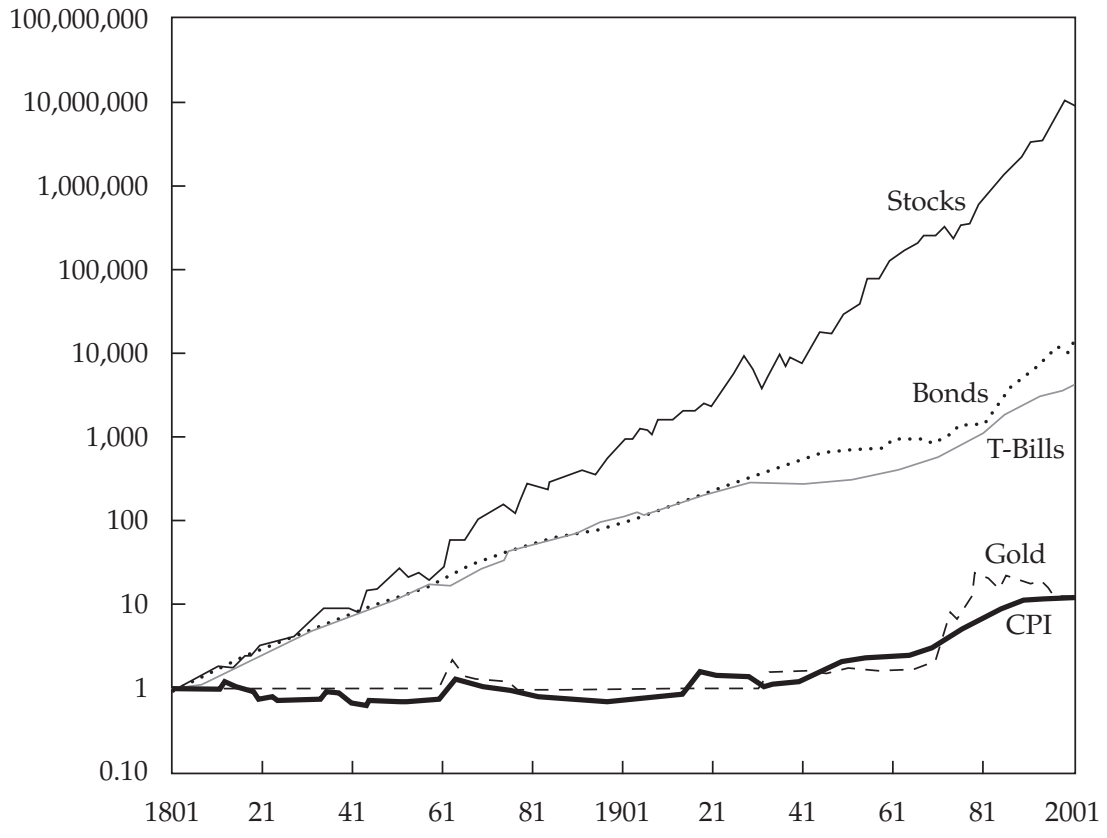

Note: $\mathrm{CPI}=$ Consumer Price Index.

Source: Based on data from Siegel.

measures are easy to devise using the Kallberg-Ziemba (1983) results; just assign Arrow-Pratt risk-aversion values, as I have done in the second column of Table 2.8. Values over 100 percent mean more than 100 percent stocks or a levered long position, which would be a short position in bonds or cash.

5. For stochastic programming asset/liability models, we need scenarios over long periods. So, a major issue is how long the trouble might last.

6. Stochastic programming models handle extreme event scenarios in a natural way. There is little chance of anyone predicting such events as the 9/11 attacks, but scenarios that represent the effect of such events in terms of their impact on market returns can be included. If such events have never occurred before, scenarios can be devised from similar events in other markets and their possible outcomes. 


\section{Figure 2.15. The DJIA}

Index Value

A. Real DJIA

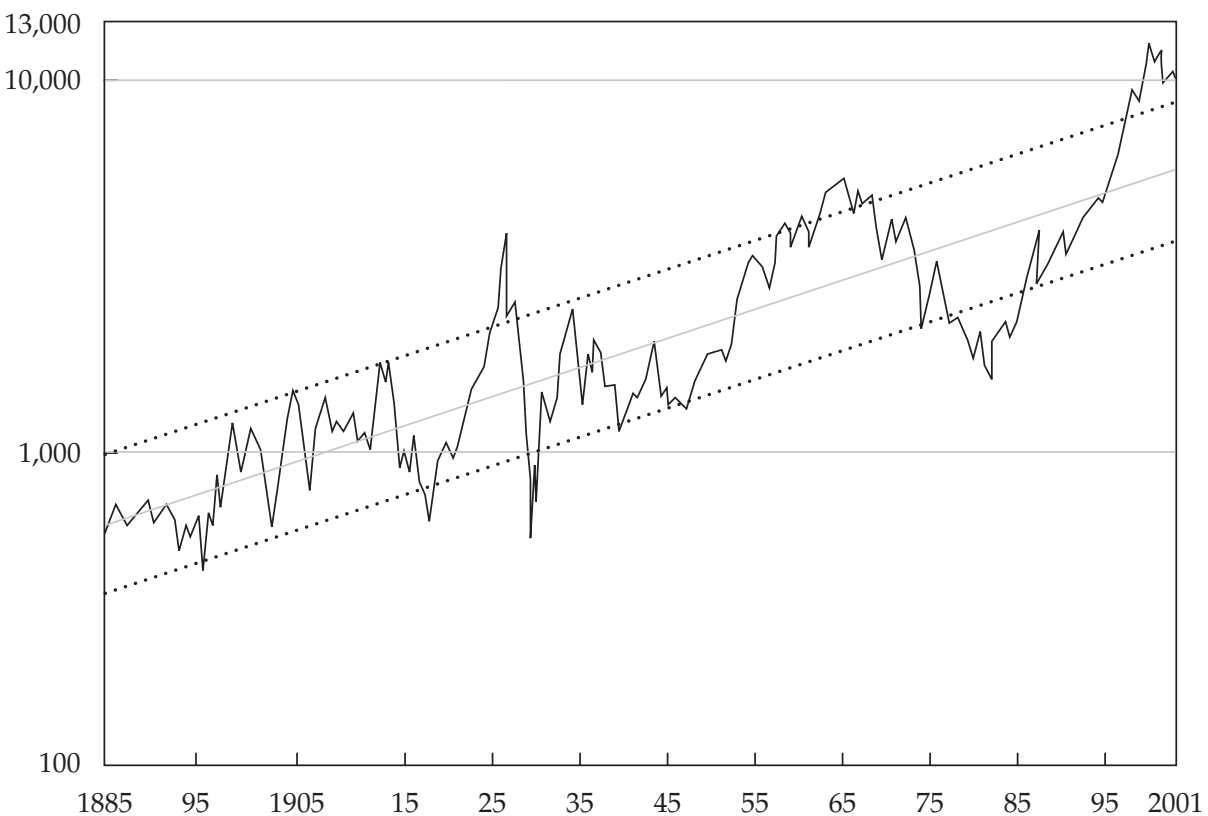

B. Nominal DJIA

Index Value

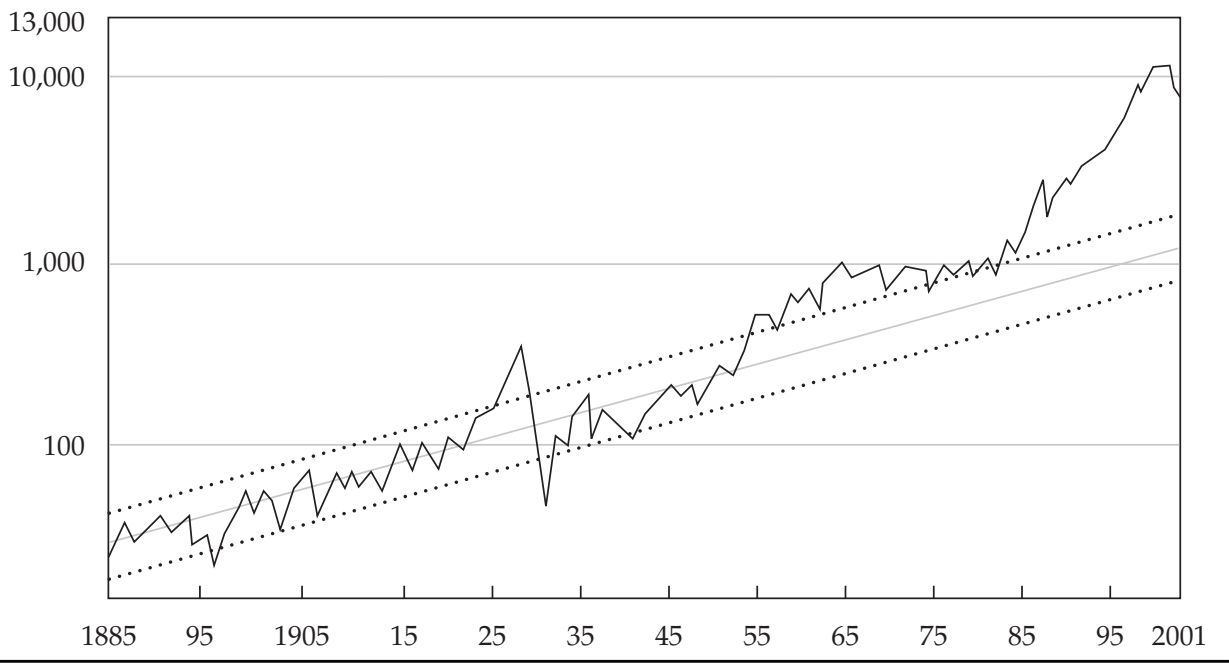

Note: In 2001 U.S. dollars.

Source: Based on data from Siegel. 


\section{Figure 2.16. The Correlation Between U.S. Equity and Government Bond} Returns, 1930-00

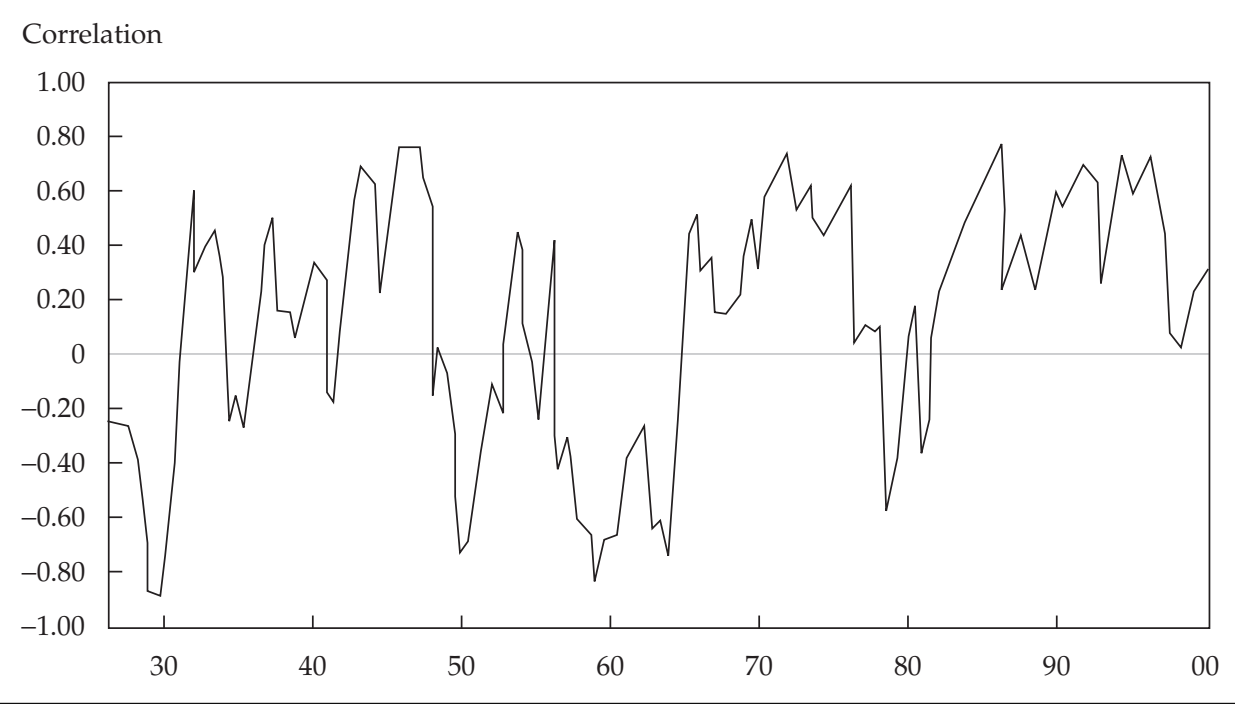

Source: Based on data from Schroder Investment Management Ltd.

7. Successful models will generate scenarios in many ways. The next section discusses some of the ways scenarios can be generated. Figure 2.13, Figure 2.16, and Figure 2.17 are useful in this regard. A clear pattern emerges; the position of stocks as over or under fair value has signaled market swings.

Table 2.8. Portfolio Allocation: Percentage of Portfolio Recommended in Stocks Based on All Historical Data

\begin{tabular}{lrrccc}
\hline & \multicolumn{5}{c}{ Holding Period } \\
\cline { 2 - 6 } Risk Tolerance & $R_{A}$ & 1 Year & 5 Years & 10 Years & 30 Years \\
\hline Ultraconservative & 10 & $8.1 \%$ & $23.3 \%$ & $39.5 \%$ & $71.4 \%$ \\
Conservative & 6 & 25.0 & 40.6 & 60.1 & 89.7 \\
Moderate & 4 & 50.0 & 63.1 & 87.2 & 114.9 \\
Risk taking & 2 & 75.0 & 79.8 & 108.3 & 136.5 \\
\hline
\end{tabular}

Note: $R_{A}=$ risk-aversion index.

Source: Based on data from Siegel. 
Figure 2.17. Race to the Bottom: Percentage of S\&P 500 over or under Fair Value, 1980-2002

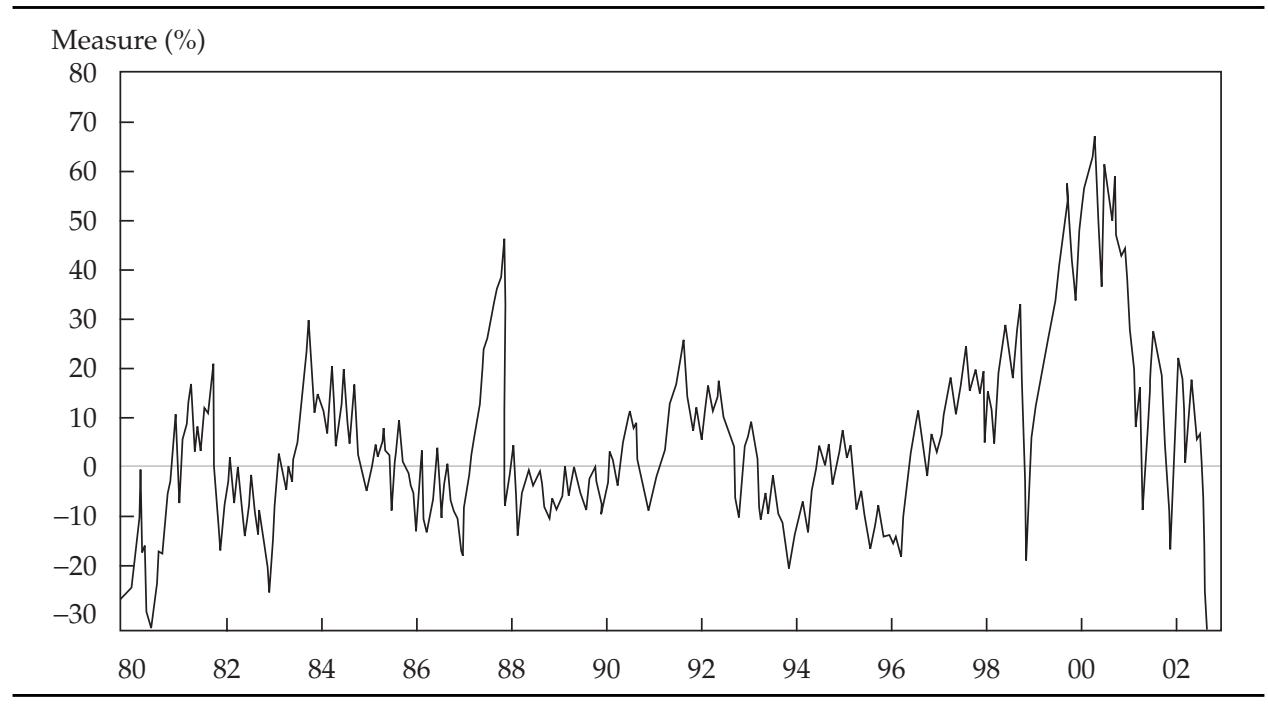

Source: Based on data from Ned Davis Research.

Figure 2.17 shows the late 2002 values for the crash indicator with the Fed (U.S. Federal Reserve) model. The model uses 10-year bond yields and computes the ratio of the bond and stock yields in terms of percentage over- or undervalued. This measure is close to that of the stock-bond return crash danger model. Figure 2.17 indicates that since 1980, very undervalued markets have historically had high returns. When the measure is above 15 percent, mean S\&P returns average a loss of 6.7 percent; from $5-15$ percent, the return is 4.9 percent; and below -5 percent, the return is 31.7 percent. In late 2002 and early 2003, the market was at one of its steepest discounts to fair value. Figure 2.18 provides my calculations, which mirror those in Figure 2.17. The length and depth of the 2000-03 decline is seen in the jagged parts of Figure 2.17 and Figure 2.18. One sees the initial danger zone for the measure in 1999, but then the market returned to the danger zone in late 2001 because stock prices fell but earnings fell even more. Consensus future earnings forecasts were invariably far too optimistic during this period. The S\&P 500 fell 37 percent, from 1,460.25 at the end of December 1999 to 885.76 on 31 October 2002.

Another valuation measure, thanks to Warren Buffett, is the market value of all publicly traded stocks relative to GNP. Buffett suggests that if the measure is 70 or 80 percent, it is a buy, and if it is over 200 percent, as in 1999, it is a sell. The measure was 133 percent in late 2001 and was lower in early 
Figure 2.18. The Fed Model, 1980-May 2003

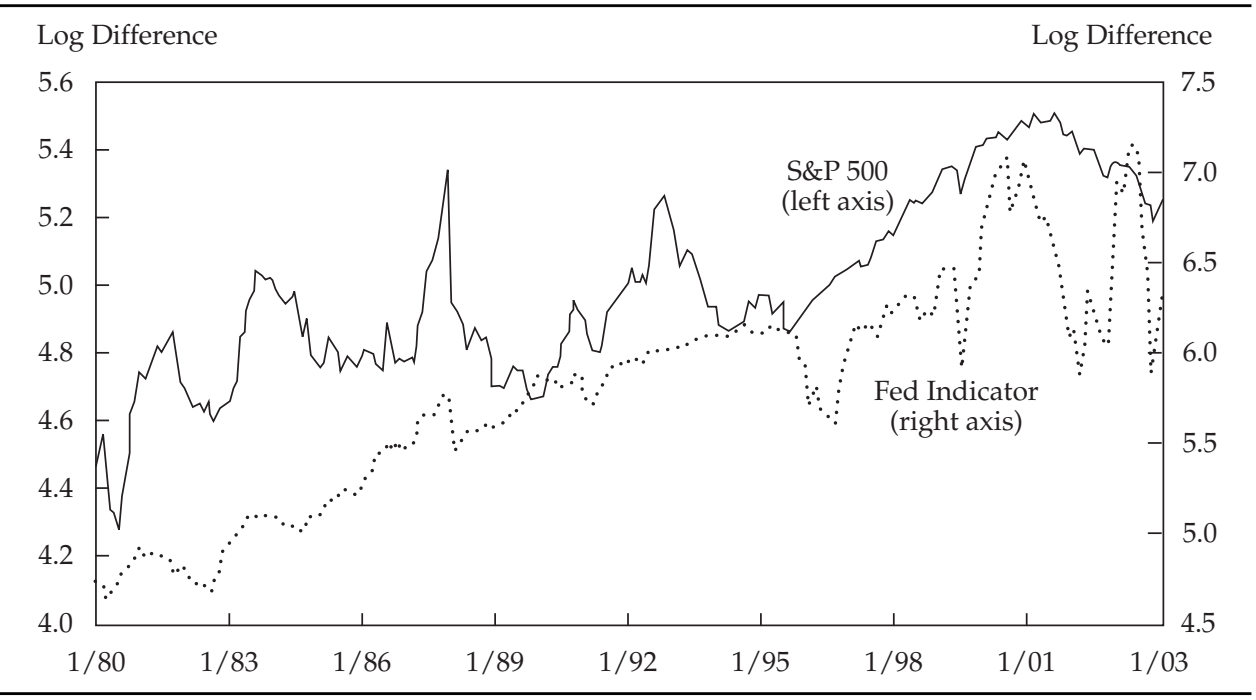

Source: Based on data from Koivu, Pennanen, and Ziemba (2003).

2003 because the stock market fell more than GNP fell. This measure, like that in Figure 2.17, signals a recovery in stock prices in 2003.10

Nonetheless, 41 percent of the stocks in the S\&P 500 did not fall or actually rose during this period, and an additional 19 percent declined by 10 percent or less annualized.11 The fall in the S\&P 500 was mainly in three areasinformation technology, telecommunications, and large-cap stocks. From 1 January to 31 October 2002, information technology stocks in the S\&P 500 fell 64 percent and telecommunications stocks fell 60 percent. The largest-cap stocks (with market caps of US\$50 billion plus) lost 37 percent. But most other stocks either lost only a little or actually gained. Materials fell 10 percent, but consumer discretionary gained 4.5 percent, consumer staples gained 21 percent, energy gained 12 percent, financial services gained 19 percent, health care gained 29 percent, industrials gained 7 percent, and utilities gained 2 percent. Equally weighted, the S\&P 500 index lost only 3 percent. These

10The crash and evaluation measures discussed in this monograph are based on economic evaluations combined with sentiment. Another interesting approach is through chaos models; a survey of this area and presentation of results are in Corcos, Eckmann, Malaspinas, and Malevergne (2002) and Sornette and Zhou (2002).

11These were small-cap stocks with market values of US\$10 billion or less. See Figures 2 and 3 in Appendix B (pp. 6 and 7), which is available online in the Supplementary Material area at www.aimrpubs.org/rf/issues/v2003n6/pdf/AppendixB.pdf. 
values include dividends. The stocks that gained were the very small-cap stocks with market caps below US\$10 billion. Some 138 companies with market caps between US\$5-10 billion gained 4 percent, on average, and 157 companies with market caps below US\$5 billion gained 23 percent, on average.

\section{Procedures for Scenario Generation}

One of the things capital markets do is consider possible worlds. The level and direction of prices reflect the markets' assessment of the probabilities of possible worlds becoming actual. . . There are advocates for many of these views. Investors consider the risks and rewards and allocate their money accordingly.

So wrote Bill Miller-the famed manager of the Legg Mason Value Trust mutual fund (who has consistently beaten the S\&P 500 year after year since 1990)_in a report in early 2003. He described scenarios in this way in reference to a book by David Lewis, a philosophy professor, on the plurality of worlds that argues that all possible worlds exist in the same sense that this world does.

There are many methods to estimate scenarios, and in this section, I discuss the main ideas of some of them. Scenarios are a means to describe and approximate possible future economic environments. In my modeling applications, scenarios are represented as discrete probabilities of specific events. Together, all the scenarios represent the possible evolution of the future world. The basic idea is to have a set of $T$ period scenarios of the form $S^{T}=\left(S_{1}, S_{2}, \ldots, S_{T}\right)$, where $s_{t} \in S_{t}$ are the possible outcomes of all random problem elements and where $s_{t}$ occurs in period $t$ with probability $p_{t}\left(s_{t}\right)$.

A typical scenario tree is shown in Figure 2.19. $S_{1}$ has three possible outcomes, $S_{2}$ has three, and $S_{3}$ has two. There are 18 separate economic

Figure 2.19. Typical Scenario Tree

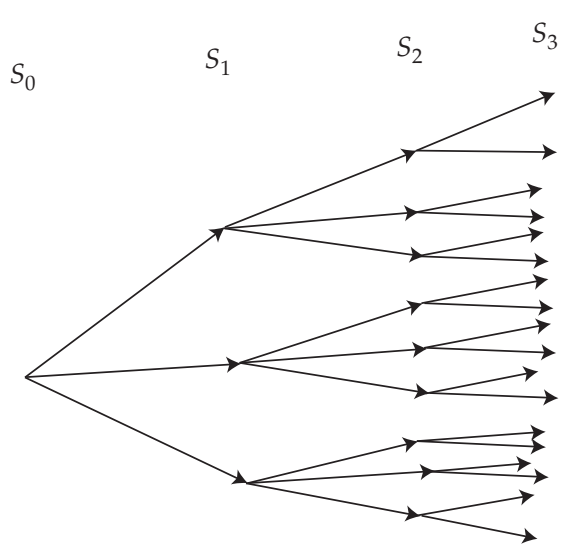


futures, usually with different chances/probabilities of occurrence. Each can occur, and together, they approximate the possible future evolution of the economic environment relevant to the problem at hand. For asset/liability modeling, the most important parts of the distribution are the mean and the left tail. The mean drives the returns, and the left tail, the losses. I cannot include all possible scenarios; instead, I focus on a discrete set that well approximates the possible important events that could happen. Because I have $S^{T}$ total scenarios, I can include those I want. Once a scenario is included, the problem must react to the consequences of that scenario. This important and flexible feature of stochastic programming modeling is not usually available in other approaches. 12 I frequently aggregate scenarios to pick the best $N$ out of the $S^{T}$ so that the modeling effort is manageable.

The generation of good scenarios that well represent the future evolution of the key parameters is crucial to the success of the modeling effort. Scenario generation, sampling, and aggregation are complex subjects, and I will discuss them by describing key elements and providing various developed and implemented models. 13

Scenarios should consider the following, among other things:

- mean reversion of asset prices;

- volatility clumping, in which a period of high volatility is followed by another period of high volatility;

- volatility increases when prices fall and decreases when they rise;

- trending of currency, interest rates, and bond prices;

- ways to estimate mean returns;

- ways to estimate fat tails; and

- ways to eliminate arbitrage opportunities or minimize their effects.

The true distribution $P$ is approximated by a finite number of points $(w 1$, $\ldots, w S)$ with positive probability $p^{s}$ for each scenario $s$. The sum of all scenario probabilities is 1 .

Scenarios come from diverse sources and are used in many applications. They can come from a known discrete probability distribution or as the approximation of a continuous or other probability distribution that is estimated from past data, economic forecasting models, or comparison with similar past

\footnotetext{
12 The inclusion of such extreme scenarios means that the model must react to the possibility of that scenario occurring. This inclusion is one of the ways a stochastic programming overall model would have helped mitigate the 1998 losses and the collapse of LTCM. The model would not have let LTCM hold such large positions (see the discussion in Chapter 6).

13Some more technical aspects of scenario generation appear in Appendix B, which is available online in the Supplementary Material area at www.aimrpubs.org/rf/issues/v2003n6/pdf/ AppendixB.pdf.
} 
events. The latter is especially useful for situations that have never occurredfor example, if there is a potential crisis in Brazil whose effects must be estimated and no data or models are available, but similar crises have occurred in Russia, where the effects have been well estimated. These data are useful for scenario estimation, especially for disastrous scenarios.

Economic variables and actuarial predictions drive the liability side, whereas economic variables and sentiment drive financial markets and security prices. Hence, estimating scenarios for liabilities may be easier than estimating them for assets because of the presence of mortality tables, actuarial risks, and legal requirements, such as pension or social security rules, well-established policies, and so on. (See Embrechts 2000). Such scenarios may come from simulation models embedded in the optimization models that attempt to model the complex interaction between the economy, financial markets, and liability values. Examples include Kingsland (1982), Winklevoss (1982), and Boender (1997).

Abaffy, Bertocchi, Dupačovà, and Moriggia (2000) and Dupačovà, Consigli and Wallace (2000) surveyed scenario estimation and aggregation methods that represent a larger number of scenarios by a smaller number. We can use the following classifications: 14

1. There can be full knowledge of the exact probability distribution. This knowledge usually comes from a theoretical model, but it is possible to use historical data or an expert's experience.

2. There can be a known parametric family based on a theoretical model whose parameters are estimated from available and possibly forecasted data. For example, much literature exists for scenario generations using the 1977 Vasicek, the 1990 Heath-Jarrow-Morton, and the 1990 BlackDerman-Toy and other interest rate models for interest rate, fixedincome, and bond portfolio management. For example, the prices of T-bonds can be computed on a lattice subject to the initial yield curve. Then, the prices of other relevant interest-rate-dependent securities can be estimated. Also, stochastic differential equation modeling can be used to generate scenarios for asset returns and liability commitments by using a cascade of models that feed one into another. 15 Methods used to

\footnotetext{
14For technical details, see Appendix B (p. 4), which is available online in the Supplementary Material area at www.aimrpubs.org/rf/issues/v2003n6/pdf/AppendixB.pdf.

15See, for example, Jamshidian and Zhu (1996); Chan, Karolyi, Longstaff, and Sanders (1992); the Towers Perrin scenario-generation system based on Mulvey (1996); and Mulvey and Thorlacius (1998), discussed in Appendix B (p. 7), which is available online in the Supplementary Material area at www.aimrpubs.org/rf/issues/v2003n6/pdf/AppendixB.pdf.
} 
evaluate value at risk can also be used to create scenarios because they estimate probability distributions. 16

3. Scenarios can be formed by sample-moment information that aggregates large numbers of scenarios into a smaller, easier set or generates scenarios from assumed probability distributions.

4. The simplest idea is to use past data that reflect comparable circumstances and then assign them equal probabilities. This idea can be implemented by using the raw data or through procedures, such as vector autoregressive modeling or bootstrapping, that sample from the past data.

5. When no reliable data exist, one can use an expert's forecasts (e.g., Markowitz and Perold 1981) or governmental regulations. Abaffy et al. pointed out that to test the surplus adequacy of an insurer, New York State Regulation 126 suggests seven interest rate scenarios to simulate the performance of the surplus. Liability commitments are frequently easier to estimate than assets because of demographic data, regulations, and so on.

The list of inputs depicted in Exhibit 2.1 is typical. Whatever method is used to generate the scenarios, in relying on the meshing of decision-maker subjective estimates, expert judgment, and empirical estimation, it is crucial to validate the estimated distributions and to make sure that the decision maker has not defined the range too narrowly. Perhaps reflecting on the distribution by asking what would make the value be outside the range and then assessing the probability would help expand the range and make the probability assessment more realistic.

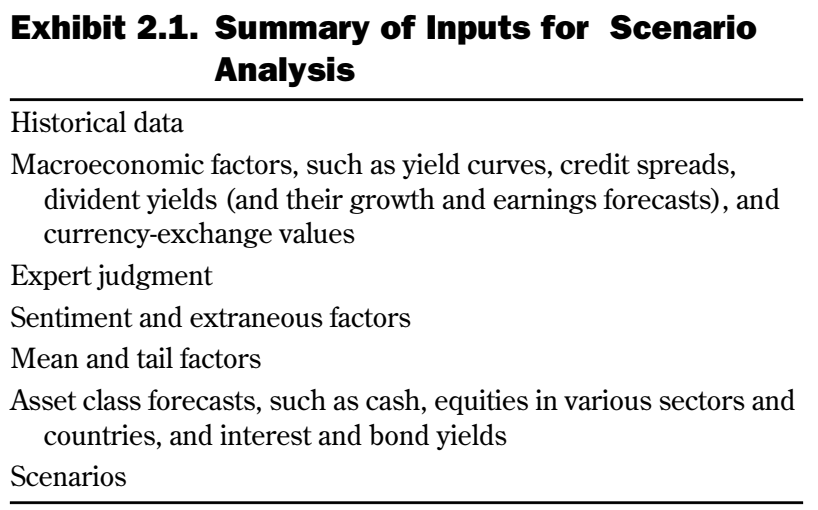

\footnotetext{
16Examples include Jorion (2000b) and Jamshidian and Zhu (1996), who estimated market and currency risk. See also Jobst and Zenios (2003) and Duffie and Singleton (2003), who estimated market and credit risk.
} 


\section{Fixed-Mix and Strategic Asset Allocation}

Fixed-mix strategies, in which the asset allocation weights are fixed and the assets are rebalanced to the initial weights at each decision point, are common and yield good results. An attractive feature is an effective form of volatility pumping because the strategies rebalance by selling assets high and buying them low. Fixed-mix strategies compare well with buy-and-hold strategies. See, for example, Figure 2.20, which shows the 1982-94 risk-return performance of a number of asset categories, such as mixtures of the Europe, Australasia, and Far East (EAFE) Index, S\&P 500, bonds, the Russell 2000 Small-Cap Index, and cash.

The theoretical properties of fixed-mix strategies are discussed by Dempster, Evstigneev, and Schenk-Hoppé (2003) and Merton (1990), who show their advantages in stationary markets, in which the return distributions are the same each year. The long-run growth of wealth is exponential with a probability

Figure 2.20. Historical Performance of Some Asset Categories, 1 January 1982-31 December 1994

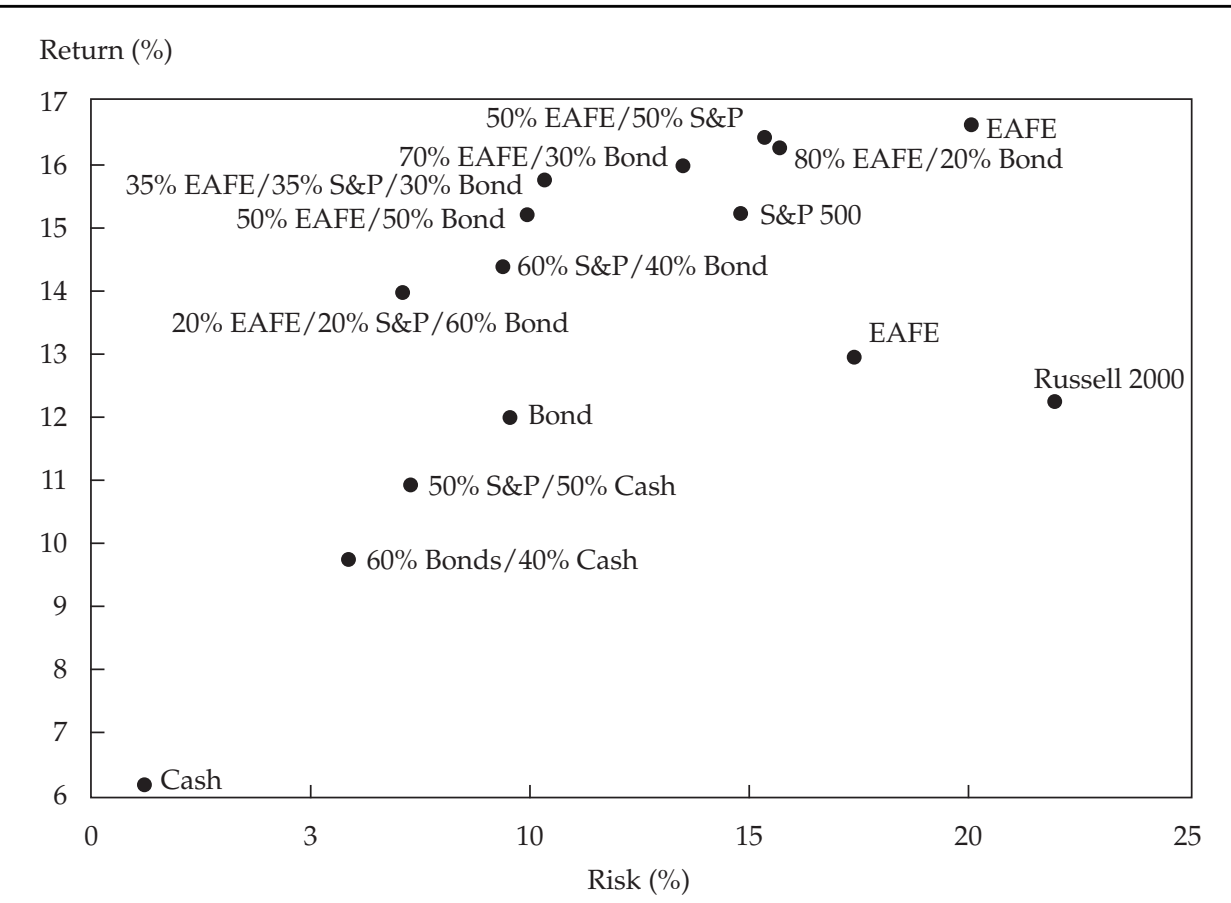

Source: Based on data from Ziemba and Mulvey (1998). 
of 1 . I argue in this monograph that the stationary assumption is fine for longrun behavior, but for short time horizons, even up to 10 to 30 years, using scenarios to represent the future generally gives better results.

Hensel, Ezra, and Ilkiow (1991) showed the value of strategic asset allocation. They evaluated the results of seven representative Frank Russell Company U.S. clients who were having their assets managed by approved professional managers (who are supposed to beat their benchmarks with lower risk). The study was conducted for 16 quarters from January 1985 to December 1988. A fixed-mix naive benchmark was U.S. equity (50 percent), non-U.S. equity (5 percent), U.S. fixed income (30 percent), real estate (5 percent), and cash (10 percent). Table 2.9 shows the mean quarterly return and the variation explained. Most of the volatility (94.35 percent of the total) is explained by the naive policy allocation, similar to the 93.6 percent in Brinson, Hood, and Beebower (1986) and in Brinson, Singer, and Beebower (1991). Also, T-bill returns (1.62 percent) and the fixed-mix strategy (2.13 percent) explain most of the mean returns. The managers returned 3.86 percent versus 3.75 percent for T-bills plus fixed mix, so they added value. This added value was from their superior strategic asset allocation into stocks, bonds, and cash. The managers were unable to market time or to pick securities better than the fixed-mix strategy.

Further evidence that strategic asset allocation accounts for most of the time-series variation in portfolio returns and that market timing and asset selection are far less important has been provided by Blake, Lehmann, and Timmermann (1999). They used a nine-year (1986-94) monthly dataset on

\begin{tabular}{lcc} 
Table 2.9. & \multicolumn{3}{c}{$\begin{array}{c}\text { Average Return and Return } \\
\text { Variation Explained } \\
\text { (quarterly by the seven clients) }\end{array}$} \\
\hline & $\begin{array}{c}\text { Average } \\
\text { Contribution }\end{array}$ & $\begin{array}{c}\text { Additional Variation } \\
\text { Explained (volatility) }\end{array}$ \\
\hline Decision Level & $1.62 \%$ & $2.66 \%$ \\
\hline Minimum risk (T-bills) & 2.13 & 94.35 \\
Naive allocation (fixed mix) & 0.49 & 0.50 \\
Specific policy allocation & $(0.10)$ & 0.14 \\
Market timing & $(0.23)$ & 0.40 \\
Security selection & $(0.005)$ & 1.95 \\
Interaction and activity & $3.86 \%$ & $100.00 \%$ \\
$\quad$ Total & 3.75 & \\
T-bills and fixed mix &
\end{tabular}

Source: Based on data from Hensel et al. 
306 U.K. pension funds having eight asset classes. They also found a slow mean reversion in the funds' portfolio weights toward a common, time-varying strategic asset allocation.

The U.K. pension industry is concentrated in very few management companies. Indeed, four companies control 80 percent of the market. In contrast, in the United States, the largest company in 1992 had a 3.7 percent share of the market, according to Lakonishok, Shleifer, and Vishny (1994). During the 1980s, the pensions were about 50 percent overfunded. Fees are related to performance, usually relative to a benchmark or peer group. Blake et al. concluded that:

1. U.K. pension fund managers have a weak incentive to add value and face constraints on how they try to do it. Although strategic asset allocation may be set by the trustees, these strategies are flexible, have a wide tolerance for short-run deviations, and can be renegotiated.

2. Fund managers know that relative, rather than absolute, performance determines their long-term survival in the industry.

3. Fund managers earn fees related to the value of assets under management, not to their relative performance against a benchmark or their peers, with no specific penalty for underperforming or reward for outperforming.

4. The concentration in the industry leads to portfolios being dominated by a small number of similar house positions for asset allocation to reduce the risk of relative underperformance.

The asset classes from WM Company data were U.K. equities, international equities, U.K. bonds, international bonds, cash, U.K. property, and international property. U.K. portfolios are heavily equity weighted. For example, the 1994 weights for these eight asset classes for the 306 pension funds were $53.6,22.5,5.3,2.8,3.6,4.2,7.6$, and 0.4 percent, respectively. In contrast, U.S. pension funds had 44.8, 8.3, 34.2, 2.0, 0.0, 7.5, 3.2, and 0.0 percent, respectively.

Most of the 306 funds had similar returns year by year. The semiinterquartile range was 11.47 to 12.59 percent, and the 5 th and 95 th percentiles were less than 3 percent apart.

The returns on different asset classes were not great, except for international property. The eight classes averaged value weighted 12.97, 11.23, 10.76, $10.03,8.12,9.01,9.52$, and -8.13 percent (for the international property), and overall, 11.73 percent a year. Bonds and cash kept up with equities quite well in this period. Similar to previous studies, Blake et al. found that for U.K. equities, a high percentage (91.13 percent) of the variance in differential returns across funds occurred because of strategic asset allocation. For the other asset classes, this variance was lower-60.31 percent (international 
equities), 39.82 percent (U.K. bonds), 16.10 percent (international bonds), 40.06 percent (U.K. index bonds), 15.18 percent (cash), 76.31 percent (U.K. property), and 50.91 percent (international property). For these other asset classes, variations in net cash flow differentials and covariance relationships explain the rest of the variation.

\section{Stochastic Programming versus Fixed Mix}

Despite these good results, fixed-mix and buy-and-hold strategies do not use new information from return occurrences in their construction. As Cariño and Turner (1998) illustrated, by making the strategy scenario dependent and using a multiperiod stochastic programming model, a better outcome is possible.

Consider a three-period model with periods of one, two, and two years. The investor starts at Year 0 and ends at Year 5, with the goal of maximizing expected final wealth, net of risk. Risk is measured as one-sided downside risk based on nonachievement of a target wealth goal at Year 5. The target is 4 percent return a year, or 21.7 percent at Year 5. Figure 2.21 shows the shortfall cost function. The penalty for not achieving the target becomes steeper and steeper as the nonachievement grows larger. For example, at 100 percent of the target or more, there is no penalty; at 95-100 percent, it is a steeper, more expensive penalty; and at 90-95 percent, it is steeper still. This shape preserves the convexity of the risk-penalty function, and the piecewise linear function means that the stochastic programming model remains linear.

Figure 2.21. A Shortfall Cost Function: Target

4 percent a Year

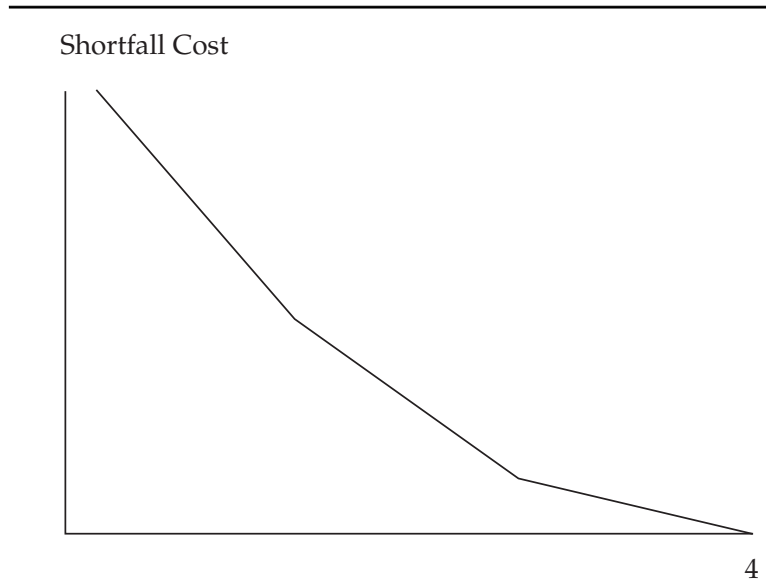

Percent Return 
The concave objective function is

Maximize E (Final wealth $\left.-\frac{\text { Accumulated penalized shortfalls }}{\text { Risk tolerance }}\right)$,

where the risk tolerance equals the reciprocal of the Arrow-Pratt absolute risk-aversion index and balances risk and return.

Assume the six asset classes have the means, variances, and covariances shown in Table 2.10. I can use scenarios to represent possible future outcomes. In this situation, that is all the possible paths of returns that can occur over the three periods. The goal is to make 4 percent each period, so cash that returns 5.7 percent will always achieve this goal. Bonds return 7.0 percent, on average, and usually return at least 4 percent, although at times, they have returns below 4 percent. Equities return 11 percent and also beat the 4 percent hurdle most of the time but fail to achieve 4 percent some of the time. Assuming that the returns are independent and identically distributed with lognormal distributions, by sampling $4 \times 3 \times 2$, I get 24 scenarios for cash, bonds, and equities, which are roughly shown in Figure 2.22; in each panel, the heavy line is the 4 percent threshold, or 121.7 percent at Year 5.

To simplify, the scenarios can be visualized over two periods. The scenario tree has nine nodes with six distinct scenarios. Three outcomes are possible in Period 1 and two are possible in Period 2, for six in total, as shown in Figure 2.23 and in Table 2.11. For example, with one-third probability, U.S. equity large caps will return 0.90754 , U.S. equity small cap, 0.534592 , and so on; in Period 2, these two return either 0.119713 or 0.461739 and -0.130465 or 0.392537 , with equal probability.

The strategy layout is

\begin{tabular}{|l|l|l} 
Period 1 & Period 2 & Period 3 \\
1 Year & 2 Years & 2 Years
\end{tabular} .

Table 2.10. Means, Variances, and Covariances of Six Asset Classes

\begin{tabular}{|c|c|c|c|c|c|c|c|c|}
\hline Asset Class & $\begin{array}{l}\text { Expected } \\
\text { Return }\end{array}$ & $\begin{array}{l}\text { Std. } \\
\text { Dev. }\end{array}$ & $\begin{array}{c}\text { U.S. } \\
\text { Large-Cap } \\
\text { Equity }\end{array}$ & $\begin{array}{c}\text { U.S. } \\
\text { Small-Cap } \\
\text { Equity }\end{array}$ & $\begin{array}{l}\text { Non-U.S. } \\
\text { Equity } \\
\text { Unhedged }\end{array}$ & $\begin{array}{l}\text { Emerging } \\
\text { Markets } \\
\text { Unhedged }\end{array}$ & $\begin{array}{l}\text { U.S. } \\
\text { Bonds }\end{array}$ & $\begin{array}{l}\text { U.S. } \\
\text { Cash }\end{array}$ \\
\hline U.S. large-cap equity & $11.0 \%$ & $17.0 \%$ & 1.0 & & & & & \\
\hline U.S. small-cap equity & 11.0 & 25.0 & 0.8 & 1.0 & & & & \\
\hline $\begin{array}{l}\text { Non-U.S. equity } \\
\text { unhedged }\end{array}$ & 11.0 & 21.0 & 0.5 & 0.3 & 1.0 & & & \\
\hline $\begin{array}{l}\text { Emerging markets } \\
\text { unhedged }\end{array}$ & 11.0 & 25.0 & 0.3 & 0.3 & 0.3 & 1.0 & & \\
\hline U.S. bonds & 7.0 & 7.0 & 0.4 & 0.3 & 0.2 & 0.0 & 1.0 & \\
\hline U.S. cash & 5.7 & 1.0 & 0.0 & 0.0 & 0.0 & 0.0 & 0.3 & 1.0 \\
\hline
\end{tabular}


Figure 2.22. Scenarios

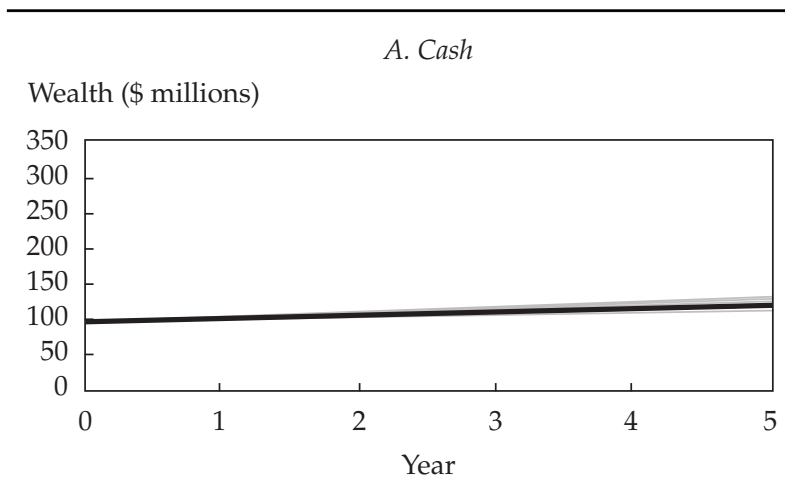

B. Bonds

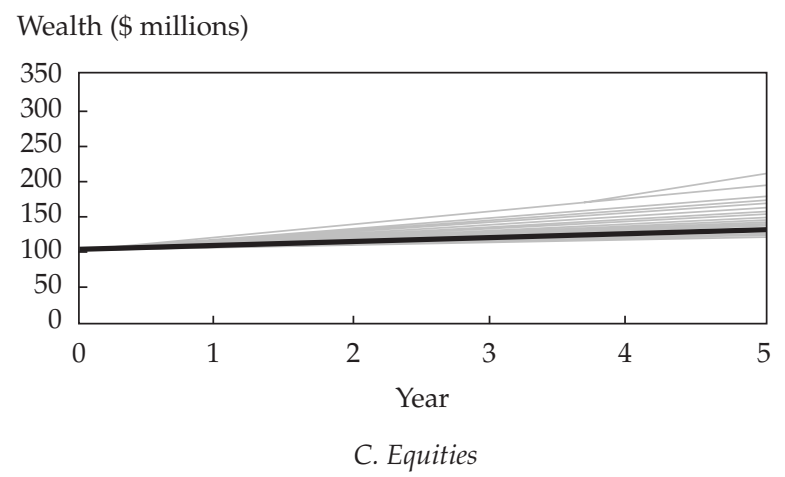

Wealth (\$ millions)

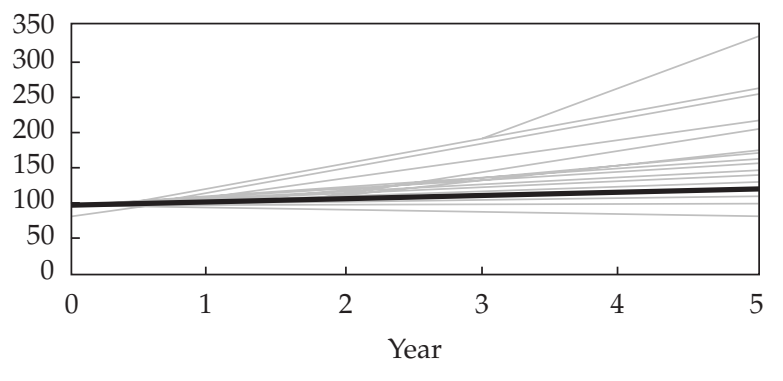

I then compare the following two strategies:

1. the dynamic stochastic programming strategy, which is the full optimization of the multiperiod model; and

2. the fixed-mix strategy, in which the portfolios from the mean-variance frontier have allocations rebalanced back to that mix at each stage-buy when low and sell when high. This strategy resembles covered calls, which is the opposite of portfolio insurance. 
Figure 2.23. Scenarios in Three Periods

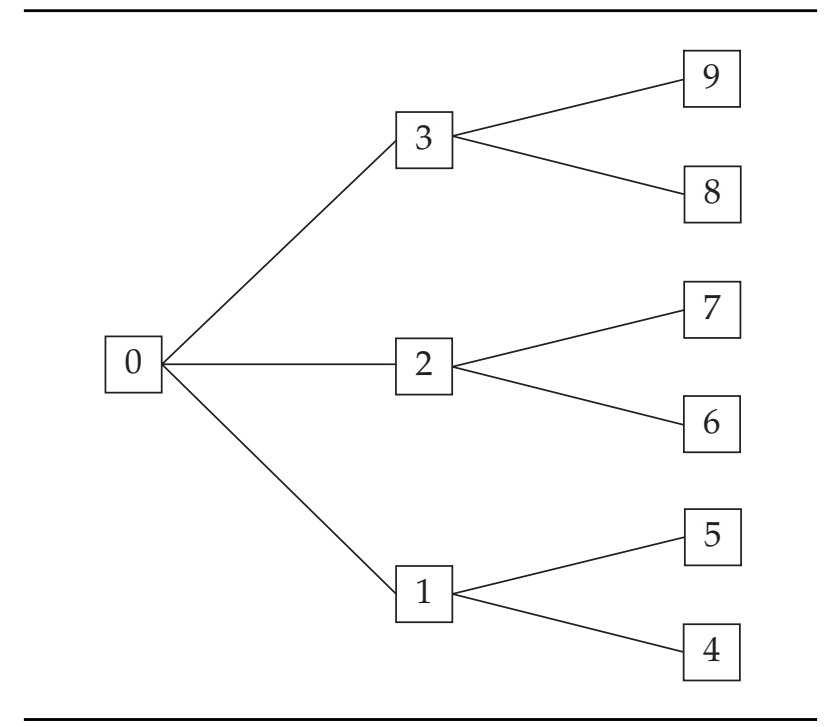

Table 2.11. Example Scenario Outcomes Listed by Node

\begin{tabular}{lcccrrrr}
\hline Node & $\begin{array}{c}\text { Conditional } \\
\text { Probability }\end{array}$ & $\begin{array}{c}\text { U.S. Large-Cap } \\
\text { Equity }\end{array}$ & $\begin{array}{c}\text { U.S. Small-Cap } \\
\text { Equity }\end{array}$ & \multicolumn{1}{c}{$\begin{array}{c}\text { Non-U.S. } \\
\text { Equity }\end{array}$} & $\begin{array}{c}\text { Emerging } \\
\text { Markets }\end{array}$ & U.S. Bonds & U.S. Cash \\
\hline 1 & 0.3333 & 0.032955 & 0.341701 & 0.041221 & 0.279216 & 0.027300 & -0.014084 \\
2 & 0.3333 & -0.091184 & 0.049939 & 0.109955 & 0.082171 & -0.128904 & 0.024156 \\
3 & 0.3333 & 0.090754 & 0.534592 & 0.120825 & 0.204917 & 0.162770 & 0.132663 \\
4 & 0.5000 & 0.035930 & 0.056592 & -0.000627 & -0.304342 & 0.061070 & 0.000830 \\
5 & 0.5000 & 0.119713 & -0.130465 & 0.193180 & 0.519016 & 0.069383 & 0.028540 \\
6 & 0.5000 & 0.461739 & 0.392537 & 0.116938 & 0.360205 & 0.089025 & 0.050224 \\
7 & 0.5000 & 0.245134 & 0.122433 & 0.568656 & 0.180286 & 0.110467 & 0.092815 \\
8 & 0.5000 & -0.090453 & -0.292077 & -0.292757 & 0.001132 & 0.129944 & 0.121655 \\
9 & 0.5000 & 0.041096 & 0.054468 & 0.118764 & -0.048986 & 0.065222 & 0.088793 \\
\hline
\end{tabular}

Consider Fixed-Mix Strategy A (64/36 percent stock/bond mix) and FixedMix Strategy B (46/54 percent stock/bond mix). The optimal stochastic programming strategy dominates, as shown in Figure 2.24.

How does the dynamic strategy achieve lower shortfall cost or higher expected wealth? For any given fixed-mix strategy, there is a dynamic strategy that has either the same expected wealth and lower shortfall cost or the same shortfall cost and higher expected wealth. The portfolio allocation for the optimal strategy starts out in a similar way to the Fixed-Mix Strategy A, with the same expected return. The split between equities and fixed-income assets 
Figure 2.24. Optimal Stochastic Strategy vs. Fixed-Mix Strategy

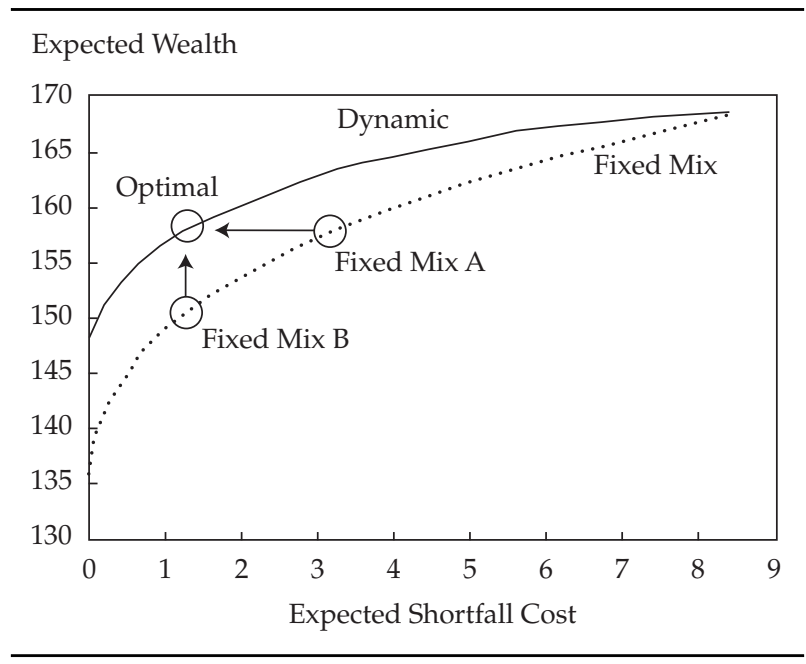

is about $60 / 40$ percent. The Fixed-Mix Strategy B, having the same risk, has a much lower allocation to equities (see Panel A of Figure 2.25).

The allocations at the end of Year 1 provide insight into the dynamic strategy (see Panel B of Figure 2.25). The allocations depend on the outcome of the first year's returns. The optimal allocations are related to the outcomes. The allocations shift to lower-return, less volatile assets as the excess over the wealth target is reduced. When the return is high, the strategy moves to a high-return riskier asset.

The model suggests that by taking advantage of the opportunities to adapt the asset mix given the current wealth level, the chances of exceeding the hurdle are increased (see Figure 2.26).

\section{More Evidence Regarding the Performance of Stochastic Dynamic versus Fixed-Mix Models}

A further study of the performance of stochastic dynamic and fixed-mix portfolio models was made by Fleten, Høyland, and Wallace (2002). They compared two alternative versions of a portfolio model for the Norwegian life insurance company Gjensidige NOR, namely, multistage stochastic linear programming and fixed-mix constant rebalancing. They found that the multiperiod stochastic programming model dominated the fixed-mix approach, but the degree of dominance was much smaller out of sample than in sample (see 
Figure 2.25. Example Portfolios

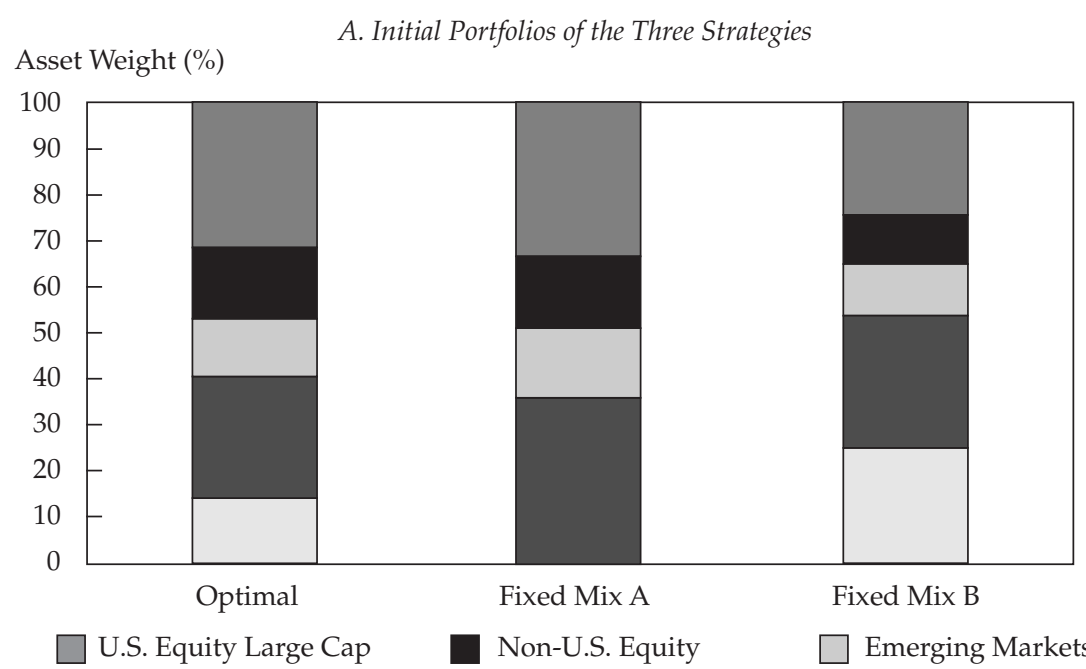

$\square$ Bonds $\square$ Cash

Asset Weight (\%)

B. Contingent Allocations at Year 1

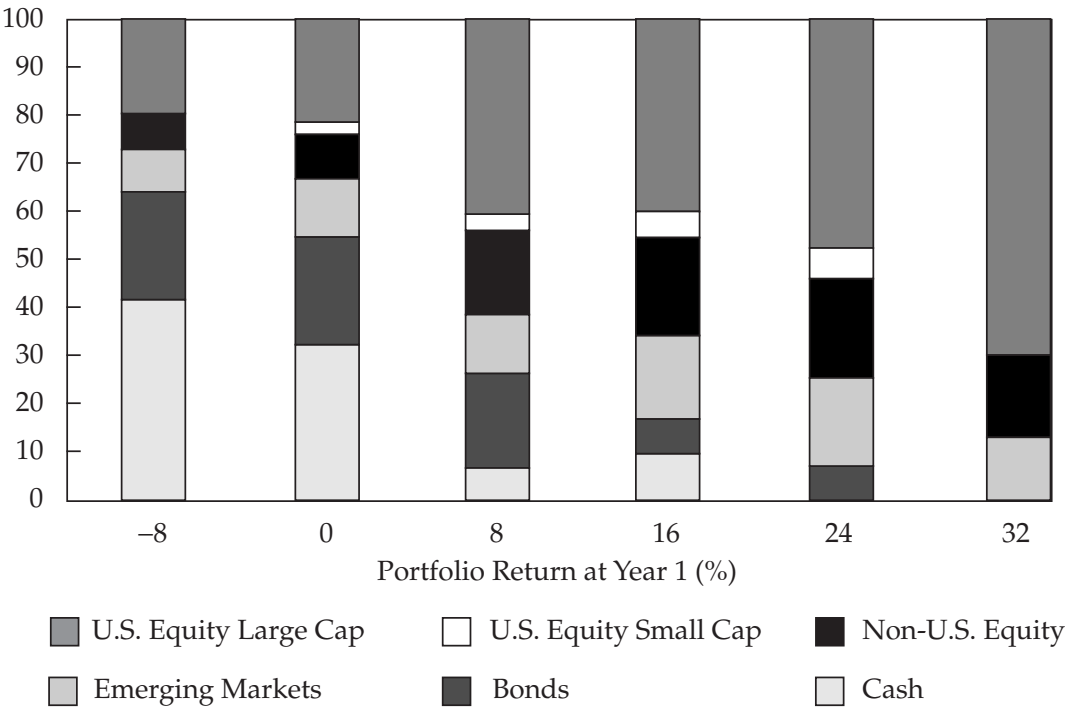




\section{Figure 2.26. Optimal Strategy versus Fixed-Mix Strategies}

A. Probability Distribution of Final Wealth at Year 5

Cumulative Probability (\%)

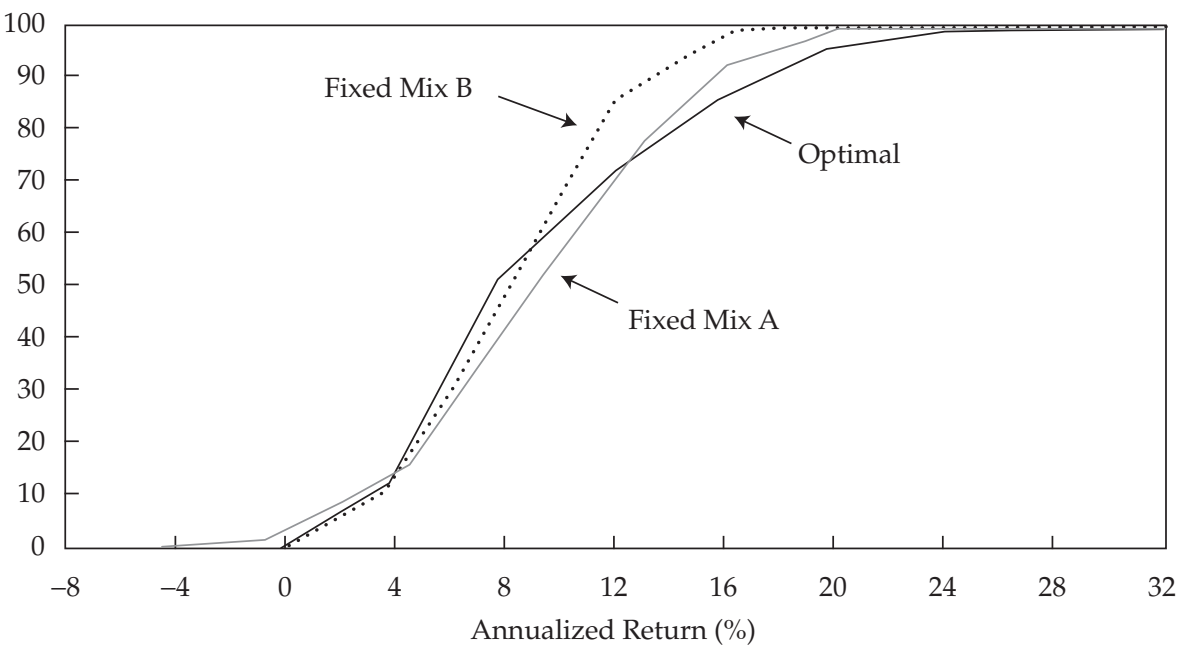

B. Annualized Return through Year 5

Probability (\%)

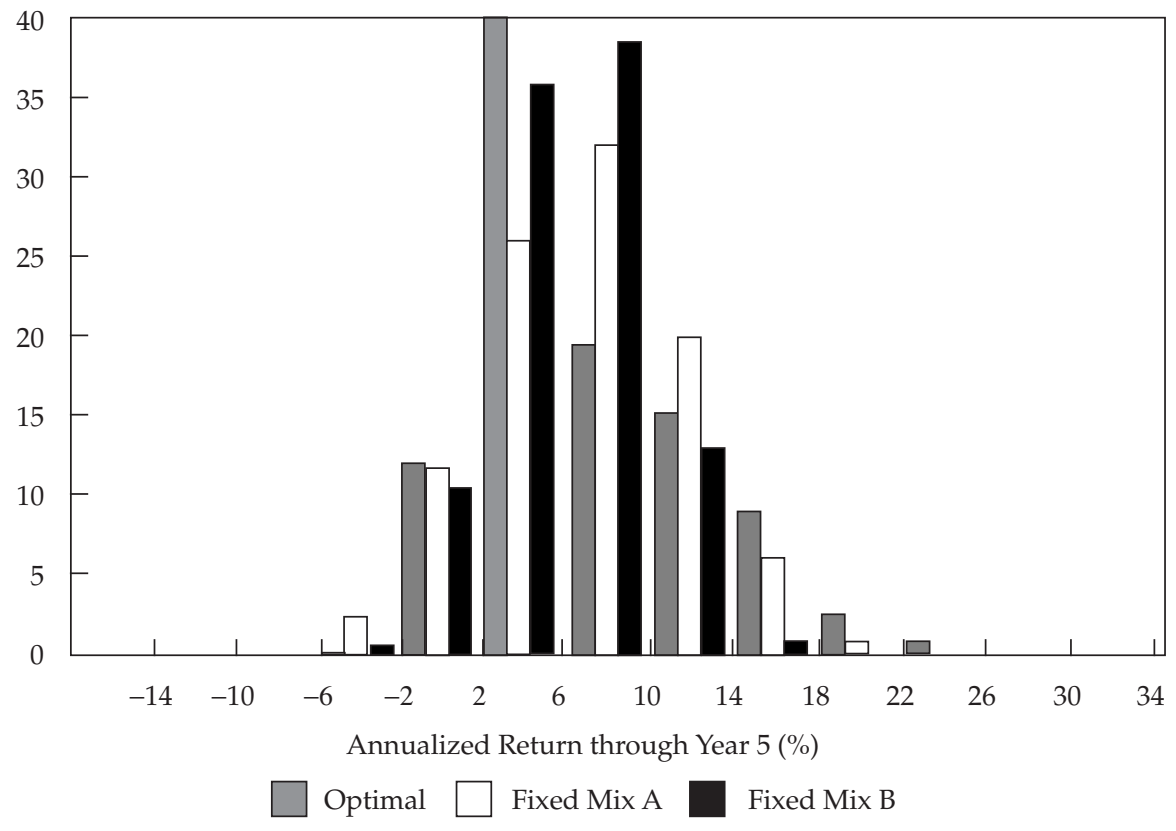


Panel A and Panel B of Figure 2.27); out of sample, the random input data are structurally different from those in sample, so the stochastic programming model loses its advantage in optimally adapting to the information available in the scenario tree. Also, the performance of the fixed-mix approach improves because the asset mix is updated at each stage.

\section{Figure 2.27. Advantage of Stochastic Programming over Fixed-Mix Model}

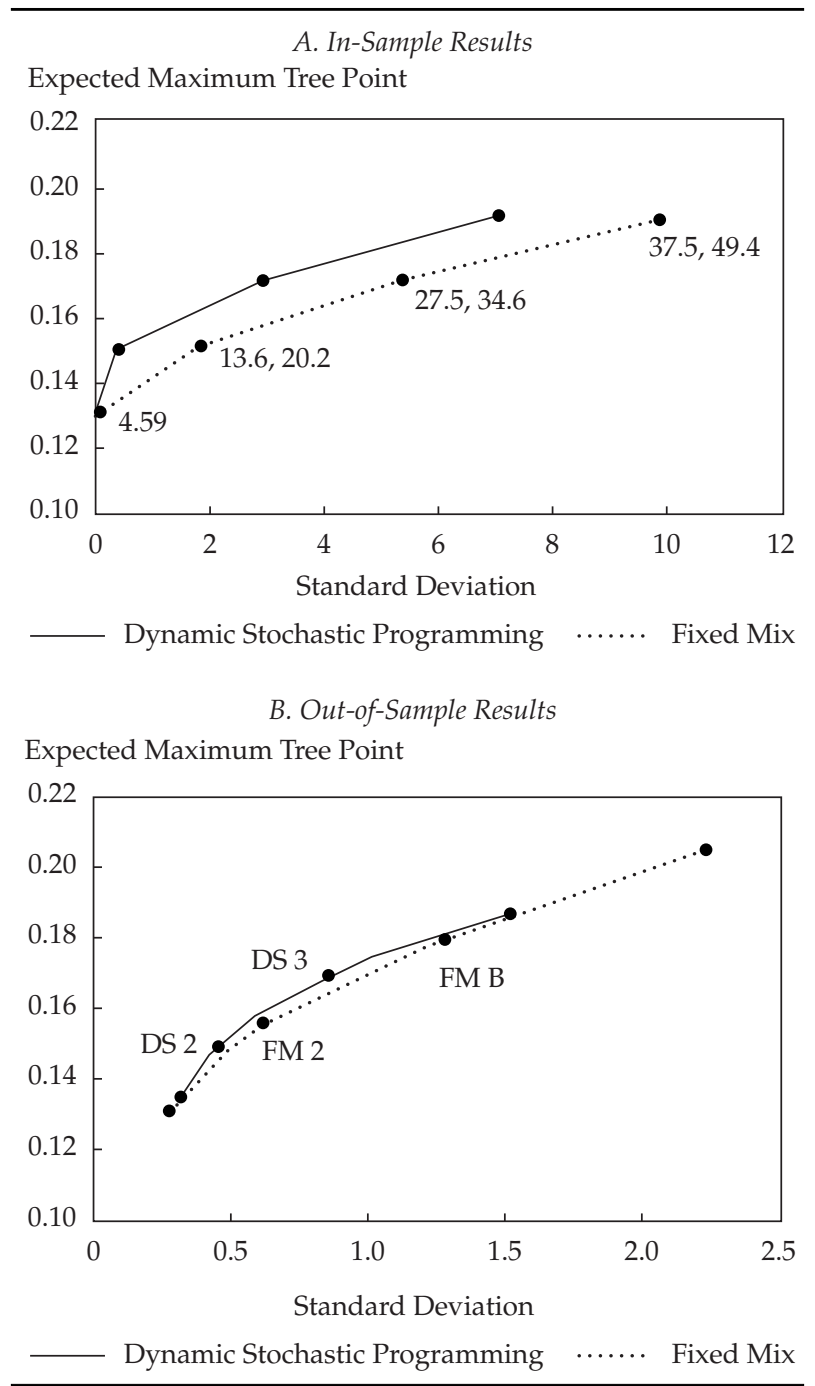

Source: Based on data from Fleten, Høyland, and Wallace. 


\section{How to Make Good Multiperiod Stochastic Programming Models}

The philosophy is as follows. Markets are understandable most (95+ percent) of the time, but real asset prices have fat tails because extreme events occur much more than lognormal or normal distributions indicate.

According to Keim and Ziemba (2000), much about asset returns is not predictable. Hence, we must have ways to combine conventional models, options pricing, and so on, that are accurate most of the time and include the irrational, unexplainable aspects that occur once in a while. Whether the extreme events are predictable or not is not the key issue-what is crucial is that we consider that they can happen in various levels with various chances.

Even apart from the instability due to speculation, there is the instability due to the characteristic of human nature that a large proportion of our positive activities depend on spontaneous optimism rather than mathematical expectations, whether moral or hedonistic or economic. Most, probably, of our decision to do something positive, the full consequences of which will be drawn out over many days to come, can only be taken as the result of animal spirits, a spontaneous urge to action rather than inaction, and not as the outcome of a weighted average of quantitative benefits multiplied by quantitative probabilities. (Keynes 1938).

Human behavior is a main factor in how markets act. Indeed, sometimes markets act quickly, violently with little warning. Ultimately, history tells us that there will be a correction of some significant dimension. I have no doubt that human nature being what it is, that it is going to happen again and again. (Greenspan 1998)

An integrative asset/liability management strategy needs alternative modeling tools, such as stochastic programming, to capture the effects of costly lower-tail outcomes, as asked in Stulz (1996), Lo (1999, 2001), and Merton (2000a, 2000b).

Dynamic and Liability Aspects. The display in Figure 2.28 shows the time flow of assets arriving and liability commitments leaving for institutions, such as insurance companies, banks, pension funds, and savings and loans, and for individuals. These problems are enormously complex. Is it possible to implement such models that will really be successful? This monograph discusses a number of successful implementations and, I hope, will convince the reader that it is possible. The models will sell themselves as more are built and used successfully.

We have the following risk ladder (see the introduction to Ziemba and Mulvey 1998) with various levels of details, aggregation, and model decisions.

- Rung 5. Total integrated risk management.

- Rung 4. Dynamic asset and liability management.

- Rung 3. Dynamic asset-only portfolios.

- Rung 2. Static asset-only portfolios.

- Rung 1. Pricing single securities. 
Figure 2.28. Time Flow of Assets

A. Institutions

Receive Policy Premiums

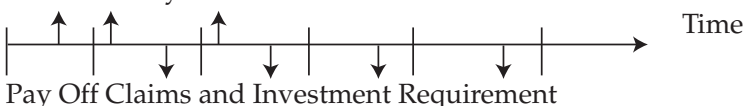

B. Individuals

Income Streams

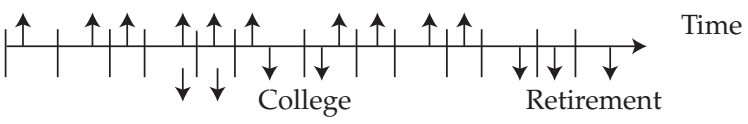

This monograph concerns mostly Rung 3 and, especially, Rung 4. Rung 5 represents overall companywide models that involve all aspects of a businessaggregated, of course. 17

The stochastic programming approach, which considers the following aspects, is ideally suited to analyzing such problems:

- Multiple time periods; possible use of end effects-steady state after the decision horizon adds one more decision period to the model; the tradeoff is an end-effects period or a larger model with one less period.

- Consistency with economic and financial theory for interest rates, bond prices, and so on.

- Discrete scenarios for random elements-returns, liabilities, and currencies.

- Scenario-dependent correlation matrixes so that correlations change for extreme scenarios.

- Use of various forecasting models that can handle fat tails.

- Institutional, legal, and policy constraints.

- Model derivatives and illiquid assets.

- Transaction costs.

- Expressions of risk in terms understandable to decision makers.

- Simple, easy-to-understand risk-averse utility functions that maximize long-run expected profits, net of expected discounted penalty costs for shortfalls; pay more and more penalty for shortfalls as they increase (highly preferable to VAR).

- Model as constraints or penalty costs for target violations in the objective function.

- Maintain adequate reserves, cash levels, and regularity requirements.

17See Zenios and Ziemba (2004) for more on this topic. 
- Can now solve realistic multiperiod problems on modern workstations and personal computers by using large-scale linear programming and stochastic programming algorithms.

- Model makes you diversify - the key for keeping out of trouble.

Some possible approaches to modeling situations with such events are as follows:

- Simulation models have too much output to understand but are useful as a check.

- Mean-variance models are static in nature and useful for such applications, but they are not useful with liquidity or other constraints, for multiperiod problems, or with liabilities, and so on.

- Expected log models yield very risky strategies that do not diversify well; fractional Kelly strategies with downside constraints are excellent for risky investment betting (see Chapter 6).

- Stochastic control models, although theoretically interesting, give hairtrigger and bang-bang policies in which one is 100 percent stocks and then zero percent stocks one second later (see, for example, the BrennanSchwartz paper in Ziemba and Mulvey and the discussion of the RudolfZiemba model in Chapter 4). The question is how to constrain the asset weight changes to be practical. Possibly, the best work on this approach has been done by Campbell and Viciera (2002), who successfully analyzed longterm asset-only allocation decisions in which the power of the technique dominates the limitations of the model (which they acknowledged). Using a theoretically sound framework, they provided useful rules of thumb for many investors. My goal is to tailor the asset allocation mix for individual investors, given their consumption and other goals, taxes, preferences, uncertainties, transactions costs, liquidity, and so on.

Among other conclusions, Campbell and Viciera showed that:

1) The riskless asset for a long-term investor is not T-bills but rather Treasury Inflation-Indexed Securities (TIPS), which deliver a predictable stream of real income.

2) A safe labor income stream is equivalent to a large position in the riskfree asset because it allows the investor to hold much more in risky assets. Fixed commitments are negative income.

3) Risky investments are extremely attractive to young households because they have a large amount of relatively safe human wealth relative to their financial wealth.

4) Business owners should have less equity exposure because their income stream is correlated with the stock market. 
5) Wealthy investors should be more risk averse because their level of consumption depends on their financial success.

6) Because stocks are mean reverting (i.e., they have lower risk over longer time horizons), investors can time the market over long horizons; because the equity risk premium is time varying, the optimal strategic asset allocation mix changes over time.

- Stochastic programming models with decision rules have policy prescriptions, such as fixed mix or buy and hold; the decision rules are intuitively appealing but are suboptimal and usually lead to nonconvex difficult optimization modeling.

- Stochastic programming models provide a good approach, as discussed in this monograph, starting with insurance applications in Chapter 3. 


\section{Insurance Company Applications}

Why Lloyd's can't sleep easy. Famous insurance syndicate unprepared for 11 September 2001.

In early 2003, Europe's embattled insurance industry was hit by another setback. Germany's Allianz was forced to provide over US\$750 million to Fireman's Fund, an American subsidiary, to cover the cost of asbestos-related claims. Meanwhile, tumbling stock markets put added strain on capital bases.

\section{Elements of the Insurance Business}

Insurance businesses have two basic sides-the collection of premiums for bearing risks for others and the investment of those premiums. Hence, they are classic asset/liability enterprises. The investment side is similar to that of other financial institutions. The idea is to invest the premiums and previous investments to yield good returns over time and provide resources for insurance claims. This investment can take many risk-return profiles. The essence is to have enough capital to weather storms from bad scenario outcomes from both the investment business and insurance claims.

In some insurance businesses, the claims have little aggregated risk, as in life insurance, if properly diversified. But in many insurance businesses, claim risk is substantial.

The insurance side generates premiums that, on average, cover future claims. These claims have distributions of losses, as with typical liabilities. The danger is in the tails. Insurance companies are frequently insuring against rare events for which the loss is many times the premium paid. A typical strategy is to diversify across such events and to pass on some of this tail risk to reinsurers.

Insurance companies have been in business for hundreds of years and have developed sophisticated mathematical analyses of claims. Still, disasters can easily occur. For example, 32 U.S. insurance companies declared bankruptcy in 1998. The danger is that the insurance policies written may not be as diversified as the calculations and experience indicate. Then, if overbetting and a disastrous scenario occurs, serious trouble may ensue. 
My approach will be to model insurance company assets and liabilities, use scenario-dependent correlation matrixes, and determine a level of insurance coverage that provides good returns that are as safe as possible. I have illustrated some examples of extreme events in Chapter 2.

\section{The Russell-Yasuda Kasai Model}

The Russell-Yasuda Kasai model was the first large-scale multiperiod stochastic programming model implemented for a major financial institution (see Henriques 1991). I designed the model while working as a consultant to the Frank Russell Company from 1989-1991. Under the direction of Research Head Andy Turner, the team of David Cariño, Taka Eguchi, David Myers, Celine Stacy, and Mike Sylvanus at Russell in Tacoma, Washington, implemented the model for the Yasuda Fire and Marine Insurance Company in Tokyo. Roger Wets and Chanaka Edirishinghe served as consultants in Tacoma, and Kats Sawaki was a consultant to Yasuda Kasai in Japan. Kats, a member of my 1974 University of British Columbia (UBC) class in stochastic programming in which we started to work on asset/liability models (ALMs), was then a professor at Nanzan University in Nagoya and acted independently of the Tacoma group. Kouji Watanabe headed the group in Tokyo, which included Y. Tayama, Y. Yazawa, Y. Ohtani, T. Amaki, I. Harada, M. Harima, T. Morozumi, and N. Ueda.

In 1990-1991, computations were a major focus of concern. We had a pretty good idea of how to formulate the model, an outgrowth of the Kusy and Ziemba (1986) model for the Vancouver Savings and Credit Union and Kallberg, White, and Ziemba (1982). David Cariño formulated most of the details. Originally, we had 10 periods and 2,048 scenarios. The model was too big to solve at that time and became an intellectual challenge for the stochastic programming community. Bob Entriken, D. Jensen, R. Clark, and Alan King of IBM Research worked on a solution but never quite cracked it. We quickly realized that 10 periods made the model far too difficult to solve; it was also too cumbersome to collect the data and interpret the results because, at the time, 2,048 scenarios were a large number to deal with. About two years later, Hercules Vladimirou, working with Alan King at IBM Research and using parallel processing on several workstations, solved the original model.

The Russell-Yasuda Kasai model was designed to satisfy the following need, as articulated by Kunihiko Sasamoto, director and deputy president of Yasuda Kasai:

The liability structure of the property and casualty insurance business has become very complex, and the insurance industry has various restrictions in terms of asset management. We concluded that existing models, such as Markowitz meanvariance, would not function well and that we needed to develop a new asset/liability 
management model. . . . The Russell-Yasuda Kasai model is now at the core of all asset/liability work for the firm. We can define our risks in concrete terms, rather than through an abstract, in business terms, measure like standard deviation. The model has provided an important side benefit by pushing the technology and efficiency of other models in Yasuda forward to complement it. The model has assisted Yasuda in determining when and how human judgment is best used in the asset/ liability process.

(Cariño, Kent, Myers, Stacy, Sylvanus, Turner, Watanabe, and Ziemba 1994, p. 49)

The model was a big success and was of great interest to both the academic and institutional investment asset/liability communities. The team won second prize in the Franz Edelmann Practice of Management Science competition in Chicago in May 1993, and the work was summarized in the January 1994 issue of Interfaces, in which all six finalists had their papers published (see Cariño et al. 1994). The full model is described in Cariño and Ziemba (1998) and Cariño, Myers, and Ziemba (1998). The main points are summarized here.

The success of the Russell-Yasuda Kasai model led to the formation of a new business unit called Russell Business Engineering. That group built three other large custom models for insurance and pension funds in Japan and Switzerland, an ALM planning system for individuals in Italy, and an assetsonly system for use in consulting for Russell's large pension fund clients (see Table 3.1 for general details of these models). This development helped spawn the field of stochastic programming in finance in relation to asset/ liability modeling. In May 1995, I was asked to organize a two-week seminar at the Isaac Newton Institute, Cambridge University, as part of a six-month program on financial mathematics. The week on ALMs led to the book by Ziemba and Mulvey (1998), and the week on security market anomalies led

Table 3.1. Russell Business Engineering Models

\begin{tabular}{|c|c|c|c|c|}
\hline Model & Type of Application & $\begin{array}{c}\text { Year } \\
\text { Delivered }\end{array}$ & $\begin{array}{l}\text { Number of } \\
\text { Scenarios }\end{array}$ & $\begin{array}{l}\text { Computer } \\
\text { Hardware }\end{array}$ \\
\hline Russell-Yasuda (Tokyo) & $\begin{array}{l}\text { Property and casualty } \\
\text { insurance }\end{array}$ & 1991 & 256 & IBM RISC 6000 \\
\hline Mitsubishi Trust (Tokyo) & Pension consulting & 1994 & 2,000 & $\begin{array}{l}\text { IBM RISC } 6000 \\
\text { with Parallel Processors }\end{array}$ \\
\hline Swiss Bank Corp. (Basle) & Pension consulting & 1996 & 8,000 & IBM UNIX2 \\
\hline $\begin{array}{r}\text { Daido Life Insurance } \\
\text { Company (Tokyo) }\end{array}$ & Life insurance & 1997 & 25,600 & IBM PC \\
\hline Banca Fideuram (Rome) & Assets only (personal) & 1997 & 10,000 & IBM UNIX2 and PC \\
\hline Consulting Clients & Assets only (institutional) & 1998 & Various & IBM UNIX2 and PC \\
\hline
\end{tabular}


to the book by Keim and Ziemba (2000). A listing over time of model origins, early models, and modern models in the introduction to Ziemba and Mulvey shows how much the field grew in the 1990s, and it has grown even more since, a part of which is described in this monograph.

The Yasuda Fire and Marine Insurance Company (Yasuda Kasai, meaning fire) is based in Tokyo. It began operations in 1888 and was the second largest Japanese property and casualty insurer and seventh largest in the world by revenue. Its main business was voluntary automobile ( 43.0 percent), personal accident (14.4 percent), compulsory automobile (13.7 percent), fire and allied (14.4 percent), and other (14.5 percent). The firm had assets of $¥ 3.47$ trillion (US\$26.2 billion) at the end of fiscal 1991 (31 March 1992). In 1988, Yasuda Kasai and Russell signed an agreement to deliver a dynamic stochastic asset allocation model by 1 April 1991. Work began in September 1989. The goal was to implement a model of Yasuda Kasai's financial planning process to improve its investment and liability payment decisions and its overall risk management.

The business goals were to 1) maximize long-run expected wealth;2) pay enough on the insurance policies to be competitive in current yield; 3) maintain adequate current and future reserves and cash levels; and 4) meet regulatory requirements, especially with the increasing number of savingsoriented policies being sold that were generating new types of liabilities. The model needed to have more-realistic definitions of operational risks and business constraints than the return variance of previous mean-variance models used at Yasuda Kasai. The implemented model determines an optimal multiperiod investment strategy that enables decision makers to define risks in tangible operational terms, such as cash shortfalls. The risk measure used is convex and penalizes target violations more and more as the violations of various kinds and in various periods increase. The objective is to maximize the discounted expected wealth at the horizon, net of expected discounted penalty costs incurred during the five periods of the model.

This objective is similar to that of a mean-variance model, except it is for five periods and counts only downside risk through target violations. I greatly prefer this approach to value at risk (VAR) or conditional value at risk (CVAR) and its variants for ALM applications because, for most people and organizations, the nonattainment of goals is more and more damaging as the nonattainment increases. The loss is not linear in the nonattainment (as in CVAR) and VAR does not consider the size of the nonattainment at all. An excellent reference on VAR and CVAR as risk measures is Artzner, Delbaen, Eber, and Heath (1999). Krokhmal, Uryasev, and Zrazhevsky (2003) applied these measures to hedge fund performance. My risk measure is coherent in their 
sense, and its theoretical properties from an axiomatic point of view are discussed in Rockafellar and Ziemba (2000). Figure 3.1 shows this measure. The piecewise linear function is used to maintain the model as a large stochastic linear program.

The model formulates and meets the complex set of regulations imposed by Japanese insurance laws and practices. The most important of the intermediate-horizon commitments is the need to produce income sufficiently high to pay the required annual interest in the savings-type insurance policies without sacrificing the goal of maximizing long-run expected wealth. During the first two years of use, fiscal 1991 and 1992, the investment strategy recommended by the model yielded a superior income return of $42 \mathrm{bps}$ (US\$79 million) over what a mean-variance model would have produced. Simulation tests also demonstrated the superiority of the stochastic programming scenario-based model over a mean-variance approach. In addition to the revenue gains, considerable organizational and informational benefits were evident.

The model equations are shown in block form in Figure 3.2, where a $\xi_{t}$ means there is uncertainty in that block. ${ }^{1}$ The model has 256 scenarios over four periods plus a fifth end-effects period. The model is flexible regarding the time horizon and length of decision periods, which are multiples of quarters. A typical application has initialization plus Period 1 to the end of Quarter 1; Period 2, the remainder of Fiscal Year 1; Period 3, the entire Fiscal Year 2; Period 4, Fiscal Year 3, 4, and 5; and Period 5, the End-Effects Year 6 on to forever. Figure 3.3 shows the decision-making process.

\section{Figure 3.1. Convex Piecewise Linear Risk Measure}

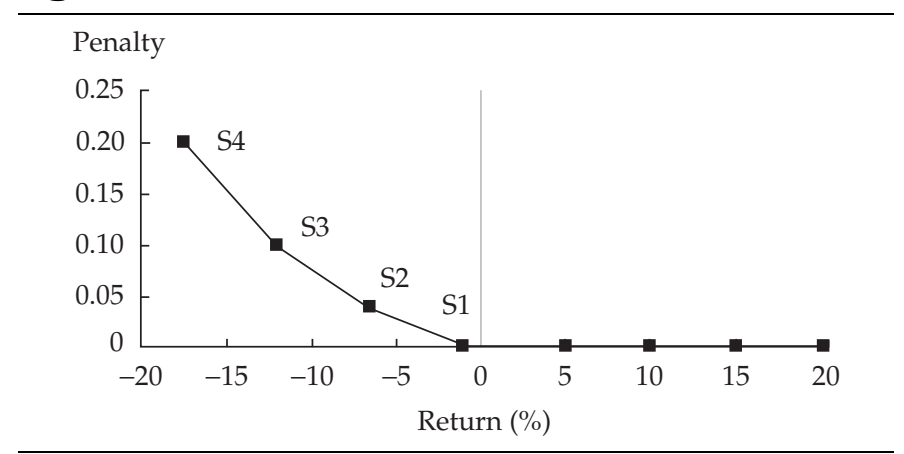

Note: $\mathrm{S}=$ slope.

\footnotetext{
1A simplified form appears in Appendix C (p. 20), which is available online in the Supplementary Material area at www.aimrpubs.org/rf/issues/v2003n6/pdf/AppendixC.pdf.
} 
Figure 3.2. Multistage Stochastic Linear Programming Structure of the Russell-Yasuda Kasai Model

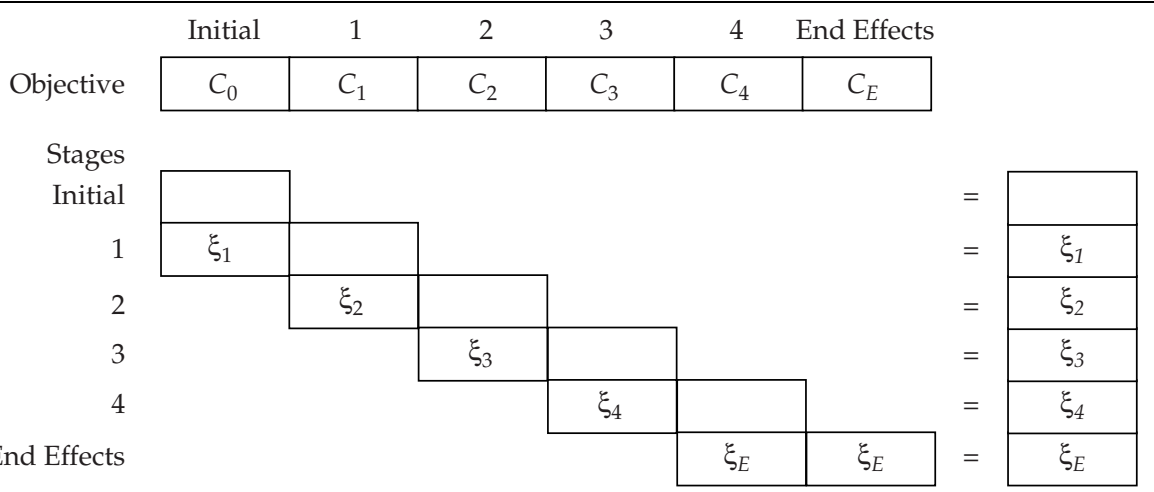

Note: $C=$ cost coefficient.

Figure 3.3. Yasuda Kasai's Asset/Liability Decision-Making Process

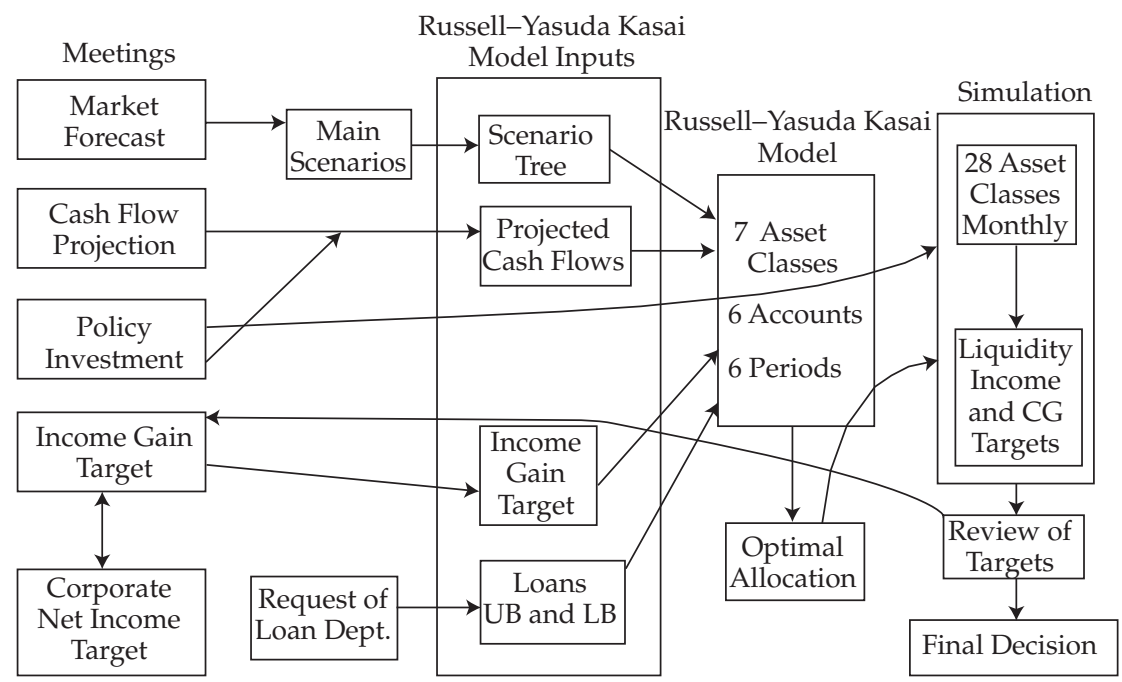

Note: $\mathrm{UB}=$ upper bound; $\mathrm{LB}=$ lower bound; $\mathrm{CG}=$ company growth . 
Yasuda Kasai faced the following situation:

- An increasing number of savings-oriented policies were being sold that had new types of liabilities.

- The Japanese Ministry of Finance imposed many restrictions through insurance laws, which led to complex constraints.

- The firm's goals included both current yield and long-run total return, so risks and objectives were multidimensional.

The insurance policies were complex, both part actual insurance and part an investment with a fixed guaranteed amount plus a bonus, dependent on general business conditions in the industry. The insurance contracts were of varying length-maturing, being renewed, or starting in various time periods-and were subject to random returns on assets managed, insurance claims paid, and bonus payments made. Table 3.2 shows the insurance company's balance sheet with various special savings accounts.

Many regulations on assets exist, including restrictions on equity, loans, real estate, foreign investment by account, foreign subsidiaries, and tokkin funds (pooled accounts). Table $\mathbf{3 . 3}$ depicts some of the regulations on

Table 3.2. Yasuda Kasai's Balance Sheet

\begin{tabular}{lc}
\hline Assets & Liabilities \\
\hline Cash & General account \\
Loans & Savings account \\
Fixed income & Special savings 1 \\
Equities & Special savings 2 \\
Foreign fixed income & Special savings 3 \\
Foreign equities & Special savings 4 \\
Other & Net worth \\
\hline
\end{tabular}

Table 3.3. Example of Regulations on Foreign Investments

\begin{tabular}{|c|c|c|c|c|c|c|c|c|}
\hline & \multicolumn{4}{|c|}{ Account 1} & \multicolumn{4}{|c|}{ Account 2} \\
\hline & Direct & Tokkin & Foreign & Subsidiaries & Direct & Tokkin & Foreign & Subsidiaries \\
\hline Cash & $\mathrm{x}$ & & & & $\mathrm{x}$ & & & \\
\hline Fixed income & $\mathrm{x}$ & & & & $\mathrm{x}$ & & & \\
\hline Equities & & $\mathrm{x}$ & $\mathrm{x}$ & $\mathrm{x}$ & & $\mathrm{x}$ & $\mathrm{x}$ & $\mathrm{x}$ \\
\hline $\begin{array}{l}\text { Foreign fixed } \\
\text { income }\end{array}$ & $\mathrm{x}$ & $\mathrm{x}$ & $\mathrm{x}$ & & $\mathrm{x}$ & $\mathrm{x}$ & $\mathrm{x}$ & \\
\hline $\begin{array}{l}\text { Foreign } \\
\text { equities }\end{array}$ & $\mathrm{x}$ & $\mathrm{x}$ & $\mathrm{x}$ & & $\mathrm{x}$ & $\mathrm{x}$ & $\mathrm{x}$ & \\
\hline
\end{tabular}

Note: $\mathrm{x}$ means the investment is allowed, and a blank means it is not. 
investing in foreign investments. How should one manage investment assets in such an environment? The goal was to implement a model of Yasuda Kasai's financial planning process to improve the investment decisions and overall risk management. Yasuda Fire and Marine staff would operate the software model independently. The model was set up to run on an IBM RS/6000 workstation and had a computing time of three hours or less. All significant input was parameterized. Risks were defined in operational terms as the difference between actual and targeted income, cash flow shortages, or capital losses. The asset classes are shown in Table 3.4.

\section{Table 3.4. Asset Classes for the Russell-Yasuda Kasai Model}

\begin{tabular}{ll}
\hline Asset & \multicolumn{1}{c}{ Associated Index } \\
\hline Cash bonds & Nomura Bond Performance Index \\
Convertible bonds & Nikko Research Convertible Bond Index \\
Domestic equities & Tokyo Stock Price Index (TOPIX) \\
Hedged foreign bonds & Salomon Brothers World Bond Index (or hedged equivalent) \\
Hedged foreign equities & Morgan Stanley World Equity Index (or hedged equivalent) \\
Unhedged foreign bonds & Salomon Brothers World Bond Index \\
Unhedged foreign equities & Morgan Stanley World Equity Index \\
Loans & Average lending rates (trust/long-term credit or long-term prime rates) \\
Money trusts and so on & Call rates (overnight with collateral) \\
\hline
\end{tabular}

Note: Life insurance company general accounts are an asset class but have no associated index.

Dividing the universe of available investments into a manageable number of asset classes involves a trade-off between detail and complexity. A large number of asset classes would increase detail at the cost of increasing size. Therefore, the model allows the number and definition of asset classes to be specified by the user. There can be different asset classes in different periods. For example, asset classes in earlier periods can be collapsed into aggregate classes in later periods.

Exhibit 3.1 presents a typical asset class list. Investment in asset classes may be done either directly or indirectly through tokkin funds, capital ownership of foreign subsidiaries, or loans to foreign subsidiaries. The regulatory rules that apply to indirect investments yield the investment types shown in Exhibit 3.2.

The model chooses an asset allocation, and variables represent the market values chosen for each class. Even though the number of allocation variables can potentially equal the product of the number of asset classes, the number 
Exhibit 3.1. Typical Asset Class List

\begin{tabular}{llll}
\hline Identifier & Description & Identifier & Description \\
\hline CJ & Cash & BF & Bonds (foreign) \\
LL & Loans (floating rate) & EU & Equity (U.S.) \\
LF & Loans (fixed rate) & EN & Equity (Non-U.S. foreign) \\
LO & Loans & EF & Equity (foreign) \\
BJ & Bonds (domestic) & FO & Foreign assets \\
EJ & Equity (domestic) & RE & Real estate \\
BU & Bonds (U.S. and Canada) & OT & Other \\
BA & Bonds (U.K. and Australia) & GE & Generic assets \\
BE & Bonds (European continent) & & \\
\hline
\end{tabular}

Exhibit 3.2. Investment Types

\begin{tabular}{ll}
\hline Identifier & Description \\
\hline $\mathrm{D}$ & Direct \\
$\mathrm{T}$ & Tokkin \\
$\mathrm{C}$ & Capital to foreign subsidiaries \\
$\mathrm{L}$ & Loans to foreign subsidiaries \\
\hline
\end{tabular}

of investment types, the number of accounts, and some asset class investmenttype account combinations are disallowed either by regulations or by company policy. An input table controls the available allocation classes of the model, and the user can specify fewer available allocation classes in later periods. A typical number of allocation variables by stage is shown in Table 3.5.

The primary recommendations provided by the model are as follows:

- a market value allocation for each asset class in each period,

- a book value allocation for each asset class in each time period,

- amount of asset purchases and sales in each time period,

Table 3.5. Allocation Variables by Stage

\begin{tabular}{lcrrrrrl}
\hline & Stage & \multicolumn{7}{c}{ Account } & \\
\cline { 3 - 6 } $\mathrm{t}$ & Name & $\mathrm{S}$ & 1 & 2 & $\mathrm{G}$ & $\mathrm{E}$ & Total \\
\hline 0 & INI & 15 & 13 & 15 & 15 & 1 & 59 \\
1 & Q01 & 15 & 13 & 15 & 15 & 1 & 59 \\
2 & Y01 & 15 & 13 & 15 & 15 & 1 & 59 \\
3 & Y02 & 7 & 7 & 7 & 7 & 1 & 29 \\
4 & Y05 & 7 & 7 & 7 & 7 & 1 & 29 \\
5 & YFF & 5 & 5 & 5 & 5 & 1 & 21 \\
\hline
\end{tabular}

Note: $\mathrm{S}=$ a savings product; $\mathrm{G}=$ general; and $\mathrm{E}=$ exogenous. 
- expected wealth at model horizon points, and

- shortfalls versus model targets in each time period.

The model had the 256 scenarios shown in Figure 3.4. The end-effects period is Year 6 to forever and is a steady-state period in insurance policy growth. All scenario trees have one scenario in the last stage.

The scenarios were generated using three models: (1) independent across periods; (2) a VAR factor model that uses interest rates measured by the long-term government bond yields, returns measured by the first section of the Tokyo Stock Exchange (Tokyo Stock Price Index [TOPIX]), and currency measured by the yen versus U.S. dollar return; and (3) a general model in which the user can specify the scenarios.

The model has the following elements: (1) a matrix generator, which creates a base linear program plus a set of random coefficient specifications for each period; (2) a scenario generator, which builds the decision-tree structure and generates the random returns for each asset class; (3) a liability generator, which, in sync with the asset scenarios, projects the random liabilities for each decision node; (4) a coefficient generator, which combines the random coefficient specifications with the random variables to generate random coefficients; and (5) a solver, which generates the optimal solution.

A major part of the information from the model is in the terms of the reports, which consist of tables and figures of model output. Actual asset allocation results from the model are confidential. But Table 3.6 shows the expected allocations in the initialization and Table 3.7 shows them for the end-effects period.

When one builds and implements a model, the question is: How good is it? The first test is: Is it better than the previous model (which was a meanvariance model)? The comparison is in the spirit of Kusy-Ziemba's (1986) comparison of their multiperiod stochastic linear programming model (solved

\section{Figure 3.4. Scenario Tree}

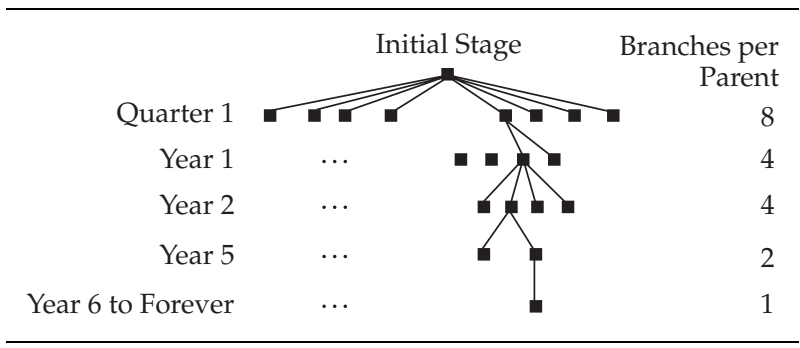

Note: Total number of scenarios was 256. Each node represents a joint outcome of all the asset class returns. 
Table 3.6. Expected Allocations for Initialization

Period: INI

\begin{tabular}{lcc}
\hline & $\begin{array}{c}\text { Total } \\
\text { (100 million) }\end{array}$ & Percentage \\
\hline Cash & 2,053 & $9 \%$ \\
Loans (floating rate) & 5,598 & 26 \\
Loans (fixed rate) & 5,674 & 26 \\
Bonds & 2,898 & 13 \\
Equity & 1,426 & 7 \\
Foreign bonds & 3,277 & 15 \\
Foreign equity & 875 & $\frac{4}{100 \%}$ \\
$\quad$ Total & 21,800 & 100 \\
\hline
\end{tabular}

Note: Total book value $1=22,510$ ( $¥ 100$ million). Total book value $2=34,875$ (¥100 million).

Table 3.7. Expected Allocations in the End-Effects Period ( $¥ 100$ million)

\begin{tabular}{|c|c|c|c|c|c|c|c|}
\hline & General & Savings & $\begin{array}{c}\text { Special } \\
\text { Savings 1 }\end{array}$ & $\begin{array}{c}\text { Special } \\
\text { Savings } 2\end{array}$ & Exogenous & Total & Percentage \\
\hline$\overline{\text { Cash }}$ & 0 & 44 & 0 & 36 & 0 & 80 & $0.1 \%$ \\
\hline Bonds & 5,945 & 17 & 14,846 & 1,311 & 0 & 22,119 & 40.1 \\
\hline Equity & 0 & 0 & 4 & 0 & 18,588 & 18,592 & 33.7 \\
\hline Foreign bonds & 2,837 & 1,094 & 0 & 0 & 0 & 3,931 & 7.1 \\
\hline Foreign equity & 0 & $\underline{4,650}$ & 6,022 & 562 & 0 & 11,234 & 20.4 \\
\hline Total & 8,782 & 5,804 & 20,072 & 1,908 & 18,588 & 55,154 & \\
\hline
\end{tabular}

Note: Total book value $1=28,566$. Total book value $2=50,547$.

via two-period technology) and the dynamic decision-tree approach of Bradley and Crane (1973). The idea was to set up plausible situations, let each model compute optimal solutions, and then compare, by simulation, how good the solutions were by using statistical tests. They found that the stochastic linear programming model was greatly superior to the decision-tree dynamic programming approach. The flexibility of stochastic programming was one reason for this superiority.

For the Russell-Yasuda Kasai application, after one year, the meanvariance model gives extremely poor solutions. This finding is shown by the effect of the number of periods that are fixed with the mean-variance allocations versus having the stochastic programming solution. Figure 3.5 shows the optimal multiperiod stochastic programming solution. This is compared 


\section{Figure 3.5. The Effect of Mean-Variance Approximations on the Optimal Stochastic Programming Solution}

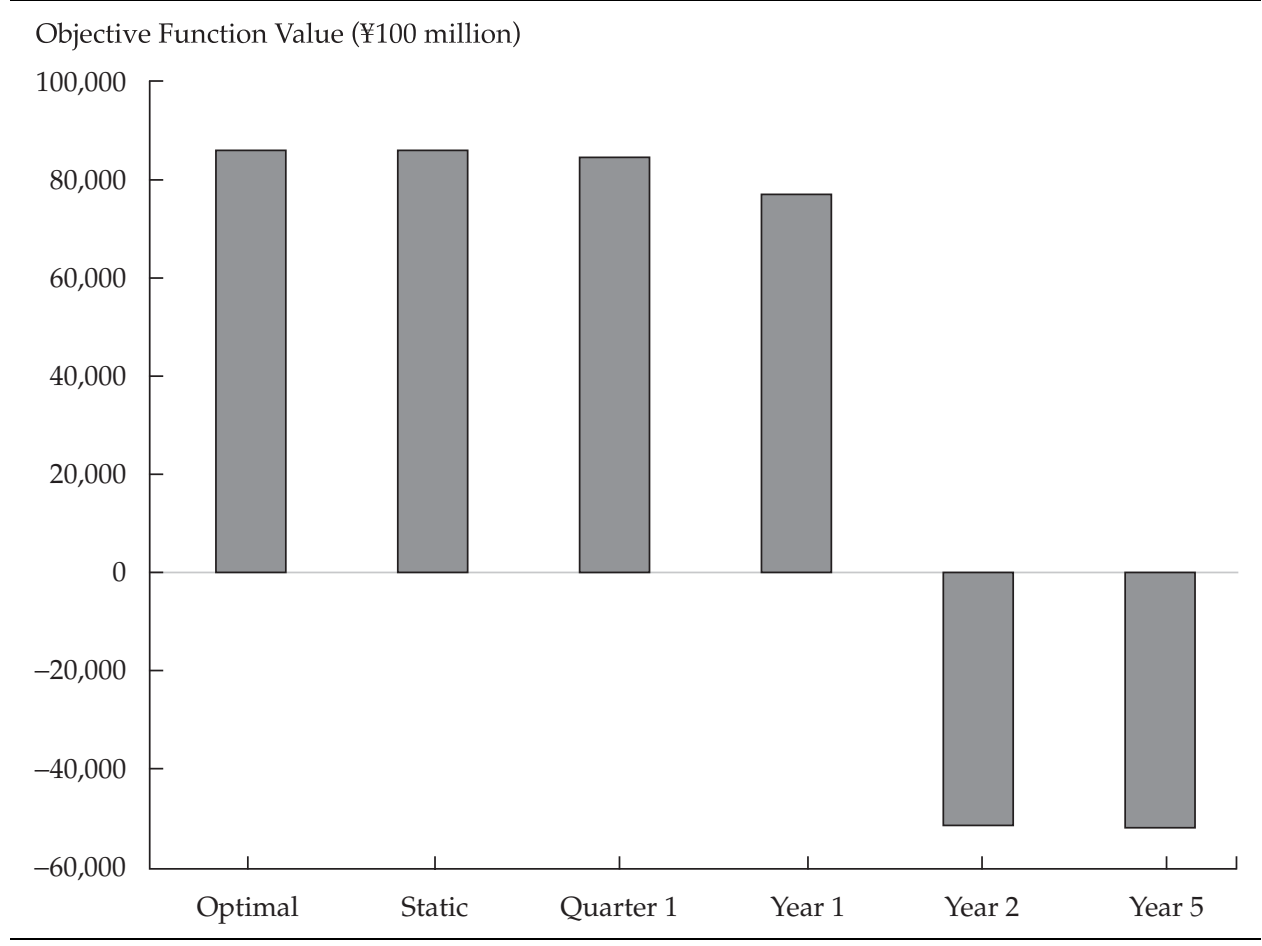

to the suboptimal policies of using the mean variance approximation for more and more periods. Extensive use of the mean variance approximation leads to poor performance relative to the optimal solution.

Another test is: How did the model allocations do in actual use with real money in fiscal 1991 and 1992 (1 April-31 March)? From Russia with Love fans will remember the phrase, "we use live targets as well"; out-of-sample tests, especially with real money, are the ultimate test of a model's success. The results are as follows: In fiscal 1991, the positive comparison versus the previous mean-variance fixed-mix strategy yielded +15 bps (US\$25 million) in income yield; in fiscal 1991-1992, it yielded a combined +42 bp improvement (US\$79 million) in income yield.

In fiscal 1991, both the actual income return and total return were more than 7 percent. During the same period, the Nikkei Stock Average lost 1.84 percent. Total return in 1991-1992 combined was +5 bps better (US $\$ 9$ million). Also, risk management was greatly improved. In summary:

- The 1991 Russell-Yasuda Kasai model was then the largest application of stochastic programming in financial services. 
- There was a significant ongoing contribution to Yasuda Kasai's financial performance-US\$79 million and US\$9 million in income and total return, respectively, over fiscal 1991-1992-and the model has been in use since then.

- The basic structure is portable to other applications because of flexible model generation.

- The model will have a substantial potential impact on the performance of financial services companies.

- The top 200 insurers worldwide have in excess of US\$10 trillion in assets.

- Worldwide pension assets are also about US\$7.5 trillion, with a US\$2.5 trillion deficit.

- The industry is also moving toward more complex products and liabilities and risk-based capital requirements.

\section{Insurance Products with Guarantees}

Selling guarantees is like smoking Cuban cigars while driving a dynamite truck; you better do it carefully.

These products are interesting and popular, but they are dangerous if the guarantees are set too high.

Many insurance companies in Japan, the United States, Europe, and elsewhere write insurance policies in which a certain investment return is guaranteed over time. This practice is risky and dangerous and frequently leads to disaster. The Russell-Yasuda Kasai model was designed to analyze such situations to evaluate their risk and determine good investment strategies.

Consiglio, Cocco, and Zenios (2001, forthcoming 2004) discussed a model for managing such insurance policies with guarantees that Prometeia has used for Italian insurers. In these policies, there are guarantees on the minimum rate of return, bonus provisions, and surrender options. These features are attractive for investors who want to combine insurance with an investment in a single product. In Italy, institutional investment and pension fund portfolios are primarily in bonds (see Table 3.8). From 1997 to 2002, however, the trend for individuals has been toward mutual funds, equities, and life and general insurance at the expense of liquid assets and bonds. In 2002 , some 44.8 percent of Italian households' traded financial assets were in mutual funds and 19.9 percent were in insurance.

Financial products with minimum rate of return guarantees can be maturity or multiperiod guarantees. In the former case, the guarantee applies only at maturity of the contract and returns above the guarantee in periods before 
Table 3.8. Pension Fund Assets: Total, as a Percentage of GDP, and Allocation, 1997

\begin{tabular}{|c|c|c|c|c|c|c|c|c|}
\hline \multirow[b]{2}{*}{ Countries } & \multirow{2}{*}{$\begin{array}{c}\text { Assets } \\
\text { (US\$ } \\
\text { billions) }\end{array}$} & \multirow{2}{*}{$\begin{array}{c}\text { GDP } \\
\text { (US\$ } \\
\text { billions) }\end{array}$} & \multirow[b]{2}{*}{$\begin{array}{c}\text { Percentage } \\
\text { of GDP }\end{array}$} & \multicolumn{5}{|c|}{ Allocation of Assets } \\
\hline & & & & Equity & $\begin{array}{l}\text { Fixed } \\
\text { Income }\end{array}$ & $\begin{array}{l}\text { Real } \\
\text { Estate }\end{array}$ & Cash & Other \\
\hline Austria & 20.9 & 181.8 & $11.5 \%$ & $4.1 \%$ & $82.4 \%$ & $1.8 \%$ & $1.6 \%$ & $10.0 \%$ \\
\hline Belgium & 10.3 & 213.8 & 4.8 & 47.3 & 41.3 & 5.2 & 5.6 & 0.6 \\
\hline Denmark & 29.3 & 143.7 & 20.4 & 23.2 & 58.6 & 5.3 & 1.8 & 11.1 \\
\hline Finland & 8.9 & 103.6 & 8.6 & 13.8 & 55.0 & 13.0 & 18.2 & 0.0 \\
\hline France & 84.4 & $1,229.1$ & 6.9 & 12.6 & 43.1 & 7.9 & 6.5 & 29.9 \\
\hline Germany & 270.7 & $1,865.4$ & 14.5 & 9.0 & 75.0 & 13.0 & 3.0 & 0.0 \\
\hline Greece & 4.6 & 105.0 & 4.4 & 7.0 & 62.9 & 8.3 & 21.8 & 0.0 \\
\hline Ireland & 34.5 & 64.1 & 53.8 & 58.6 & 27.1 & 6.0 & 8.0 & 0.4 \\
\hline Italy & 21.6 & $1,010.7$ & 2.1 & 4.8 & 76.4 & 16.7 & 2.0 & 0.0 \\
\hline Luxembourg & 0.03 & 13.7 & 0.2 & 23.7 & 59.0 & 0.0 & 6.4 & 11.0 \\
\hline Netherlands & 361.7 & 320.0 & 113.0 & 36.8 & 51.3 & 5.2 & 1.5 & 5.2 \\
\hline Portugal & 9.4 & 86.0 & 10.9 & 28.1 & 55.8 & 4.6 & 8.8 & 2.7 \\
\hline Spain & 18.7 & 470.4 & 4.0 & 11.3 & 60.0 & 3.7 & 11.5 & 13.5 \\
\hline Sweden & 96.2 & 202.4 & 47.5 & 40.3 & 53.5 & 5.4 & 0.8 & 0.1 \\
\hline \multicolumn{9}{|l|}{ United } \\
\hline Kingdom & 891.2 & $1,127.3$ & 79.1 & 72.9 & 15.1 & 5.0 & 7.0 & 0.0 \\
\hline \multicolumn{9}{|l|}{ Total } \\
\hline \multicolumn{9}{|l|}{ European } \\
\hline Union & $1,862.4$ & $7,137.0$ & 26.1 & 53.6 & 32.8 & 5.8 & 5.2 & 2.7 \\
\hline United States & & & & 52 & 36 & 4 & 8 & na \\
\hline Japan & & & & 29 & 63 & 3 & 5 & na \\
\hline
\end{tabular}

na $=$ not applicable.

Source: Based on data from the 1996 report of the European Federation for Retirement Provision.

maturity offset shortfalls at other periods. In the latter case, the time to maturity is divided into subperiods-quarterly or biannually-and the guarantee applies at the end of each period. Hence, excess returns in one subperiod cannot be used to finance shortfalls in other subperiods. Such products appear in insurance policies, guaranteed investment contracts, and some pension plans (see, for example, Hansen and Miltersen 2002).

Policyholders participate in the firm's profits; they receive a bonus when the return of the firm's portfolio exceeds the guarantee, thus creating a surplus. Bonuses are distributed at maturity, at multiple periods until maturity, or using a combination of distribution plans. Some products distribute bonuses using a smoothing formula, and others distribute a prespecified fraction of the portfolio return or portfolio value, net of liabilities. The earlier 
unit-linked policies would pay a benefit upon death or maturity whichever was the greater of the guaranteed amount and the value of the insurer's reference portfolio. These were simple maturity guarantees with a bonus paid at maturity. U.K. insurance policies declare at each subperiod a fraction of the surplus, estimated using a smoothing function, as a reversionary bonus, which is then guaranteed. The remaining surplus is managed as an investment reserve and is returned to customers as a terminal bonus if it is positive at maturity or upon death; this issue is discussed in Ross (1989), Chadburn (1997), and Kat (2001). These policies are multiperiod guarantees with bonuses paid in part at intermediate times and in part at maturity.

The Prometeia model has multiperiod guarantees with bonuses paid at each subperiod that are subsequently guaranteed. The bonus is a fraction of the portfolio's excess return above the guaranteed rate during each subperiod. Figure 3.6 shows the growth of a liability with a participation rate of 85 percent and a portfolio that guarantees a yearly return of at least 3 percent. When bonuses are paid, the liability is lifted, and the minimum guarantee applies to the increased liability. This result creates a nonlinear interaction between the rate of return of the portfolio and the total return of the liability. The asset portfolio had losses in Period 7, and the liability grew at the 3 percent

\section{Figure 3.6. Sample Returns Assuming Guarantee of 3 Percent and Participation Rate of 85 Percent}

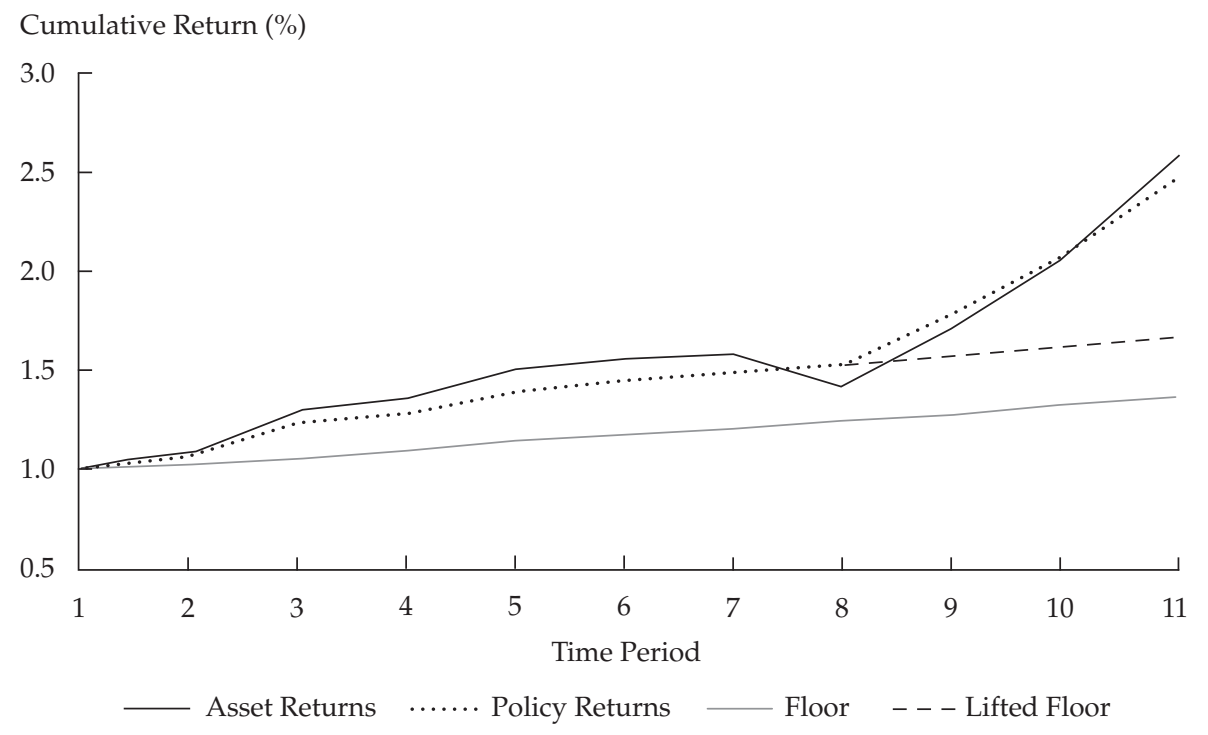

Source: Based on data from Consiglio et al. (forthcoming 2004). 
guaranteed rate. Nonetheless, asset returns allowed the firm to recoup its losses by the 10th period and achieve a positive net return at maturity.

The trend is also to higher levels of autonomy rather than delegation of asset management by wealthy investors. This trend has led to an increase in the purchase of innovative instruments. The percentage of Italian households classified as "innovators" grew from 6.7 percent in 1991 to 22.6 percent in 2001 , to some 4.3 million households. Meanwhile, the Italian insurance industry has lagged in its share of these funds. It has responded with innovative policies that offer traditional insurance and participation in the company's profits, such as the guaranteed products. These policies have minimum guaranteed rates of return, plus bonus provisions when asset returns exceed the minimum guarantee and the right, in some policies, to surrender the product at any time. Various policies are offered, and others can be designed subject to competitive pressures and regulatory restrictions. Policies can have the sum insured being payable if the event occurs before the policy horizon. Otherwise, the insured sum may be capitalized based on the returns from an asset portfolio. The policies can contain bonuses, minimum guaranteed rates of return, and lapse options to surrender policies before maturity. These policies face regulation, which must also be modeled.

With the historically low interest rates in 2002-2003, managing such policies is challenging, and fixed-income assets may not be able to yield the guaranteed rate of return. For instance, the Italian guaranteed rate since 1998 has been 3 percent, so the difference between the guaranteed rate and the 10 -year yield is only 1 percent, which is inadequate for covering a firm's costs. In Germany, the guaranteed rate since 1998 has been 3.5 percent, which is only 0.5 percent below the 10 -year yield. Danish products had guarantees of 3 percent until 1999, when they were reduced to 2 percent. In Japan, Nissan Mutual Life Insurance Company failed on a US\$2.56 billion liability arising from a 4.7 percent guaranteed policy. The loss occurred because Nissan failed to properly account for the value of options, which were a part of the policy.

The basic stochastic programming model contains various elements: the guarantee, usually from a bond; the bonus, which is a European type of option; and the surrender feature, which is an American type of option. ${ }^{2}$ The policies must satisfy regulatory requirements regarding leverage, equity-to-liability ratios, and other features. The options-pricing problem is embedded in the stochastic programming asset allocation problem by using discrete scenarios that allow one to analyze different policies. Portfolios must be designed to

2The basic stochastic programming model is shown in Appendix C (p. 22), which is available online in the Supplementary Material area at www.aimrpubs.org/rf/issues/v2003n6/pdf/ AppendixC.pdf. 
react to the uncertainty over time. This requirement involves the minimization of shortfalls from portfolio returns in various periods that are below the guaranteed amount. Scenarios are generated by sampling from a discrete approximation of continuous-time models of the interest rate, bond pricing, and other models involved.

An example from Consiglio et al. (forthcoming 2004) for the Italian insurance industry follows. They used 23 stock indexes of the major industrial sectors traded on the Milan Stock Exchange and indexes of short-, medium-, and long-term Italian government debt. The Markowitz mean-variance efficient frontier of these assets and the capital market line are shown in Figure 3.7.

The efficient portfolios are not efficient at all when a minimum guarantee exists. Portfolios A, G, and B are on the mean-variance-efficient frontier in Panel A of Figure 3.7. However, they are not efficient in the certainty-equivalent excess return to shareholders, or CEexROE (shareholders' reward versus cost of guarantee space), as shown in Panel B of Figure 3.7. Consiglio et al. (forthcoming 2004) concluded that a more aggressive portfolio strategy would be needed to achieve the minimum guaranteed return and provide excess shareholder return. This increasing appetite for high but risky returns is not monotonic. When moving from Portfolio $\mathrm{G}$ toward the most risky Portfolio B, at first, the cost of the guarantee declines and CEexROE increases. But as we approach Portfolio B, shareholder value erodes. For these volatile portfolios, the embedded option is deep in the money, and shareholders' money is used to compensate for the shortfalls without realizing any excess returns.

The management of minimum-guarantee products requires striking a balance between too much reliance on bonds without meeting the guarantee and too much reliance on stocks, which destroys shareholder value. As in most asset/liability models, the mean-variance approach considers only assets and thus does not perform well for assets and liabilities. The liabilities are endogenous to the portfolio-selection model, and the guarantee floor exists. Thus, nonlinearities exist in the model, as do highly asymmetric returns that are not conducive to mean-variance modeling.

Figure 3.8 and Figure 3.9 show results from the model using logarithmic utility and an 80 percent $(\alpha)$ participation rate. The probabilities of actuarial events are from Italian mortality tables. Probabilities of policy surrender were ignored. The allocation that provides the highest return to shareholders net of downside risk is shown for each level of the minimum guarantee. Even Portfolio $\mathrm{H}$ is dominated by the portfolios obtained from the stochastic programming model. Optimal bond-stock portfolio compositions for different levels of the minimum guarantee (5-10 percent of portfolio value) improve only over Italian stocks and bonds, as shown in Figure 3.10. For 
low levels of minimum guarantee, the large equity content of the portfolio increases shareholder value. The higher mean returns of the equities pass mostly to shareholders. For very large values of the minimum guarantee, the equity content is also large but shareholder value is reduced. Equity is the

\section{Figure 3.7. Example for the Italian Insurance Industry}

A. Mean-Variance-Efficient Portfolios of Italian Stocks and Bonds and the Capital Market Line Expected Return

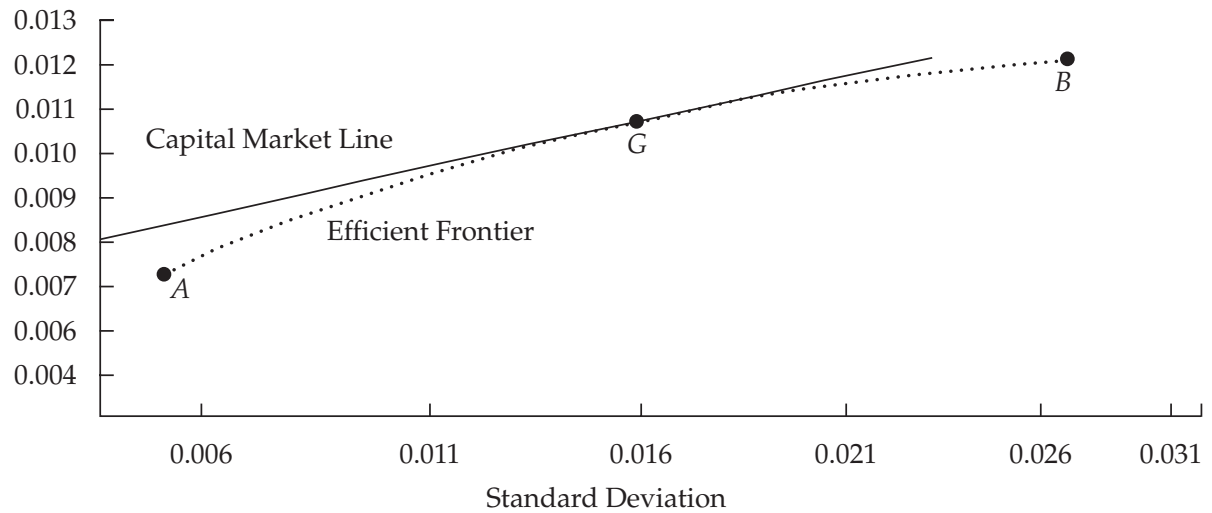

B. Corresponding Certainty-Equivalent Excess Return to Shareholders vs. Cost of Minimum Guarantee for Each Portfolio

Net CEexROE

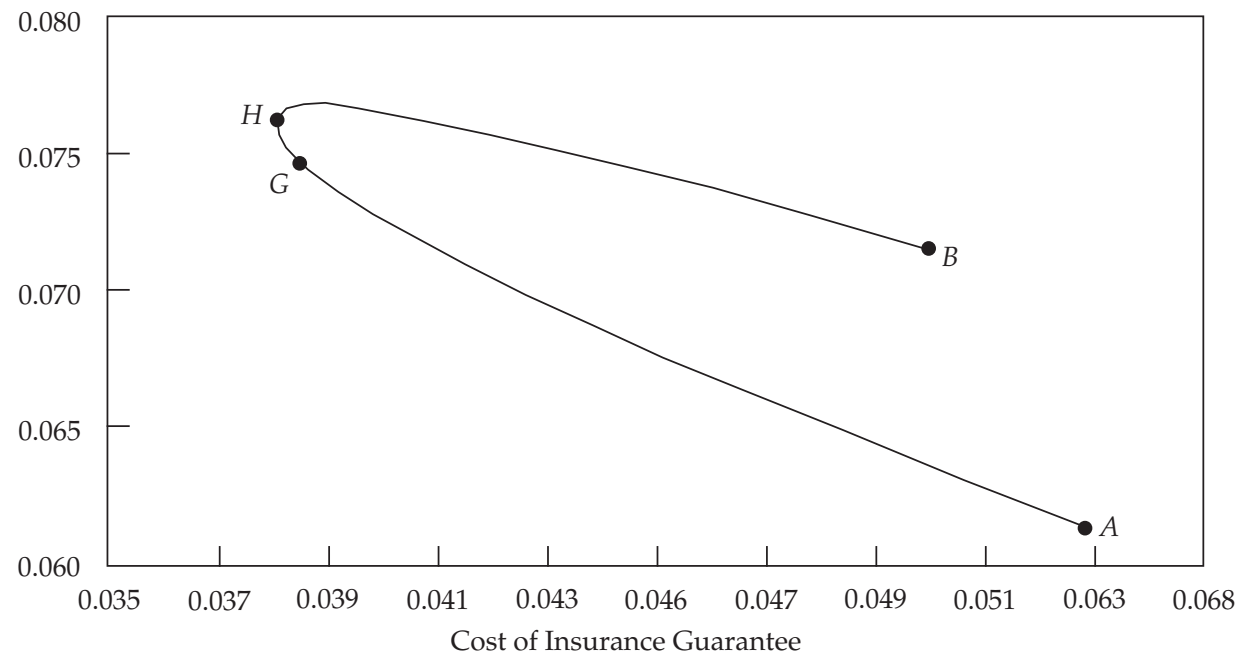

Source: Based on data from Consiglio et al. (2004). 
only way to back very large guarantees, but shareholder value declines as the firm's equity is used to fund shortfalls. Such guarantees are risky, especially if equity mean-return forecasts fail to materialize or are volatile. The optimized portfolios show that the Italian insurers should shift their portfolios toward 20-25 percent in equities for 3 percent guarantees. The stochastic programming model is useful for the design of competitive policies, prices of policies, and levels of minimum guarantees.

\section{Figure 3.8. Annualized CEexROE to Shareholders vs. Cost of the Minimum Guarantee for the Integrated Portfolios at Different Levels of Minimum Guarantee and for the Mean-Variance Efficient Portfolios}

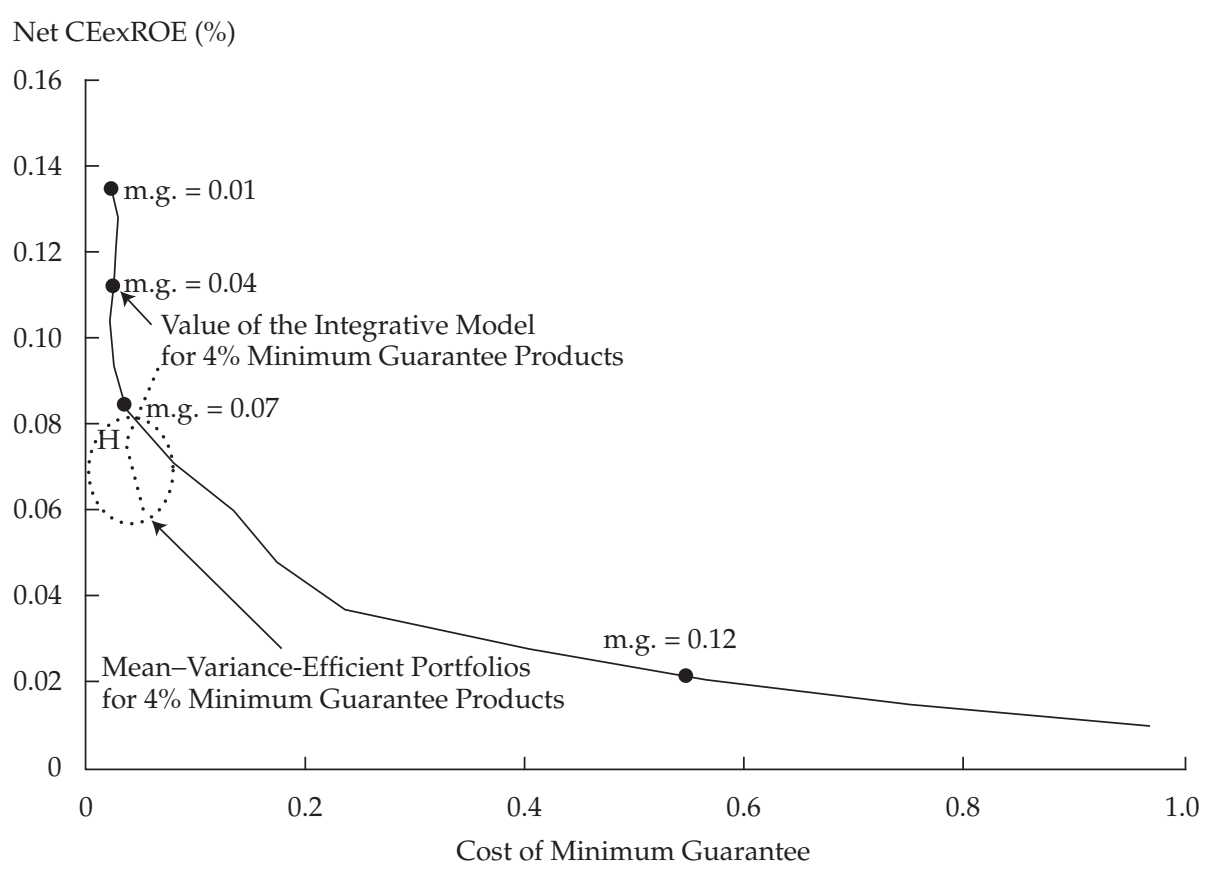

Note $:$ m.g. = minimum guarantee.

Source: Based on data from Consiglio et al. (forthcoming 2004). 
Figure 3.9. Results from the Prometeia Model Using Logarithmic Utility and an 80 Percent $(\alpha)$ Participation Rate

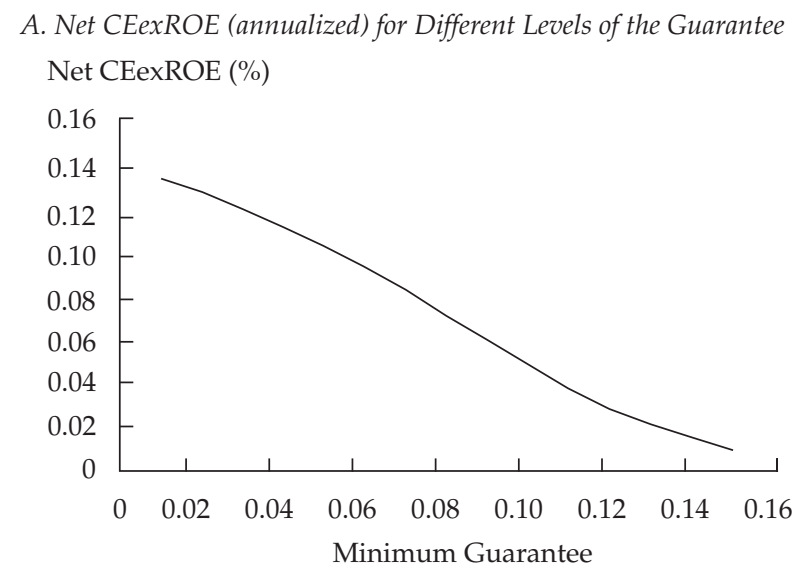

B. Corresponding Broad Asset Allocations

Asset Allocation

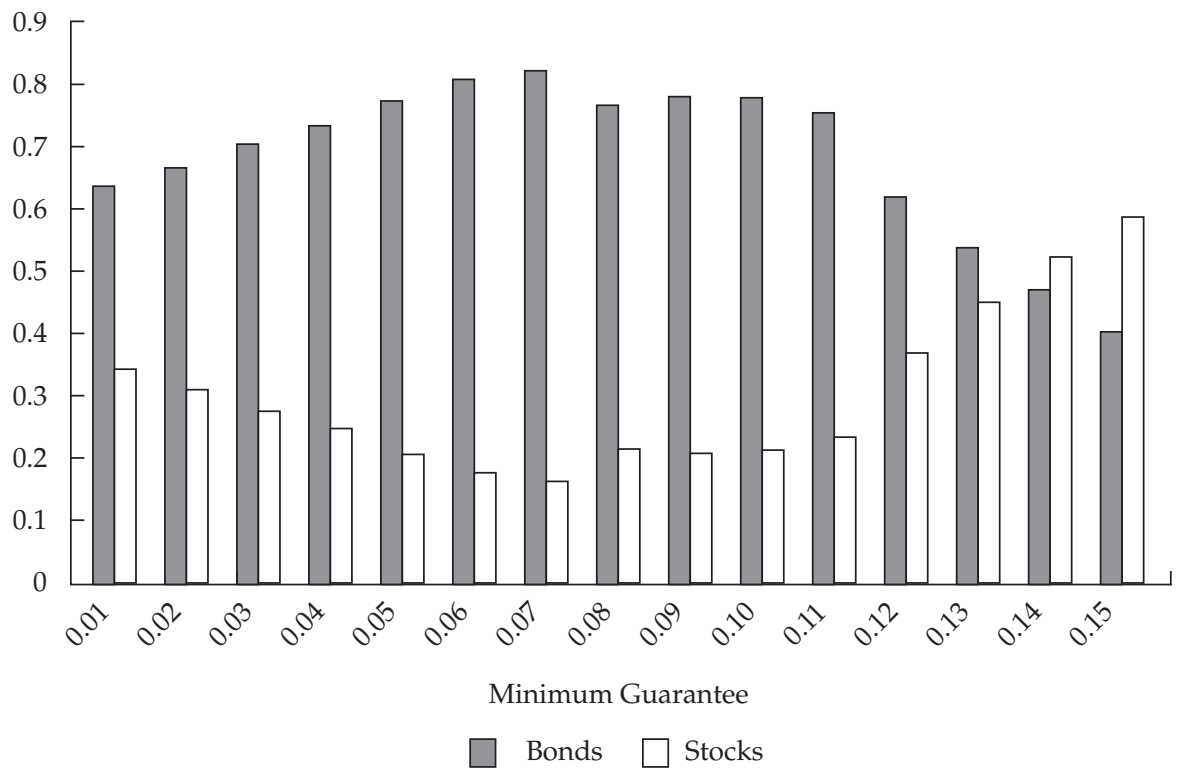

Source: Based on data from Consiglio et al. (2004). 


\section{Figure 3.10. Trade-Off of CEexROE against Cost of the Guarantee for Internationally Diversified Portfolios and Portfolios with Exposure to the Corporate Bond Markets}

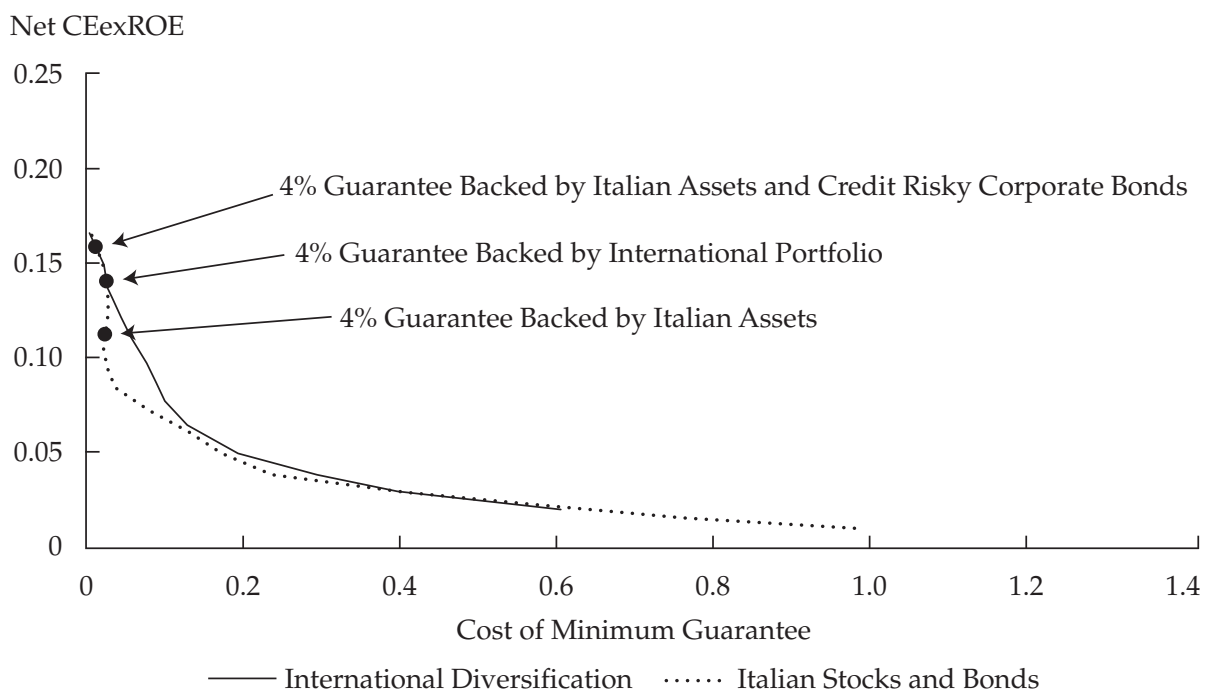

Source: Based on data from Consiglio et al. (2004). 


\section{Pension Fund Applications}

Most people spend more time planning for their vacation than for their retirement.

Citigroup

Half of the investors who hold company stock in their retirement accounts thought it carried the same or less risk than money market funds.

Boston Research Group

The brokerage firm Schwab is no longer making matching contributions to its employees' 401(k) accounts.

Various U.S. airlines want to delay contributions to underfunded pension plans for five years, until 2008. A bill in Congress would allow companies to assume that blue-collar workers will, on average, die sooner than pension plans now assume to lower their current contribution rates.

In January 2003, the pension fund consultants at Watson Wyatt Worldwide estimated that global pension funds had balance sheets of -US\$2.5 trillion (assets minus liabilities). Assets totaled US\$10.7 trillion, the same as in 1997. Liabilities are growing because people are living longer, and assets are falling because of the equity declines in 2000-2002.

\section{Aging of the World's Populations}

Pensions around the world and those who manage and guarantee them will need to deal with the serious problem that the world's populations are aging rapidly. Also, an enormous group of retirees will be needing to cash out of pension and other portfolios at the same time. In Europe, the percentage of people in the 65 and older group will roughly double from 1990-2030, from 20 percent to 40 percent (see Table 4.1). By 2030, two workers will have to support each pensioner, compared with four workers in 1990. Better living conditions, more-effective medical systems, declining fertility rates, and low immigration have all contributed to this aging phenomenon.

The European, Japanese, British, Irish, American, and Canadian pension fund situations are quite different. In Europe, the bulk of pension payments are paid by the state. These state pensions, called "Pillar 1 ," amount to about 
Table 4.1. Elderly Dependence Ratio Projections in Europe and OECD Projections of Pension Cost as a Percentage of GDP, 1990-2030

\begin{tabular}{|c|c|c|c|c|c|c|c|c|c|}
\hline \multirow[b]{2}{*}{ Country } & \multicolumn{3}{|c|}{ Dependency Ratio } & \multicolumn{6}{|c|}{ Pension Cost as Percentage of GDP } \\
\hline & 1990 & 2010 & 2030 & 1995 & 2000 & 2010 & 2020 & 2030 & 2040 \\
\hline Austria & 22.4 & 27.7 & 44.0 & NA & NA & NA & NA & NA & NA \\
\hline Belgium & 22.4 & 25.6 & 41.1 & $10.4 \%$ & $9.7 \%$ & $8.7 \%$ & $10.7 \%$ & $13.9 \%$ & $15.0 \%$ \\
\hline Denmark & 22.7 & 24.9 & 37.7 & 6.8 & 6.4 & 7.6 & 9.3 & 10.9 & 11.6 \\
\hline Finland & 19.7 & 24.3 & 41.1 & 10.1 & 9.5 & 10.7 & 15.2 & 17.8 & 18.0 \\
\hline France & 20.8 & 24.6 & 39.1 & 10.6 & 9.8 & 9.7 & 11.6 & 13.5 & 14.3 \\
\hline Germany & 21.7 & 30.3 & 49.2 & 11.1 & 11.5 & 11.8 & 12.3 & 16.5 & 18.4 \\
\hline Ireland & 18.4 & 18.0 & 25.3 & 3.6 & 2.9 & 2.6 & 2.7 & 2.8 & 2.9 \\
\hline Italy & 21.6 & 31.2 & 48.3 & 13.3 & 12.6 & 13.2 & 15.3 & 20.3 & 21.4 \\
\hline Netherlands & 19.1 & 24.2 & 45.1 & 6.0 & 5.7 & 6.1 & 8.4 & 11.2 & 12.1 \\
\hline Portugal & 19.5 & 22.0 & 33.5 & 7.1 & 6.9 & 8.1 & 9.6 & 13.0 & 15.2 \\
\hline Spain & 19.8 & 25.9 & 41.0 & 10.0 & 9.8 & 10.0 & 11.3 & 14.1 & 16.8 \\
\hline Sweden & 27.6 & 29.1 & 39.4 & 11.8 & 11.1 & 12.4 & 13.9 & 15.0 & 14.9 \\
\hline \multicolumn{10}{|l|}{ United } \\
\hline Kingdom & 24.0 & 25.8 & 38.7 & 4.5 & 4.5 & 5.2 & 5.1 & 5.5 & 5.0 \\
\hline $\begin{array}{c}\text { European } \\
\text { Union } \\
\text { average }\end{array}$ & 21.4 & 25.9 & 40.3 & & & & & & \\
\hline
\end{tabular}

$\mathrm{NA}=$ not available.

Note: Ratio is for those 65 and over as a percentage of population. OECD = Organization for Economic Cooperation and Development.

Source: Based on data from Bos, Vu, Massiah, and Bulatao (1994) and Roseveare, Leibfritz, Fore, and Wurzel (1996).

88 percent of total pension costs. Without changes, the pension payouts in much of the European Union (EU) will grow from about 10 percent of GDP in 1997 to more than 15 percent in 2030 . Contribution rates will have to be raised significantly to enable the public social security system to remain solvent. Also, effective private pension plans will need to play a more major role, given the demand for health care and other social services in addition to pensions. For some countries, however, such as the United Kingdom and Ireland, where pension schemes linked to employment (second pillar) and individual pensions (third pillar) are more prevalent, the pension costs will remain stable over the projection period (see Table 4.1).

How much in assets do these countries have in reserve? Table 3.8 shows that, except for the United Kingdom, the Netherlands, and to a lesser extent Ireland and Sweden, pension fund assets as a percentage of GDP are very low. Burtless (2003), using data from 1927 to 2001, showed that in five major 
industrial countries (France, Germany, Japan, the United Kingdom, and the United States), individual savings accounts are not sufficient for a safe retirement. Hence, retirees need additional resources.

One way to deal with the problem of large pension payments is to have good risk-adjusted returns, and the models in this monograph are an attempt to provide such results by taking into account various problem elements and uncertainties. Not surprisingly, the countries with the more aggressive pension fund managers-Ireland, the United Kingdom, and the United Stateshave had higher returns than other European countries (see Table 4.2).

\begin{tabular}{lc} 
Table 4.2. & $\begin{array}{l}\text { Average Real Annualized Pension } \\
\text { Fund Net Returns, 1984-93 }\end{array}$ \\
\hline Country & Return \\
\hline Restrictive & \\
Belgium & $8.8 \%$ \\
Denmark & 6.3 \\
Germany & 7.1 \\
Netherlands & 7.7 \\
Spain & 7.0 \\
$\quad$ Average & $7.4 \%$ \\
Aggressive & \\
Ireland & $10.3 \%$ \\
United Kingdom & 10.2 \\
United States & 9.7 \\
$\quad$ Average & $10.1 \%$ \\
\hline
\end{tabular}

Source: Based on data from the European Commission (1997).

These superior results are related to the asset allocation weights; the advanced countries have more equities, whereas most of the EU countries listed in Table 3.8 have the bulk of their capital invested in bonds. In the models developed here, these weights will be scenario and time dependent.

\section{Why Do European Pension Fund Managers Invest So Much in Bonds?}

European pension plans have a strong preference for bondholdings, as shown in Table 3.8. More "mature" Pillar 2 countries, such as the United Kingdom and Ireland, which have managed portfolios for foreign as well as domestic 
investors for a long time, have a higher equity exposure, which may better reflect the long-term aspect of pension obligations. In countries such as Austria, Germany, Italy, Spain, and France where equity markets were not developed until recently, pension plans are invested more heavily in local government bonds.

In addition, such asset structures also reflect the attitude toward equities in various countries. With the introduction of the euro in 1999, a first important step toward a more integrated capital market, especially for equities, was made. In Austria, pension funds are now starting to increase their equity positions, but it will take some time to reach a structure similar to that in the well-established U.S., U.K., and Irish pension industries. Strict regulations, the availability of investment products, a fear of foreign investment, a shortterm outlook, and tradition have led to this situation. The regulations, especially the perception of them, are still not flexible enough to allow pension managers to diversify their portfolios across asset classes, currencies, and worldwide markets.

Some changes, however, are on the horizon from the European Commission. The new proposals would allow European pensions to have more freedom to invest in equities and foreign assets and currencies. In EU countries, the limit for worldwide equities would rise to 70 percent versus the current average of about 35 percent.

The high percentage of bond allocations in European pension funds, shown in Table 3.8, has had a substantial effect on actual performance. Table 4.2 shows annualized real pension fund returns for a subset of five EU countries versus those for the United States, the United Kingdom, and Ireland. Not surprisingly, the more advanced, more aggressive investment styles of the United States, the United Kingdom, and Ireland led to returns that were about 3 percent higher a year.

Using measures such as the Sharpe ratio or the capital asset pricing model, studies, such as Dimson, March, and Staunton (2002), Keim and Ziemba (2000), and Jorion and Goetzmann (1999), indicate that over long periods, equity returns outperform bond returns in risk-adjusted terms. Moreover, the historical evidence, since 1802 for the United States and since 1700 for the United Kingdom, indicates that the longer the period, the more likely the dominance by equities. Recall the calculations in Table 2.8 from Siegel (2002); for all 20-year periods from 1926-2001, U.S. equities outperformed bonds, and for 30-year horizons, based on the past, it has been optimal (with a mean-variance model) to be more than 100 percent in stocks and to have a short position in bonds. 
Hensel and Ziemba (2000b) showed how the slow but steady outperformance of assets can lead to dramatically higher total wealth levels over long periods. For example, for the United States, during the 1942-97 period, a strategy that was 100 percent in U.S. small-cap stocks with Democratic administrations and 100 percent in large-cap stocks in Republican administrations had, in 1997, 24.5 times as much wealth as the typical 60/40 percent stock/bond mix used in most U.S. pension funds. How much to invest in cash, stocks, and bonds over time is a deep and complex issue. For a theoretical analysis in which the uncertainty of mean reversion is part of the model, see Barbaris (2000). One thing is clear: Equities have had an enormous advantage over cash and bonds during most periods in most countries, so the optimal blend is to have much more equity than 5 percent.

The case for equities, however, is not as clear-cut as Figure 2.14 might indicate. Figure 2.15 shows how bumpy the gains have been for the DJIA in real terms. Hence, investors who need funds for liability commitments, such as pensioners, may well have much poorer results. Indeed, despite the near linearity of the growth of equity values in Figure 2.14, there were three long subperiods of essentially zero nominal equity growth, not counting dividends, in the 20th century: 1900-1920, 1929-1954, and 1964-1981.

For example, the DJIA was at 66.08 on 31 December 1899 and at 71.95 on 31 December 1920, a rise of 0.4 percent a year. By September 1929, the DJIA was at 381 , a 430 percent increase in less than nine years. But then it fell to 177 in 1946, half its 1929 level. Then, on 31 December 1964, the DJIA was at 874.12 , and it was essentially the same, at 875.00, on 31 December 1981, 17 years later. But 17 years later on 31 December 1998, it was more than 10 times higher, at 9181.43. Interest rates were crucial because long-term U.S. government bonds were yielding 4.20 percent on 31 December 1964, 13.65 percent on 31 December 1981, and 5.09 percent on 31 December 1998.

So, the conclusion, to paraphrase Warren Buffett (2001), is that equity prices have risen dramatically since 1900 in the United States, but during three long periods of 20,25 , and 17 years, stocks had essentially zero gains, or even losses, in nominal terms.

In the United States, notable examples of institutions close to pension funds that have had very high risk-adjusted returns from a variety of private placement hedge fund and other investments without high equity exposures are the endowments of Harvard and Yale universities and the Ford Foundation (see Swensen 2000 and Clifford, Kroner, and Siegel 2001). A higher equity proportion or other way to increase real returns would have resulted in betterfunded pension plans, higher pension payments, or lower contribution rates for companies. Of course, this outperformance is predicated on a continuing 
high equity risk premium and is volatility dependent. Between 1982 and 1999 , the return of equities over bonds was more than 10 percent a year in EU countries. These high equity returns of the distant past and the bull market of the late 1990s, however, led to valuations of $\mathrm{P} / \mathrm{E}$ and other measures that were at historically high levels in Europe, the United States, and elsewhere. Studies by Campbell and Shiller (1998, 2001), Siegel, Shiller (2000), and Berge and Ziemba (2003) have suggested that this outperformance is unsustainable, and the weak equity returns of 2000-2003 are consistent with this view. The long-run results indicate equity outperformance, however, and in the future, this historical result may well be continued and thus needs to be reflected in the scenarios. (See the discussion in Chapter 2.)

Pension fund managers that have been mostly invested in bonds face a dilemma. Should they move more into assets that have historically had higher mean returns and higher variance or stick with what has worked satisfactorily, if not spectacularly, in the past? Of course, what other pension funds do is a factor in evaluating fund performance, especially in the use of specified benchmark performance evaluation levels. The specification of the type of benchmark (a linear combination of assets) around which the fund is to be evaluated greatly influences pension investment behavior. InnoALM, the Innovest Austrian pension fund financial planning model described below, was designed to help pension fund managers prudently make these choices by taking essentially all aspects of the problem into account.

For example, Austrian pension fund managers have had considerably more flexibility in their asset allocation decisions than the investment rules shown in Exhibit 4.1 might indicate. For example, if an investment vehicle is more than 50 percent invested in bonds, then that vehicle is considered to be a bond fund. So, investment in 45 percent stocks and 55 percent in bond funds (whose average bond and stock weightings are 60/40 percent) yields

\section{Exhibit 4.1. National Investment Restrictions on Pension Plans}

\begin{tabular}{ll}
\hline Country & Investment Restrictions \\
\hline Germany & Maximum: $30 \%$ equities/5\% foreign bonds \\
Austria & Maximum: $40 \%$ equities/45\% foreign securities; minimum: 40\% Eurobonds \\
France & Minimum: $50 \%$ Eurobonds \\
Portugal & Maximum: $35 \%$ equities \\
Sweden & Maximum: $25 \%$ equities \\
United Kingdom & Prudent man rule \\
United States & Prudent man rule
\end{tabular}

Source: Based on data from the European Commission (1997). 
an average equity of the portfolio of 67 percent, which is similar to that of the higher-performing U.K. managers. Moreover, currency hedged assets are considered to be euro denominated. Hence, the minimum of 40 percent in Eurobonds is effectively a 40 percent limit on worldwide bonds, but because of the above rules on the weighting of assets, this limit is not really binding. In addition, the 5 percent rule on option premiums means that managers have had effectively full freedom for worldwide asset allocations. Such use of the rules, however, has not been typical of actual pension fund managers. In some scenarios, such allocations away from the asset allocation typical in other Austrian pension funds could have led to disaster. So, without being armed with a model such as InnoALM that can calculate the possible consequences of asset weight decisions, it has been safest for managers to go with the crowd.

The European Commission (1999) stressed the importance of a relaxation of restrictive quantitative rules on pension fund investing. The diversification of investments is more important than the rules on different investments. It recommends the use of modern asset/liability management techniques to achieve this diversification goal.

The following section describes a model for the effective operation of private pension funds in Austria. These funds usually work on a funded basis, whereby the pension benefits depend on an employment contract or the pursuit of a particular profession. Schemes are administered by private institutions, and benefits are not guaranteed by the state. These occupational pension schemes are widespread throughout Europe. Normally, contributions to such systems are made by the employer and on an optional basis for additional benefits by employees. The contribution level may depend on the wage level or the position within a company. Defined-contribution plans (DCPs) have fixed contributions, and the payout depends on the capital accumulation of the plan. Defined-benefit plans (DBPs) have payouts guaranteed by the company, and the contribution is variable, depending on the capital accumulation over time.

An important difference between these two methods is the risk-bearer position. In DBPs, the employer guarantees the pension payment, which is usually tied to some wage at or near retirement. Hence, the company has to inject money into the pension plan if asset returns do not cover pension liabilities; however, the company gains or, equivalently, reduces future contributions if the asset returns of the plan are higher than required to fund the liabilities. For DCPs, which have become more popular, the employees and pensioners bear the risk of low asset returns. Their pensions are not fixed and depend on the asset returns. High returns will increase pensions and vice versa. No direct financial risk for the employer is incurred, although with poor 
returns, the employer could suffer from a negative image, if, for example, the following headline appeared: "Pensions for the Siemens Pensioners Have to be Reduced by 3 Percent in the Next Year." The Siemens pension plan for Austria is a DCP, but InnoALM was designed to handle either pension system.

The steep fall in worldwide equity prices in 2000-2003, especially in 2002, has caused a major crisis for insurance companies and pension funds and many others that have considerable long equity positions. Particularly in trouble are DBPs, which guarantee fixed payments until the death of the pensioners and their spouses. In England, this issue is already causing many discussions of rule changes, such as changing the age at which someone can receive retirement benefits to 70 instead of the current 65 , and asset allocation decisions, such as shifting into bonds from equities at very depressed prices, thereby locking in large losses. The U.K. company Boots Group has moved completely into bonds, a move that has had good success in the short term but appears to be suboptimal in the long term. The University of Toronto pension fund lost US\$484 million in the year ending April 2003 by using similar suboptimal strategies. At least Boots did the bond allocation before equities fell and bonds rose and matched liabilities to these assets.

The case for bond-only pension funds was made by Bodie (2001). The theoretical idea is to eliminate liabilities with a series of bonds of varying durations held to maturity; thus, the liabilities are taken care of and the interest rate risk is eliminated. TIPS (U.S. Treasury inflation-indexed securities) that return 3.4 percent plus inflation over a 30 -year cycle can be used to mitigate the effects of inflation. The view in this monograph is to consider all assets in relation to the future scenarios in one's asset allocation mix, including TIPS. A policy that uses only one asset class must be suboptimal. Nonetheless, the idea is of interest to those who cannot predict scenarios, such as strict efficient market proponents. Oxford, Cambridge, Stanford, Princeton, Columbia, and other universities have successfully used a similar idea to buy land and housing to subsidize students and faculty.

\section{InnoALM, the Innovest Austrian Pension Fund Financial Planning Model}

Siemens Oesterreich, part of the global Siemens Corporation, is the largest privately owned industrial company in Austria. Its businesses, which had revenues of $€ 2.4$ billion in 1999, include information and communication networks, information and communication products, business services, energy and traveling technology, and medical equipment. Its pension fund, established in 1998, is the largest corporate pension plan in Austria and is a DCP. More than 15,000 employees and 5,000 pensioners are members of the 
pension plan, which had $€ 510$ million in assets under management as of December 1999.

Innovest Finanzdienstleistungs, founded in 1998, is the investment manager for Siemens Oesterreich, the Siemens pension plan, and other institutional investors in Austria. With €2.2 billion in assets under management, Innovest focuses on asset management for institutional money and pension funds. Of 17 plans analyzed in the 1999-2000 period, it was rated as the best plan in Austria. The motivation to build InnoALM, as described in Geyer, Herold, Kontriner, and Ziemba (2003), was based on the desire to have superior performance and good decision aids to help achieve this ranking.

Various uncertain factors-possible future economic scenarios; stocks, bonds, and other investments; transaction costs; liquidity; currency aspects; liability commitments over time; Austrian pension fund law; and company policy-suggested that a good way to approach this asset/liability problem was via a multiperiod stochastic linear programming model. Various models evolved from Kusy and Ziemba (1986), Cariño, Kent, Meyers, Stacy, Sylvanus, Turner, Watanabe, and Ziemba (1994), Cariño and Ziemba (1998), Cariño, Meyers, and Ziemba (1998), and Ziemba and Mulvey (1998). This model has innovative features, such as state-dependent correlation matrixes, fat-tailed asset return distributions, simple computational schemes, and output.

InnoALM was produced in six months in 2000, with Geyer and Ziemba serving as consultants and with Herold and Kontriner, Innovest employees. InnoALM demonstrated that a small team of researchers with a limited budget could quickly produce a valuable modeling system that could easily be operated by nonstochastic programming specialists on a single personal computer (PC). The IBM OSL stochastic programming software provided a good solver. The solver was interfaced with user-friendly input and output capabilities. Calculation times on the PC are such that different modeling situations can be easily developed and the implications of policy, scenario, and other changes can be seen quickly. The graphical output provides pension fund management with essential information to aid in the making of informed investment decisions and understanding the probable outcomes and risk involved with these actions. The model can be used to explore possible European, Austrian, and Innovest policy alternatives.

The liability side of the Siemens pension plan consists of employees for whom Siemens is contributing DCP payments and retired employees who receive pension payments. Contributions are based on a fixed fraction of salaries, which varies across employees. Active employees are assumed to be in steady state; thus, employees are replaced by a new employee with the same qualification and sex so that there is a constant number of similar employees. 
Newly employed staff start with less salary than retired staff, which implies that total contributions grow less rapidly than individual salaries. Figure 4.1 shows the expected index of total payments for active and retired employees until 2030.

The set of retired employees is modeled using Austrian mortality and marital tables. Widows receive 60 percent of the pension payments. Retired employees receive pension payments after reaching age 65 for men and 60 for women. Payments to retired employees are based on the individually accumulated contribution and the fund performance during active employment. The annual pension payments are based on a discount rate of 6 percent and the remaining life expectancy at the time of retirement. These annuities grow by 1.5 percent annually to compensate for inflation. Hence, the wealth of the pension fund must grow by 7.5 percent a year to match liability commitments. Another output of the computations is the expected annual net cash flow of plan contributions minus payments. Because the number of pensioners is rising faster than plan contributions, these cash flows are negative and the plan is declining in size.

Figure 4.1. Index of Expected Payments for Active and Retired Employees, 2000-30

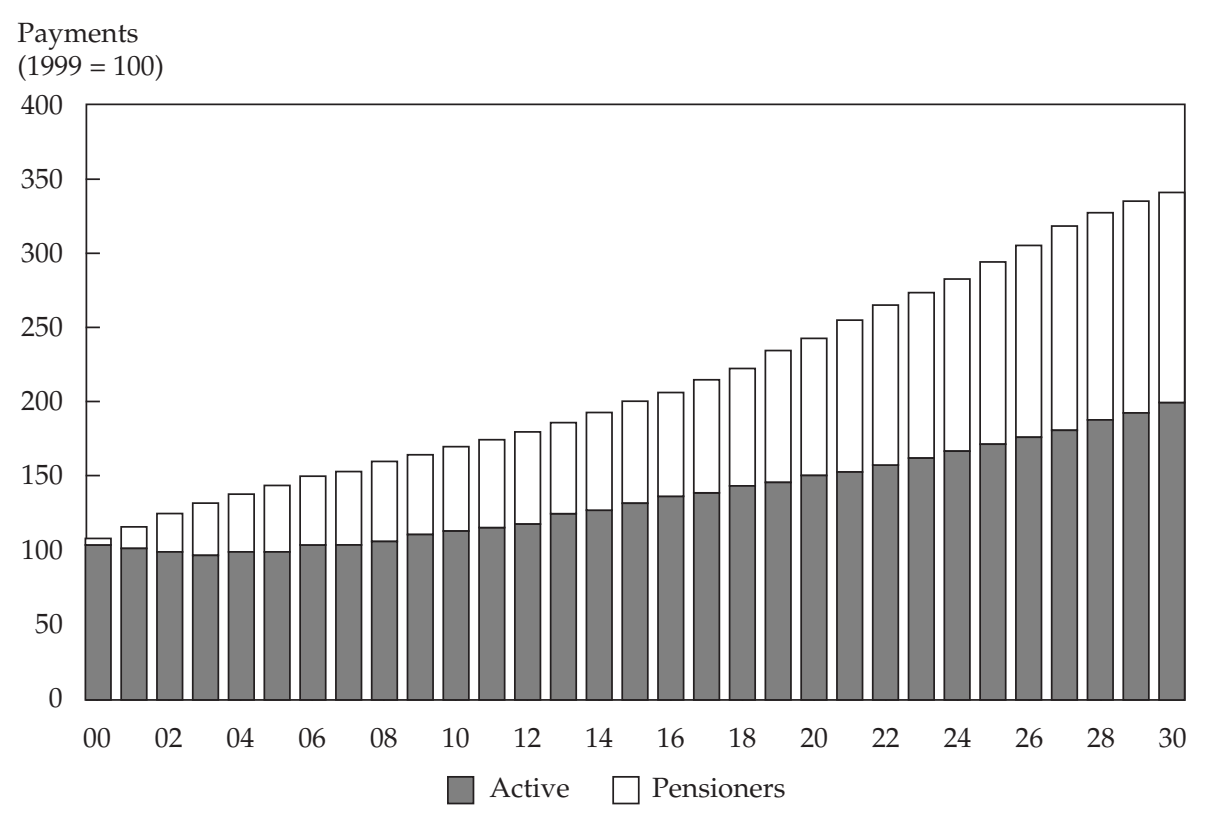

Source: Based on data from Geyer et al. 
The model determines the optimal purchases and sales for each of $N$ assets in each of $T$ planning periods. Typical asset classes used at Innovest are U.S., Pacific, European, and emerging market equities and U.S, U.K., Japanese, and European bonds. The objective is to maximize the concave riskaverse utility function "expected terminal wealth" less convex penalty costs subject to various linear constraints. The effect of such constraints is evaluated in the examples that follow, including Austria's limits of 40 percent maximum in equities, 45 percent maximum in foreign securities, and 40 percent minimum in Eurobonds. The convex risk measure is approximated by a piecewise linear function, so the model is a multiperiod stochastic linear program. Typical targets that the model tries to achieve (and is penalized for if it does not) are for growth of 7.5 percent a year in wealth (the fund's assets) and for portfolio performance returns to exceed benchmarks. Excess wealth is placed into surplus reserves, and a portion of the excess is paid out in succeeding years.

The elements of InnoALM are described in Figure 4.2. The interface to read in data and problem elements uses Excel. Statistical calculations use the program Gauss, and these data are fed into the IBM OSL solver, which generates the optimal solution to the stochastic program. The output, some of which is shown in the next section, uses Gauss to generate various tables and graphs and retains key variables in memory to allow for future modeling calculations. 1

Some Typical Applications. To illustrate the model's use, I will present results for a problem with four asset classes (European stocks, U.S. stocks, European bonds, and U.S. bonds) with five periods (six stages). The periods are twice 1 year, twice 2 years, and 4 years (10 years in total). I assume discrete compounding, which implies that the mean return for asset $i\left(\mu_{i}\right)$ used in simulations is $\mu_{i}=\exp (\bar{y})_{i}-1$ (where $\bar{y}$ is the mean, based on log returns). Using a $100-5-5-2-2$ node structure, I generate 10,000 scenarios. Initial wealth equals 100 units, and the wealth target is assumed to grow at an annual rate of 7.5 percent. To make the results more general, I do not consider a benchmark target or cash in- and outflows in this sample application. I use a risk-aversion index of $R_{A}=4$, and the discount factor equals 5 percent, which corresponds roughly with a simple static mean-variance model and a standard 60/40 stock/bond pension fund mix (see Kallberg and Ziemba 1983).

Assumptions about the statistical properties of returns measured in nominal euros are based on a sample of monthly data from January 1970 for stocks

1Details of the model formulation are in Appendix D (p. 27), which is available online in the Supplementary Material area at www.aimrpubs.org/rf/issues/v2003n6/pdf/AppendixD.pdf. 


\section{Figure 4.2. Elements of InnoALM}

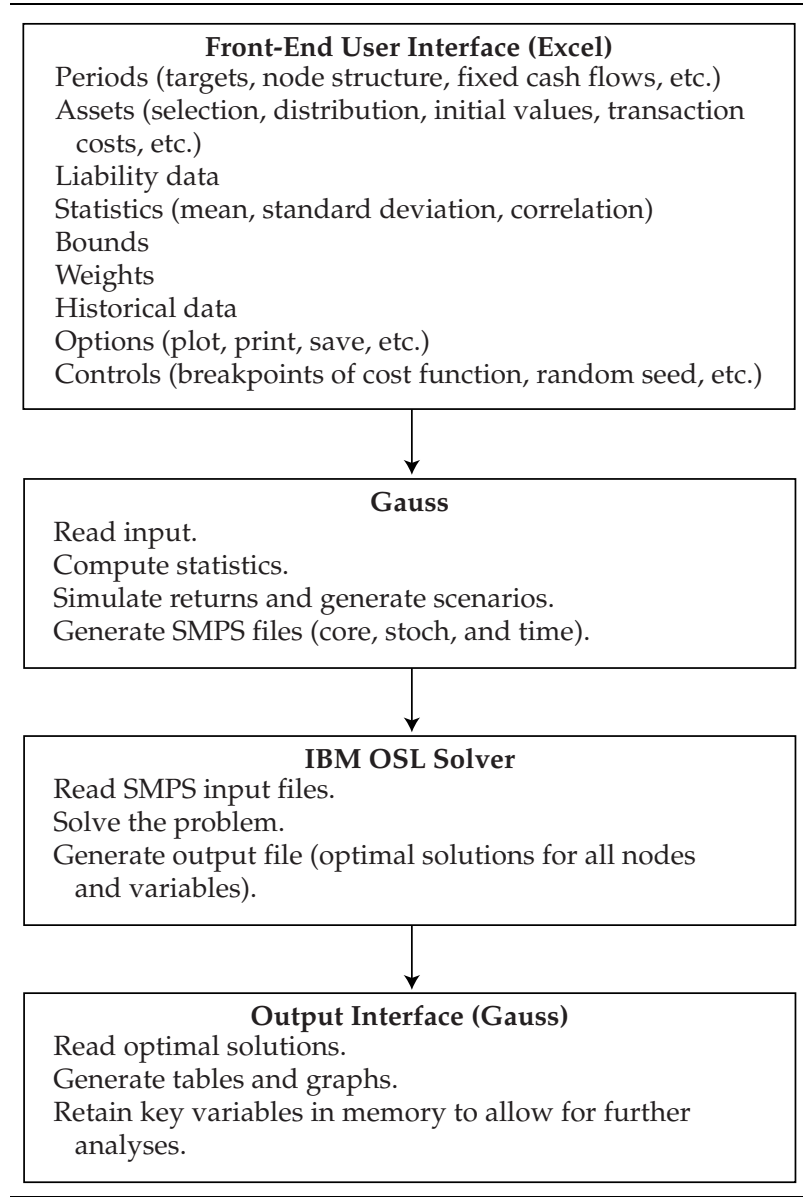

Source: Based on data from Geyer et al.

and 1986 for bonds to September 2000. Summary statistics for monthly and annual $\log$ returns are shown in Table 4.3. The U.S. and European equity means for the longer 1970-2000 period were much lower and slightly less volatile than those for the 1986-2000 period. The monthly stock returns were nonnormal and negatively skewed. Monthly stock returns were fat tailed, whereas monthly bond returns were close to normal (the critical value of the Jarque-Bera test for $a=0.01$ is 9.2).

For long-term planning models such as InnoALM with a one-year review period, however, properties of monthly returns are less relevant. The bottom panel of Table 4.3 shows statistics for annual returns. Although average 
Table 4.3. Statistical Properties of Asset Returns

\begin{tabular}{|c|c|c|c|c|c|c|}
\hline \multirow[b]{2}{*}{ Returns } & \multicolumn{2}{|c|}{ European Stocks } & \multicolumn{2}{|c|}{ U.S. Stocks } & \multirow{2}{*}{$\begin{array}{c}\begin{array}{c}\text { European } \\
\text { Bonds }\end{array} \\
1 / 86- \\
9 / 00\end{array}$} & \multirow{2}{*}{$\begin{array}{c}\text { U.S. } \\
\text { Bonds } \\
1 / 86- \\
9 / 00\end{array}$} \\
\hline & $\begin{array}{c}1 / 70- \\
9 / 00\end{array}$ & $\begin{array}{c}1 / 86- \\
9 / 00\end{array}$ & $\begin{array}{c}1 / 70- \\
9 / 00\end{array}$ & $\begin{array}{c}1 / 86- \\
9 / 00\end{array}$ & & \\
\hline \multicolumn{7}{|l|}{ Monthly } \\
\hline Mean (\%) a & 10.60 & 13.30 & 10.70 & 14.80 & 6.50 & 7.20 \\
\hline Standard deviation (\%) a & 16.10 & 17.40 & 19.0 & 20.200 & 3.70 & 11.3 \\
\hline Skewness & -0.90 & -1.43 & -0.72 & -1.04 & -0.50 & 0.52 \\
\hline Kurtosis & 7.05 & 8.43 & 5.79 & 7.09 & 3.25 & 3.30 \\
\hline Jarque-Bera Test & 302.60 & 277.30 & 151.90 & 155.6 & 7.70 & 8.50 \\
\hline \multicolumn{7}{|l|}{ Annual } \\
\hline Mean (\%) & 11.10 & 13.30 & 11.0 & 15.20 & 6.50 & 6.90 \\
\hline Standard deviation (\%) & 17.20 & 16.20 & 20.10 & 18.40 & 4.80 & 12.10 \\
\hline Skewness & -0.53 & -0.10 & -0.23 & -0.28 & -0.20 & -0.42 \\
\hline Kurtosis & 3.23 & 2.28 & 2.56 & 2.45 & 2.25 & 2.26 \\
\hline Jarque-Bera test & 17.40 & 3.90 & 6.20 & 4.20 & 5.00 & 8.70 \\
\hline
\end{tabular}

a annualized.

Source: Based on data from Geyer et al.

returns and volatilities remained about the same (I lost one year of data when I computed annual returns), the distributional properties changed dramatically. I still found negative skewness, but no evidence existed for fat tails in annual returns, except for European stocks (1970-2000) and U.S. bonds.

The mean returns from this sample are comparable to the 1900-2000 101-year mean returns estimated by Dimson et al. Their estimate of the nominal mean equity return was 12.0 percent for the United States and 13.6 percent for Germany and the United Kingdom (the simple average of the two countries' means). They estimated the mean bond return to be 5.1 percent for the United States and 5.4 percent for Germany and the United Kingdom.

Assumptions about means, standard deviations, and correlations for the applications of InnoALM appear in Table $\mathbf{4 . 4}$ and are based on the sample statistics presented in Table 4.5. Projecting future rates of return from past data is difficult. The equity means from the $1970-2000$ period are used because the 1986-2000 period had an exceptionally good performance of stocks that is not assumed to prevail in the long run.

The correlation matrixes in Table 4.4 for the three different regimes are based on the regression approach of Solnik, Boucrelle, and Le Fur (1996). Moving average estimates of correlations among all assets are functions of 
Table 4.4. Mean, Standard Deviation, and Correlation Assumptions

\begin{tabular}{|c|c|c|c|c|}
\hline Asset Class & European Stocks & $\begin{array}{l}\text { U.S. } \\
\text { Stocks }\end{array}$ & European Bonds & $\begin{array}{l}\text { U.S. } \\
\text { Bonds }\end{array}$ \\
\hline \multicolumn{5}{|c|}{ Normal periods (70\% of the time) } \\
\hline U.S. stocks & 0.755 & & & \\
\hline European bonds & 0.334 & 0.286 & & \\
\hline U.S. bonds & 0.514 & 0.780 & 0.333 & \\
\hline Standard deviation & $14.6 \%$ & $17.3 \%$ & $3.3 \%$ & $10.9 \%$ \\
\hline \multicolumn{5}{|c|}{ High volatility (20\% of the time) } \\
\hline U.S. stocks & 0.786 & & & \\
\hline European bonds & 0.171 & 0.100 & & \\
\hline U.S. bonds & 0.435 & 0.715 & 0.159 & \\
\hline Standard deviation & $19.2 \%$ & $21.1 \%$ & $4.1 \%$ & $12.4 \%$ \\
\hline \multicolumn{5}{|c|}{ Extreme periods ( $10 \%$ of the time) } \\
\hline U.S. stocks & 0.832 & & & \\
\hline European bonds & -0.075 & -0.182 & & \\
\hline U.S. bonds & 0.315 & 0.618 & -0.104 & \\
\hline Standard deviation & $21.7 \%$ & $27.1 \%$ & $4.4 \%$ & $12.9 \%$ \\
\hline \multicolumn{5}{|l|}{ Average period } \\
\hline U.S. stocks & 0.769 & & & \\
\hline European bonds & 0.261 & 0.202 & & \\
\hline U.S. bonds & 0.478 & 0.751 & 0.255 & \\
\hline Standard deviation & $16.4 \%$ & $19.3 \%$ & $3.6 \%$ & $11.4 \%$ \\
\hline \multicolumn{5}{|l|}{ All periods } \\
\hline Mean & $10.6 \%$ & $10.7 \%$ & $6.5 \%$ & $7.2 \%$ \\
\hline
\end{tabular}

Source: Based on data from Geyer et al.

Table 4.5. Regression Equations Relating Asset Correlations and U.S. Stock Return Volatility

\begin{tabular}{|c|c|c|c|c|}
\hline Correlation & Constant & $\begin{array}{l}\text { Slope with } \\
\text { respect to U.S. } \\
\text { Stock Volatility }\end{array}$ & $\begin{array}{c}t \text {-Statistic } \\
\text { of Slope }\end{array}$ & $R^{2}$ \\
\hline European stocks-U.S. stocks & 0.62 & 2.7 & 6.5 & 0.23 \\
\hline European stocks-European bonds & 1.05 & -14.4 & -16.9 & 0.67 \\
\hline European stocks-U.S. bonds & 0.86 & -7.0 & -9.7 & 0.40 \\
\hline U.S. stocks-European bonds & 1.11 & -16.5 & -25.2 & 0.82 \\
\hline U.S. Stocks-U.S. bonds & 1.07 & -5.7 & -11.2 & 0.48 \\
\hline European bonds-U.S. bonds & 1.10 & -15.4 & -12.8 & 0.54 \\
\hline
\end{tabular}

Source: Based on data from Geyer et al. 
standard deviations of U.S. equity returns. The estimated regression equations are then used to predict the correlations in the three regimes shown in Table 4.4. Results for the estimated regression equations appear in Table 4.5. Three regimes are considered, and the assumption is that 10 percent of the time, equity markets are extremely volatile; 20 percent of the time, markets are characterized by high volatility; and 70 percent of the time, markets are normal. The 35 percent quantile of U.S. equity return volatility defines "normal" periods. "Highly volatile" periods are based on the 80 percent volatility quantile, and "extreme" periods, on the 95 percent quartile. The associated correlations reflect the return relationships that typically prevailed during those market conditions. The correlations in Table 4.4 show a distinct pattern across the three regimes. Correlations among stocks tend to increase as stock return volatility rises, whereas the correlations between stocks and bonds tend to decrease. European bonds may serve as a hedge for equities during extremely volatile periods because bond and stock returns, which are usually positively correlated, are then negatively correlated. The latter is a major reason that scenario-dependent correlation matrixes are a major advance over sensitivity and stress testing a single average correlation matrix.

Optimal portfolios were calculated for seven cases-with and without mixing of correlations and with normal, $t$-, and historical distributions. The "mixing" cases NM, TM, HM use mixing correlations. Case NM assumes normal distributions for all assets. Case HM uses the historical distributions of each asset. Case TM assumes $t$-distributions with five degrees of freedom for stock returns, whereas bond returns are assumed to have normal distributions. The "average" cases NA, HA, and TA use the same distribution assumptions but with no mixing of correlation matrixes. Instead, the correlations and standard deviations used in these cases correspond to an "average" period in which 10 percent, 20 percent, and 70 percent weights are used to compute the averages of correlations and standard deviations in the three different regimes. Comparisons of the average (A) cases and mixing (M) cases are mainly intended to investigate the effect of mixing correlations. TMC maintains all assumptions of case TM but uses Austria's constraints on asset weights (see Exhibit 4.1). Eurobonds must be at least 40 percent and equity at most 40 percent, and these constraints are binding.

Some Test Results. Table $\mathbf{4 . 6}$ shows the optimal initial asset weights at Stage 1 for the various cases. Table 4.7 shows results for the final stage (expected weights, expected terminal wealth, expected reserves, and shortfall probabilities). These tables exhibit a distinct pattern: The mixing-correlation cases initially assign a much lower weight to European bonds than the average-period cases. Single-period, mean-variance optimization, and 
average-period cases (NA, HA, and TA) suggest an approximate $45 / 55$ percent stock/bond mix. The mixing-correlation cases (NM, HM, and TM) imply a $65 / 35$ percent stock/bond mix. Investing in U.S. bonds is not optimal at Stage 1 in any of the cases, an apparent result of the relatively high volatility of U.S. bonds.

Table 4.7 shows that the distinction between $A$ and $M$ cases becomes less pronounced over time. European equities, however, still have a consistently

Table 4.6. Optimal Initial Asset Weights at Stage 1 by Case

\begin{tabular}{lcccc}
\hline Case & $\begin{array}{c}\text { European } \\
\text { Stocks }\end{array}$ & $\begin{array}{c}\text { U.S. } \\
\text { Stocks }\end{array}$ & $\begin{array}{c}\text { European } \\
\text { Bonds }\end{array}$ & $\begin{array}{c}\text { U.S. } \\
\text { Bonds }\end{array}$ \\
\hline $\begin{array}{l}\text { Single-period, mean-variance optimal weights } \\
\quad \text { (average periods) }\end{array}$ & $34.8 \%$ & $9.6 \%$ & $55.6 \%$ & $0.0 \%$ \\
$\begin{array}{l}\text { NA: No mixing (average periods) normal distributions } \\
\text { HA: No mixing (average periods) historical }\end{array}$ & 27.2 & 10.5 & 62.3 & 0.0 \\
$\quad$ distributions & 40.0 & 4.1 & 55.9 & 0.0 \\
$\begin{array}{l}\text { TA: No mixing (average periods) } t \text {-distributions for } \\
\quad \text { stocks }\end{array}$ & 44.2 & 1.1 & 54.7 & 0.0 \\
$\begin{array}{l}\text { NM: Mixing correlations normal distributions } \\
\text { HM: Mixing correlations historical distributions }\end{array}$ & 47.0 & 27.6 & 25.4 & 0.0 \\
TM: Mixing correlations $t$-distributions for stocks & 53.4 & 25.2 & 36.8 & 0.0 \\
TMC: Mixing correlations historical distributions; & & 11.1 & 35.5 & 0.0 \\
$\quad$ constraints on asset weights & 35.1 & 4.9 & 60.0 & 0.0 \\
\hline
\end{tabular}

Source: Based on data from Geyer et al.

Table 4.7. Final Stage Results

\begin{tabular}{lccccccc}
\hline Case & $\begin{array}{c}\text { European } \\
\text { Stocks }\end{array}$ & $\begin{array}{c}\text { U.S. } \\
\text { Stocks }\end{array}$ & $\begin{array}{c}\text { European } \\
\text { Bonds }\end{array}$ & $\begin{array}{c}\text { U.S. } \\
\text { Bonds }\end{array}$ & $\begin{array}{c}\text { Expected } \\
\text { Terminal } \\
\text { Wealth }\end{array}$ & $\begin{array}{c}\text { Expected } \\
\text { Reserves } \\
\text { at Stage 6 } 6\end{array}$ & $\begin{array}{c}\text { Probability } \\
\text { of Target } \\
\text { Shortfall }\end{array}$ \\
\hline NA & $34.3 \%$ & $49.6 \%$ & $11.7 \%$ & $4.4 \%$ & 328.9 & 202.8 & $11.2 \%$ \\
HA & 33.5 & 48.1 & 13.6 & 4.8 & 328.9 & 205.2 & 13.7 \\
TA & 35.5 & 50.2 & 11.4 & 2.9 & 327.9 & 202.2 & 10.9 \\
NM & 38.0 & 49.7 & 8.3 & 4.0 & 349.8 & 240.1 & 9.3 \\
HM & 39.3 & 46.9 & 10.1 & 3.7 & 349.1 & 235.2 & 10.0 \\
TM & 38.1 & 51.5 & 7.4 & 2.9 & 342.8 & 226.6 & 8.3 \\
TMC & 20.4 & 20.8 & 46.3 & 12.4 & 253.1 & 86.9 & 16.1 \\
\hline
\end{tabular}

Source: Based on data from Geyer et al. 
higher weight in the mixing cases than in the no-mixing cases. This higher weight is mainly at the expense of Eurobonds. In general, the proportion of equities at the final stage is much higher than in the first stage. This result may be explained by the fact that the expected portfolio wealth at later stages is far above the target wealth level (206.1 at Stage 6), and the higher risk associated with stocks is less important. The constraints in case TMC lead to lower expected portfolio wealth throughout the horizon and to a higher shortfall probability than in any other case. Calculations show that initial wealth would have to be 35 percent higher to compensate for the loss in terminal expected wealth stemming from those constraints. In all cases, the optimal weight of equities is much higher than the historical 4.1 percent in Austria.

The expected terminal wealth levels and the shortfall probabilities at the final stage shown in Table 4.7 make the difference between mixing and nomixing cases even clearer. The mixing-correlation cases yield higher levels of terminal wealth and lower shortfall probabilities.

If the level of portfolio wealth exceeds the target, the surplus, $\tilde{D}_{j}$ in period $\mathrm{j}$, is allocated to a reserve account. The reserves in $t$ are computed from $\sum_{j=1}^{t} \tilde{D}_{j}$ and are shown in Table 4.7 for the final stage. These values are in monetary units given an initial wealth level of 100 . They can be compared with the wealth target 206.1 at Stage 6. Expected reserves exceed the target level at the final stage by up to 16 percent. Depending on the scenario, the reserves can be as high as 1,800. Their standard deviation (across scenarios) ranges from 5 at the first stage to 200 at the final stage. The constraints in case TMC lead to a much lower level of reserves compared with the other cases, which implies, in fact, less security against future increases of pension payments.

We thus find that optimal allocations, expected wealth, and shortfall probabilities are mainly affected by considering mixing correlations, but the type of distribution chosen has a smaller impact. This distinction is primarily the result of the higher proportion allocated to equities if different market conditions are taken into account by mixing correlations.

The results of any asset allocation strategy depend crucially on mean returns. I can investigate the effect by parameterizing the forecasted future means of equity returns. Assume that an econometric model forecasts that the future mean return for U.S. equities is some value between 5-15 percent. The mean of European equities is adjusted accordingly so that the ratio of equity means and the mean bond returns shown in Table 4.7 are maintained. I retain all other assumptions of case NM (normal distribution and mixing correlations). Figure 4.3 summarizes the effects of these mean changes in terms of the optimal initial weights. As expected, the results are sensitive to the choice 
Figure 4.3. Optimal Asset Weights at Stage 1

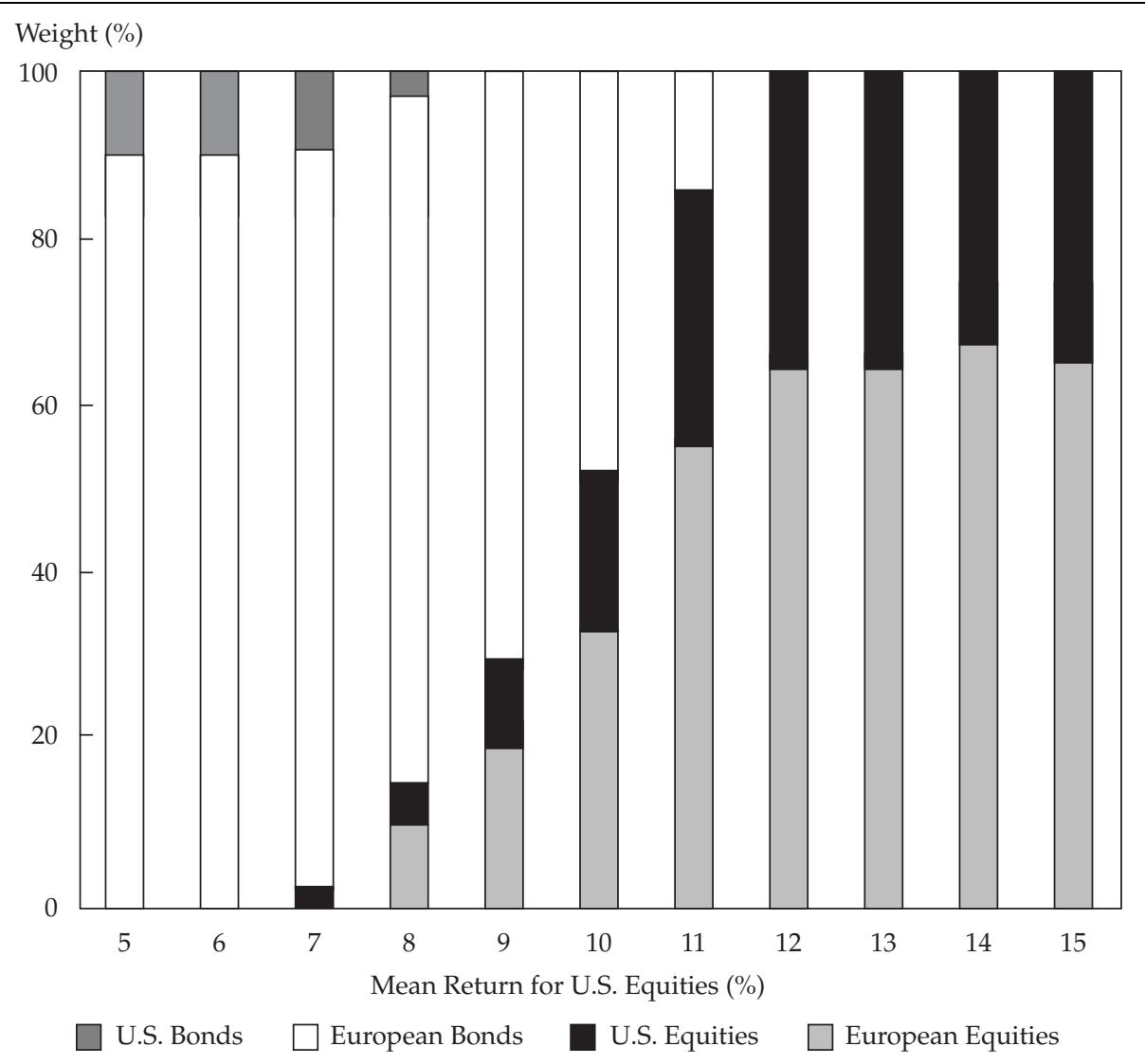

Source: Based on data from Geyer et al.

of the mean return; see Chopra and Ziemba (1993) and Kallberg and Ziemba $(1981,1983)$. If the mean return for U.S. stocks is assumed to equal the longrun mean of 12 percent, as estimated by Dimson et al., the model yields an optimal weight for equities of 100 percent. A mean return for U.S. stocks of 9 percent, however, implies an optimal weight of less than 30 percent for equities.

Model Tests. Because state-dependent correlations have a significant impact on asset allocation decisions, it is worthwhile to further investigate their nature and implications from the perspective of testing the model. Positive effects on pension fund performance induced by the stochastic, multiperiod planning approach will be realized only if the portfolio is dynamically 
rebalanced, as implied by the optimal scenario tree. I tested the performance of the model considering this aspect. As a starting point, I broke down the rebalancing decisions at later stages into groups of achieved wealth levels. This process reveals the "decision rule" implied by the model, depending on the current state. Consider case TM. I formed quintiles of wealth at Stage 2, computed the average optimal weights assigned to each quintile, and did the same using quintiles of wealth at Stage 5 .

Panel A and Panel B of Figure 4.4 depict the distribution of weights for each of the five average levels of wealth at the two stages. Although the average allocation at Stage 5 is essentially independent of the wealth level achieved (the target wealth at Stage 5 is 154.3), the distribution at Stage 2 depends on the wealth level in a specific way. If average attained wealth is 103.4, which is slightly below the target, I would choose a cautious strategy. Bonds have the highest weight in this case (almost 50 percent). In this situation, the model implies that the risk of even stronger underachievement of the target is to be minimized. The model relies on the low, but more certain, expected return of bonds to move back to the target level. If attained wealth is far below the target (97.1), the model implies more than 70 percent equities and a high share (10.9 percent) of relatively risky U.S. bonds. With such strong underachievement, a cautious strategy has no room to attain the target level again. If average attained wealth equals 107.9 , which is close to the target wealth of 107.5, the highest proportion would be invested in U.S. assets, with 49.6 percent in equities and 22.8 percent in bonds. The U.S. assets are more risky than the corresponding European assets, which is acceptable because portfolio wealth is close to the target and risk does not play a large role. For wealth levels above the target, I would switch most of the portfolio to European assets, which are safer than U.S. assets. This "decision" may be interpreted as an attempt to preserve the high levels of attained wealth.

The decision rules implied by the optimal solution can be used to perform a test of the model using the following rebalancing strategy. Consider the 10-year period from January 1992 to January 2002. In the first month of this period, I assume that wealth is allocated according to the optimal solution for Stage 1, given in Table 4.6. In each of the subsequent months, I rebalance the portfolio as follows. First, I identify the current volatility regime (extreme, highly volatile, or normal) based on the observed U.S. stock return volatility. Then, I search the scenario tree to find a node that corresponds to the current volatility regime and has the same or a similar level of wealth. The optimal weights from that node determine the rebalancing decision. For the no-mixing cases NA, TA, and HA, the information about the current volatility regime 
Figure 4.4. Optimal Weights Conditional on Quintiles of Portfolio Wealth at Stages 2 and 5

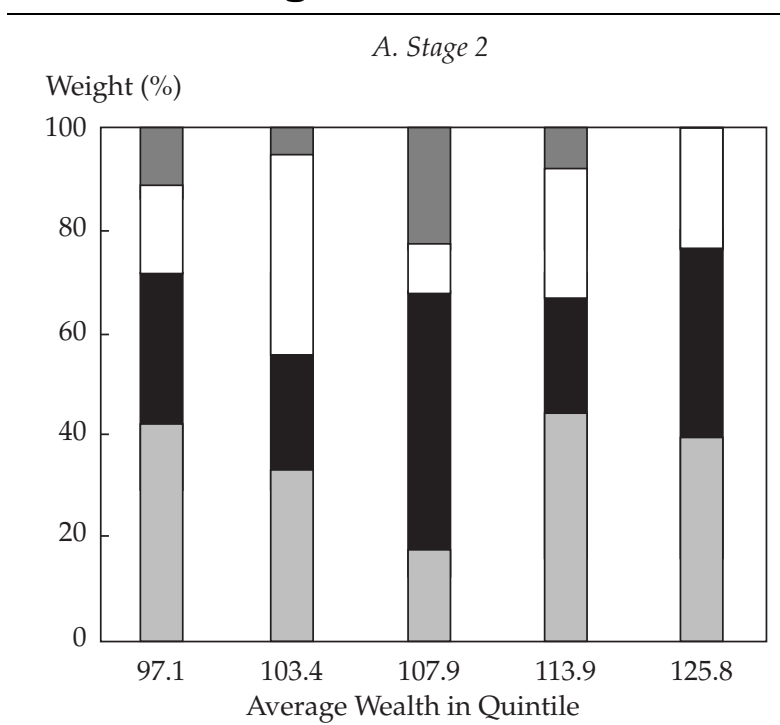

B. Stage 5

Weight $(\%)$

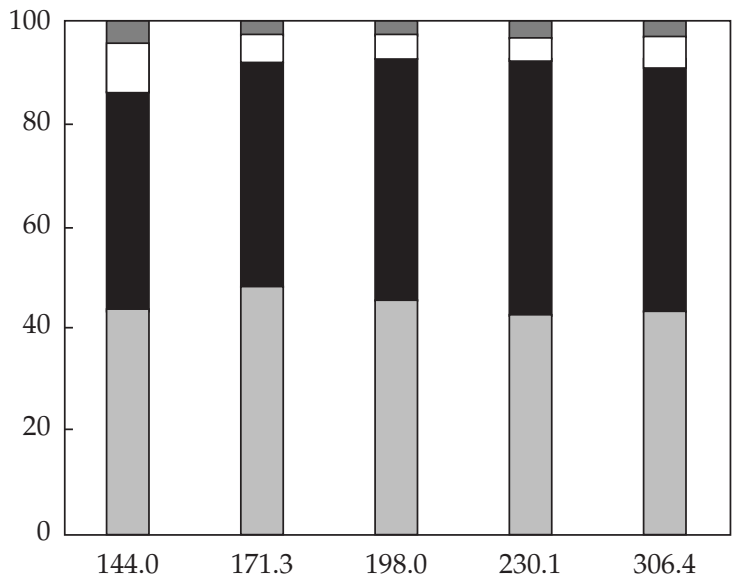

Average Wealth in Quintile

$\square$ U.S. Bonds $\quad \square$ European Bonds

U.S. Equities $\quad \square$ European Equities

Source: Based on data from Geyer et al. 
cannot be used to identify optimal weights. In those cases, I use the weights from a node with a level of wealth as close as possible to the current level of wealth.

Table 4.8 presents summary statistics for the complete sample and outof-sample periods. The mixing-correlation solutions assuming normal and $t$-distributions (cases NM and TM) provided a higher average return with lower standard deviation than the corresponding no-mixing cases (NA and TA). The advantage may be substantial, as indicated by the 14.9 percent average return of TM compared with 10.0 percent for TA. The $t$-statistic for this difference was 1.7 and was significant at the 5 percent level (one-sided test). Using the historical-distribution and mixing-correlation case (HM) yielded a lower average return than the no-mixing case (HA). In the constrained case (TMC), the average return for the complete sample was in the same range as for the unconstrained cases. This result stems primarily from the relatively high weights assigned to U.S. bonds; U.S. bonds performed well during the test period, whereas stocks performed poorly. The standard deviation of returns was much lower because the constraints imply a lower degree of rebalancing.

To emphasize the difference between the cases TM and TA, Figure 4.5 compares the cumulated monthly returns obtained from the rebalancing strategy for the two cases with a buy-and-hold strategy that assumes that the portfolio weights on January 1992 were fixed at the optimal TM weights throughout the test period. In comparison to the buy-and-hold strategy or the performance using TA results, for which rebalancing does not account for

\section{Table 4.8. Results of Asset-Allocation Strategies Using the Decision Rule Implied by the Optimal Scenario Tree}

\begin{tabular}{llcccc}
\hline & \multicolumn{2}{c}{ Complete Sample } & & \multicolumn{3}{c}{ Out of Sample } \\
\cline { 2 - 3 } \cline { 5 - 6 } Case & \multicolumn{2}{c}{$1 / 92-1 / 02$} & & \multicolumn{2}{c}{$10 / 00-1 / 02$} \\
\hline NA & Mean & Standard Deviation & & Mean & Standard Deviation \\
NM & $11.6 \%$ & $16.1 \%$ & & $-17.1 \%$ & $18.6 \%$ \\
HA & 13.1 & 15.5 & & -9.6 & 16.9 \\
HM & 12.6 & 16.5 & & -15.7 & 21.1 \\
TA & 11.8 & 16.5 & & -15.8 & 19.3 \\
TM & 10.0 & 16.0 & & -14.6 & 18.9 \\
TMC & 14.9 & 15.9 & & -10.8 & 17.6 \\
\hline
\end{tabular}

Source: Based on data from Geyer et al. 


\section{Figure 4.5. Cumulative Monthly Returns for Different Strategies,}

\section{2-2002}

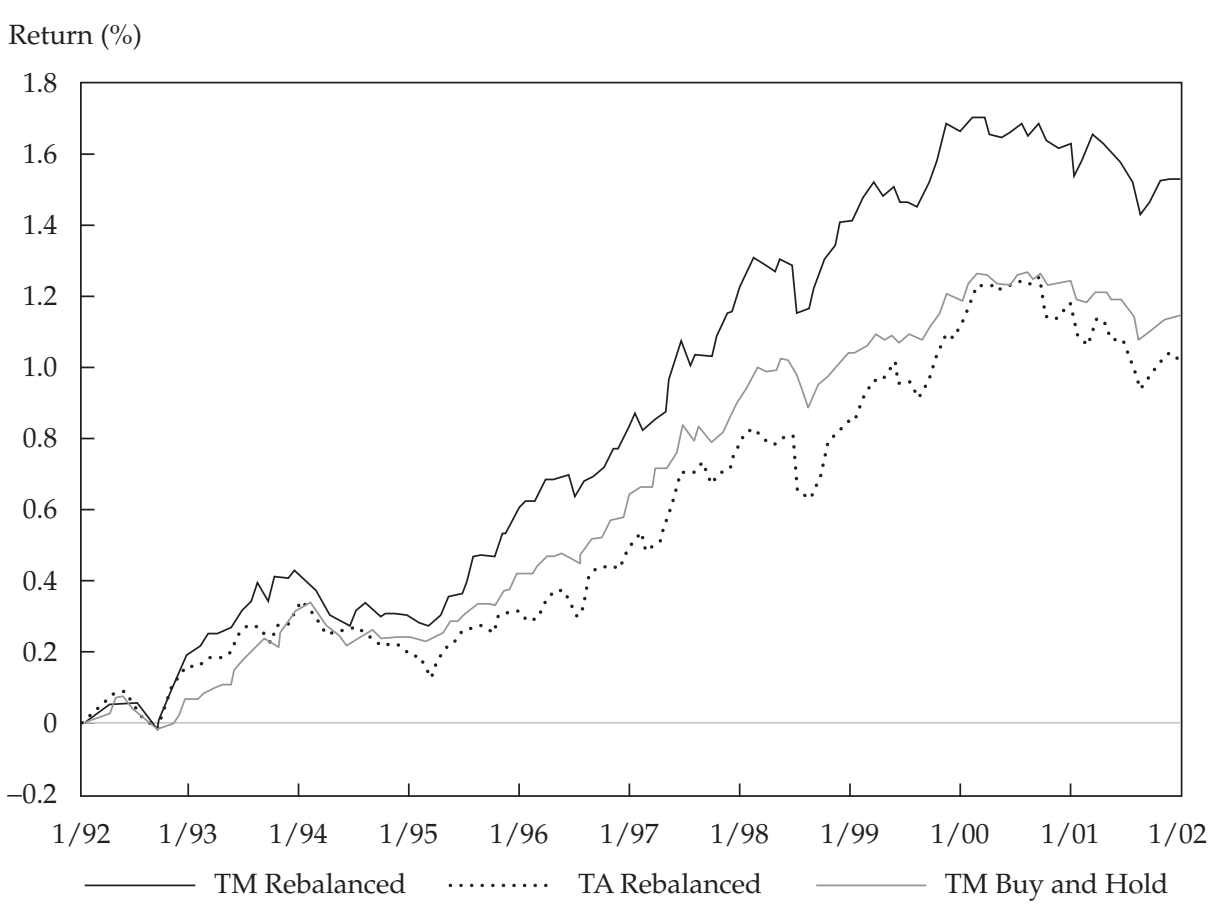

Source: Based on data from Geyer et al.

different correlation and volatility regimes, rebalancing on the basis of the optimal TM scenario tree provided a substantial gain.

Such in- and out-of-sample comparisons depend on the asset returns and test period. To isolate the potential benefits from considering state-dependent correlations, we perform the following controlled simulation experiment. Consider 1,000 10-year periods in which simulated annual returns of the four assets are assumed to have the statistical properties summarized in Table 4.4. One of the 10 years is assumed to be an "extreme" year, two years correspond to "highly volatile" markets, and seven years are "normal" years. We compare the average annual return of two strategies: (1) a buy-and-hold strategy using the optimal TM weights from Table 4.6 throughout the 10-year period, and (2) a rebalancing strategy that uses the implied decision rules of the optimal scenario tree as explained in the in- and out-of-sample tests above. For simplicity, we assume that the current volatility regime is known in each period. The average annual returns for 1,000 repetitions of the two strategies 
are 9.8 percent (rebalancing) and 9.2 percent (buy and hold). The $t$-statistic for the mean difference is 5.4 , thus indicating the highly significant advantage of the rebalancing strategy, which exploits the information about state-dependent correlations.

For comparison, we use the optimal weights from the constrained case TMC and repeat the same experiment. We obtain the same average mean of 8.1 percent for both strategies. This result indicates that the constraints imply insufficient rebalancing capacity. Therefore, knowledge about the volatility regime cannot be sufficiently exploited to achieve superior performance relative to a buy-and-hold strategy. This result also shows that the relatively good performance of the TMC rebalancing strategy in the sample 1992-2002 period was positively biased by the favorable conditions during that time.

\section{Risk in 401(k) and Other Company Pension Plans}

The stock market decline of 2000-2003 has been hard on pension funds in several ways:

- Shortfalls were created in DBPs. For instance, at the start of 2002, General Motors had obligations of US\$76.4 billion and assets of US\$67.3 billion, for a shortfall of US\$9.1 billion. Despite contributions of US\$3.2 billion in 2002 , the shortfall was projected to be US\$23 billion at the end of 2002 . Ford had an underfunding of US\$6.5 billion on 30 September 2002 that was projected to be about US\$10 billion by the end of 2002 .

- For companies with DCPs, company image and employee morale have suffered.

The collapse of Enron Corporation in late 2001—when the stock fell 99 percent from US\$90 to under US\$1.00 and employees lost their jobs and most of their pensions-highlights a problem well known to professional analysts. Having a pension fund largely in one asset carries a lot of risk, and the risk is even larger if that asset is correlated with one's income. Enron employees lost more than US\$1 billion in total, some 60 percent of their $401(\mathrm{k})$ pension-a classic example of overbetting and lack of diversification.

Table 4.9 shows that for many major companies, own-company stock is a high percentage of $401(\mathrm{k})$ plans. In total, according to Mitchell and Utkus (2002), about 5 million 401(k) plan participants hold 60 percent of their assets in own-company stock, and those that do generally have large amounts. In total, own-company stock is about 19 percent of assets. But for those who have any company stock, it is 29 percent of assets. Not surprisingly, employees have a lower percentage of own-company stock, 22 percent, when they have free choice versus 53 percent when the company decides. 
Table 4.9. Share of Own-Company Stock in 401(k) Pension Plans

\begin{tabular}{lccc}
\hline & \multirow{2}{*}{$\begin{array}{c}\text { Own-Company Share } \\
\text { in 401(k) Assets }\end{array}$} & 2001 & 2002 \\
\cline { 3 - 4 } Company & $94.7 \%$ & $-2.2 \%$ & $11.5 \%$ \\
Proctor \& Gamble & 85.5 & -12.3 & -22.0 \\
Coca-Cola & 81.5 & -25.1 & -5.5 \\
General Electric & 77.4 & -23.3 & -37.4 \\
Enron & 57.7 & -99.1 & -85.4 \\
Texas Instruments & 75.7 & -34.5 & -46.1 \\
McDonald's & 74.3 & -22.1 & -39.3 \\
Ford & 57.0 & -28.9 & -38.3 \\
Qwest & 53.0 & -69.7 & -64.6 \\
AOL Time Warner & 52.0 & -8.1 & -59.2 \\
\hline
\end{tabular}

Source: Based on data from the Economist.

Why do companies and employees invest so much of their own-company stock in their pensions? Companies can either purchase shares in the open market, as Microsoft Corporation does, or they can issue shares just like options to key employees and slightly dilute the stock price, which is economical for the company.

Employees who invest in their company's shares solve two problems, in theory. They resolve the issue of agency costs that arises between shareholders and the people hired to work on their behalf. And, . . . they reap the benefits of capital appreciation, a fundamental component of capitalism. The results can be spectacular. America is filled with tales of people who held jobs as cash-register clerks at WalMart, or on the diaper-making line at Procter \& Gamble, who survived on their wages but have made fortunes through steady accumulation of company stock in retirement plans. (Economist, p. 60)

Other spectacular examples include Microsoft, Intel Corporation, and Nokia Corporation.

Employees can frequently purchase own-company shares at a discount to current market price or acquire the shares through options given for free. The pressure of corporate culture is also present. In Japan in 1988-1989, for example, employees of the Yamaichi Research Institute were obliged by moral suasion and peer pressure to buy stock in Yamaichi Securities, which went bankrupt in 1995.

Enron has refocused attention on this risk that has been around a long time. As a result, rule changes are likely to be enacted. A key is the risk-bearer position of employees and employers. In 1942, laws were passed to limit owncompany stock to 10 percent in DBPs that bore employer risk. The $401(\mathrm{k}) \mathrm{s}$ 
are DCPs that shift the risk to the employees. The Procter \& Gamble Company maintains that the welfare of the company and the employee are inseparable. That attitude may be the American way, but at 95+ percent job risk, employees are taking a lot of risk. This concentration usually leads to either very high or very low returns.

What is the real risk of the own-company stock and job risk concentration? Douglass, Wu, and Ziemba (2003) estimated this risk using mean-variance and stochastic programming assets-only models. Before discussing these models, recall how volatility destroys wealth, as discussed by Mitchell and Utkus. They consider three workers who earn US\$50,000 a year and contribute 10 percent to a $401(\mathrm{k})$. They assume an inflation rate of 3 percent a year and that the stock market index and company stock return 10 percent a year, with annual standard deviations of 20 percent and 40 percent, respectively. After 30 years, the median employee who invested 100 percent in the market index has US\$830,000; with 50/50 percent in the market index and company stock, the employee has US\$615,000; and with 100 percent in company stock, US\$411,000. This result stems from the geometric arithmetic inequality caused by the volatility of the company stock-gaining 50 percent and then losing 50 percent does not make one even; 100 becomes 75 , with a rate of return of -13.4 percent. The greater the volatility, the lower the geometric mean, which determines long-run wealth gains for constant arithmetic mean.

Douglass et al. consider the following situation: An investor chooses from the market index (S\&P 500), a bond index (Lehman Brothers U.S. Aggregate), cash, and own-company stock. The parameter assumptions, estimated from 1985-2002 monthly data from DataStream, mirror long-run stock, bond, and cash returns from Constantinides (2002), Dimson et al., and Siegel. Yearly mean returns are 1.10, 1.05, 1.00, and 1.125 percent for these four assets, respectively; standard deviations are $0.20,0.04,0.01$, and 0.50 percent, and the covariance matrix is

$$
\left(\begin{array}{llll}
1.000 & 0.750 & 0.058 & 0.500 \\
0.750 & 1.000 & 0.250 & 0.550 \\
0.058 & 0.250 & 1.000 & 0.029 \\
0.500 & 0.550 & 0.029 & 1.000
\end{array}\right) .
$$

These assumptions yield mean returns relative to cash and higher expected returns, with much higher volatility, for own-company stock (two and a half times the S\&P 500, which is typical for midcap equities). Figure 4.6 shows the results from the mean-variance model as a function of investor risk aversion with (Panel B) and without (Panel A) company stock and as a 
Figure 4.6. Mean-Variance Model: Optimal Portfolios as a Function of Risk Aversion and Expected Return on Company Stock

A. Risk Aversion without Company Stock

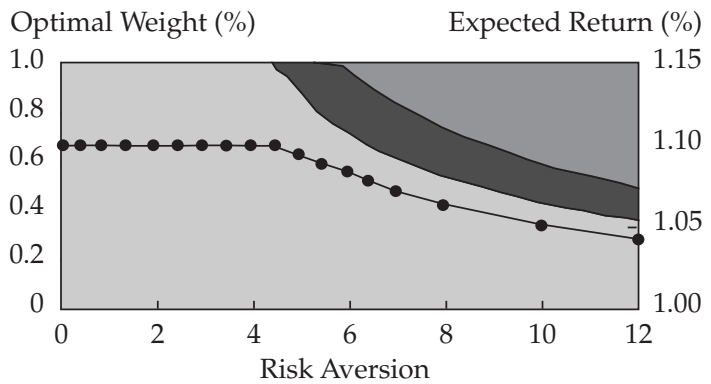

B. Risk Aversion with Company Stock
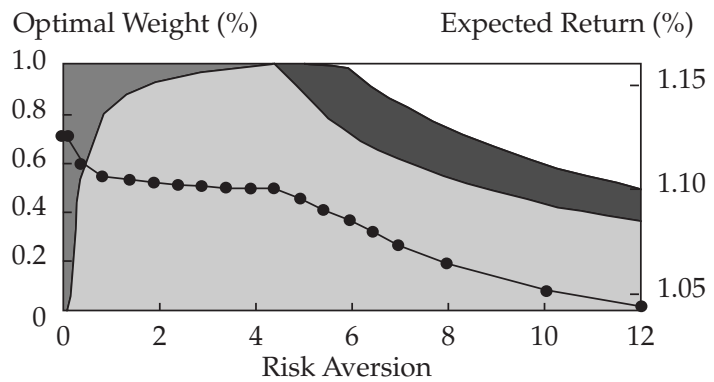

C. Company Stock Mean Return
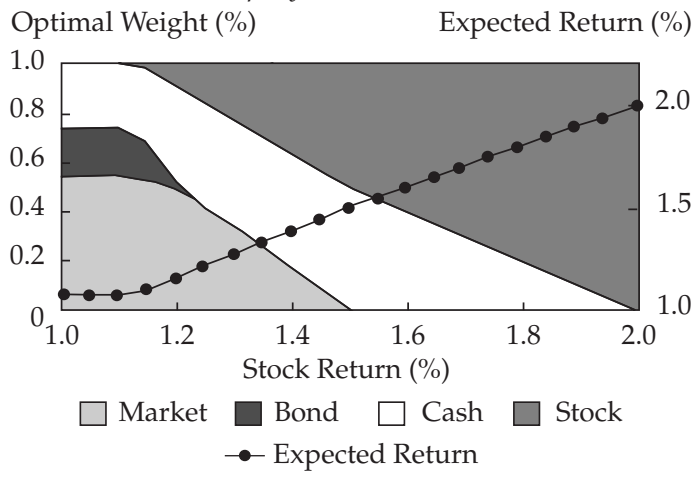

Note: The shaded regions indicate portfolio weights (left axis). The line represents the expected return on the optimal portfolio (right axis). The circles indicate values of the independent variable for which calculations were performed. Results for the three-asset case with no own-company stock are in Panel A, and results for the fourasset case are in Panel B and Panel C.

Source: Based on data from Douglass et al. 
function of company stock mean return (Panel $\mathrm{C}$ ). When risk aversion is 8 , there is a $60 / 40$ percent stock/bond mix.

The optimal portfolio in Panel A of Figure 4.6 has no own-company stockholdings. Hence, without trading constraints and with a risk aversion of 8 , it is not optimal to hold own-company stock. For investors with trading constraints, such as the inability to short sell, however, owning some owncompany stock can be optimal. Own-company stock appears as an optimal portfolio choice if the investor's risk aversion is very low or the expected return for the stock is high. At a risk aversion of 5, the short-selling constraint becomes binding and the optimal portfolio begins to shift to the riskier stock investment (Panel B of Figure 4.6). To obtain company stockholdings above 50 percent, as shown in Table 4.9, requires a risk-aversion parameter below 0.5. Alternatively, an own-company stockholding of 50 percent is obtained if the employee is presumed to have an expected return for own-company stock of more than 50 percent (Panel C of Figure 4.6). Own-company stock enters the optimal portfolio when its mean return approaches 20 percent (i.e., double the S\&P 500 mean return). The expected return of own-company stock must be more than 50 percent or five times the S\&P 500 for the optimal allocation of own-company stock to reach 50 percent.

This analysis assumes that all employee wealth is contained in the company pension plan. This assumption is reasonable considering that many North Americans save little beyond what they have in their tax-sheltered accounts. Panel B of Figure 4.6 shows, however, what proportion of wealth has to be held outside the plan in order to support a 50 percent own-company stockholding within the plan. Employees with a risk aversion of 8 and 50 percent of their pension plan in own-company stock have to have 50 percent of their retirement savings outside the company plan.

The effect of human capital on investment choice is modeled as an additional risky asset in the employee's portfolio in Figure 4.7. The value of the untradeable asset is determined by assuming an expected initial annual income, $i_{0}$, and income growth rate, $g$. The value of the asset is

$$
v_{h c}=\left(i_{0} * \sum_{j=0}^{t-1} g^{j}\right)^{1 / t},
$$

where income loss depends on own-company stock return; only when returns have losses greater than 50 percent is there an effect on income return. Then, as returns become lower, the effect is more dramatic.

Consider an employee with 20 years to retirement and starting income equal to 20 percent of wealth (in the retirement plan). The present value of 
Figure 4.7. Optimal Portfolio Results of the Mean-Variance Analysis When Human Capital Is Modeled as an Untradeable Asset

A. As a Function of Risk Aversion

Optimal Weight (\%) Expected Return (\%)

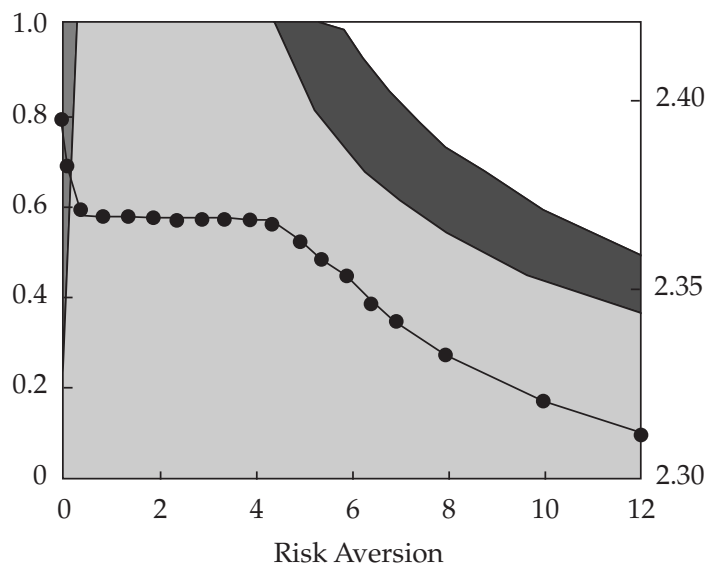

B. As a Function of Expected Return on Company Stock Optimal Weight (\%) Expected Return (\%)

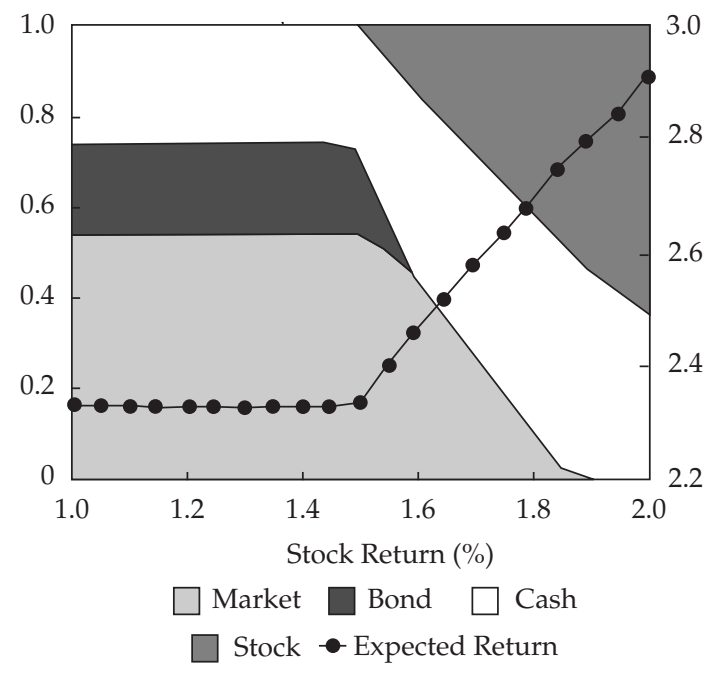

Note: The shaded regions indicate portfolio weights (left axis). The line represents the expected return on the optimal portfolio (right axis). The circles indicate values of the independent variable for which calculations were performed.

Source: Based on data from Douglass et al. 
human capital would be 1.12 times wealth. The base case scenario assumes a 20 percent income volatility and 80 percent correlation between income and return on own-company stock. Optimal asset choices versus risk aversion as a percentage of income are shown in Panel A of Figure 4.7 and of expected stock return in Panel B of Figure 4.7. In both cases, the parameter choice required to obtain a large own-company stockholding becomes more extreme with inclusion of the untradeable asset. This result confirms Viceira's (2001) conclusion that in a continuous-time setting, investors with an untradeable asset tend to hold less risky portfolios.

The conclusion is that in a mean-variance portfolio setting, large owncompany stockholdings can be explained only by extremely low values of risk aversion or a high expected return for own-company stock. These values become only more extreme once the restrictive assumptions required for mean-variance analysis, such as normality of asset returns, are relaxed.

A stochastic programming model can handle the fat tails in real assets that the mean-variance model cannot. The likely nonnormality of the S\&P 500 also exists for the own-company stock and the wealth loss from possible job loss. Douglass et al. used a one-period version of the InnoALM model to analyze these results. ${ }^{2}$

The probability of job loss increases if the company runs into serious difficulties. To account for this possibility, the employee is terminated with scenario-dependent probability $\gamma_{t}\left(s_{t}\right)$. Employee termination does not necessarily have to be accompanied by company default or vice versa. Thus, Douglass et al. do not explicitly model company default. Instead, they assume that probability of termination is a nonlinear function of the stock price factors, that increases rapidly as the stock price approaches zero. They use a logit function to model the probability of termination: $\gamma=1 /[1+a \exp (b X)]$, where $a$ and $b$ are parameters and $X$ is the stock return. The probability of termination approaches one as the return approaches zero. Thus, the parameter, $a$, takes on a small value; $b$ sets the rate at which termination probability decays as price factors increase.

Douglass et al. consider a scenario in which the employee receives an income, $i$, equal to 10 percent of starting wealth. They multiply the expected income in each scenario by the probability of job retention: $1-\gamma$. When job loss is high, company stock return drops below 0.5 percent and rapidly rises to almost certain job loss in the case of zero return or bankruptcy (see Panel $\mathrm{B}$ of Figure 4.8). They assume that the employee considers the loss of labor income as an addition to any shortfall.

2See Appendix D (p. 30), which is available online in the Supplementary Material area at www.aimrpubs.org/rf/issues/v2003n6/pdf/AppendixD.pdf. 


\section{Figure 4.8. Solution of Employee's Problem Formulated as a Stochastic Program}

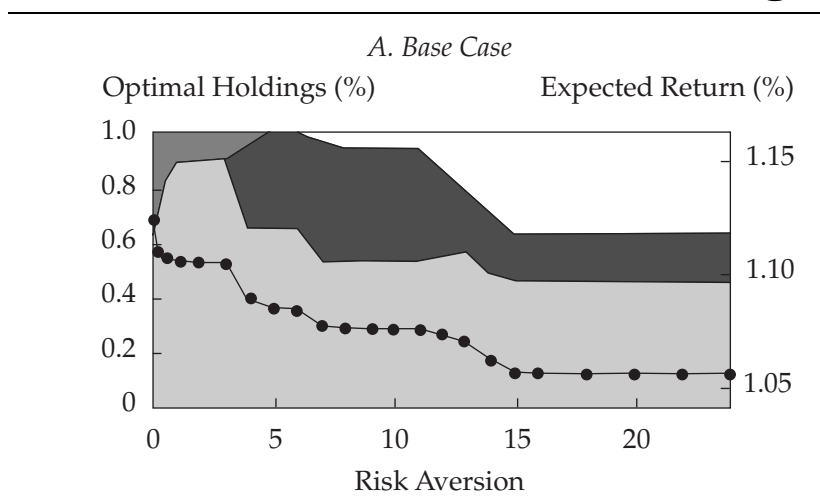

B. Probability of Job Retention vs. Company Stock Return Income Loss (\%)

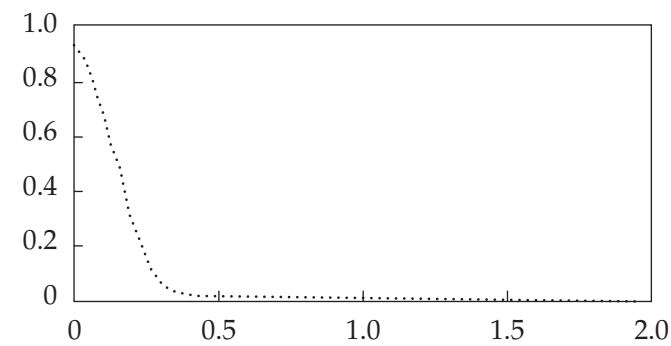

Return on Company Stock (\%)

C. Human Capital Returns as Logit Function of Wealth

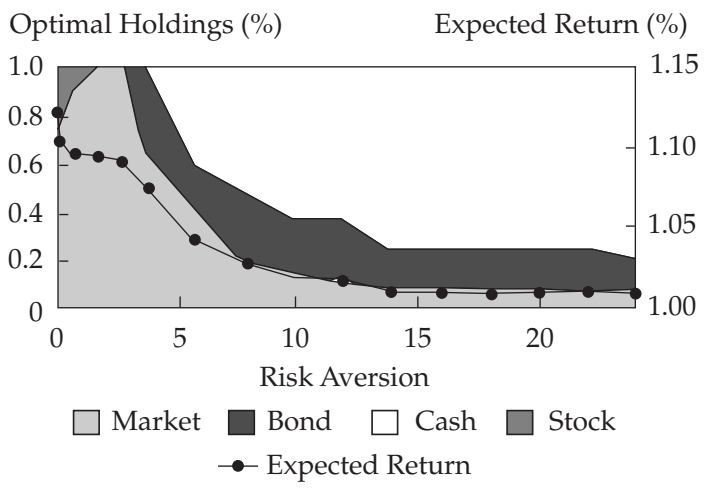

Note: The logit function used in the model is in Panel B. In Panel A and Panel B, portfolio weights (shaded regions, left axis) and expected return on the optimal portfolio (line, right axis) are a function of the risk-aversion parameter, $\lambda$. The plots are interpolated between $\lambda$ values, indicated by circles.

Source: Based on data from Douglass et al. 
Panel A of Figure 4.8 shows the optimal portfolio weights for various riskaversion values for the four asset classes when there is no possibility of job loss. Panel C of Figure 4.8 shows the optimal portfolio weights for the four asset classes when there is the possibility of job loss. The results indicate a shift to a more conservative portfolio when potential loss of labor income is included in the portfolio-choice problem. At low levels of risk aversion, company stockholdings are replaced by holdings in the market. At higher risk aversion, the total holdings of bonds and cash are much higher than those observed when potential income loss is not included in the analysis.

Large holdings of own-company stock in pension accounts cannot be explained by traditional models of rational portfolio choice. Explanation of the exceptionally high observed holdings thus relies on behavioral explanations. This finding, however, presupposes some ignorance on the part of the employee or an ability of the employer to dupe the employee, even though having large holdings in own-company stock is a phenomenon that has persisted for decades. Thus, employees seem to have been making the same errors in their portfolio choices for a long time. One would expect the irrationality of employee choices to lessen over time, as employees learn from previous actions and consequences. Thus, other factors must be included in rational-choice models to explain own-company stockholdings.

Employers, as plan fiduciaries, may be in a position to influence employee decisions and steer them toward own-company stock; employees may interpret the channeling of employer contributions into own-company stock as an endorsement of that investment (Mitchell and Utkus). Alternatively, employees may choose own-company stock simply because it is listed as an investment option. Benartzi and Thaler (2001) found that many DCP investors follow some version of the $1 / n$ strategy (i.e., they divide their contributions evenly across plan offerings). In addition, employees may be myopic when evaluating risk of company stock. In a 2001 survey of DCP participants conducted during a period of stock market growth, John Hancock Financial Services reported that DCP participants rated own-company stock as less risky than an equity mutual fund. Other factors, such as loyalty, taxes, and peer pressure, may also influence employee investment decisions.

Trading constraints have also been discussed as explanations for large own-company stockholdings. For example, many companies that match contributions to pension plans deposit own-company stock. Often, an employee is restricted from trading this stock. Douglass et al. were interested in exploring potential explanations for extremely high own-company stock weights, such as those listed in Table 4.9. In most cases, any minimum-holding 
constraint for own-company stock is not binding. Employees hold more company stock than they have to (Mitchell and Utkus).

\section{A Continuous-Time Approach to Surplus Management}

Rudolf and Ziemba (forthcoming 2004) presented a continuous-time model for pension or insurance company surplus management over time. Such lifetime intertemporal portfolio investment models date to Samuelson (1969) in discrete time and Merton (1969) in continuous time. Rudolf and Ziemba used an extension of the Merton $(1973,1990)$ model that maximizes the intertemporal expected utility of the surplus of assets, net of liabilities, by using liabilities as a new variable. They assume that both the asset and the liability returns follow Ito processes as functions of a risky state variable. The optimum occurs for investors holding four funds-the market portfolio, the hedge portfolio for the state variable, the hedge portfolio for the liabilities, and the riskless asset. This model is a four-fund capital asset pricing model (CAPM), whereas Merton's is a three-fund CAPM and the ordinary SharpeLintner-Mossin CAPM has two funds.

Rudolf and Ziemba found that the hedge portfolio provides maximum correlation to the state variable; that is, it provides the best possible hedge against the variance of the state variable. In contrast to Merton's result in the asset-only case, the liability hedge is independent of preferences and depends only on the funding ratio. With hyperabsolute risk-aversion utility, which includes negative exponential, power, and log, the investments in the state variable hedge portfolio are also preference independent, and with log utility, the market portfolio investment depends only on the current funding ratio. The following summarizes the main points.

Life and other insurance companies, pension funds, and other organizations try to achieve having a surplus over time. In both life insurance companies and pension funds, parts of the surplus are distributed to the clients, usually once every year. Hence, optimizing their investment strategy is well represented by maximizing the expected lifetime utility of the surplus. 3

Rudolf and Ziemba provided a case study illustrating the reasons, in practice, that discrete-time, constrained stochastic programming models are preferred to unconstrained, continuous-time models. I will discuss why these continuous-time models are so popular with finance academics; they have a simple elegance that yields direct answers to economic questions.

3The model is summarized in Appendix D (p. 31), which is available online in the Supplementary Material area at www.aimrpubs.org/rf/issues/v2003n6/pdf/AppendixD.pdf. 
Consider a U.S.-dollar-based surplus optimizer investing in the stock and bond markets of the United States, the United Kingdom, Japan, the European Monetary Union (EMU) countries, Canada, and Switzerland. The results are shown in Table 4.10. Monthly MSCI data between January 1987 and July 2000 (163 observations) are used for the stock markets. The monthly J.P. Morgan indexes are used for the bond markets in this period (Salomon Brothers for Switzerland). The stochastic benchmark is the quarterly Thomson Financial DataStream index for U.S. wages and salaries. Quarterly data is

Table 4.10. Basic Monthly Data in U.S. Dollars, January 1987-July 2000

\begin{tabular}{lccrrrrr}
\hline & Mean & & Beta & $\begin{array}{r}\text { Beta } \\
\text { JPY }\end{array}$ & $\begin{array}{r}\text { Beta } \\
\text { EUR }\end{array}$ & $\begin{array}{r}\text { Beta } \\
\text { CAD }\end{array}$ & $\begin{array}{r}\text { Beta } \\
\text { CHF }\end{array}$ \\
\hline Stocks & & & & & & & \\
United States & $13.47 \%$ & $14.74 \%$ & 0.18 & 0.05 & 0.35 & -0.59 & 0.35 \\
United Kingdom & 9.97 & 17.96 & -0.47 & -0.36 & -0.29 & -0.48 & -0.14 \\
Japan & 3.42 & 25.99 & -0.61 & -1.11 & -0.45 & -0.44 & -0.43 \\
EMU & 10.48 & 15.80 & -0.32 & -0.27 & -0.26 & -0.45 & -0.11 \\
Canada & 5.52 & 18.07 & 0.05 & -0.02 & 0.27 & -1.44 & 0.34 \\
Switzerland & 11.56 & 18.17 & -0.14 & -0.32 & -0.26 & 0.13 & -0.32 \\
Bonds & & & & & & & \\
United States & $5.04 \%$ & $4.50 \%$ & -0.03 & 0.00 & -0.06 & -0.04 & -0.06 \\
United Kingdom & 6.86 & 12.51 & -0.92 & -0.44 & -0.80 & -0.39 & -0.59 \\
Japan & 3.77 & 14.46 & -0.53 & -1.04 & -0.75 & 0.09 & -0.72 \\
EMU & & & & & \\
Canada & 7.78 & 10.57 & -0.69 & -0.42 & -0.93 & -0.06 & -0.74 \\
Switzerland & 5.16 & 8.44 & -0.09 & 0.03 & -0.02 & -1.14 & 0.02 \\
Exchange Rates in & 3.56 & 12.09 & -0.67 & -0.53 & -1.03 & 0.19 & -0.99 \\
GBP & & & & & & & \\
JPY & $0.11 \%$ & $11.13 \%$ & 1.00 & 0.37 & 0.86 & 0.42 & 0.64 \\
EUR & -2.75 & 12.54 & 0.48 & 1.00 & 0.65 & 0.04 & 0.61 \\
CAD & 1.13 & 10.08 & 0.70 & 0.42 & 1.00 & 0.10 & 0.79 \\
CHF & 0.79 & 4.73 & 0.08 & 0.00 & 0.02 & 1.00 & -0.02 \\
Wage and salary & 0.32 & 11.57 & 0.69 & 0.52 & 1.04 & -0.13 & 1.00 \\
$\quad$ & & & & & & & \\
\multicolumn{1}{l}{ growth rates } & 5.71 & 4.00 & 0.00 & 0.01 & 0.00 & -0.01 & 0.00 \\
\hline
\end{tabular}

Note: Mean returns and volatilities are in percent per year. GBP = British pound; JPY = Japanese yen; EUR $=$ euro; $\mathrm{CAD}=$ Canadian dollar; and $\mathrm{CHF}=$ Swiss franc. The stock market data are based on MSCI indexes and the bond data, on JP Morgan indexes (Switzerland is based on Salomon Brothers data). The wage and salary growth rates are from Datastream.

aEuropean currency unit before January 1999.

Source: Based on data from Rudolf and Ziemba. 
linearly interpolated in order to obtain monthly wages and salaries data. The average growth rate of wages and salaries in the United States between January 1987 and July 2000 was 5.7 percent a year, with annualized volatility of 4.0 percent. Table 4.10 also contains the stock and bond market descriptive statistics in U.S. dollars and the currency betas of the indexes.

All foreign currencies except the Canadian dollar (CAD) (i.e., the British pound [GBP], Japanese yen [JPY], the euro [EUR], and Swiss franc [CHF]) had volatility of about 12 percent a year, and all currencies except JPY depreciated against the USD by a little more than zero percent to 1.13 percent a year. From a USD viewpoint, the GBP beta was especially high (absolute value) for the U.K. bond market. The Japanese stock and bond markets revealed JPY betas of -1.11 and -1.04, respectively, and the EMU bond market had a EUR beta of -0.93 . These betas are the percentage change in the variable of interest caused by a percentage change in the independent variable. Furthermore, the $\mathrm{CAD}$ beta of the Canadian bond market was -1.14 , and the $\mathrm{CHF}$ beta of the Swiss bond market was -0.99. All other countries had substantially lower currency betas. Because the betas were close to zero, the wages and salaries did not depend on currency movements.

The investor faces an exposure against five foreign currencies (GBP, JPY, $\mathrm{EUR}, \mathrm{CAD}$, and $\mathrm{CHF}$ ) and has to invest in eight funds. Five funds are hedge portfolios for the state variables, which are assumed to be currency returns, and the others, by portfolio separation, are the market portfolios, the riskless asset, and the liability-hedge portfolio. The compositions of the eight mutual funds appear in Table 4.11.

The holdings of the six fund situations shown in Table 4.12 depend only on the funding ratio and on the currency betas of the distinct markets. For a funding ratio of 1.0, there is no investment in the market portfolio and only diminishing investment in the currency hedge portfolios. The portfolio betas against the five currencies are close to zero for all funding ratios. The higher the funding ratio, the higher the investment in the market portfolio, the lower the investment in the liability and the state-variable hedge portfolios, and the lower the investment in the riskless fund. Negative currency hedge portfolios imply an increase of the currency exposure instead of a hedge against it. The increase of the market portfolio holdings and the reduction of the hedge portfolio holdings and the riskless fund for increasing funding ratios show that the funding ratio is directly related to the ability to bear risk. Rather than riskaversion coefficients, the funding ratio provides an objective measure to quantify attitudes towards risk.

The positive features of the study and approach are that the portfolio is able to hedge out all five currency risks. The strategy is very conservative, 
Table 4.11. Optimal Portfolio Weights, Assuming a Riskless Interest Rate of 2 Percent

\begin{tabular}{|c|c|c|c|c|c|c|c|}
\hline \multirow[b]{2}{*}{ Asset/Country } & \multirow{2}{*}{$\begin{array}{c}\text { Market } \\
\text { Portfolio }\end{array}$} & \multirow{2}{*}{$\begin{array}{l}\text { Liability- } \\
\text { Hedge } \\
\text { Positions }\end{array}$} & \multicolumn{5}{|c|}{ Hedge Portfolio } \\
\hline & & & GBP & JPY & EUR & $\mathrm{CAD}$ & $\mathrm{CHF}$ \\
\hline \multicolumn{8}{|l|}{ Stocks } \\
\hline United States & $83.9 \%$ & $-30.4 \%$ & $3.9 \%$ & $-4.5 \%$ & $-7.5 \%$ & $60.9 \%$ & $-5.1 \%$ \\
\hline United Kingdom & -14.8 & 60.6 & -31.0 & -1.1 & -8.6 & -85.3 & 1.9 \\
\hline Japan & -6.7 & 2.7 & 6.1 & 8.9 & -2.4 & -4.0 & -0.7 \\
\hline EMU & -19.2 & -68.3 & 35.3 & 12.8 & 23.5 & 138.3 & -3.8 \\
\hline Canada & -39.2 & 5.1 & 14.6 & 13.6 & 5.5 & -2.6 & -0.9 \\
\hline Switzerland & 21.6 & 1.5 & -24.8 & -14.6 & -14.7 & -100.7 & 1.0 \\
\hline \multicolumn{8}{|l|}{ Bonds } \\
\hline United States & $14.8 \%$ & $126.0 \%$ & $-126.4 \%$ & $-28.6 \%$ & $-41.2 \%$ & $-627.3 \%$ & $-35.9 \%$ \\
\hline United Kingdom & -9.7 & -56.8 & 189.7 & 7.9 & -3.4 & 97.5 & -8.5 \\
\hline Japan & 0.6 & 39.1 & -31.2 & 133.9 & -3.6 & -30.1 & 6.4 \\
\hline EMU & 138.5 & 9.6 & -16.4 & -38.0 & 97.3 & -170.1 & 34.0 \\
\hline Canada & 7.9 & 5.0 & -11.8 & -32.6 & -7.9 & 679.6 & 0.9 \\
\hline Switzerland & 77.7 & 5.9 & 91.9 & 42.4 & 62.9 & 143.8 & 110.7 \\
\hline
\end{tabular}

Source: Based on data from Rudolf and Ziemba.

Table 4.12. Optimal Portfolio Weights with Log Utility and Differing Funding Ratios

\begin{tabular}{lcccccc}
\hline Funding Ratio & 0.9 & 1 & 1.1 & 1.2 & 1.3 & 1.5 \\
\hline Market portfolio & $-11.5 \%$ & $0.0 \%$ & $6.3 \%$ & $12.3 \%$ & $18.2 \%$ & $24.6 \%$ \\
Liability-hedge portfolio & 14.8 & 13.3 & 12.1 & 11.1 & 10.2 & 8.9 \\
Hedge portfolio GBP & -0.6 & -0.5 & -0.5 & -0.5 & -0.4 & -0.4 \\
Hedge portfolio JPY & 1.2 & 1.1 & 1.0 & 0.9 & 0.9 & 0.8 \\
Hedge portfolio EUR & 0.3 & 0.2 & 0.1 & 0.0 & 0.0 & -0.1 \\
Hedge portfolio CAD & -0.1 & -0.1 & -0.1 & -0.1 & -0.1 & -0.1 \\
Hedge portfolio CHF & 1.1 & 1.0 & 0.9 & 0.8 & 0.8 & 0.7 \\
Riskless assets & $94.9 \%$ & $85.1 \%$ & $80.2 \%$ & $75.3 \%$ & $70.4 \%$ & $65.6 \%$ \\
Portfolio beta vs. GBP & -0.01 & -0.01 & -0.01 & -0.01 & -0.01 & -0.01 \\
Portfolio beta vs. JPY & 0.02 & 0.02 & 0.02 & 0.02 & 0.02 & 0.02 \\
Portfolio beta vs. EUR & 0.01 & 0.00 & 0.00 & 0.00 & 0.00 & 0.00 \\
Portfolio beta vs. CAD & -0.02 & -0.02 & -0.01 & -0.01 & -0.01 & -0.01 \\
Portfolio beta vs. CHF & 0.02 & 0.01 & 0.01 & 0.01 & 0.01 & 0.01 \\
\hline
\end{tabular}

Source: Based on data from Rudolf and Ziemba. 
with a high investment in riskless assets; 85.1 percent of the portfolio is in riskless assets with a funding ratio, $F$, of 1.0 , when assets match liabilities. This ratio drops monotonically to 65.6 percent with a funding ratio of 1.5 . Small changes in funding ratios change the asset weights significantly but in a reasonable way. Market weights range from zero percent at $F=1$ to 12.3 percent at $F=1.2$ to 24.6 percent at $F=1.5$. Because the market portfolio is composed of stocks and bonds, the equity component of these values are still low compared with typical insurance and pension fund weightings. Compare these results with those of the InnoALM model calculations in Tables 4.6 and 4.7. The sensitivity of the continuous-time model is less dramatic here than in many applications. More dramatic are the weights in the market and hedge portfolios (see Tables 4.13 and 4.14).

The equity portfolio is short 39.2 percent Canadian stocks and 14.8 percent U.K. stocks; long 83.9 percent U.S. stocks and 21.6 percent Swiss stocks; and long 138.5 percent Eurobonds and short 77.7 percent Swiss bonds. Although optimal in the model, these weightings are more like a hedge fund than a pension or insurance portfolio. The hedge fund portfolios have similar huge long and short positions, namely, long 679.6 percent Canadian bonds and 97.5 percent U.K. bonds and short 627.3 percent U.S. bonds and 170.1 percent EMU bonds.

Hence, in practice, these results must be viewed with caution. In addition, in a continuous-time model, the portfolio is being constantly revised, and this model and most other continuous-time models omit transaction costs. The recommendation is to understand such models and look at their calculations, but given that investment decisions have transaction costs, are made at intervals of one quarter or one year, and have many other complications, the discrete-time, scenario-based, constrained stochastic programming models are usually more practical. 


\section{Individual Asset/Liability Planning Models}

- Individual asset/liability models (ALMs) are for lifetime financial planning.

- Preferences, taxes, constraints, hidden assets, and other difficulties make individual ALMs much more complex than institutional ALMs.

\section{Models for Wealthy Individuals and Families}

... taxes, taxes, taxes and the rest.

Wealthy individuals and families have usually accumulated their wealth from a private or public business, successful investing, or some form of entertainment services. These individuals may have a small or large cash flow. Taxes are always crucial.

Consider the case of Henry Highgate, a wealthy individual whose assets and liabilities are depicted in Table 5.1. Henry is a 60-year-old business owner who sold his business to a public company in the past year. He holds a substantial amount of the acquiring company's stock and is an aggressive investor with his remaining wealth. Henry's wife, Mary, is 58, and his 16-yearold son James is in high school. Henry relies on the advice of his attorney, accountant, several brokers, private bankers, and money managers. He is a sophisticated investor who is in the highest tax bracket (49 percent). He wants US\$6 million in cash flow annually and has no other sources of income except for his assets.

The tax basis, or book value, and the current market value must be kept track of. Henry currently has eight asset classes. Other asset classes should be considered. The US\$6 million annual cash flow is only 1.5 percent of his net wealth, so the penalty function for this cash flow will be easy to meet. But with random returns, Henry may need more than the US\$6 million in later years. Other targets can be added, especially on the benchmark returns of the asset classes. As an aggressive investor, Henry has a low $R_{A}$ value of about 2 . Now that he is 60 years old and has no employment income, however, he should consider being a little more risk averse. The tax aspects of the real estate and investment loans need to be considered carefully. The bulk of the portfolio is in somewhat illiquid restricted stock and real estate. The cash, 
Table 5.1. Wealthy Individual Example

\begin{tabular}{|c|c|c|c|}
\hline & Tax Basis & Value & Cash Flow \\
\hline \multicolumn{4}{|l|}{ Assets } \\
\hline Cash and marketable securities & $\$ 29,523,641$ & $\$ 41,047,448$ & $\$ 1,231,423$ \\
\hline Closed-end funds & $38,642,851$ & $60,088,774$ & 660,977 \\
\hline Restricted stock & $195,453,200$ & $286,722,100$ & 661,000 \\
\hline Illiquid assets & $1,195,275$ & $2,751,915$ & \\
\hline Insurance & $1,006,000$ & $1,142,117$ & \\
\hline Limited partnerships & $5,364,780$ & $12,806,664$ & 650,000 \\
\hline Commercial real estate & $165,300,000$ & $205,400,000$ & $12,000,000$ \\
\hline Personal real estate & $18,500,000$ & $22,400,000$ & \\
\hline Total assets & $\$ 454,985,747$ & $\$ 632,359,018$ & $\$ 15,203,400$ \\
\hline \multicolumn{4}{|l|}{ Liabilities and equity } \\
\hline Credit cards and ST Loans & & 87,543 & $\$ \quad(87,543)$ \\
\hline Margin loans & & $10,324,312$ & $(2,100,000)$ \\
\hline Commercial R/E loans & & $82,160,000$ & $(7,394,400)$ \\
\hline Personal R/E loans & & $15,680,000$ & $(1,411,200)$ \\
\hline Unfunded equity commitments & & $88,878,692$ & \\
\hline Total liabilities & & $197,130,547$ & \\
\hline Net equity & & $\underline{435,228,471}$ & \\
\hline Total liabilities and equity & & $\$ \overline{632,359,018}$ & $\$(10,993,143)$ \\
\hline Current annual income & & & $\$ 15,203,400$ \\
\hline $\begin{array}{l}\text { Current annual expenses and } \\
\text { liabilities }\end{array}$ & & & $\underline{(10,993,143)}$ \\
\hline Net cash flow & & & $4,210,257$ \\
\hline Cash flow required & & & $(6,000,000)$ \\
\hline Cash flow shortfall & & & $(1,789,743)$ \\
\hline
\end{tabular}

marketable securities, and closed-end funds provide cash flow and liquid assets. Total loans and other liabilities are about half of net assets-an aggressive and dangerous position. The model will suggest reducing this risk because, although Henry is in a strong financial position relative to his needs, a bad scenario could lead to considerable losses. Hedge funds, enhanced portfolio strategies, and private placements can be considered, along with a decrease in loans, to lower the net risky exposure. A yearly model seems appropriate because quarterly aspects are dominated by yearly tax and other considerations. Quarterly estimated taxes are due, however, and the impact of this liability commitment must be modeled.

Hence, a model structure of the family-first quarter, rest of Year 1, Year 2, Years 3 to 5, and Years 5 to 20-seems appropriate. One then needs scenarios over these five periods that provide a plan until Henry is 80 years 
old. Henry and his wife need to generate target goals for her and James. Because Henry has so much capital, James' college costs are minor, but they still need to be modeled. James may wish to start a new business, which would require more capital. Hence, Henry will need to establish target cash flows over the five periods and to penalize their nonfulfillment. The key decision area in which the model can be helpful is to move, in a good tax effective way, into an overall portfolio that is less risky while still achieving Henry's goals.

The next example is that of a family business, as described in Table 5.2. John James manages a family office as his full-time job. The family's wealth is held in various liquid and illiquid assets. James is particularly interested in the net tax effects of the investment choices he can make. He is not concerned about short-term shifts in individual parts of the family portfolio because he wants to make all decisions from a long-term perspective.

The family has four members, and the modeling system must consider the entire estate as the main item to be maximized. The income needs of the four individuals are well modeled using the four separate targets, each with their own convex penalty functions in each period. These targets over time must reflect possible shifts across individuals and across time for separate

\section{Table 5.2. Family Office Example}

\begin{tabular}{|c|c|c|c|}
\hline Family members & Tax Bracket & Income Needs & \\
\hline John James & $49 \%$ & $\$ 650,000$ & \\
\hline Susan James (sister) & 49 & 800,000 & \\
\hline Frank James (brother) & 15 & $1,000,000$ & \\
\hline Michael James (son) & $37.6 \%$ & 250,000 & \\
\hline Total income required & & $\overline{2,700,000}$ & \\
\hline Assets & $\underline{\text { Value }}$ & Tax Basis & Cash Flow \\
\hline Hedge funds & $\$ \overline{4,500,000}$ & $\$ \overline{3,400,000}$ & $\overline{0}$ \\
\hline U.S. equity funds & $6,700,000$ & $3,600,000$ & 107,200 \\
\hline Foreign funds & $3,800,000$ & $2,700,000$ & 68,400 \\
\hline Taxable bonds & $3,500,000$ & $3,100,000$ & 227,500 \\
\hline Tax-exempt bonds & $6,000,000$ & $4,700,000$ & 324,000 \\
\hline Private equity & $6,400,000$ & 850,000 & 0 \\
\hline Family business & $35,000,000$ & $1,200,000$ & 850,000 \\
\hline Family trust (untouchable) & $40,000,000$ & $1,100,000$ & 220,000 \\
\hline Real estate & $6,500,000$ & $1,400,000$ & 150,000 \\
\hline Total & $\overline{\$ 112,400,000}$ & $\$ 22,050,000$ & $\overline{\$ 1,947,100}$ \\
\hline \multicolumn{4}{|l|}{ Liabilities } \\
\hline Family business debt & $\$ 15,000,000$ & $\$ 15,000,000$ & $\$(1,312,500)$ \\
\hline
\end{tabular}


individuals. Hence, the targets do not need to be quite as tight as those listed in Table 5.2. The penalty functions will help organize these targets. Also crucial is the way the funds are allocated to the various individuals to lessen taxes and thereby maximize the overall net wealth of the family. So, overall family wealth targets, net of taxes in various periods, are also necessary.

In future periods, the individuals' tax situation will change, and the modeling system can handle that. Shifts in the family portfolio can be modeled, and relevant constraints can be imposed. Currently, assets are in nine classes. Book and current values of assets are needed in the model formulation. Liabilities in terms of income needed per year and debt are small in relation to total net assets. This family has a large tax liability that needs to be dealt with carefully. Also, the family business and family trust are illiquid, but they contribute to the yearly cash flow liability. From a long-term perspective, this portfolio is light on equity in relation to bonds (which look like they can be lightened up without much tax liability). A moderately aggressive risk structure with an $R_{A}$ of about 3 seems appropriate. A yearly model seems appropriate because quarterly aspects are dominated by yearly tax and other aspects (except that quarterly estimated taxes need to be handled properly).

Hence, an appropriate model structure is the first quarter, the rest of the Year 1, Years 2 to 5, and Years 6 to 20. John's long-term goals can be modeled by placing more weight on the 2 - to 5 - and 6- to 20 -year time periods. Shifting of assets among family members can occur, and the tax and cash flow aspects can be taken into account. The way John has laid out the assets needs to be more detailed; the ownership of specific assets across the four family members must be delineated with joint family assets, such as keeping the trust as a separate asset holder. Hence, the model should consider five separate parties with overall and individual goal targets.

John has done a good job of putting the family in a position whereby a bad scenario will not hurt much. With debt of only a little more than 10 percent of assets, the family is not taking much risk. The asset classes are quite broad and provide considerable real diversification because domestic and foreign assets, stocks and bonds, hedge funds, real estate, private equity, and the family business are already in the portfolio. The stochastic programming asset/liability management approach will probably help Henry more than John because Henry is much more levered. The model can be helpful to John in delineating the details of the individual family members' holdings, their differing needs over time, and the balancing of individual needs and long-run family wealth. 


\section{Retirement}

As the stock market hit a seven-year low this week, it became clearer than ever that anyone approaching retirement will have to carry on working.

\section{Margaret Hughes (2003)}

Retirement models must be conservative because the possibility of recouping lost wealth is more difficult for retirees, who have no labor income. The Henry Highgate example is typical of a retirement model for a wealthy individual or family. He has plenty of assets, and the planning problem is to make them last indefinitely while providing for a lavish lifestyle. Most people have far fewer assets and can easily run into trouble if asset returns are too low or negative and spending is too high. Retirement and individual ALMs can be made for specific parties on a customized basis or en masse for a class of individuals. Frank Russell Company's Italian Bank Federeuen model is an example of the latter (see Murray, 1997, 1998). It was designed for clients of the bank to be implemented by some 2,500 account executives, each of whom would be responsible for about 500 separate accounts. The procedure was to interview clients to assess their assets, liabilities, target goals, and preferences. Based on this information, a tentative plan was developed, and the plan was implemented after a second discussion was held. Then, the portfolio was to be revised yearly. The implementation and project were successful, but the problem has the following complexities, which are not found in institutional models:

- ascertaining all client assets and valuing them because assets may be hidden for personal or other reasons;

- determining the relative importance of different goals because individuals tend to think that everything is important; scales are needed to balance the preferences;

- tax aspects are crucial and must be modeled carefully;

- providing client security and protection against bad scenarios, given the lack of labor income;

- agency problems of account executives pushing products with high commissions rather than those in the best interests of the client; and

- operational problems of account executives unable or unwilling to use the stochastic programming approach.

These complexities have been studied using other approaches by individuals at the Centers for Retirement Research at Boston College and the University of Michigan and at brokerage firms, which provide rules for guidance. 
Stochastic programming scenario-based optimization approaches clearly have a role to play in improving the performance of retirement planning.

\section{Endowments}

Major foundations, such as the Carnegie, Ford, and Rockefeller, and universities such as Harvard, Princeton, and Stanford have large multibillion dollar endowments. These funds, which came from wealthy donors, are used for humanitarian and other purposes and to improve and preserve educational institutions. Because of inflation, endowment spending usually increases. The endowments must manage their funds so that current spending can increase without depleting much of the capital to be used for future spending. Capital campaigns occur from time to time, as do bequests, and income comes from tuition, grants, research contracts, and other sources. To maintain this level of spending, however, good investment performance is crucial.

Yale University has approached this problem with a heavy emphasis on private equity rather than publicly traded equity (see Swensen 2000). The Yale endowment made 19.1 percent on its private equity portfolio and 17.6 percent on the whole portfolio during the 16 years from 1982-1997, which is higher than U.S. bonds, U.S. equity, development equity, emerging equity, real estate, and cash. Adding two more years for the 18 years from 1982-1999, the annualized return was 16.9 percent, which was in the top 1 percent of institutional funds during this period. The asset allocation as of June 1997 was 22.5 percent in domestic equity, 12.5 percent in domestic fixed income, 12.5 percent in foreign equity, 32.5 percent in private assets, and 20.0 percent in other marketable securities. The high amount of private assets reflects the belief that large-scale inefficiencies frequently exist in illiquid markets; the illiquidity provides a premium so that positions can be entered at discounts, and these markets are not well understood. So, Yale is an example in which private equity can have high returns over long periods that include bear markets (see Table 5.3). Yale's returns were statistically significantly higher than the other asset classes.

Venture capital investors live by either feast or famine. The best managers (including Swensen at Yale) are extremely careful and have good returns, but most others have poor returns. (See Table 5.4 and Table 5.5.)

An important way to preserve capital is not to lose it during weak markets. Table 5.6 shows that the Ford Foundation, Berkshire Hathaway, Fidelity Magellan, and Barclays Global Investors Tactical Asset Allocation funds were able to preserve capital from 1977 to 2001 . Bear markets are defined as July 1977 to February 1978, December 1980 to July 1982, September to November 
Table 5.3. Net Returns from Various Asset Classes, 1982-97

\begin{tabular}{|c|c|c|c|c|c|c|c|c|}
\hline \multirow[b]{2}{*}{ Measure } & \multirow[b]{2}{*}{$\begin{array}{l}\text { U.S. } \\
\text { Bonds }\end{array}$} & \multirow[b]{2}{*}{$\begin{array}{l}\text { U.S. } \\
\text { Equity }\end{array}$} & \multirow[b]{2}{*}{$\begin{array}{l}\text { Developed } \\
\text { Equity }\end{array}$} & \multirow[b]{2}{*}{$\begin{array}{c}\text { Emerging } \\
\text { Equity }\end{array}$} & \multirow[b]{2}{*}{$\begin{array}{l}\text { Real } \\
\text { Estate }\end{array}$} & \multirow[b]{2}{*}{ Cash } & \multicolumn{2}{|c|}{ Yale } \\
\hline & & & & & & & $\begin{array}{l}\text { Absolute } \\
\text { Return }\end{array}$ & $\begin{array}{l}\text { Private } \\
\text { Equity }\end{array}$ \\
\hline Years & 72 & 72 & 38 & 13 & 21 & 72 & 20 & 16 \\
\hline $\begin{array}{l}\text { Arithmetic } \\
\quad \text { return (\%) }\end{array}$ & 1.2 & 9.2 & 6.3 & 11.1 & 3.5 & -0.4 & 17.6 & 19.1 \\
\hline $\begin{array}{l}\text { Standard } \\
\quad \text { deviation (\%) }\end{array}$ & 6.5 & 21.7 & 18.9 & 27.9 & 5.1 & 4.1 & 11.8 & 20.0 \\
\hline Growth rate (\%) & 1.0 & 7.0 & 4.7 & 7.7 & 3.4 & -0.5 & 17.0 & 17.5 \\
\hline
\end{tabular}

Table 5.4. Dispersion of Active Management Returns, January 1988December 1997

\begin{tabular}{lcccc}
\hline Asset Class & First Quartile & Median & Third Quartile & Range \\
\hline U.S. fixed income $^{\mathrm{a}}$ & $9.7 \%$ & $9.2 \%$ & $8.5 \%$ & $1.2 \%$ \\
U.S. equity $^{\mathrm{a}}$ & 19.5 & 18.3 & 17.0 & 2.5 \\
International equity $^{\mathrm{a}}$ & 12.6 & 11.0 & 9.7 & 2.9 \\
Real estate $^{\mathrm{b}}$ & 5.9 & 3.9 & 1.2 & 4.7 \\
Leveraged buyouts $^{\mathrm{c}}$ & 23.1 & 16.9 & 10.1 & 13.0 \\
Venture capital $^{\mathrm{c}}$ & 25.1 & 12.4 & 3.9 & 21.2 \\
\hline
\end{tabular}

Note: Venture capital and leveraged buyout data represent returns on funds formed between 1988 and 1993, excluding more recent funds so that mature investments will not influence reported results.

aBased on data from Piper Managed Accounts.

${ }^{\mathrm{b}}$ Based on data from Institutional Property Consultants.

${ }^{\mathrm{c}}$ Based on data from Venture Economics.

Source: Based on data from Swenson.

1987, June to October 1990, and July to August 1998. Other periods are defined as bull markets, even if there was little gain, as in 1984 and 1994.

The problem of how to invest in risky assets and cash dynamically in time so that a given spending rule will allow spending to never decrease has been considered by Dybvig (1999), based on his 1988 and 1995 research papers. This problem, illustrated in Figure 5.1, Figure 5.2, and Figure 5.3, is similar to the 1992 constant proportional portfolio insurance model of Black and Perold. 1

1The model is summarized in Appendix E (p. 34), which is available online in the Supplementary Material area at www.aimrpubs.org/rf/issues/v2003n6/pdf/AppendixE.pdf. 
Table 5.5. Comparison of Asset Classes: Investment Fund Returns, 1980-97

\begin{tabular}{lccccc}
\hline & $\begin{array}{c}\text { Real } \\
\text { Estate }^{\mathrm{a}}\end{array}$ & $\begin{array}{c}\text { Venture } \\
\text { Capital }^{\mathrm{b}}\end{array}$ & $\begin{array}{c}\text { Leveraged } \\
\text { Buyouts }^{\mathrm{b}}\end{array}$ & $\begin{array}{c}\text { Domestic } \\
\text { Equity }^{\mathrm{c}}\end{array}$ & $\begin{array}{c}\text { Foreign } \\
\text { Equity }^{\mathrm{c}}\end{array}$ \\
\hline Maximum & $\mathrm{NA}$ & $498.2 \%$ & $243.9 \%$ & $18.1 \%$ & $19.5 \%$ \\
First quartile & $9.9 \%$ & 17.1 & 23.8 & 16.6 & 16.1 \\
Median & 7.8 & 8.1 & 13.2 & 15.5 & 14.9 \\
Third quartile & 5.9 & 0.6 & 1.1 & 14.9 & 14.0 \\
Minimum & $\mathrm{NA}$ & -89.7 & -65.9 & 13.2 & 11.1 \\
First to third quartile range & 4.0 & 16.5 & 22.7 & 1.7 & 2.1 \\
Standard deviation & 2.5 & 30.0 & 35.7 & 1.3 & 2.1 \\
\hline
\end{tabular}

$\mathrm{NA}=$ not available.

aBased on data from Institutional Property Consultants.

${ }^{b}$ Based on data from Venture Economics.

${ }^{\mathrm{c}}$ Based on data from Piper Managed Accounts.

Source: Based on data from Swenson.

Table 5.6. Four Funds' Performance in Bull and Bear Markets, 1977-2001

\begin{tabular}{|c|c|c|c|c|c|c|}
\hline \multirow[b]{3}{*}{ Fund } & \multicolumn{2}{|c|}{$\begin{array}{l}\text { Bull and Bear } \\
\text { Markets }\end{array}$} & \multicolumn{2}{|c|}{$\begin{array}{c}\text { Crashes of } \\
1987 \text { and } 1998\end{array}$} & \multirow{3}{*}{$\begin{array}{c}\text { Market } \\
\text { Volatility } \\
\text { Correlation }^{\mathrm{a}} \\
\end{array}$} & \multirow{3}{*}{$\begin{array}{c}\text { Sharpe } \\
\text { Ratio } \\
1 / 80-3 / 00\end{array}$} \\
\hline & \multicolumn{2}{|c|}{$\begin{array}{l}\text { Average Monthly Return in } \\
\text { Excess of Benchmark }\end{array}$} & \multicolumn{2}{|c|}{$\begin{array}{c}\text { Monthly Return in } \\
\text { Excess of Benchmark }\end{array}$} & & \\
\hline & Bulls & Bears & $10 / 87$ & $8 / 98$ & & \\
\hline Berkshire Hathaway & $1.21 \%$ & $1.70 \%$ & $0.40 \%$ & $0.89 \%$ & -0.14 & 0.786 \\
\hline BGI TAA & 0.10 & 0.73 & 20.38 & -1.74 & 0.54 & 0.906 \\
\hline Ford Foundation & 0.11 & -0.08 & -1.11 & -2.11 & -0.09 & 0.818 \\
\hline Magellan & 0.52 & 0.88 & -5.46 & -1.20 & -0.04 & 0.844 \\
\hline
\end{tabular}

${ }^{a}$ Correlation of monthly return in excess of benchmark with volatility measure.

Source: Based on data from Clifford, Kroner, and Siegel (2001).

Panel A of Figure 5.1 depicts the 1946-96 performance of a fixed-mix strategy with equal proportions of large-cap U.S. stocks and 3-month U.S. Treasury Inflation-Indexed Securities (TIPS, assumed to be a risk-free asset in real terms). The spending rate is 4.5 percent of beginning initial wealth each year with an initial endowment to US\$100 million. With the fixed-mix strategy, the weights change as the stock portfolio rises and falls, as shown in Panel B of Figure 5.1. A protected part is invested in the TIPS and the remainder is in 


\section{Figure 5.1. Performance and Portfolio Composition of a Simple Portfolio Strategy and Spending Rule, 1946-96}

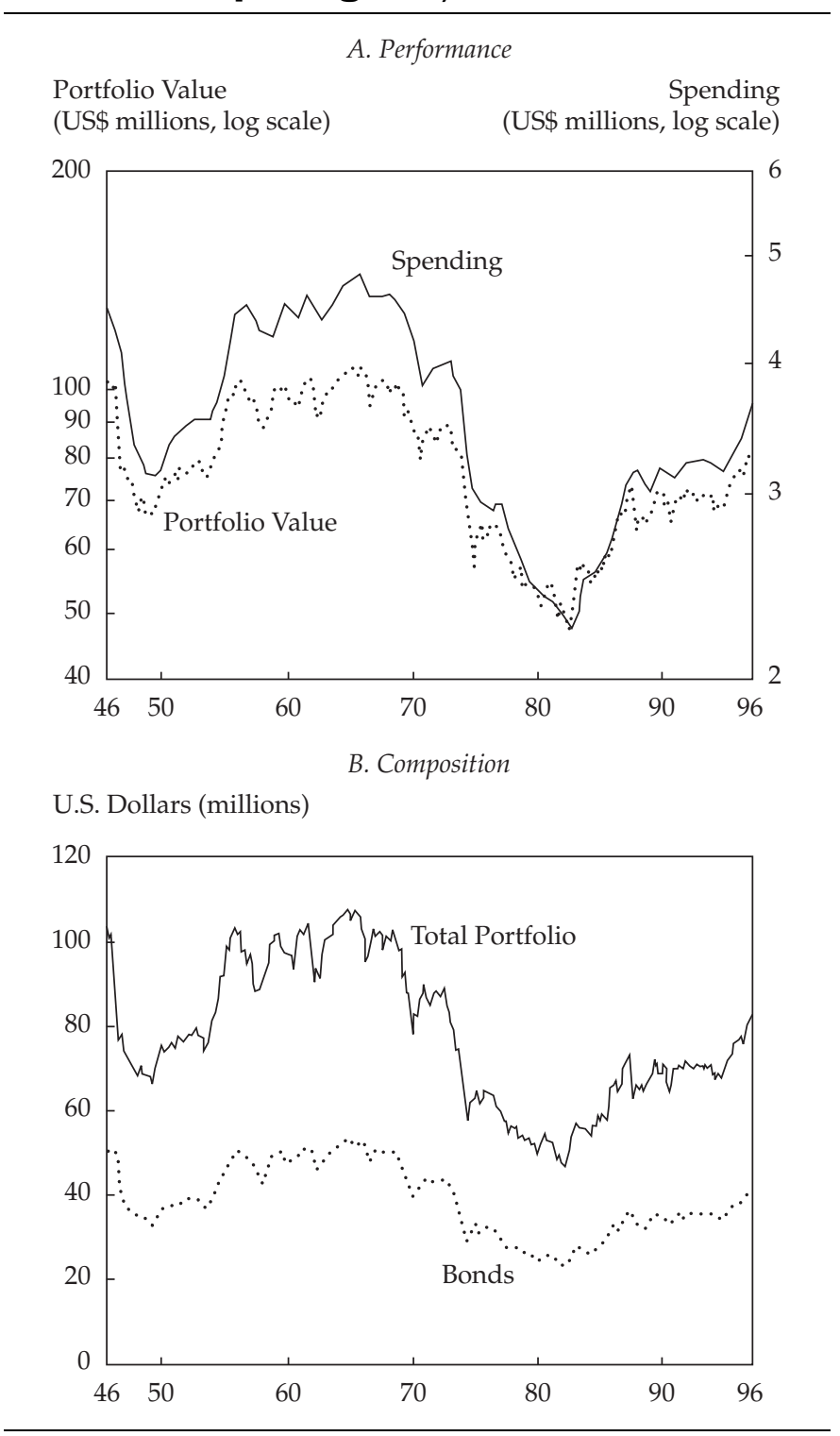

Source: Based on data from Dybvig. 


\section{Figure 5.2. Performance and Portfolio Composition of the Proposed Expenditure-Protected Policy, 1946-96}

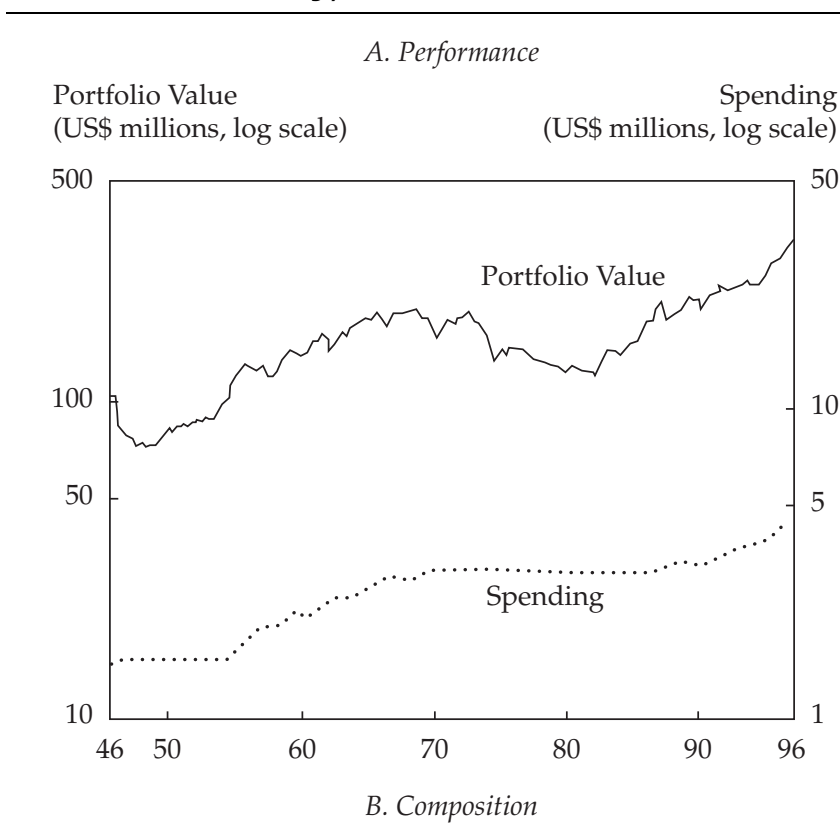

U.S. Dollars (millions)

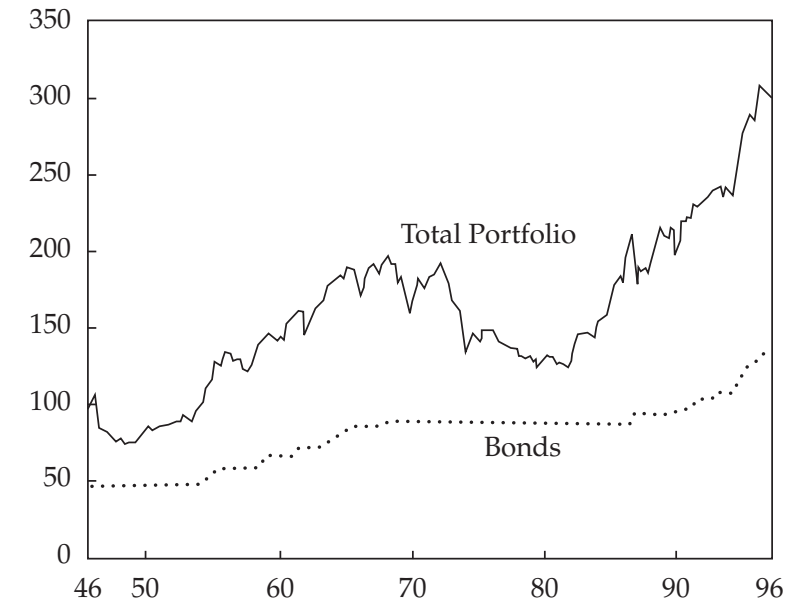

Source: Based on data from Dybvig. 


\section{Figure 5.3. Performance and Portfolio Composition of a Diluted Version of the Expenditure- Protected Policy, 1946-96}

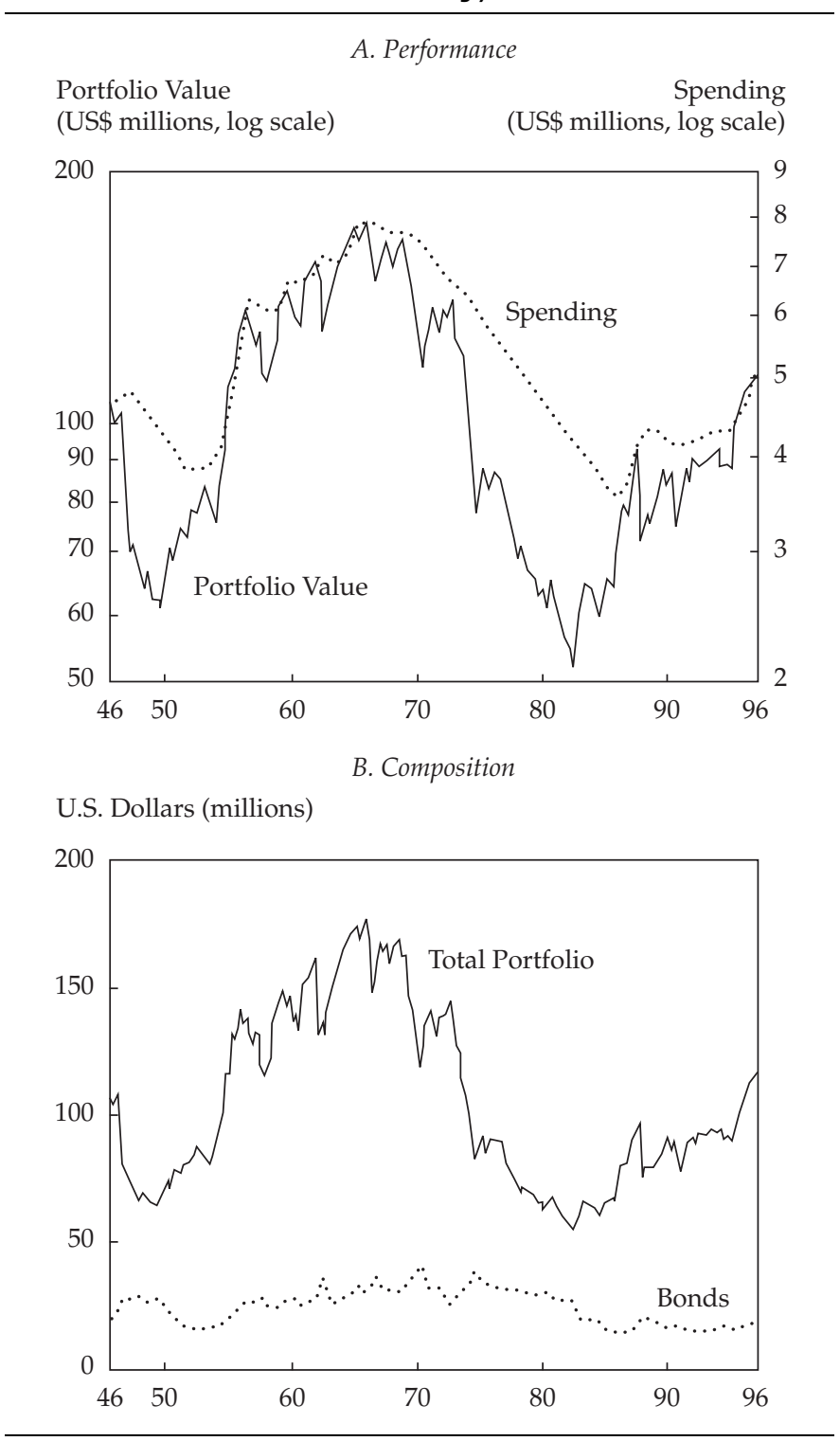

Source: Based on data from Dybvig. 
stocks. The protected strategy, like portfolio insurance, moves into safer assets when the market falls. The strategy avoids spending cuts while still allowing for significant participation in rising equity markets.

One can smooth the spending pattern in Panel A of Figure 5.1 and base spending on the average wealth levels over several years, but this is an ad hoc approach. Figure 5.2 shows Dybvig's approach, in which spending never decreases, even in periods in which the portfolio value declines. The strategy does require low spending rates, which may be below current spending for some plans. Many variants are possible, such as beginning with higher spending rates and allowing the spending rate to decline at a small, continuous rate. In Figure 5.3, for example, spending fell by nearly half following the 197374 oil price crisis.

This interesting strategy performs best in rising or falling markets and not so well in choppy markets. As with all continuous-time models, the choice of parameters is crucial, and the portfolio weights will change dramatically as market expectations, especially the means, change. 


\section{Hedge Fund Applications}

Eifuku Master Fund, a \$300 million Japanese hedge fund, collapsed. Eifuku, which means eternal luck in Japanese, lost nearly everything in a week's trading in January 2003.

If I hadn't lost everything I'd definitely be buying now.

\section{Leo Cullum \\ Barron's cartoon}

Hedge funds can clearly get into trouble by overbetting and not being truly diversified, and being vulnerable, they can get caught by low-probability but plausible disaster scenarios. It is exactly then-when hedge funds are in trouble- that they need access to new cash, and because new cash is usually not available, it makes sense to plan ahead for such contingencies by not overbetting and being truly diversified in advance.

Hedge funds are pooled investments that attempt to obtain superior returns for their mostly wealthy investors. The name "hedge fund" is misleading; it is a vehicle to trade a pool of money from a number of investors in various financial markets. The general partner runs the fund and collects fees to compensate for expenses and receives bonuses for superior performance. Typically, the general partner is an investor in the fund, a strategy known as "eating your own cooking." It gives investors added confidence, increases the incentive for the manager to perform well, and dampens the incentive to take excessive risks. The latter is especially important because operating a hedge fund is essentially a call option on the investors' wealth. In addition, the general partner conveniently stores fees collected month by month or quarter by quarter in the fund.

The hedge fund industry has grown explosively since 1980. The first official hedge fund was established in 1949. By the late 1980s, the number of funds had increased to about 100. In 1997, more than 1,200 hedge funds existed, managing a total of more than US\$200 billion. As of May 2003, about 6,000 hedge funds worldwide had more than US\$600 billion in assets about a third of which is in funds of hedge funds.

Although hedge funds are small in number and size compared with mutual funds, their growth reflects the importance of alternative investments for institutional investors and wealthy individuals. In addition, hedge funds frequently exert an influence on financial markets that is much greater than their size. An important example is the hedge fund Long-Term Capital Management (LTCM), whose collapse in 1998 jeopardized several large financial institutions 
and was considered a threat to the world economy by the U.S. Federal Reserve (Fed). Hence, the study of risk taking in the hedge fund industry is relevant for the financial system as a whole.

Some hedge funds actually use hedging, such as those using long-short convergence trades and statistical arbitrage. Others, called "macro funds," use strategies that take directional bets on currencies, stock indexes, and so on. A list of 10 distinct types of hedge funds appears in Exhibit 6.1. Risks in macro and other directional funds are much greater than in long-short or convergencetype funds. In this chapter, I will describe some aspects of hedge fund operation and the results. Stochastic programming strategies are useful for risk control and optimal betting strategies. Statistical arbitrage, such as pairs trading of individual or groups of stocks, is currently popular in many hedge funds.

\section{Exhibit 6.1. Selected Types of Pure Hedge Fund Strategy Categories}

\section{Market-neutral strategies}

- Fixed-income arbitrage. Long and short bond positions via cash or derivative markets in government, corporate, and/or asset-backed securities. The risk varies, depending on duration, credit exposure, and the degree of leverage.

- Event driven. A strategy that attempts to benefit from mispricing arising in different events, such as merger arbitrage, restructurings, and so on. Positions are taken in undervalued securities anticipated to rise in value because of events such as mergers, reorganizations, or takeovers. The main risk is nonrealization of the event.

- Equity convergence hedge. Investing in equity or equity derivative instruments whose net exposure (gross long minus short) is low. The manager may invest globally or have a more defined geographic industry or capitalization focus. The risk primarily pertains to the specific risk of the long and short positions.

- Restructuring. Buying and occasionally shorting securities of companies under Chapter 11 and/ or those undergoing some form of reorganization. The securities range from senior secured debt to common stock. The liquidation of financially distressed companies is the main source of risk.

- Event arbitrage. Purchasing securities of a company being acquired and shorting the acquiring company. This risk relates to the deal risk rather than market risk.

- Capital structure arbitrage. Buying and selling different securities of the same issuer (e.g., convertibles/common stock) and attempting to obtain low-volatility returns by exploiting the relative mispricing of these securities.

\section{Directional strategies}

- Macro. An attempt to capitalize on country, regional, and/or economic change affecting securities, commodities, interest rates, and currency rates. Asset allocation can be aggressive, using leverage and derivatives. The method and degree of hedging can vary significantly.

- Long. A growth, value, or other model approach to investing in equities with no shorting or hedging to minimize market risk. These funds mainly invest in emerging markets, in which restrictions on short sales may exist.

- Long bias. Similar to equity convergence hedge but with a net long exposure.

- Short. Selling short overvalued securities and attempting to repurchase them in the future at a lower price.

Source: Modified from Agarwal and Naik (1999). 
Since 1997, a number of academic studies have tried to estimate the returns and risks of investing in hedge funds. Chen and Passow (2003); Fung and Hsieh (2001); Brown, Goetzman, and Ibbotson (1997); Ackerman, McEnally, and Ravenscraft (1999); Agarwal and Naik (2001); Amin and Kat (2003); and Kouwenberg (2003) have all contributed to this research. Obtaining data for empirical studies has been difficult because hedge funds are not required to report their returns to the public. As a result, each study typically investigates a subset of the total hedge fund universe, depending on which data happen to be available. Another factor is that the best and worst funds prefer to be silent on their performance; the best are oversubscribed and the worst do not need more publicity. Hence, private data sources have more accurate and complete databases.

In general, the empirical studies seem to agree on one important point: Hedge funds significantly improve the trade-off between risk and return when added to a traditional portfolio of bonds, mutual funds, and stock indexes. This result stems from the fact that some hedge funds have relatively little exposure to sources of general market risk. Except for Ackerman, McEnally, and Ravenscraft, the studies have also found that individual hedge funds provide better risk-adjusted performance (after fees) than a broadly diversified stock index, usually the S\&P 500 Index. According to Van Hedge Advisors International, the international hedge fund industry grew from US\$311 billion to US\$600 billion in 2002. In 2001, the average hedge fund returned 5.8 percent versus a loss of 12.6 percent for the average equity fund. In 2002, hedge funds lost 0.4 percent, on average, their first loss in 14 years. Meanwhile, equity funds lost 20.3 percent in 2002 .

Not much persistence exists in hedge fund performance: Winners may easily become losers. Although the hedge fund industry as a whole provides good opportunities for investors, some successful hedge fund managers tend to lose their magic now and then. As I mentioned, a well-known and noteworthy example of a winner that turned into a loser is LTCM. (See Edwards 1999, Jorion 2000a, Ross 1999, and Ziemba 2000.) And after many years of high returns, Julian Robertson's Tiger Fund and George Soros' Quantum Fund closed in 2000 because of poor returns. In addition, the real risk in hedge funds that are highly levered through borrowing or derivatives is frequently greatly understated by the monthly or quarterly reporting periods and by using such risk measures as standard deviation or the Sharpe ratio.

The theoretical literature concerning hedge funds is small. Typically, papers focus on the optimal fee structure for investment funds (Heinkel and Stoughton 1994; Maug and Naik 1995; and Dybvig, Farnsworth, and Carpenter 1999), exploiting arbitrage opportunities with restrictions on short selling (Liu 
and Longstaff 2000 and Loewenstein and Willard 2000), and applying option pricing to calculate the value of the incentive fees paid to hedge fund managers (Goetzmann, Ingersoll, and Ross 2003).

Heinkel and Stoughton; Maug and Naik; and Dybvig, Farnsworth, and Carpenter investigated the relationship between fee contracts and fund management. Their studies applied the principal agent framework developed by Ross in 1973 in order to derive the optimal management contract from the point of view of the investor.

Liu and Longstaff and Loewenstein and Willard investigated the equilibrium impact of investors that exploit arbitrage opportunities (hedge fund managers). In the model of Loewenstein and Willard, hedge fund managers provide liquidity to institutional investors who face uncertain cash withdrawals. Liu and Longstaff investigated a market with a pure arbitrage opportunity and hedge fund managers that face restrictions on short selling. Similar studies about the risks of arbitrage strategies can be found in Shleifer (2000).

Goetzmann, Ingersoll, and Ross developed a continuous-time BlackScholes-like environment to model the high-watermark incentive system used by many hedge funds. That is, fees are a flat amount per unit of time plus an incentive that is a percentage above a benchmark (which they take to be zero). They assume that the hedge fund returns the mean rate of return of the market and goes on forever with continuous redemptions, unless it is closed by poor return scenario outcomes. Given these assumptions, they estimate the value of the fees paid to the manager as a call option on the investors' wealth.

Kouwenberg and Ziemba (2003) discussed incentives and risk taking in hedge funds. Their theoretical model uses a prospect theory preference framework. When hedge fund managers have incentives, then taking excessive risk is optimal. This risk is greatly reduced, however, if the manager has a substantial amount of his or her own money in the fund. In an empirical study, they found that managers with incentive fees have higher downside risk than funds without such a compensation contract. Mean returns are lower in both absolute and risk-adjusted terms when managers have incentive fees.

\section{Keynes as a Hedge Fund Manager}

Unofficial (i.e., private) hedge funds have been run for centuries using futures, equities, and other financial instruments. Futures in rice trading in Japan date from the 1700s, and futures trading in Chicago was active in the mid-1800s. An interesting early hedge fund was the Chest Fund at King's College, Cambridge, which was managed by the first bursar, the famous economic theorist John Maynard Keynes, from 1927-1945. The following discussion is based on and extends Chua and Woodward (1983). 
In November 1919, Keynes was appointed second bursar. Up to this time, King's College investments had been only in fixed-income trustee securities and the college's own land and buildings. By June 1920, Keynes convinced the college to start a separate fund containing stocks, currency, and commodity futures. Keynes became first bursar in 1924 and held this post, which had final authority on investment decisions, until his death in 1945. Keynes (1938) emphasized three principles of successful investing:

1) a careful selection of a few investments (or a few types of investments), having regard to their cheapness in relation to their probable actual and potential intrinsic value over a period of years ahead and in relation to alternative investments at the time;

2) a steadfast holding of these investments in fairly large units through thick and thin, perhaps for several years, until either they have fulfilled their promise or it is evident that they were purchased by mistake;

3) a balanced investment position (i.e., a variety of risks in spite of large individual holdings and, if possible, opposed risks).

And he did not believe in market timing:

We have not proved able to take much advantage of a general systematic movement out of and into ordinary shares as a whole at different phases of the trade cycle dots.... As a result of these experiences I am clear that the idea of wholesale shifts is for various reasons impracticable and indeed undesirable. Most of those who attempt to sell too late and buy too late, and do both too often, incurring heavy expenses and developing too unsettled and speculative a state of mind, which, if it is widespread, has besides the grave social disadvantage of aggravating the scale of the fluctuations.

By emphasizing value, large holdings, and patience, Keynes' ideas overlap to some extent with those used by Warren Buffett in his Berkshire Hathaway Fund. Buffett has also added effective side businesses, such as insurance, and a greater level of involvement in the management of his holdings. Keynes' approach of having a small number of positions even partially hedged naturally led to fairly high volatility, as shown Table 6.1 and Figure 6.1. Details of the holdings over time, as with hedge funds, are not known, but it is known that in 1937, the fund had 130 separate positions.

The returns in Table 6.1 do not include dividends and interest. The income, which is not public information, was spent on modernizing and refurbishing King's College. The index's dividend yield was under 3 percent. A capital asset pricing model (CAPM) analysis suggests that Keynes was an aggressive investor with a beta of 1.78 versus the benchmark U.K. market return, a Sharpe ratio of 0.385 , and geometric mean returns of 9.12 percent a year versus -0.89 percent for the benchmark. Keynes had a yearly standard deviation of 29.28 percent versus 12.55 percent for the benchmark. 
Table 6.1. Absolute and Relative Performance of Keynes' Chest Fund, 1927-1945

\begin{tabular}{|c|c|c|c|c|c|c|}
\hline \multirow[b]{2}{*}{ Year } & \multicolumn{2}{|c|}{ Chest Fund } & \multicolumn{2}{|c|}{ U.K. Market } & \multicolumn{2}{|c|}{ U.K. T-Bill } \\
\hline & Index & Return & Index & Return & Index & Return \\
\hline 1927 & 100.0 & & 100.0 & & 100.0 & \\
\hline 1928 & 96.6 & $-3.4 \%$ & 107.9 & $7.9 \%$ & 104.2 & $4.2 \%$ \\
\hline 1929 & 97.4 & 0.8 & 115.0 & 6.6 & 109.7 & 5.3 \\
\hline 1930 & 65.8 & -32.4 & 91.7 & -20.3 & 112.5 & 2.5 \\
\hline 1931 & 49.6 & -24.6 & 68.8 & -25.0 & 116.5 & 3.6 \\
\hline 1932 & 71.8 & 44.8 & 64.8 & -5.8 & 118.3 & 1.5 \\
\hline 1933 & 97.0 & 35.1 & 78.7 & 21.5 & 119.0 & 0.6 \\
\hline 1934 & 129.1 & 33.1 & 78.1 & -0.7 & 119.8 & 0.7 \\
\hline 1935 & 186.3 & 44.3 & 82.3 & 5.3 & 120.4 & 0.5 \\
\hline 1936 & 290.6 & 56.0 & 90.7 & 10.2 & 121.1 & 0.6 \\
\hline 1937 & 315.4 & 8.5 & 90.2 & -0.5 & 121.9 & 0.6 \\
\hline 1938 & 188.9 & -40.1 & 75.7 & -16.1 & 122.6 & 0.6 \\
\hline 1939 & 213.2 & 12.9 & 70.2 & -7.2 & 124.2 & 1.3 \\
\hline 1940 & 179.9 & -15.6 & 61.2 & -12.9 & 125.4 & 1.0 \\
\hline 1941 & 240.2 & 33.5 & 68.8 & 12.5 & 126.7 & 1.0 \\
\hline 1942 & 238.0 & -0.9 & 69.4 & 0.8 & 127.9 & 1.0 \\
\hline 1943 & 366.2 & 53.9 & 80.2 & 15.6 & 129.2 & 1.0 \\
\hline 1944 & 419.3 & 14.5 & 84.5 & 5.4 & 130.5 & 1.0 \\
\hline 1945 & 480.3 & 14.6 & 85.2 & 0.8 & 131.8 & 1.0 \\
\hline Arithmetic mean & & $13.06 \%$ & & $-0.11 \%$ & & $1.56 \%$ \\
\hline Geometric mean & & $9.12 \%$ & & $-0.89 \%$ & & \\
\hline Standard deviation & & $29.28 \%$ & & $12.58 \%$ & & \\
\hline Beta & & 1.78 & & & & \\
\hline Sharpe index & & 0.385 & -0.129 & & & \\
\hline Treynor index & & 6.46 & -1.86 & & & \\
\hline Jensen index & & 14.45 & & & & \\
\hline Standard error & & $4.69 \%$ & & & & \\
\hline
\end{tabular}

Source: Based on data from Chua and Woodward.

The drawdown from 100 in 1927 to 49.6 in 1931, with losses of 32.4 percent in 1930 and 24.6 percent in 1931 , was more than 50 percent, but this drawdown occurred during the depression, when the index fell 20.3 percent and 25.0 percent, respectively. The College's patience with Keynes was rewarded in the substantial rise in the index from 1932 to 1937 to 315.4. Keynes' aggressive approach caught up with him as Britain prepared for World War II in 19381940, when the index fell to 179.9. Then, during the war, 1941-1945, Keynes had a strong record. 


\section{Figure 6.1. Performance of Keynes' Chest \\ Fund, 1927-45}

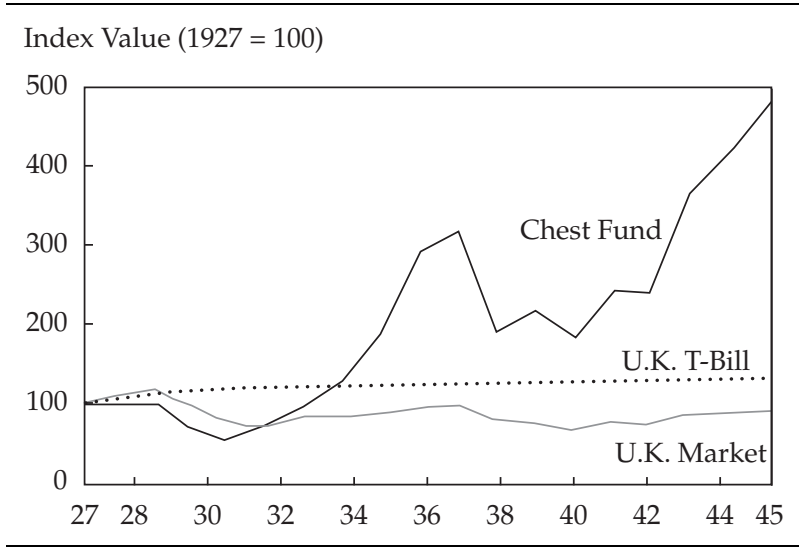

Keynes' turning 100 into 480.3 in 18 years, versus 85.2 for the index, plus dividends and interest given to the College, gives Keynes a good record as a hedge fund manager. Keynes' aggressive style (which is similar to the Kelly betting I discuss later) led to great returns-and some losses and embarrassments. When a grain contract was not covered in time, Keynes had to take delivery and fill up the famous King's College chapel, which was fortunately large enough to store the grain safely until it could be sold. The Sharpe ratios and CAPM results are based on normality, and a better way to calculate Keynes' B's is through Leland's (1999) B's (discussed in Chapter 1), which applies for the fat tails that Keynes had. For example, Keynes' aggressive style is close to log utility, so a relative risk aversion, $\gamma$, of 1.25 approximates his behavior, compared with $1 / \gamma=80$ percent in the log optimal portfolio and 20 percent in cash.

\section{Gamblers as Hedge Fund Managers}

I have been fortunate to work and consult with four individuals who used investment market anomalies and imperfections and hedge funds ideas to turn a humble beginning with essentially zero wealth into hundreds of millions of dollars. They shared several common characteristics-a gambling background obtained by playing blackjack professionally; a focused, fully researched, computerized system for asset-position selection; and careful attention to the possibility of loss-and focused more on not losing than on winning. Two were relative value long-short managers who consistently eked out small edges. One was a futures trader who took bets on a large number of liquid financial assets based on favorable trends (interest rates, bonds, and currencies were the best). The fourth was a Hong Kong horserace bettor (see 
Benter in Hausch, Lo, and Ziemba 1994). Their gambling backgrounds led them to conservative investment behavior and excellent results, both absolute and risk adjusted. They had their losses, but rarely did they overbet or lack sufficient diversification. Good systems for diversification and bet size, as discussed in this chapter and the rest of this monograph, were crucial in avoiding major blowouts.

Edward Thorp, a mathematician with a $\mathrm{PhD}$ from the University of California at Los Angeles, became famous in 1960 after devising a simple-touse card-counting system for use in the card game blackjack. In 1966, Thorp wrote a follow-up to his book Beat the Dealer called Beat the Market, which outline a system for obtaining edges in warrant markets. Thorp was close to finding the Black-Scholes formula for pricing options, at least from an approximate, empirical, and discrete-time point of view, and some of his ideas were used in his hedge fund Princeton Newport Partners (PNP). ${ }^{1}$ He ran this fund, with offices in Newport Beach, California, and Princeton, New Jersey, from 1969 to 1988 and used a variety of strategies, many of which can be classified as convergence or long-short strategies. See Figure 6.2 and Table 6.2 for PNP's performance record. Actual trades and positions used by Thorp and his colleagues are not public information, but a Nikkei put warrant risk-arbitrage trade that Thorp and I jointly executed based on my ideas discussed in Appendix E gives some idea of the approach. ${ }^{2}$ The basic idea is to sell $A$ at an expensive price, hedge it with the much cheaper close substitute $A^{\prime}$, and then wait until the prices converge and cash out, remembering not to overbet.

PNP gained 15.1 percent, net of fees (which were about 4 percent given the 20 percent profit fee structure), versus 10.2 percent for the S\&P 500 and 8.1 percent for T-bills. An initial index of 100 on 1 November 1969 became 148,200 at the end of December 1988 versus 64,500 for the S\&P 500 and 44,500 for T-bills. But what is impressive and a central lesson of this chapter is that the risk control, by using various stochastic optimization procedures, led to no years with losses and a high Sharpe ratio, which, based on monthly data, approached 3.0. Of course, Thorp had an easier market to deal with than Keynes. For example, the S\&P 500 had negative returns only in 1973, 1974, and 1976.

1Thorp wrote the foreword to my book, Beat the Racetrack written with Donald Hausch. By using probabilities estimated from the simpler win market, we provided a simple-to-use winning system for racetrack betting based on weak market inefficiencies in the complex place and show markets.

2See Appendix E (p. 37), which is available online in the Supplementary Material area at www.aimrpubs.org/rf/issues/v2003n6/pdf/AppendixE.pdf. 


\section{Figure 6.2. PNP's Cumulative Results, November 1968-December 1988}

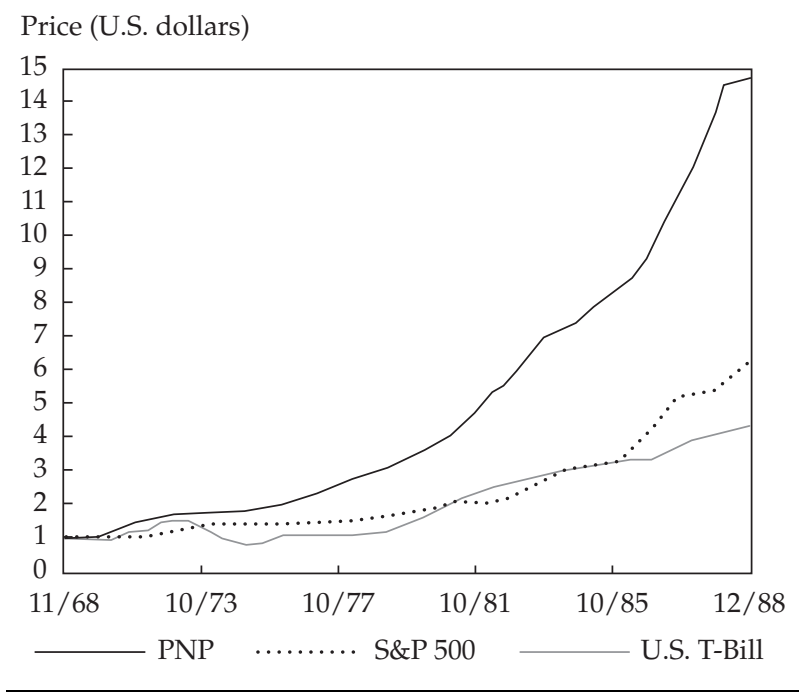

As a comparison with Keynes' and Thorp's performance, Figure 6.3 shows the brilliant record of Warren Buffett's Berkshire Hathaway closed-end fund from December 1985 to June 2000, which is run like a hedge fund with an emphasis on value investing, insurance businesses, and other ventures. Buffett also had a great record from 1977 to 1985, turning the index value of 100 into 1,429.87 in 1985 and 65,852.40 in April 2000. This graph also shows the records of George Soros' Quantum Fund, John Neff's Windsor Fund, Julian Robertson's Tiger Fund, and the Ford Foundation. ${ }^{3}$

Capital growth or Kelly criterion fans, such as Thorp and I, prefer Buffett's long-term growth record. Indeed, Thorp (1997) has argued that Buffett largely uses Kelly-like strategies. Keynes and Buffett have many common characteristics in addition to their aggressive style, namely, an emphasis on value, large holdings, and patience.

From January 1980 to March 2000, Buffett's Sharpe ratio was 0.786, whereas the Ford Foundation's was 0.818 . So, by the Sharpe ratio measure, the Ford Foundation beat Berkshire Hathaway because it had good growth with little variation. But much of Berkshire Hathaway's variation was on gains, and the total wealth at the horizon was much greater. Using the symmetric downside risk measure discussed in Chapter 1 provides a fairer evaluation-with

3Thanks go to Larry Siegel of the Ford Foundation for these data. 
Table 6.2. PNP's Record, 1969-1988

\begin{tabular}{|c|c|c|c|c|c|c|c|c|}
\hline $\begin{array}{l}\text { Begin } \\
\text { Period }\end{array}$ & $\begin{array}{l}\text { End } \\
\text { Period }\end{array}$ & $\begin{array}{c}\text { Begin Capital } \\
\text { (US\$ } \\
\text { thousands) }\end{array}$ & $\begin{array}{c}\text { Profit/Loss } \\
\text { (US\$ } \\
\text { thousands) }\end{array}$ & $\begin{array}{c}\text { End Capital } \\
\text { (US\$ } \\
\text { thousands) }\end{array}$ & $\begin{array}{c}\text { Added Capital } \\
\text { (US\$ } \\
\text { thousands) }\end{array}$ & $\begin{array}{c}\text { PNP } \\
\text { Return } \\
(\%)\end{array}$ & $\begin{array}{l}\text { S\&P } 500 \\
\text { Return } \\
(\%)\end{array}$ & $\begin{array}{c}\text { 3-Month } \\
\text { T-Bill Return } \\
\text { (\%) }\end{array}$ \\
\hline $1 / \mathrm{Nov} / 69$ & $31 / \mathrm{Dec} / 69$ & 1,400 & 57 & 1,457 & 544 & 4.1 & 4.7 & 3.0 \\
\hline 1/Jan/70 & $31 / \mathrm{Dec} / 70$ & 2,001 & 364 & 2,365 & 737 & 18.2 & 4.0 & 6.2 \\
\hline 1/Jan/71 & $31 / \mathrm{Dec} / 71$ & 3,102 & 1,281 & 4,383 & 1,944 & 41.3 & 14.3 & 4.4 \\
\hline 1/Jan/72 & 31/Dec/72 & 6,327 & 1,046 & 7,373 & 1,134 & 16.5 & 19.0 & 4.6 \\
\hline 1/Jan/73 & 31/Dec/73 & 8,507 & 711 & 9,218 & $(2,550)$ & 8.4 & -14.7 & 7.5 \\
\hline 1/Jan/74 & 31/Dec/74 & 6,668 & 751 & 7,419 & (70) & 11.3 & -26.5 & 7.9 \\
\hline 1/Jan/75 & $31 / \mathrm{Oct} / 75$ & 7,349 & 961 & 8,310 & 596 & 13.1 & 34.3 & 5.1 \\
\hline $1 / \mathrm{Nov} / 75$ & $31 /$ Oct/76 & 8,906 & 1,793 & 10,699 & 1,106 & 20.1 & 20.1 & 5.2 \\
\hline $1 /$ Nov/76 & $31 /$ Oct/77 & 11,805 & 2,350 & 14,155 & 3,843 & 19.9 & -6.2 & 5.5 \\
\hline $1 /$ Nov/77 & $31 / \mathrm{Oct} / 78$ & 17,998 & 2,797 & 20,795 & (635) & 15.5 & 6.4 & 7.4 \\
\hline $1 /$ Nov/78 & 31/Oct/79 & 20,160 & 4,122 & 24,282 & 4,349 & 20.4 & 15.3 & 10.9 \\
\hline 1/Nov/79 & $31 / \mathrm{Oct} / 80$ & 28,631 & 7,950 & 36,581 & 9,728 & 27.8 & 21.4 & 12.0 \\
\hline $1 / \mathrm{Nov} / 80$ & 31/Oct/81 & 46,309 & 13,227 & 59,536 & 2,343 & 28.6 & 22.8 & 16.0 \\
\hline 1/Nov/81 & $31 /$ Oct/82 & 61,879 & 18,747 & 80,626 & 18,235 & 30.3 & 21.8 & 12.1 \\
\hline $1 /$ Nov/82 & $31 /$ Oct/83 & 98,861 & 13,842 & 112,703 & 26,342 & 14.0 & 10.5 & 9.1 \\
\hline $1 /$ Nov/83 & $31 /$ Oct/84 & 139,045 & 20,193 & 159,238 & $(6,195)$ & 14.5 & 11.6 & 10.4 \\
\hline $1 / \mathrm{Nov} / 84$ & 31/Oct/85 & 153,043 & 21,813 & 174,856 & $(40,244)$ & 14.3 & 11.4 & 8.0 \\
\hline $1 /$ Nov/85 & $31 / \mathrm{Oct} / 86$ & 134,612 & 41,143 & 175,755 & $(21,727)$ & 30.6 & 24.5 & 6.3 \\
\hline $1 /$ Nov/86 & 31/Dec/87 & 154,028 & 52,451 & 206,479 & 17,722 & 34.1 & 26.7 & 7.1 \\
\hline \multirow[t]{3}{*}{ 1/Jan/88 } & 31/Dec/88 & 224,201 & 8,918 & 233,119 & $(232,118)$ & 4.0 & 3.2 & 7.4 \\
\hline & & & & & & $1,382.0$ & 545.5 & 345.0 \\
\hline & & & & & & 15.10 & 10.2 & 8.1 \\
\hline
\end{tabular}

Berkshire Hathaway dominating, as Figure 6.3 indicates. Starting from July 1977, Berkshire Hathaway's Sharpe ratio was 0.850 versus Ford's 0.765, and the S\&P's was 0.676, and geometric mean returns were 32.07 percent (Berkshire Hathaway), 14.88 percent (Ford), and 16.71 percent (S\&P 500).

\section{Typical Hedge Fund Trades}

Hedge funds and others have many possible trades, and they can be made in combination. Following are a few typical pure trades that allow for analysis of gain-and-loss functions, scenarios, and so on.

The Yen Carry Trade. Start with $\$ U S$ cash.

- Use this cash as collateral to borrow $¥ Y @ y_{0}$ (JPY/USD) exchange rate, so you owe about $1 / 2$ percent per year on this $¥ Y$ because Japanese interest rates are very low.

- Change the $¥ Y$ into $Y / y_{0}$ US\$. 


\section{Figure 6.3. Growth of Assets for Various High-Performing Funds,} December 1985-June 2000

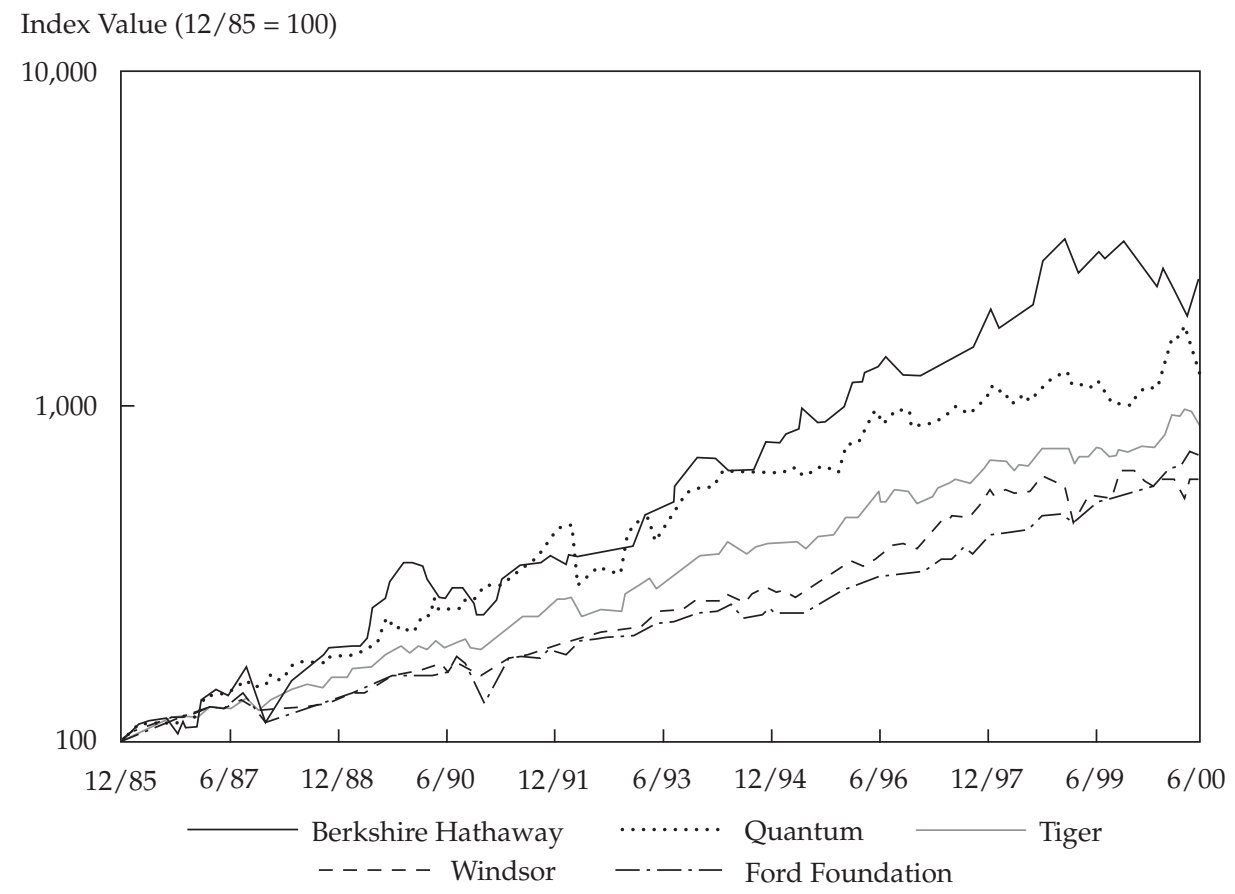

- Buy US\$ assets that have a yearly return greater than $1 / 2$ percent plus the loss on JPY/USD exchange rate moves. A typical investment is in U.S. 10- or 30-year Treasuries.

- Receive $i=5-6$ percent in fixed-income payments.

- Plus, receive the gain in the value of the bond if interest rates drop (Warren Buffett made billions on this one-way [macro] bet with zeros in 1998).

This trade was a big money maker for hedge funds when the yen was falling against the U.S. dollar from mid-1995 to 1998 and interest rates, $i$, were falling as well. The profit function is

$$
\begin{array}{clll}
\pi=i \frac{Y}{y_{0}}+\phi\left(i_{0}-i\right) \frac{Y}{y_{0}}+\left(\frac{Y}{y}-\frac{Y}{y_{0}}\right) & -0.005 Y \\
\uparrow & \uparrow & \uparrow & \multicolumn{1}{c}{\uparrow} \\
\text { Coupon } & \text { Gain or } & \text { Gain or } & \text { Pay interest } \\
\text { interest } & \text { loss } & \text { loss } & \text { on borrowed } \\
\text { on T-bonds } & \text { on bonds } & \text { on yen } & \text { yen }
\end{array} .
$$


The two shocks in July 1998 and September 1998 shown in Figure 6.4, which were plausible but low-probability scenarios, led to considerable losses for holders of such trades who did not quickly neutralize their positions through stops or other actions. In July 1998, there was U.S. coordinated intervention in the yen market (Panel A). In September 1998, there was a hedge fund unwinding disaster associated with the LTCM failure and associated trades in other hedge funds that had to be closed out to cover losses elsewhere (Panels B and C, which has interest rates).

To model the profit function, one needs scenarios on:

1. Where are long-term interest rates $(i)$ going?

2. Where is the JPY/USD exchange rate $(y)$ going?

In addition, unforeseen factors include:

1. Intervention, which is always a danger and may or may not be signaled by market actions; and

Figure 6.4. Two Shocks and U.S. Coordinated Intervention, 1998

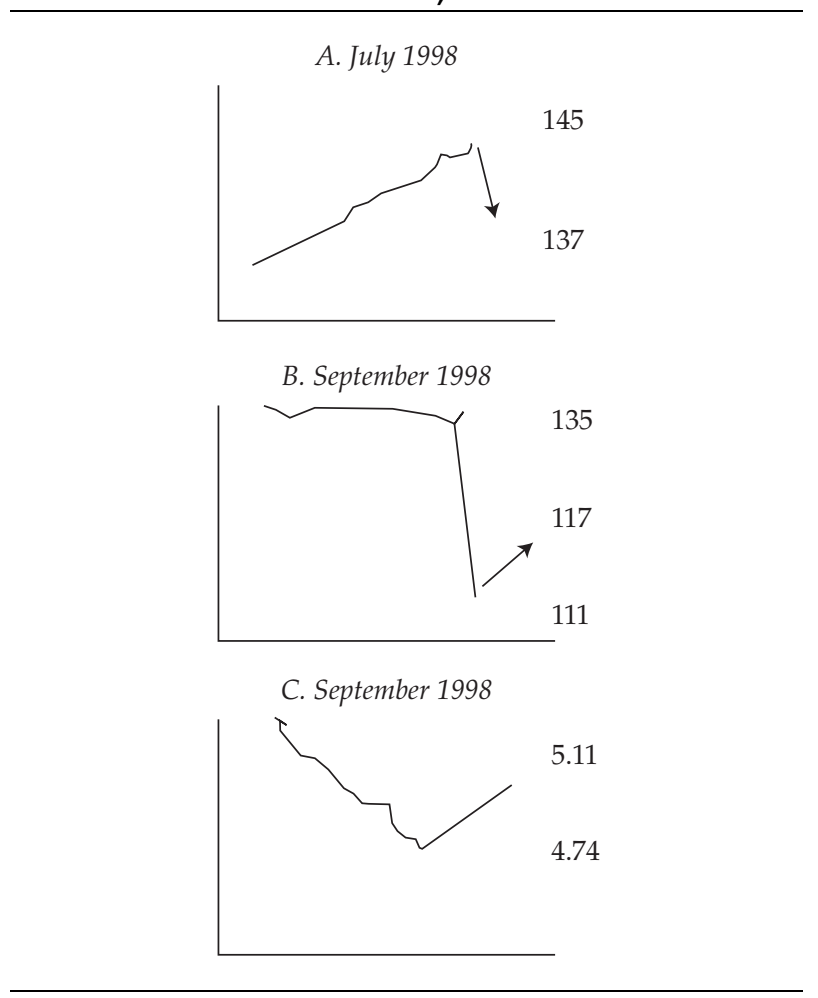


2. hedge funds in trouble may need to unwind other trades to raise cash, which serves as a reminder of another danger in today's markets. One derivative disaster can lead to others because hedge fund traders have intertwined positions; raising cash to deal with one disaster can create another one for someone else.

Hence, investors must diversify: Investors cannot have too much invested in any one strategy and should use protective procedures, such as stops, to limit losses. ${ }^{4}$ A multiperiod stochastic programming model is useful here.

Volatility and Spread Trading, Long-Short across Countries. Perhaps the most common hedge fund equity trade is through spreads. These trades can be long-short (possibly market neutral, zero beta) across stocks, country indexes, or groups of stocks or futures contracts. They can be modeled with scenarios for the longs and shorts, with risk control through stops. The key is not to overbet.

Investment in T-Bills or Other High-Yield Instruments in Countries with High Interest Rates. The idea is to collect more interest than one loses from slow, steady currency depreciation and to avoid a large loss from a sudden devaluation. The trade is based on the concept that in such countries, interest rates exceed the devaluation rates and large devaluations are partially predictable from foreign reserve and other economic variables.

Let $X$ be the initial investment in U.S. dollars and $X_{i t}$ the amount converted into country $i$ 's currency at time $t$, where $X=\sum_{t=1}^{T} \sum_{i=1}^{I_{t}} X_{i t}$. The present value of U.S. money in period $t$ is $c_{t}$, so the total investment is $I=\sum_{t=1}^{T}\left(1+c_{t}\right) \sum_{i=1}^{I_{t}} X_{i t}$. The return in currency $i$ from the $x_{i t}$ invested in country $i$ during period $t$ to $t+1$ is $r_{i t}$, and the exchange rate into currency $i$ is $e_{i t}$ at time $t$. Hence, the profit from all the investments in the $T$ periods is the return minus the investment, namely,

$$
\pi=\sum_{t=1}^{T} \sum_{i=1}^{I_{t}} \frac{r_{i t} X_{i t} e_{i t}}{e_{i t}}-\sum_{t=1}^{T}\left(i+c_{t}\right) \sum_{i=1}^{I_{t}} X_{i t},
$$

for some given scenario. But investors must average over scenarios and diversify so that the effect of bad scenarios is not disastrous. The main uncertainty is in the $e_{i t}$ 's. Assume that in the period from $t$ to $t+1, e_{1 t}, \ldots, e_{I t}$

\footnotetext{
4The setting of stop losses is largely an art with little good theory behind it because the problem is complicated. A useful recent paper is Warburton and Zhang (2002).
} 
has the joint distribution function $F_{t}\left(e_{1 t}, \ldots, e_{I t}\right)$, where the $F_{t}$ 's have some dependency. There is also uncertainty in the $r_{i t}$ 's and the $c_{t}$ 's represented by $G_{t}\left(r_{1 t}, \ldots, r_{I t}\right.$ and $H_{t}\left(C_{t}\right)$, respectively. The $F_{t}$ 's and $G_{t}$ 's are highly related because high interest rates in country $i$ at time $t$ are a signal that the expected devaluation during $t$ to $t+1$ is also high. The $h_{t}$ 's may be related as well because of two main effects-worldwide interest rate levels and movements and the economic situation in various countries at this time.

I first started going to Turkey in 1970, when the exchange rate was 7 Turkish lira to the U.S. dollar; in March 2003, it hit 1.746 million. According to Berument (2001), inflation typically ranged from 40 to 120 percent a year, averaging 52.3 percent from 1975 to 2000 . Interest rates in 2003 were in the 60-70 percent range (see Figure 6.5 for 1998-2003 interest rates and inflation). As an oriental rug trader and author (see Ziemba, Akatay, and Schwartz, 1979, which was one of the first books about Turkish kilims and flatweaves), I was well aware, as were the rug dealers, that such assets should be priced in hard currencies, such as the German mark or U.S. dollar. 5 Still, with the astronomical devaluation over the past 32 years, hedge fund investors who changed U.S. dollars into lira and collected T-bill interest made profits when they converted the money back to U.S. dollars. Those who were able to predict the large currency devaluations based on economic factors, such as foreign reserves, had even higher gains.

This strategy has been successful in a number of high-yield countries from time to time. The gains are risky, however, and can be lost with a sudden large devaluation. One such devaluation, which caused a Fidelity Investments fund manager to lose his job of managing a $\$ 10$ billion fund, happened in December 1994/January 1995 in Mexico. For several years, the manager's strategy returned 14-18 percent on Mexican T-bills, net a 2-4 percent average annual decline in the currency against the U.S. dollar, until the major December 1994 devaluation that occurred largely because Mexico's foreign currency reserves declined sharply to low levels. Judging such a changing economic environment is difficult, and even the enormous resources of Fidelity did not allow the manager to obtain sufficient information to exit the Mexican position before the major devaluation occurred.

\section{How to Lose Money in Derivatives}

The derivative industry deals with products in which zero-sum games are the norm-what one party gains the other party loses. Hence, there are bound to

\footnotetext{
$5 \mathrm{My}$ analysis was intuitive, but for a learned analysis of the politics of currency unions, currency boards, and case studies of Turkey, Montenegro, Argentina and Ecuador, see R. Ziemba (2003).
} 


\section{Figure 6.5. Turkish Interest Rates and Inflation, 1998-2003}

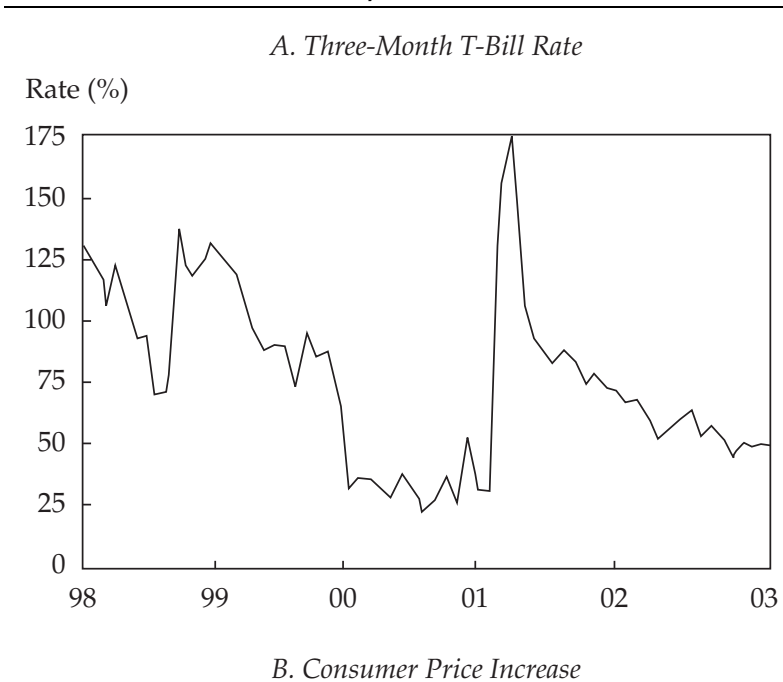

Price Increase from a Year Ago (\%)

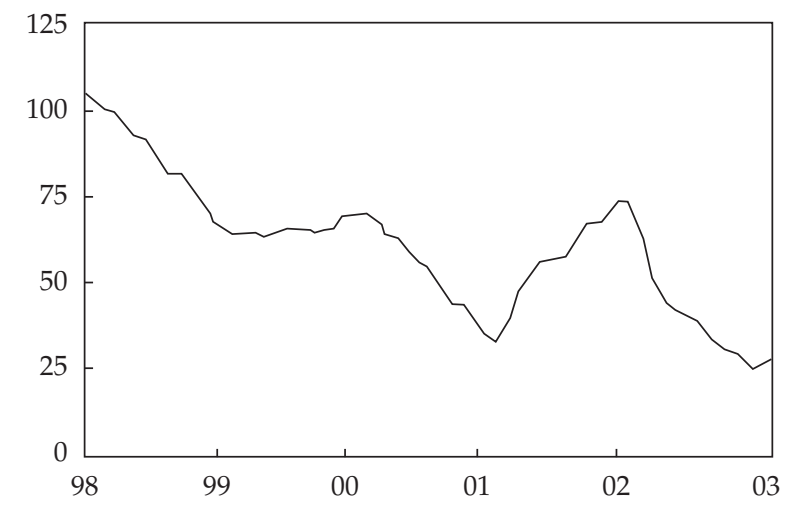

Note: 2003 data through May.

be large winners and large losers. The size of the gains and losses are magnified by the leverage and overbetting, which invariably lead to large losses when a bad scenario occurs.

Who loses in derivative disasters? This monograph is concerned with procedures to avoid or limit financial disasters that occur because the investor is not properly diversified or financed. Miller (1996) discussed the social costs of various derivative disasters and took the view that in most cases, such disasters are a zero-sum situation in which one side's loss is the other side's 
gain. Indirect social costs, such as bankruptcy, are present, but because the institutions and physical assets, such as buildings, are likely to survive, their impact is small. Hence, Miller argues, more regulation is not needed; rather, "more understanding by top management of how to manage risk (and less hubris on the part of . . . treasurers convinced they could forecast interest rates" is needed.

Figlewski (1994) categorized derivative disasters as follows:

1. Hedge. In an ordinary hedge, one loses money on one side of the transaction in an effort to reduce risk. The correct way to evaluate the performance of a hedge is to consider all aspects of the transaction. In sophisticated hedges, where one delta hedges but is a net seller of options, there is volatility (gamma) risk, which can lead to losses if prices move much up or down. Also, accounting problems can lead to losses if gains and losses on all sides of a derivative hedge are recorded in the firm's financial statements at the same time.

2. Counterparty default. Credit risk is the fastest growing area of derivatives, and a common hedge fund strategy is to be short overpriced credit default derivatives. There are many ways to lose on these shorts if they are not hedged properly, even if they have an edge.

3. Speculation. Derivatives have many purposes, including transferring risk from those who do not wish to have it (hedgers) to those who do (speculators). Speculators who take naked unhedged positions take the purest bet and win or lose monies related to the size of the move of the underlying security. Bets on currencies, interest rates, bonds, or stock market moves are leading examples.

Human agency problems frequently lead to large losses for traders holding losing positions, which, if cashed out, would lead to lost jobs or bonuses. Some traders, whose motivations are largely driven by shortterm performance targets (which if not met will result in losing client money) will increase exposure exactly when they should reduce it in the hope that a market turnaround will allow them to cash out with a small gain before their superiors find out about the true situation and force them to liquidate. Because the job or bonus is already lost, the trader's interests are in conflict with the firm's and huge losses may occur. Writing options, which typically gain small profits most of the time, is a common vehicle for this problem because the size of the position accelerates quickly as the underlying security moves in the wrong direction. Because trades between large institutions frequently are not collateralized market to market, large paper losses can accumulate without visible signs, such as a margin call. Nick Leeson's loss betting on short puts and calls on the Nikkei Stock Average is one of many such examples. The 1995 Kobe earthquake in Japan was the bad scenario that bankrupted Barings Bank. 
A proper accounting of trading success is to evaluate all gains and losses so that the extent of some current loss can be weighed against previous gains. Derivative losses should also be compared with losses on underlying securities. For example, from 3 January to 30 June 1994, 30year T-bonds fell 13.6 percent. Hence, holders of bonds lost considerable sums as well because interest rates rose quickly.

4. Forced liquidation at unfavorable prices. Gap moves through stops are one example of forced liquidation. Portfolio insurance strategies based on selling futures during the 18 October 1987 stock market crash were unable to keep up with the rapidly declining market, whose futures fell 29 percent that day. Forced liquidation stemming from margin problems is even more difficult when others have similar positions and predicaments. The August 1998 problems of LTCM in bond and other markets were made more difficult because others had followed their lead with similar positions. When trouble arose, buyers were scarce and sellers were everywhere. Another example is Metallgellschaft's crude oil futures hedging losses of more than $\$ 1.3$ billion. The company had long-term contracts to supply oil at fixed prices for several years-a similar problem to the insurance guarantees discussed in Chapter 3. These commitments were hedged with long oil futures. But when spot oil prices fell rapidly, the contracts to sell oil at high prices rose in value but did not provide current cash to cover the mark-to-market futures losses. A management error led to the unwinding of the hedge near the bottom of the oil market and the disaster.

Potential problems are greater in illiquid markets. Such positions are typically long term, and liquidation must be done by matching sales with available buyers. Hence, forced liquidation can lead to large bid-ask spreads. Askin Capital Management's failure in the bond market in 1994 was exacerbated because it held sophisticated securities that were traded only by a few counterparties; once they learned of Askin's liquidity problems and weak bargaining position, they further lowered their bids. The firm was then able to gain large liquidity premiums.

5. Misunderstanding the risk exposure. As derivative securities have become more complex, so has investors' understanding of them. The Nikkei put warrant risk-arbitrage trade I mentioned was successful because Thorp and I had done a careful analysis to fairly price the securities. ${ }^{6}$ In many cases, losses are the result of unsophisticated investors' trading in highrisk financial instruments. Lawsuits have arisen by investors attempting

${ }^{6}$ See the discussion of this trade in Appendix E (p. 37), which is available online in the Supplementary Material area at www.aimrpubs.org/rf/issues/v2003n6/pdf/AppendixE.pdf. 
to recover some of their losses; they claim that they were misled or not properly briefed concerning the risks of the positions taken. Because the general public, and thus judges and juries, find derivatives confusing and risky even when they are used to reduce risk, such cases or the threat of them may be successful.

A great risk exposure is the extreme scenario that investors assume has zero probability but in fact has low but positive probability. Investors are frequently unprepared for interest rate, currency, or stock price changes so large and so fast that they are considered to be impossible to occur. The move of some bond interest rate spreads from 3 percent a year earlier to 17 percent in August/September 1998 led even the savvy investor and sophisticated LTCM researchers and traders down this road. Their extensive stress testing failed; the extreme events, such as the August 1998 Russian default, had both the extreme low-probability event plus the changing correlations. As argued in this monograph, scenariodependent correlation matrixes, rather than simulation around the past correlations, is suggested. This strategy was implemented, for example, in the Innovest pension plan model, discussed in Chapter 4, which did not involve levered derivative positions. The key for staying out of trouble, especially with highly levered positions, is to fully consider the range of possible future outcomes and to have enough capital, or access to capital, to weather bad scenario storms so that any required liquidation can be done in an orderly manner.

Figlewski (1994) noted that the risk in mortgage-backed securities is especially difficult to understand. Interest-only securities (IOs), which provide only a share of the interest as part of the underlying mortgage pool's payment stream, are a good example. When interest rates rise, IOs rise because payments are reduced and the stream of interest payments is larger. But when rates rise sharply, IOs fall in value like other fixedincome instruments because the future interest payments are more heavily discounted. This sign-changing interest rate exposure was one of the difficulties in Askin's losses in 1994. Similarly, the sign change between stocks and bonds during stock market crashes, as in 2000 to 2003, has caused other similar losses. Scenario-dependent matrixes are especially useful and needed in such situations.

6. Forgetting that high returns involve high risk. If investors seek high returns, then they will usually have some large losses. The Kelly criterion strategy and its variants in this chapter provide a theory to achieve high long-term returns, but large losses will also occur. These losses are magnified with derivative securities, especially with large derivative positions in relation to the investor's available capital. 
Stochastic programming models, such as those discussed in this monograph, provide a good way to try to avoid problems $1-6$ by carefully modeling the situation at hand and considering the possible economic futures in an organized way.

\section{The Failure of LTCM}

Of the many hedge fund failures, LTCM stands out as a particularly public one. The firm started with the talents of the core bond traders from John Meriwether's group at Salomon Brothers, who were successful for a number of years. When Warren Buffett came on board at Salomon, the culture of this group clashed with Buffett's apparently more conservative style, although in truth, Buffett's record is Kelly-like and not all that different from Meriwether's group. A new group was formed with an all-star cast of top academics, including two future Nobel Laureates and a number of top professors and students, many of whom were linked to Massachusetts Institute of Technology. In addition, top government officials were involved. The team was dubbed as being "too smart to lose," and several billion was raised, despite the lack of a real track record; fees were high (25 percent of profits), and entry investment (\$100 million minimum) was also high. The idea, according to Myron Scholes, was to be a big vacuum cleaner, sucking up nickels all over the world.

There were many types of trades, but the essence of the bond risk arbitrage was to buy underpriced bonds in various locales and sell overpriced bonds in other locales and then wait for the prices to revert to their theoretical efficient market prices and unwind the position. These trades were similar to the Nikkei put warrant risk-arbitrage trade that Thorp and I did, only LTCM used much more leverage. I call such bond trades "buy Italy and sell Florence" trades. As shown in Figure 6.6, the interest rate implied by the bond prices is higher in Italy than in Florence. But the theory is that Florence, a smaller city, would have more risk. Hence, the trade should have an advantage and be unwound once the prices revert to their true risk-priced values.

LTCM analysts made many such trades, most of which were much more complex, all around the world. They also had many other complex and innovative trades. Their belief that markets were efficient and would snap back quickly when temporarily out of whack and the continuous lognormal assumptions of option-pricing hedging led them to take large positions that, according to their theory, were close to riskless. The plan worked. Net returns for the part of 1994 that the fund operated were 19.9 percent. The fund had superb results in 1995 and 1996, with returns of 42.8 percent and 40.8 percent, respectively. Indeed, for the principals whose money grew fee-less, the net returns were 63 percent and 57 percent, respectively, with taxes deferred. By 1997, however, it became harder to find profitable trades and the gains fell to 17.1 percent. 


\section{Figure 6.6. "Buy Italy, Sell Florence" Trades}

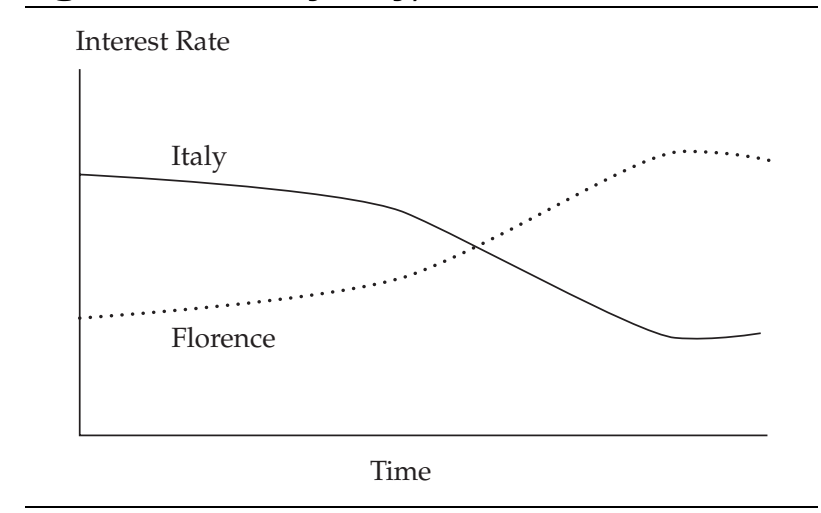

Although a good record for most, it was not satisfactory to LTCM's principals. The action was to return US\$2.7 billion of the US\$6.7 billion investor money and to put in an additional US\$100 million of personal loans to the principals from banks. Banks and most others were keen to loan to or invest with this group, and investors were not happy to leave the fund. The difficulties in 1998 were exacerbated by the 17 August Russian ruble devaluation and bond default. Russian bonds denominated in rubles trading for, say, 60 rubles fell rapidly to 3 rubles, whereas Russian bonds denominated in German marks or dollars fell only a few percent because they were not subject to default. So, long 60/short 95, say, became long 3/short 92 .

Such losses occur from time to time in various markets, and hedge funds that overbet are vulnerable. LTCM had US\$1.25 trillion in positions (i.e., about 1 percent of the current [May 2003] value of the world's derivatives and an even higher percentage in 1998) and US\$125 billion in borrowed money, but although the trades were all over the world and hence seemed to be diversified, they were not. As a result, a scenario-dependent correlation situation occurred, such as that modeled in the Innovest pension application in Chapter 4. The underlying variable that frequently rears its ugly head in disasters-investor confidence-played a role. As shown in Figure 6.7, from August to October 1998, the difference in high-yield bond rates and U.S. Treasury rates increased from roughly 4 percent to 6 percent. For example, emerging market debt was trading for 3.3 percent above U.S. T-bonds in October 1997, 6 percent in July 1998, and then an astounding 17 percent in September 1998.

LTCM was unable to weather the storm of this enormous crisis of confidence and lost about 95 percent of its US\$4 billion, including most of the principals' and employees' considerable accumulated fees. The US\$100 million loan put some of them into bankruptcy, although others came out better 


\section{Figure 6.7. Difference in Yields between High-Yield Bonds and U.S. Treasuries, 1998}

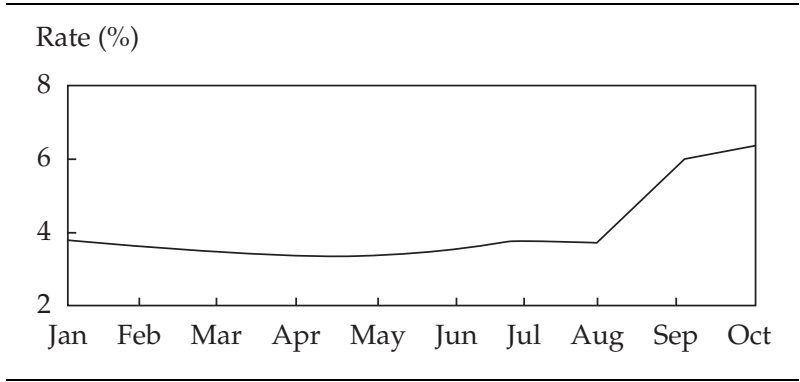

Source: Based on data from Salomon Smith Barney.

financially. It did not help that they unwound liquid positions first rather than across all liquidity levels, as the Nobel Laureates recommended. Nor did it help that many other copycat firms had similar positions; that LTCM had created enemies by being so good and so brash; that the lack of monitoring of margin by brokers eager for business allowed the positions to grow to way overbet dangerous levels; and that the $\$ 2.8$ billion was gone and they could not draw on it when it was most needed. ${ }^{7}$ Smart people bounce back and learn from their mistakes, as has this group of traders with new hedge funds and other ventures. The lessons for the purposes of this monograph are:

- Do not overbet, it is too dangerous.

- VAR-type systems are inadequate to measure true risk, but see Jorion's (2000b) book on VAR and Dunbar's (2000) discussion of the VAR calculations used by LTCM. LTCM analysts did a careful analysis, but the problem was that the risk-control method of VAR used in regulations does not protect highly levered hedge funds; you are not penalized enough for large losses. Indeed, if you lose US\$10 million, it is penalized the same as losing US\$100 million if the VAR number is US\$9 million of losses. LTCM was not subject to VAR regulations but still used it. What you really need are convex penalties so that penalties are more than proportional to losses.

- Be aware of and consider extreme scenarios.

- Allow for extra illiquidity and contract defaults. LTCM also suffered because of the copycat firms that put on similar positions and unwound them at the same time in August/September 1998.

\footnotetext{
7In the section that follows on the Kelly criterion, I argue that investors should never bet more than the log optimal amount and betting more (as LTCM did) is stochastically dominated because of lower growth rates and higher risk.
} 
- Really diversify (as Soros said, we risked 10 percent of our funds in Russia and lost it, US\$2 billion, but we were still up 21 percent in 1998).

- Historical correlations work when you do not need them and fail when you need them in a crisis when they approach 1.0. Real correlations are scenario dependent.

Good information on the demise of LTCM and the subsequent US\$3.5 billion bailout by major brokerage firms that was organized by the Fed are in Perold (1999), Jorion (2000a) and Edwards (1999). Eventually, the positions converged and the bailout team was able to emerge with a profit on its investment.

The Russian ruble devaluation of some two-thirds was no surprise to me. In 1992, my family and I were in St. Petersburg as guests of Professor Zari Rachev, an expert in stable and heavy-tail distributions (see Rachev 2003). As we arrived, I gave him a $\$ 100$ bill and he gave me six inches of 25 ruble notes. Our dinner out cost two inches for the four of us, and drinks were extra in hard currency. So, I am in the Soros camp: Make bets in Russia if you have an edge but do not risk too much of your wealth.

Where was the money lost? The score card, according to Dunbar, was a loss of US\$4.6 billion. Emerging market trades, such as those similar to my "buy Italy, sell Florence” trades, lost US\$430 million. Directional, macro trades lost US\$371 million. Equity pairs trading lost US\$306 million. Short long-term equity options, long short-term equity lost US\$1.314 billion. Fixed-income arbitrage lost US\$1.628 billion

The bad scenario of investor confidence that led to much higher interest rates for lower-quality debt and much higher implied equity volatility had a serious effect on all the trades. The long-short equity option trades, largely in the CAC40 and Dax equity indexes, were based on a historical volatility of about 15 percent versus implied volatilities of about 22 percent. Unfortunately, in the bad scenario, the implieds reached 30 percent and then 40 percent. With smaller positions, the fund could have waited it out, but with such huge levered positions, it could not. Equity implieds can reach 70 percent or higher, as Japan's Nikkei Stock Average did in 1990-1991, and stay there for many months.

\section{The Imported Crash of 27 and 28 October 1997}

A currency crisis developed in various Asian countries in mid-1997. It started in Thailand and moved all across the region. The problem was lack of foreign reserves, which occurred because spending and expectations that had led to borrowing were too high and Japan, the main driver of these economies, was facing a consumer slowdown and its imports had dropped. Also, loans were denominated in what was then considered a weak currency, the U.S. dollar; 
these countries were thus effectively long yen and short dollars. A large increase in the U.S. currency in yen terms exacerbated the crisis. The countries devalued their currencies, interest rates rose, and stock prices fell. A wellknown hedge fund failure in 1997 was Victor Niederhoffer's fund, which had an excellent previous record with only modest drawdowns. A large long bet on cheap Thai stocks that became cheaper and cheaper turned US\$120 million into US\$70 million. Buying on dips added to losses. Then, the fund created a large short position in out-of-the-money S\&P 500 futures index puts. A typical position was November 830 puts trading for about US\$4-6 at various times around August/September 1997.

The crisis devastated the small economies of Malaysia, Singapore, Indonesia, and so on. Finally, it spread to Hong Kong. There, the currency was pegged to the U.S. dollar at around 7.8. The peg was useful for Hong Kong's trade and was to be defended at all costs. The weapon used was higher interest rates, which almost always led to a stock market crash but with a lag. (See the discussion in Chapter 2.) The S\&P 500 was not in the danger zone in October 1997, by my models and I presume those of others, and the trade with Hong Kong and Asia was substantial but only a small part of U.S. trade. U.S. investors thought that this Asian currency crisis was a small problem because it did not affect Japan very much. In fact, Japan caused a lot of it. In my opinion, whenever a boom or bust occurs in Asia, look to Japan and you will likely find much of the cause there.

The week of October 20-25 was difficult, with the Hang Seng dropping sharply. The S\&P 500 was also shaky, so the November 830 puts were 60 cents on Monday, Tuesday, and Wednesday but rose to 1.20 on Thursday and 2.40 on Friday. The Hang Seng dropped more than 20 percent in a short period, including a 10 percent drop on Friday, October 25. The S\&P 500 was at 976, way above 830, as of Friday's close. A further 5 percent drop on Monday, October 27 in Hong Kong led to a panic in the S\&P 500 futures later on Monday in the United States. The fall was 7 percent, from 976 to 906 , which was still considerably above 830 . On Tuesday morning, there was a further fall of 3 percent to 876 , which still kept the 830 puts out of the money. The full fall in the S\&P 500 was then 10 percent.

But the volatility exploded and the 830 s were in the $\$ 16$ area. Refco called in Niederhoffer's puts in the midmorning. They took a loss of about US\$20 million. So Niederhoffer's US\$70 million fund was bankrupt and in the red because the large position in these puts and other instruments turned US\$70 million into-US $\$ 20$ million. The S\&P 500 bottomed out at around 876 , moved violently in a narrow range, and then settled and moved up by the end of the week to around 976 . So, it really was a tempest in a teapot. The November 
830 puts expired worthless. Investors who were short equity November 830 puts were required to put up so much margin that that they had to have small positions; they weathered the storm, and their US\$4-\$6, while temporarily behind at US\$16, did eventually go to zero. The futures puts went to zero as well, but futures shorters are not required to post as much margin; if they did not have adequate margin, it was because they had too many positions. They could have easily been forced to cover at a large loss. I argue that futures margins, at least for equity index products, do not fully capture the real risk inherent in these positions. I follow closely the academic studies on risk measures and none of them deal with this issue properly. When in doubt, always bet less. Niederhoffer is back in business after having profited by this experience.

One of my Vancouver neighbors, I learned later, lost US\$16 million in one account and US\$4 million in another account, the difference being the time given to cash out and cover the short puts. I was in this market also and won in the equity market and lost in futures. I learned how much margin you actually need in futures, a lesson I use now in trading for myself and in private accounts, which has been very profitable, with a few wrinkles to protect oneself. One of the naked strategies won 64 out of 65 times from 1985 to 2003. A hedged strategy had a 45 percent geometric mean, with 60 of 65 winners with the five ruled too risky by a cash, option-price danger control measure out of the 70 possible plays in those 18 years and a seven symmetric downside Sharpe (as discussed in Chapter 1).

The lessons for hedge funds are similar to those taught by LTCM. Do not overbet, do diversify, watch out for extreme scenarios. Even the measure to keep one out of potentially large falls (the 5 of 70 above) did not work in October 1997. That was an imported fear-induced crash, which was not really based on U.S. economics. My experience is that most crashes occur when interest rates relative to $\mathrm{P} / \mathrm{Es}$ are too high, as discussed in Chapter 2. A minicrash caused by some extraneous event can occur at any time. So, to protect oneself, derivative positions must not be too large or they must be hedged or have proper stop-loss provisions.

\section{The Kelly and Fractional Kelly Wagering Strategies}

In the mathematics of investing, the basic goal is to turn gambles (with negative expectations) into investments (with positive expectations) through the development of good playing strategies and intelligent wagers. Strategy development follows general principles but is somewhat different for each particular situation. The wagering, or money management, concepts apply to all games. The difference in application depends on the edge and the probability of 
winning. The size of the wager depends on the edge but much more so on the probability of winning, if one takes a long-run rate of growth of profit approach.

I will consider situations in which the player has an edge and develop playing strategies to exploit that edge. These are situations in which, on average, the player can win using a workable system. The analyses will use concepts from modern financial economics investment theory and related mathematical optimization, psychological, statistical, and computer techniques and apply them to gambling situations in order to yield profitable systems. This process frequently involves the identification of a security market imperfection or anomaly or partially predictable prices. Naturally, in gambling situations, all players cannot win, so the potential gain will depend on how good the system is, how well it is played, how many are using it or other profitable systems, and, most crucially, the risk control system in use. Not every game has a useful, favorable system by which one can make profits, on average. Consider, for example, baccarat or chemin de fer. Virtually every financial market, however, has strategies that can lead to winning investment situations.

Two considerations should be taken into account in the analysis of each situation: When should one bet and how much should be bet? These considerations may be referred to as "strategy development" and "money management." They are equally important. The strategy development aspect is fairly well understood by many people. The money management (risk control) element is more subtle, however, and errors in this area can lead to financial disasters. Using the capital growth/Kelly and fractional Kelly betting systems, I will discuss the basic theory of gambling/investing over time and apply it to blackjack, horseracing, lotteries, and futures trading.

The maximization of logarithmic utility as a desirable objective dates back at least to the letters from Daniel Bernoulli in the 1700s. In his view, log has smoothly declining marginal utility and is risk averse (i.e., concave). Log is a risky utility function, however, because its Arrow-Pratt absolute riskaversion index $\left[-u^{\prime \prime}(w) / u^{\prime}(w)\right]$ is $1 / w$, which for wealth $w$ at any reasonable level is essentially zero. I argue that log is the most risky utility function one should ever consider and betting more than that suggested by log is stochastically dominated.

Log utility is related to negative power utility, namely, $\alpha w^{\alpha}$ for parameter $\alpha<0$, because negative power converges to $\log$ when $\alpha \rightarrow 0$. Kelly (1956) discovered that log utility investors are in possession of the best utility function, provided they are long-run investors. The asymptotic rate of asset growth is

$$
G=\lim _{N \rightarrow \infty} \log \left(\frac{w_{N}}{w_{0}}\right)^{1 / N},
$$


$w_{N}$ is period $N$ 's wealth and $w_{0}$ is initial wealth. Consider Bernoulli trials that win +1 with probability, $p$, and lose -1 with probability $1-p$. If $M$ out of $N$ of these independent trials are won,

$$
w_{N}=w_{0}(1+f)^{M}(1-f)^{N-M},
$$

where $f$ is the fraction of the wealth bet in each period, then

$$
G(f)=\lim _{N \rightarrow \infty}\left[\frac{M}{N} \log (1+f)+\frac{N-M}{N} \log (1-f)\right],
$$

which by the strong law of large numbers is

$$
G(f)=p \log (1+f)+q \log (1-f)=\mathrm{E}(\log w),
$$

where E represents expectation. Hence, the criterion of maximizing the longrun exponential rate of asset growth is equivalent to maximizing the oneperiod expected logarithm of wealth. To maximize long-run (asymptotic) wealth, then, maximizing expected log is the way to do it period by period.

The optimal fractional bet, obtained by setting the derivative of $G(f)$ to zero, is $f *=p-q$, which is simply the investor's edge or expected gain on the bet. 8 If the bets are win $O+1$ or lose 1 (i.e., the odds are $O$ to 1 to win), then the optimal Kelly bet is $f *=(p-q / O)$ or the Edge/Odds. So edge is a mean concept and odds is a risk concept and the bettor wagers more with higher mean and less with higher risk.

In continuous time,

$$
f^{*}=\frac{\mu-r}{\sigma^{2}}=\frac{E d g e}{R i s k(o d d s)},
$$

with optimal growth rate

$$
G^{*}=\frac{1}{2}\left(\frac{\mu-r}{\sigma}\right)^{2}+r=\frac{1}{2}(\text { Sharpe ratio })^{2}+\text { Risk-free asset },
$$

where $\mu$ is the mean portfolio return, $r$ is the risk-free return, and $\sigma^{2}$ is the portfolio return variance.

Kelly bets can be large. Recall Bernoulli trials in which the bettor wins 1 or loses 1 with probabilities $p$ and $1-p$, respectively; then,

\footnotetext{
8 If there are two independent wagers and the size of the bets does not influence the odds, then an analytic expression can be derived (see Thorp 1997, pp. 19-20). In general, to solve for the optimal wagers in cases in which the bets influence the odds, there is dependence, or for cases with three or more wagers, one must solve a nonconvex linear program (see Ziemba and Hausch 1984 and 1987 for technique). This strategy gives the optimal wager and takes into account the effect of bets on the odds (prices).
} 


$\begin{array}{ccccccc}p & 0.5 & 0.51 & 0.6 & 0.8 & 0.9 & 0.99 \\ 1-p & 0.5 & 0.49 & 0.4 & 0.2 & 0.1 & 0.01 \\ f^{*} & 0.0 & 0.02 & 0.2 & 0.6 & 0.8 & 0.98\end{array}$

The bets $f *$ become larger and larger as the edge increases with constant risk. Hence, wealth grows on a bumpy path, as shown in the top line in Figure 6.8.

But the Kelly bettor is sure to win in the end if the horizon is long enough. Breiman (1961) was the first to clean up the math from Kelly's 1956 and Latane's 1957 heuristic analyses. He proved that

$$
\lim _{N \rightarrow \infty} \frac{w_{K B}(N)}{w_{B}(N)} \rightarrow \infty,
$$

where $w_{K B}(N)$ and $w_{B}(N)$ are the wealth levels of the Kelly bettor and another essentially different bettor after $N$ play; that is, the Kelly bettor wins infinitely more than bettor $B$ and moves further and further ahead as the long time
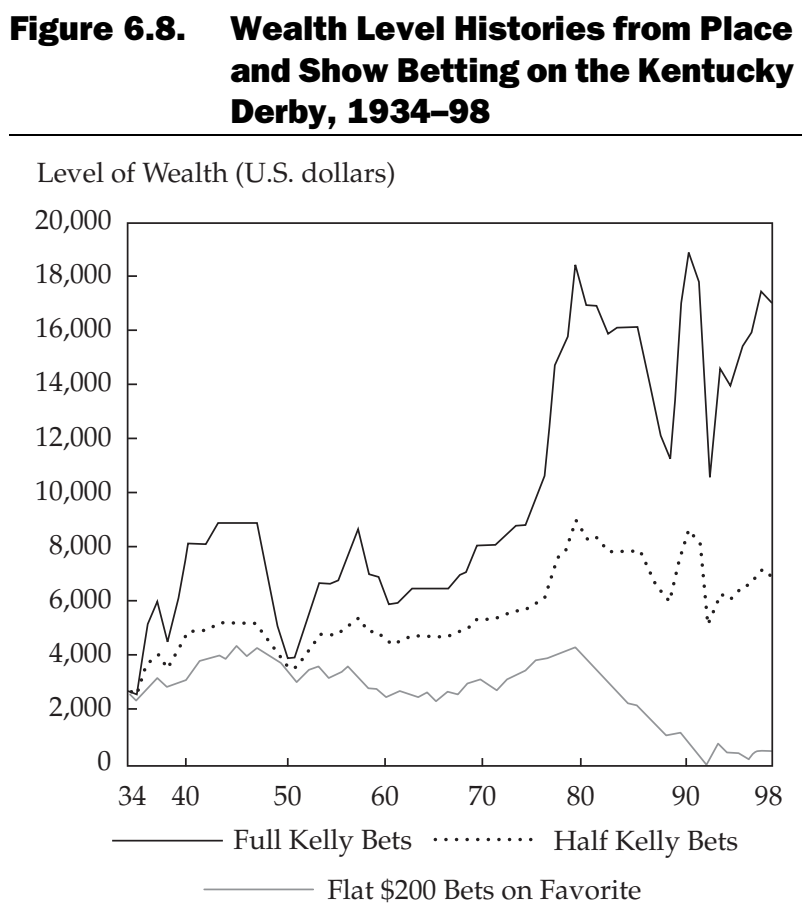

Note: With system using a 4.00 dosage index filter rule with full and half Kelly wagering from $\$ 200$ flat bets on the favorite. Initial wealth $=\$ 2,500$. 
horizon becomes more distant. ${ }^{9}$ Recall from Chapter 4, the Hensel-Ziemba (2000b) calculation that from 1942-1997, a 100 percent long investor solely in large-cap stocks with Republican administrations and solely in small-cap stocks with Democratic administrations had 24.5 times as much wealth as a $60 / 40$ percent large-cap stock/bond investor. That is the idea of Kelly betting, more or less. Keynes and Buffett are essentially Kelly bettors (see Figure 6.1 and Figure 6.3, respectively). Kelly bettors have bumpy investment paths, but they end up with more money than other types of investors.

I have worked with Professor Leonard MacLean of Dalhousie University since 1986 on approaches to tone down the danger of $\log$ while retaining its growth properties. I will discuss some of our work here.

The Kelly criterion has been used by gamblers since its discovery. The leading champion of its use in blackjack and other games of chance, sports betting, and the stock market is Thorp. Thorp can hardly be considered to be a gambler; as shown in Figure 6.2 and Table 6.2, he had a very smooth hedge fund record that looks nothing like the top line in Figure 6.8. Instead, he learned from gambling theory how to be a conservative investor, which is what I am trying to show in this section of the monograph.

The risk of Kelly strategies can be reduced by blending them with cash. A fractional Kelly strategy is $\delta$ percent in the Kelly strategy and $1-\delta$ percent in cash. Fractional Kelly strategies have smoother wealth paths, such as that shown in Figure 6.8 for bets on the Kentucky Derby using the system devised in Hausch, Ziemba, and Rubinstein (1981), refined in Hausch and Ziemba (1985), and popularized in my books with Hausch $(1984,1986,1987)$, plus using a breeding concept called "dosage" (see Bain, Hausch, and Ziemba 2002).

The fractional Kelly strategies $0<\delta<1$ are related to the coefficients $\alpha<0$ in the negative power utility function because $\delta=(1 / 1-\alpha)$. So, $\delta=1 / 2$, or half Kelly, is $\alpha=-1$ or $-w^{-1}$, and $\delta=1 / 4$, or quarter Kelly, is $-w^{-3}$. This calculation is exact for lognormally distributed assets in continuous time and normally distributed assets in discrete time and approximately correct with other distributions; a proof is provided in MacLean, Ziemba, and Li (2002).

The simulation study by Ziemba and Hausch (1986) illustrates typical Kelly and half Kelly behavior with shorter time horizons. An investor starts with US $\$ 1,000$ and makes 700 wagers 1,000 different times. The wagers all have an expected return of 14 percent but have different chances of winning and odds

\footnotetext{
${ }^{9}$ Bettor $B$ must use an essentially different strategy than the Kelly bettor for this outcome to be true, so the strategies differ infinitely often. For example, they are the same for the first 10 years, then every second trial is different. This point is technical, to get proofs correct, but it is nothing much to worry about in practice because nonlog strategies differ infinitely often.
} 
according to the values shown in Table 6.3. The edge over odds gives $f *$ equal to 0.14 down to 0.028 for bets with $1-1$ versus $5-1$ odds. The results are shown in Table 6.4.

The minimum of 18 in the first column shows that a Kelly bettor can make 700 independent wagers-all with a 14 percent edge having a 19 percent to 57 percent chance of winning each wager-and still lose more than 98 percent of his or her wealth. But the last column shows that 16.6 percent of the time, the Kelly bettor's initial wealth increases hundredfold. The half Kelly strategy is much safer; the chance of being ahead after the 700 wagers is 95.4 percent versus 87 percent for the full Kelly strategy. But the growth rate is much lower because the 16.6 percent chance increasing wealth hundredfold is only 0.1 percent for half Kelly wagerers. The Kelly bettor accumulates more wealth but with a much riskier time path of wealth accumulation. The Kelly bettor can take a long time to get ahead of another bettor, as shown in Figure 6.8 for the Kentucky Derby dosage bets; the full and half Kelly winning strategies are compared with the losing strategy of simply betting on the favorite, the lowest odds' horse. 10

Table 6.3. Value of Odds on Wagers in the ZiembaHausch (1986) Simulation

\begin{tabular}{lccc}
\hline $\begin{array}{l}\text { Probability of } \\
\text { Winning }\end{array}$ & Odds & $\begin{array}{c}\text { Probability of Being } \\
\text { Chosen in the Simulation } \\
\text { at Each Decision Point }\end{array}$ & $\begin{array}{c}\text { Optimal Kelly } \\
\text { Fraction of } \\
\text { Current Wealth }\end{array}$ \\
\hline 0.570 & $1-1$ & 0.1 & 0.140 \\
0.380 & $2-1$ & 0.3 & 0.070 \\
0.285 & $3-1$ & 0.3 & 0.047 \\
0.228 & $4-1$ & 0.2 & 0.035 \\
0.190 & $5-1$ & 0.1 & 0.028 \\
\hline
\end{tabular}

\section{Table 6.4. Distributions of Final Wealth in Dollars for Kelly and Half Kelly Wagers in the Ziemba-Hausch (1986) Simulation Starting with US\$1000}

\begin{tabular}{|c|c|c|c|c|c|c|c|c|c|}
\hline \multirow{2}{*}{$\begin{array}{l}\text { Final Wealth } \\
\text { Strategy }\end{array}$} & \multirow[b]{2}{*}{ Minimum } & \multirow[b]{2}{*}{ Maximum } & \multirow[b]{2}{*}{ Mean } & \multirow[b]{2}{*}{ Median } & \multicolumn{5}{|c|}{$\begin{array}{l}\text { Number of Times the Final Wealth } \\
\text { out of } 1,000 \text { Trials Was: }\end{array}$} \\
\hline & & & & & $>500$ & $>1,000$ & $>10,000$ & $>50,000$ & $>100,000$ \\
\hline Kelly & 18 & 483,883 & 48,135 & 17,269 & 916 & 870 & 598 & 302 & 166 \\
\hline Half Kelly & 145 & 111,770 & 13,069 & 8,043 & 990 & 954 & 480 & 30 & 1 \\
\hline
\end{tabular}

10See the discussion of properties in Appendix E (p. 53), which is available online in the Supplementary Material area at www.aimrpubs.org/rf/issues/v2003n6/pdf/AppendixE.pdf. 
Dosage bets in Figure 6.8 on the Kentucky Derby from 1934-1998 were made using an inefficient market system; probabilities from a simple market (win) were used in a more complex market (place and show) and were coupled with a breeding filter rule (dosage filter 4.00) to eliminate horses lacking sufficient stamina. Basically, you bet on horses that have the stamina to finish first, second, or third and are underbet to come in second or better or third or better relative to their true chances estimated from their odds to win.

The full Kelly log bettor has the most total wealth at the horizon but has the most bumpy ride-US\$2,500 becomes US\$16,861. The half Kelly bettor ends up with much less, US\$6,945, but has a much smoother ride. A comparison with random betting proxied by betting on the favorite in the race shows how tough it is to win at horseracing, particularly with the 16 percent track take plus breakage (rounding payoffs down) at Churchill Downs. Betting on the favorite turns US\$2,500 into US\$480. Actual random betting has even lower final wealth at the horizon because favorites are underbet.

The difference between full and fractional Kelly investing and the resulting size of the optimal investment bets is illustrated via a trade-off of growth versus security. This difference, akin to the static mean versus variance so often used in portfolio management, yields two-dimensional graphs that aid in the investment decision-making process. 11

The Kelly criterion can also be used for betting on favorable (unpopular) numbers in lotto games. 12 Even with a substantial edge and large payoffs if the bettor wins, the bets are extremely tiny because the chance of losing most or all of the bettor's money is high.

What has been learned from this exercise?

1. Lotto games are, in principle, beatable, but the Kelly and fractional Kelly wagers are so small that it takes virtually forever to have confidence in winning. Of course, the bettor could win earlier, and the bettor has a positive mean on all bets. My studies have shown that the largest jackpots contain about 47 percent of the 19 most unpopular numbers in 1986 versus 17 percent of the most unpopular numbers in the smallest jackpots. My six most unpopular numbers produced a $\$ 10$ million jackpot in Florida a few years ago. Hence, emphasizing unpopular numbers is a valuable strategy to employ. Could more be bet? Sorry, $\log$ is the most one should ever bet.

11This difference is illustrated in Appendix E (p. 43) by the game of blackjack, in which fractional Kelly strategies have been used by professional players. Appendix E is available online in the Supplementary Material area at www.aimrpubs.org/rf/issues/v2003n6/pdf/ AppendixE.pdf.

12For details, see Appendix E (p. 44), which is available online in the Supplementary Material area at www.aimrpubs.org/rf/issues/v2003n6/pdf/AppendixE.pdf. 
2. The Kelly and fractional Kelly wagering schemes are useful in practice, but the size of the wagers varies from tiny to enormous. My best advice: Never overbet; it will eventually lead to trouble unless it is controlled somehow, which is hard to do!

\section{Commodity Trading: Investing in the Turn-of-the-Year Effect with Index Futures}

Repeated investments in commodity trades are well modeled by the capital growth theory, with modifications for margin, daily mark-to-market account variation, and other practical details. An interesting example is the turn-of-theyear effect in U.S. small-cap stocks in January. Figure 6.9 shows the mean excess return of the smallest minus largest decile of U.S. stocks for the 192693 period by month. In 11 of the months, the advantage was small or negative; a large advantage, however, occurred in January. The 10.36 percent mean difference in January provided a strong advantage with high reliability; a smallcap stock advantage occurred in 63 of the 68 years.

\section{Figure 6.9. Average Excess Return of \\ Smallest minus Largest Decile of \\ U.S. Stocks, 1926-93}

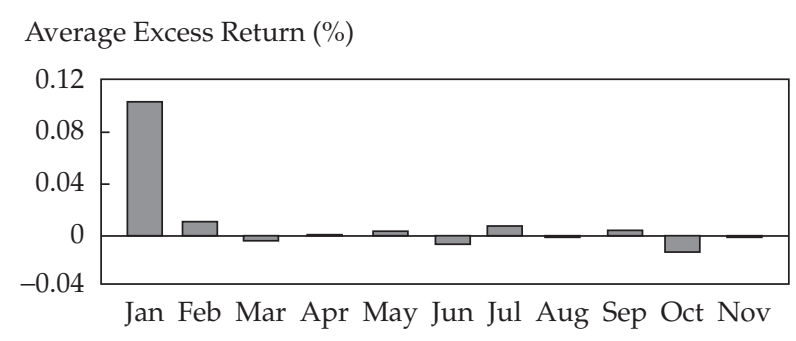

Source: Based on data from Ibbotson Associates.

One way to invest in this anomaly is to hold long positions in a small-cap stock index and short positions in large-cap stock indexes because the transaction costs (commission plus market impact) are less than a tenth of that of trading the corresponding basket of securities. An example from Clark and Ziemba (1987) using data from 1976-1977 to 1986-1987 follows. During the time of this study, the March Value Line (VL) Index was an equally weighted geometric average of the prices of about 1,700 securities emphasizing small-cap stocks, whereas the S\&P 500 was a value-weighted index of 500 large-cap stocks. Hence, the VL/S\&P 500 spread was long in small-cap stocks. 
Each point change in the index spread was worth US\$500. The spread was entered in mid-December, before futures anticipation bid up the lightly traded VL Index. On average, the 15 December to $(-1)$ day gain on the spread, that is, the futures anticipation, was 0.57 points. By 15 January, the largest average gains were over and the risks had increased. On average, the spread dropped 0.92 points in this period, with a high variance. The projected gain from a successful trade was $0-5$ points and averaged 2.85 points or $\$ 1,342.50$ per spread, assuming a commission of $1.5 \times \$ 55$.

The average standard deviation of the VL/S\&P 500 spread was about 3.0. Table 6.5 shows an approximate return distribution with a mean of 2.85 points for the trade. The optimal Kelly investment, based on the return distribution, is 74 percent of one's fortune! Such high wagers are typical for profitable situations with a small probability of loss. Given the uncertainty of the estimates involved and the volatility and margin requirements of the exchanges, a much smaller wager is suggested.

\section{Table 6.5. Approximate Return Distribution}

\begin{tabular}{lccccccccc}
\hline Gain & 7 & 6 & 5 & 4 & 3 & 2 & 1 & 0 & -1 \\
Probability & 0.007 & 0.024 & 0.0700 & 0.146 & 0.217 & 0.229 & 0.171 & 0.091 & 0.045 \\
\hline
\end{tabular}

Panel A of Figure $\mathbf{6 . 1 0}$ displays the growth rate and probability of doubling, tripling, and tenfolding one's fortune before losing half of it for various fractional Kelly strategies. At fractional strategies of 25 percent or less, the probability of tenfolding one's fortune before halving it exceeds 90 percent, with a growth rate in excess of 50 percent of the maximal growth rate. Panel $\mathrm{B}$ of Figure 6.10 gives the probability of reaching the distant goal of $\$ 10$ million before ruin for Kelly, half Kelly, and quarter Kelly strategies, with wealth levels in the range of US\$0-10 million. The results indicate that the quarter Kelly strategy seems safe, with a 99 percent chance of achieving this goal. The markets have become much more dangerous than during the period of this study, however, so an even lower Kelly fraction is suggested.

These concepts were used in a US $\$ 100,000$ speculative account by a Canadian investment management firm. Five VL/S\&P 500 spreads were purchased to approximate a slightly less than 25 percent fractional Kelly strategy. Watching the market carefully, the firm bought them on 17 December 1986 at a spread of -22.18 points, which was close to the minimum that the spread traded at around 15 December. The spread continued to gain, and the position was cashed out at -16.47 points on 14 January for a gain of 5.55 


\section{Figure 6.10. Turn-of-the-Year Effect}

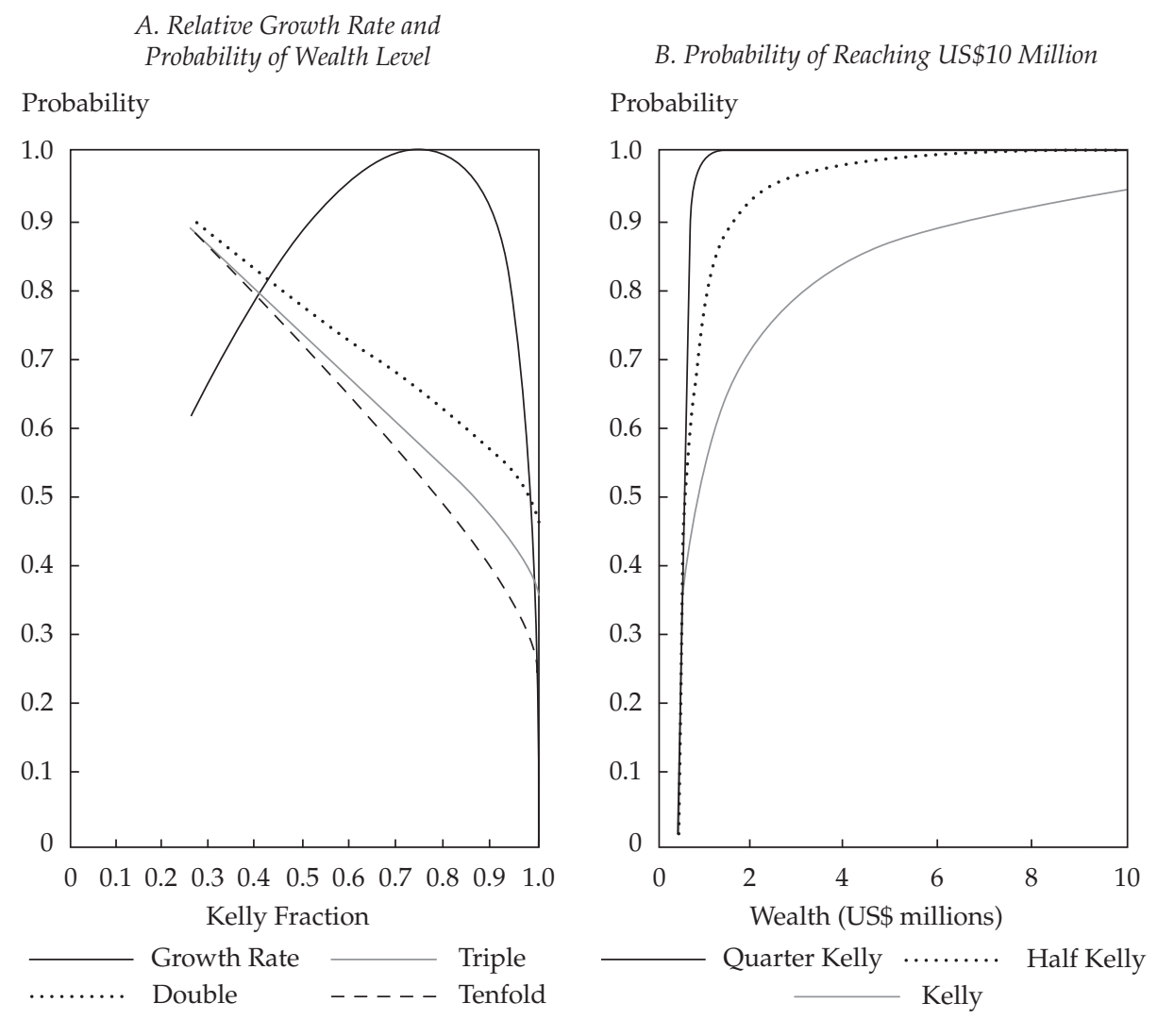

Source: Based on data from Clark and Ziemba.

points per contract, or US\$14,278.50, after transaction costs. Additional discussion of many of the issues in this section appears in Clark and Ziemba and is updated in Ziemba (1994a) and in Hensel and Ziemba (2000a).

Throughout the 1980s and up to the mid-1990s, the data were consistent with the past substantial small-cap stock advantage. The market has changed in the past few years, however, and the advantage has not been apparent, except for shorter periods in the futures markets (see Hensel and Ziemba 2000a, who provide year-by-year daily data plots of the spread up to 19992000.) The January effect is still alive, at least in the futures markets in December. Spreads using the Russell 2000 Index (small caps) have more liquidity than those using the Value Line Index. 


\section{Calculating the Optimal Kelly Fraction}

Most applications of fractional Kelly strategies pick the fractional Kelly strategy in an ad hoc fashion. MacLean, Ziemba, and Li showed that growth and security trade-offs are effective for general return distributions in the sense that growth is monotone decreasing in security (i.e., as growth rises, security falls, and vice versa). But with general return distributions, this trade-off is not necessarily efficient in the sense of Markowitz generalized growth playing the role of mean and security, or variance. If returns are lognormal, however, the trade-off is efficient. MacLean, Ziemba, and Li also developed an investment strategy whereby the investor sets upper and lower targets and rebalances when those targets are achieved. Empirical tests in MacLean, Zhao, and Ziemba (2003a, 2003b) proved the advantage of this approach.

A solution to the problem of how to pick an optimal Kelly function appears in MacLean, Sangre, Zhao, and Ziemba (forthcoming 2004). As illustrated in Figure 6.11, staying above a wealth path while using a Kelly strategy is difficult because the more attractive the investment opportunity, the larger the bet size and, hence, the larger the chance of falling below the path. 13

The capital growth or Kelly criterion is an interesting and valuable betting strategy that is useful in a variety of applications. 14

\footnotetext{
${ }^{13}$ An example applying this idea to the fundamental problem of asset allocation over time, namely, the determination of optimal fractions over time in cash, bonds, and stock, is in Appendix E (p. 50), which is available online in the Supplementary Material area at www.aimrpubs.org/rf/issues/v2003n6/pdf/AppendixE.pdf.

14Further information on its important properties, good and bad, appears in Appendix E (p. 53), which is available online in the Supplementary Material area at www.aimrpubs.org/rf/issues/ v2003n6/pdf/AppendixE.pdf.
} 
Figure 6.11. Kelly Fractions and Path Achievement

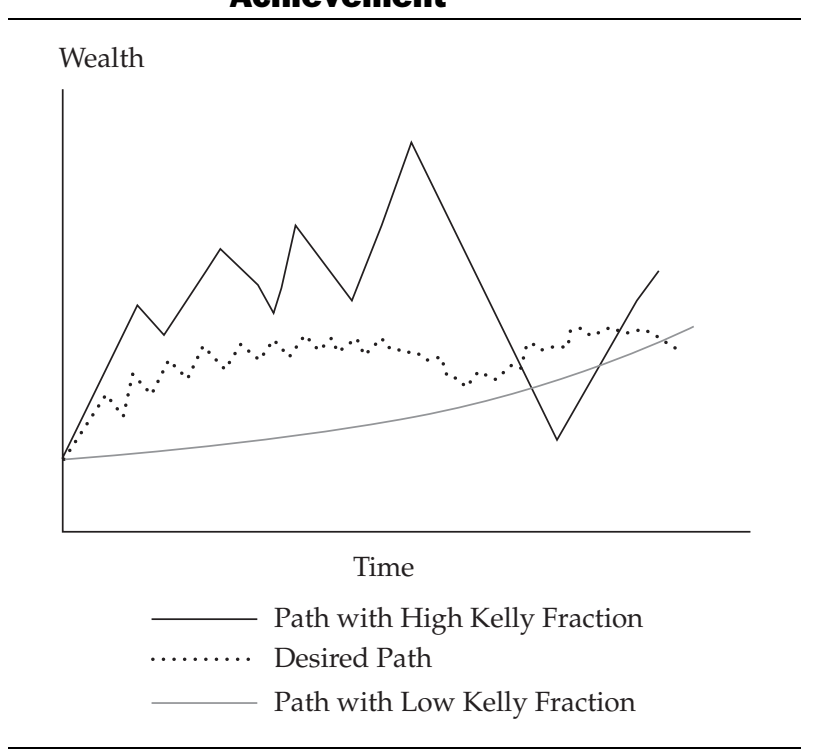




\section{The Top 10 Points to Remember}

Following are the key points to remember about the stochastic programming approach to asset, liability, and wealth management.

- Point 1. Means are by far the most important part of the distribution of returns, especially the direction. Thus, you must estimate future means well or you can quickly travel in the wrong direction, which usually leads to losses or underperformance.

- Point 2. Mean-variance models are useful as a basic guideline when you are in an assets-only situation. Professionals adjust means using meanreversion, James-Stein, or truncated estimators and constrain output weights. Do not change asset positions unless the advantage of the change is significant. Do not use mean-variance analysis with liabilities and other major market imperfections, except as a first test analysis.

- Point 3. Trouble arises when you overbet and a bad scenario occurs. Thus, do not overbet when there is any possibility of a bad scenario occurring, unless the bet is protected by some type of hedge or stop loss.

- Point 4. Trouble is exacerbated when the expected diversification does not hold in the scenario that occurs. Thus, you must use scenariodependent correlation matrixes because simulations around historical correlation matrixes are inadequate for extreme scenarios.

- Point 5. When a large decline in the stock market occurs, the positive correlation between stocks and bonds fails and they become negatively correlated. Thus, when the mean of the stock market is negative, bonds are more attractive, as is cash.

- Point 6. Stochastic programming scenario-based models are useful when you want to look at aggregate overall decisions-with liabilities, liquidity, taxes, policy, legal, and other constraints-and have targets and goals you want to achieve. It thus pays to make a complex stochastic programming model when a lot is at stake and the essential problem has many complications.

- Point 7. Other approaches, such as continuous-time finance, decision-rulebased stochastic programming, control theory, and so on, are useful for 
problem insights and theoretical results. But in actual use, they may lead to disaster unless modified. The Black-Scholes theory says you can hedge perfectly with lognormal assets, which can lead to overbetting. Fat tails and jumps arise frequently and can occur without warning. The S\&P 500 opened limit down 60 points or 6 percent when trading resumed after $9 / 11$, and it fell 14 percent that week. Thus, be careful of the assumptions, including implicit ones, of theoretical models. Use the results with caution no matter how complex and elegant the math or how smart or famous the author. Remember, you have to be very smart to lose millions and even smarter to lose billions.

- Point 8. Do not be concerned with getting all the scenarios exactly right when using stochastic programming models. You cannot do so, and it does not matter that much anyway. Instead, worry about having the problem periods laid out reasonably and make sure the scenarios basically cover the means, the tails, and the chance of what could happen. If the current situation has never occurred before, use one that is similar to add scenarios. For a crisis in Brazil, use Russian crisis data, for example. The results of stochastic programming will give you good advice when times are normal and keep you out of severe trouble when times are bad. Those using stochastic programming models may lose 5,10 , or 15 percent, but they will not lose 50,70, or 95 percent, as some investors and hedge funds have. Thus, if the scenarios are more or less accurate and the problem elements are reasonably modeled, stochastic programming will give good advice. You may slightly outperform in normal markets, but you will greatly outperform in bad markets, when other approaches may blow up.

- Point 9. Stochastic programming models for asset/liability management were very expensive in the 1980s and early 1990s but are not expensive now. Vancouver analysts using a large linear programming model to plan lumber operations at MacMillan Blodel used to fly to San Francisco to use a large computer that would run all day to run the model once. Now, models of this complexity take only seconds to run on inexpensive personal computers. Thus, advances in computing power and modeling expertise have made stochastic programming modeling much less expensive. Such models, which are still complex and require approximately six months to develop and test, cost a couple hundred thousand dollars. A small team can make a model for a complex organization quite quickly at fairly low cost compared with what is at stake. See www.numerikaalm.com or my website, homepage.mac.com/wtzimi/ index.htm, or contact the author at wtzimi@mac.com. 
- Point 10. Eventually, as more disasters occur and more successful stochastic programming models are built and used, they will become popular. Thus, the ultimate goal is to have them in regulations, such as value at risk is now. Although value at risk does more good than harm, its safety is questionable in many applications. Conditional value at risk is an improvement, but for most people and organizations, the nonattainment of goals is more than proportional (i.e., convex) in the nonattainment. 


\section{References}

Abaffy, Jozsef, Marida Bertocchi, Jitka Dupačovà, and Vittorio Moriggia. 2000. "On Generating Scenarios for Bond Portfolios.” Bulletin of the Czech Econometric Society, vol. 11 (February):3-27.

Ackerman, Carl, Richard McEnally, and David Ravenscraft. 1999. "The Performance of Hedge Funds: Risk, Return, and Incentives.” Journal of Finance, vol. 54, no. 3 (June):833-874.

Agarwal, Vikas, and Narayan Naik. 2000. "On Taking the Alternative Route: Risks, Rewards, Style, and Performance Persistence of Hedge Funds." Journal of Alternative Investments, vol. 2, no. 4 (Spring):6-23.

. 2001. "Characterizing the Risk and Return of Equity with Buy-and-Hold and Option-Based Strategies.” Working paper, Georgia State University and London Business School.

. 2002. "Risks and Portfolio Decisions Involving Hedge Funds." Institute of Finance and Accounting, London Business School Working Paper No. 364.

Ali, Mukhtar M. 1979. "Some Evidence of the Efficiency of a Speculative Market." Econometrica, vol. 47, no. 2 (March):387-392.

Amin, Gaurav S., and Harry M. Kat. 2003. "Hedge Fund Performance 1990-2000: Do the Money Machines Really Add Value?" Journal of Financial and Quantitative Analysis, vol. 38, no. 2 (June):251-274.

Arrow, Kenneth J. 1965. "Aspects of the Theory of Risk Bearing.” Technical report, Yrjö Jahnsson Foundation.

Artzner, Philippe, Freddy Delbaen, Jean-Marc Eber, and David Heath. 1999. "Coherent Measures of Risk.” Mathematical Finance, vol. 9, no. 3 (July):203-228.

Bagnell, Paul. 1999. Globe and Mail (November 26).

Bain, Roderick S., Donald B. Hausch, and William T. Ziemba. 2002. "An Application of Expert Information to Win Betting on the Kentucky Derby, 1981-2001.” Working paper, University of British Columbia.

Barberis, Nicholas M. 2000. "Investing for the Long Run When Returns Are Predictable." Journal of Finance, vol. 55, no. 1 (February):225-264.

Bell, David. 1995. "Risk, Return and Utility.” Management Science, vol. 41 (January):23-30.

Benartzi, Shlomo, and Richard Thaler. 2001. "Naive Diversification Strategies in Retirement Saving Plans." American Economic Review, vol. 91, no. 1 (March):79-98.

Berge, Klaus, and William T. Ziemba. 2003. "Predictive Ability of Bond versus Stock Earnings Yield Differences.” Working paper, Faculty of Commerce, University of British Columbia. 
Berkelaar, Arjan, and Roy Kouwenberg. 2003. "Retirement Savings with Contribution Payments and Labor Income as a Benchmark for Investments." Journal of Economic Dynamics and Control, vol. 27, no. 6 (April):1069-97.

Bernardo, Antonio E., and Oliver Ledoit. 2000. “Gain, Loss, and Asset Pricing.” Journal of Political Economy, vol. 108, no. 1 (February):144-172.

Berument, Hakan. 2001. "Measuring Monetary Policy for a Small Open Economy: Turkey." Working paper, Bilkent University.

Black, Fischer, and Myron S. Scholes. 1973. "The Pricing of Options and Corporate Liabilities.” Journal of Political Economy, vol. 81, no. 3 (May/June):637-654.

Blake, David, Bruce N. Lehmann, and Allan Timmermann. 1999. "Asset Allocation Dynamics and Pension Fund Performance.” Journal of Business, vol. 72, no. 4 (October):429-461.

Bodie, Zvi. 2001. "Retirement Investing: A New Approach.” Mimeo, Boston University. Boender, Guus C.E. 1997. "A Hybrid Simulation/Optimization Scenario Model for Asset Liability Management.” European Journal of Operational Research, vol. 99, no. 1 (May):126-135.

Bos, Eduard, My T. Vu, Ernest Massiah, and Rodolfo Bulatao. 1994. World Population Projections 1994-95 Edition: Estimates and Projections with Related Demographic Statistics. Washington, DC: World Bank.

Bradley, Stephen P., and Dwight B. Crane. 1973. "Management of Commercial Bank Government Security Portfolios: An Optimization Approach under Uncertainty." Journal of Bank Research, vol. 4:18-30.

Breiman, Leo. 1961. "Optimal Gambling System for Favorable Games.” In Proceedings of the 4th Berkeley Symposium on Mathematical Statistics and Probability:63-68.

Brennan, Michael. J., and Eduardo S. Schwartz. 1976. "The Pricing of Equity-Linked Life Insurance Policies with an Asset Value Guarantee.” Journal of Financial Economics, vol. 3:195-213.

—. 1979. "Alternative Investment Strategies for the Issuers of Equity Linked Life Insurance Policies with an Asset Value Guarantee.” Journal of Business, vol. 52, no. 1 (January):63-93.

Brinson, Gary P., L. Randolph Hood, and Gilbert L. Beebower. 1986. "Determinants of Portfolio Performance." Financial Analysts Journal, vol. 42, no. 4 (July/ August):39-44.

Brinson, Gary P., Brian D. Singer, and Gilbert L. Beebower. 1991. "Determinants of Portfolio Performance II: An Update.” Financial Analysts Journal, vol. 47, no. 3 (May/ June):40-48.

Brown, Stephen J., William N. Goetzmann, and Roger G. Ibbotson. 1997. "Offshore Hedge Funds: Survival and Performance 1989-1995.” National Bureau of Economic Research Working Paper 5909. 
Buffett, Warren B. 2001. "Warren Buffett on the Stock Market." Fortune (10 December): 80 .

Burtless, Gary. 2003. "What Do We Know about the Risk of Individual Account Pensions?: Evidence from Industrial Countries.” American Economic Review, vol. 93, no. 2 (May):354-359.

Busche, Kelly. 1984. "Efficient Market Results in an Asian Setting." In Efficiency of Racetrack Betting Markets. Edited by Donald B. Hausch, Victor Lo, and William T. Ziemba. San Diego: Academic Press:615-616.

Busche, Kelly, and Christopher D. Hall. 1988. "An Exception to the Risk Preference Anomaly.” Journal of Business, vol. 61, no. 3 (July):337-346.

Campbell, John Y., and Robert J. Shiller. 1998. "Valuation Ratios and the Long-Run Stock Market Outlook.” Journal of Portfolio Management, vol. 24, no. 2 (Winter):11-26.

- 2001. "Valuation Ratios and the Long-Run Stock Market Outlook: An Update.” National Bureau of Economic Research Working Paper No. 8221 (April).

Campbell, John Y. and Luis M. Vicera. 2002. Strategic Asset Allocation: Portfolio Choice for Long-Term Investors. Oxford, U.K.: Oxford University Press.

Cariño, David R., and Andrew L. Turner. 1998. "Multiperiod Asset Allocation with Derivative Assets." In Worldwide Asset and Liability Modeling. Edited by William T. Ziemba and John M. Mulvey. Cambridge, U.K.: Cambridge University Press:182-204.

Cariño, David R., and William T. Ziemba. 1998. "Formulation of Russell-Yasuda Kasai Financial Planning Model.” Operations Research, vol. 46, no. 4 (July/August):433-449.

Cariño, David R., David Myers, and William T. Ziemba. 1998. "Concepts, Technical Issues and Uses of the Russell-Yasuda Kasai Financial Planning Model." Operations Research, vol. 46, no. 4 (July/August):450-462.

Cariño, David R., Terry Kent, David H. Myers, Celine Stacy, Mike Sylvanus, Andrew L. Turner, Kouji Watanabe, and William T. Ziemba. 1994. "The Russell-Yasuda Kasai Model: An Asset/Liability Model for a Japanese Insurance Company Using Multistage Stochastic Programming." Interfaces, vol. 24, no. 1 (January/February):29-49.

Chadburn, Robert G. 1997. "The Use of Capital, Bonus Policy and Investment Policy in the Control of Solvency for With-Profits Life Insurance Companies in the U.K." Actuarial Research Paper No. 95 (April). London, U.K.: City University.

Chan, K.C., G. Andrew Karolyi, Francis A. Longstaff, and Anthony B. Sanders. 1992. "An Empirical Comparison of Alternative Models of the Short Term Interest Rate." Journal of Finance, vol. 47, no. 3 (July):1209-27.

Chen, K., and A. Passow. 2003. "Quantitative Selection of Long-Short Hedge Funds." Mimeo, University of Lausanne.

Chopra, Vijay Kumar. 1993. "Improving Optimization.” Journal of Investing, vol. 2, no. 3 (Fall):51-59. 
Chopra, Vijay Kumar, and William T. Ziemba. 1993. "The Effect of Errors in Mean, Variance and Co-Variance Estimates on Optimal Portfolio Choice." Journal of Portfolio Management, vol. 19, no. 2 (Winter):6-11.

Chua, Jess H., and Richard S. Woodward. 1983. "J.M. Keynes's Investment Performance: A Note." Journal of Finance, vol. 38, no. 1 (March):232-235.

Clark, Ross, and William T. Ziemba. 1987. "Playing the Turn of the Year Effect with Index Futures." Operations Research, vol. 35, no. 6 (November/December):799-813.

Clifford, Scott W., Kenneth F. Kroner, and Laurence B. Siegel. 2001. "In Pursuit of Performance: The Greatest Return Stories Ever Told." Investment Insights, vol. 4, no. 1 (Summer). San Francisco, CA: Barclays Global Investors:1-25.

Comolli, Luis R., and William T. Ziemba. 2000. “Japanese Security Market Regularities, 1990-1994." In Security Market Imperfections in World Wide Equity Markets. Edited by Donald B. Keim and William T. Ziemba. Cambridge, U.K.: Cambridge University Press:458-491.

Consiglio, Andrea, Flavio Cocco, and Stavros A. Zenios. 2001. "The Value of Integrative Risk Management for Insurance Products with Guarantees.” Journal of Risk Finance, vol. 2, no. 3 (Spring):6-16.

—. Forthcoming 2004. "The Prometia Model for Managing Insurance Policies with Guarantees." In Handbook of Asset and Liability Management. Edited by Stavros A. Zenios and William T. Ziemba. Amsterdam, the Netherlands: North-Holland Press.

Constantinides, George M. 1982. "Intertemporal Asset Pricing with Heterogeneous Consumers and without Demand Aggregation.” Journal of Business, vol. 55, no. 2 (April):253-268. 1567-91.

Corcos, Anne, Jean-Pierre Eckmann, Andreas Malaspinas, and Yannick Malevergne. 2002. "Imitation and Contrarian Behaviour: Hyperbolic Bubbles, Crashes and Chaos." Quantitative Finance, vol. 2, no. 4 (August):264-281.

De Ryck, Koen. 1996. European Pension Funds: Their Impact on Capital Markets and Competitiveness. Brussels, Belgium: European Federation for Retirement Provision.

Dempster, Michael A.H., Igor V. Evstigneev, and Klaus R. Schenk-Hoppé. 2003. "Exponential Growth of Fixed Mix Assets in Stationary Markets." Finance and Stochastics, vol. 7, no. 2 (April):263-276.

Dimson, Elroy, Paul Marsh, and Mike Staunton. 2002. Triumph of the Optimists: 101 Years of Global Investment Returns. Princeton, NJ: Princeton University Press.

Douglass, Julian, Owen Wu, and William T. Ziemba. 2003. "Stock Ownership Decisions in DC Pension Plans.” Working paper, University of British Columbia.

Duffie, Darrell, and Kenneth Singleton. 2003. Credit Risk: Pricing, Management, and Measurement. Princeton, NJ: Princeton University Press. 
Dugan, Ianthe Jeanne, Tomas Burton, and Carrick Mollenkamp. 2002. "Portrait of a Loss: Chicago Art Institute Learns Tough Lesson About Hedge Funds." Wall Street Journal (1 February):A1.

Dumas, Bernard, Jeff Fleming, and Robert E. Whaley (1998). "Implied Volatility Functions: Empirical Tests.” Journal of Finance, vol. 53, no. 6 (December):20592106.

Dunbar, N. 2000. Inventing Money: The Story of Long-Term Capital Management and the Legends Behind It. New York: John Wiley \& Sons.

Dupačovà, Jitka, Giorgio Consigli, and Stein W. Wallace. 2000. "Scenarios for Multistage Stochastic Programs." Annals of Operations Research, vol. 100, no. 1 (December):25-53.

Dybvig, Philip H. 1999. "Using Asset Allocation to Protect Spending." Financial Analysts Journal, vol. 55, no. 1 (January/February):49-61.

Dybvig, Philip H., Heber K. Farnsworth, and Jennifer N. Carpenter. 1999. "Portfolio Performance and Agency.” Working paper, Washington University.

Economist. 2002. "Pensions; Time to Grow Up; A Survey of Pensions." London Economist (16 February).

Edwards, Franklin R. 1999. "Hedge Funds and the Collapse of Long-Term Capital Management." Journal of Economic Perspectives, vol. 13, no. 2 (Spring):189-210.

Embrechts, Paul. 2000. "Actuarial versus Financial Pricing of Insurance.” Journal of Risk Finance, vol. 1, no. 4 (Summer):17-26.

Embrechts, Paul, Sidney Resnick, and Gennady Samovodmitsky. 1998. "Living on the Edge.” Risk, vol. 11, no. 1 (January):96-100.

European Commission. 1997. Supplementary Pensions in the Single Market, A Green Paper. Commission Communication, COM.

- 1999. Towards a Single Market for Supplementary Pensions. Commission Communication, COM.

European Federation for Retirement Provision. 1996. European Pension Funds: Their Impact on Capital Markets and Competitiveness. Brussels, Belgium.

Figgis, E. Lennox. 1974. "Rates of Return from Flat Race Betting in England in 1973." Sporting Life (11 March):3.

Figlewski, Stephen. 1989. "What Does an Option Pricing Model Tell Us About Option Prices?” Financial Analysts Journal, vol. 45, no. 5 (September/October):12-15.

- 1994. "How to Lose Money in Derivatives." Journal of Derivatives, vol. 2, no. 2 (Winter):75-82.

Fleten, Stein-Erik, Kjetil Høyland, and Stein W. Wallace. 2002. "The Performance of Stochastic Dynamic and Fixed Mixed Portfolio Models." European Journal of Operational Research, vol. 140, no. 1 (July):37-49. 
Fung, William, and David A. Hsieh. 1991. "Estimating the Dynamics of Foreign Currency Futures," Review of Futures Markets, vol. 10, no. 3 (May):490-514.

- 2001. "The Risk in Hedge Fund Strategies: Theory and Evidence from Trend Followers." Review of Financial Studies, vol. 14, no. 2 (May):490-514.

Geyer, Alois, Wolfgang Herold, Konrad Kontriner, and William T. Ziemba. 2003. "The Innovest Austrian Pension Fund Financial Planning Model InnoALM." Working paper, University of British Columbia.

Goetzmann, William N., Jonathan Ingersoll, Jr., and Stephen A. Ross. 2003. "High Water Marks." Journal of Finance, vol. 58, no. 4 (August):1685-1717.

Goetzmann, William N., Jonathan Ingersoll, Matthew Spiegel, and Ivo Welch. 2002. "Sharpening Sharpe Ratios." Working paper, Yale School of Management.

Gondzio, Jacek, Roy Kouwenberg, and Ton Vorst. 2003. "Hedging Options under Transactions Costs and Stochastic Volatility." Journal of Economic Dynamics and Control, vol. 27, no. 6 (April):1045-68.

Greenspan, Alan. 1998. Speech before the Committee on Banking and Social Services, U.S. House of Representatives, 24 July.

Hanoch, Giora, and Haim Levy. 1969. "The Efficiency Analysis of Choices Involving Risk.” Review of Economic Studies, vol. 36, no. 107 (July):335-346.

Hansen, Mette, and Kristian R. Miltersen. 2002. "Minimum Rate of Return Guarantees: The Danish Case." Scandinavian Actuarial Journal, vol 4:280-318.

Harrison, Michael, and David Kreps. 1979. "Martingale and Multiperiod Securities Markets." Journal of Economic Theory, vol. 20 (June):382-408.

Hausch, Donald B., and William T. Ziemba. 1985. "Transactions Costs, Entries and Extent of Inefficiencies in a Racetrack Betting Model.” Management Science, vol. 31, no. 4:381-394.

\footnotetext{
- Forthcoming 2004. Handbook of Investments: Volume 6 Sports and Lottery Investment Markets. Amsterdam, the Netherlands: North-Holland Press.

Hausch, Donald B., Victor S. Lo, and William T. Ziemba. 1994. Efficiency of Racetrack Betting Markets. San Diego, CA: Academic Press. (Available from the author.)

Hausch, Donald B., William T. Ziemba, and Mark E. Rubinstein. 1981. "Efficiency of the Market for Racetrack Betting." Management Science, vol. 27, no. 12 (December):1435-52.

He, Hua, and Hayne Leland. 1993. "On Equilibrium Asset Price Processes.” Review of Financial Studies, vol. 6, no. 3 (Winter):593-617.
}

Heinkel, Robert, and Neal M. Stoughton. 1994. "The Dynamics of Portfolio Management Contracts." Review of Financial Studies, vol. 7, no. 2 (Summer):351-387.

Henriques, Diana B. 1991. "A Better Way to Back Your Assets." New York Times (Sunday, 31 March, Section 3, Business):11. 
Hensel, Chris R., and Andrew L. Turner. 1998. "Making Superior Asset Allocation Decisions: A Practitioner's Guide.” In Worldwide Asset and Liability Management. Edited by William T. Ziemba and John M. Mulvey. Cambridge, U.K.: Cambridge University Press:62-83.

Hensel, Chris R., and William T. Ziemba. 2000a. "Anticipation in the January Effect in the U.S. Futures Markets." In Security Market Imperfections in World Wide Equity Markets. Edited by Donald B. Keim and William T. Ziemba. Cambridge, U.K.: Cambridge University Press:179-202.

2000b. "How Did Clinton Stand Up to History? U.S. Stock Market Returns and Presidential Party Affiliations." In Security Market Imperfections in World Wide Equity Markets. Edited by Donald B. Keim and William T. Ziemba. Cambridge, U.K.: Cambridge University Press:203-217.

Hensel, Chris R., D. Don Ezra, and John H. Ilkiow. 1991. "The Importance of the Asset Allocation Decision." Financial Analysts Journal, vol. 47, no. 4 (July/August): 65-72.

Hodges, Stewart. 1998. "A Generalization of the Sharpe Ratio and Its Applications to Valuation Bounds and Risk Measures.” Technical report, Financial Options Research Centre, Warwick Business School.

Jackwerth, Jens Cartsen, and Mark Rubinstein. 1996. "Recovering Probability Distributions from Option Prices.” Journal of Finance, vol. 51, no. 5 (December):1611-31.

Jamshidian, Farshid, and Yu Zhu. 1996. "Scenario Simulation: Theory and Methodology.” Finance and Stochastics, vol. 1, no. 1 (December):43-76.

Janacek, Karel. 1998. "Optimal Growth in Gambling and Investing." MSc. Thesis, Charles University.

Jobst, Norbert J., and Stavros A. Zenios. 2003. "Tracking Bond Indices in an Integrated Market and Credit Risk Environment." Quantitative Finance, vol. 3, no. 2 (April):117-135.

Jorion, Philippe. 1985. "International Portfolio Diversification with Estimation Risk." Journal of Business, vol. 58, no. 3 (July):259-278.

_. 2000a. "Risk Management Lessons from Long-Term Capital Management." European Financial Management, vol. 6, no. 2 (September):277-300.

2000b. Value at Risk: The New Benchmark for Controlling Market Risk. 2nd ed. Chicago, IL: Irwin Professional Publishing.

Jorion, Philippe, and William Goetzmann. 1999. "Global Stock Markets in the Twentieth Century.” Journal of Finance, vol. 54, no. 3 (June):953-980.

Kahneman, Daniel, and Amos Tversky. 1979. "Choices, Values, and Frames." Econometrica, vol. 47, no. 2:263-291. 
Kallberg, Jarl G., and William T. Ziemba. 1981. "Remarks on Optimal Portfolio Selection." In Methods of Operations Research. Edited by Gunter Bamberg and Otto Optiz. Cambridge, MA: Oelgeschlager, Gunn \& Hain:507-520.

- 1983. "Comparison of Alternative Utility Functions in Portfolio Selection Problems.” Management Science, vol. 29, no. 11 (November):1257-76.

1984. "Mis-Specifications in Portfolio Selection Problems." In Risk and Capital. Edited by Gunter Bamberg and Klaus Spremann. New York: Springer Verlag:74-87.

Kallberg, Jarl G, Robert White, and William T. Ziemba. 1982. "Short Term Financial Planning Under Uncertainty.” Management Science vol. 28:670-682.

Kat, Harry M. 2001. Structured Equity Derivatives: The Definitive Guide to Exotic Options and Structured Notes. New York: John Wiley \& Sons.

Keim, Donald B., and William T. Ziemba. 2000. Security Market Imperfections in World Wide Equity Markets. Cambridge, U.K.: Cambridge University Press.

Kelly, J. 1956. "A New Interpretation of Information Rate.” Bell System Technology Journal, vol. 35:917-26.

Keynes, John M. 1938. "Investment Policy Report on the Chest Fund.” Cambridge, U.K.: Kings College.

Kingsland, L. 1982. "Projecting the Financial Condition of a Pension Plan Using Plan Simulation Analysis." Journal of Finance, vol. 37, no. 2:577-584.

Koivu, Malti, Teemu Pennanen, and William T. Ziemba. 2003. "Cointegration Analysis of the Fed Model.” Working paper, Helsinki School of Economics.

Kouwenberg, Roy. 2003. "Do Hedge Funds Add Value to a Passive Portfolio?: Corrective for Non-Normal Returns and Disappearing Funds." Journal of Asset Management, vol. 3, no. 4 (March):361-382.

Kouwenberg, Roy, and William T. Ziemba. 2003. "Incentives and Risk Taking in Hedge Funds.” Mimeo, Erasmus University.

Krokhmal, Pavlo, Stanislav Uryasev, and Grigory Zrazhevsky. Forthcoming 2004. "Numerical Comparison of CVar and CDaR Approaches: Application to Hedge Funds." In Applications of Stochastic Programming. Edited by Stein W. Wallace and William T. Ziemba. Philadelphia, PA: SIAM Mathematical Programming Series on Optimization.

Kusy, Martin I., and William T. Ziemba. 1986. "A Bank Asset and Liability Management Model.” Operations Research, vol. 34, no. 3 (May/June):356-376.

Lakonishok, Josef, Andrei Shleifer, and Robert Vishny. 1994. "Contrarian Investment Extrapolation and Risk.” Journal of Finance, vol. 49, no. 5 (September):1541-78.

Latane, Henry. 1959. "Criteria for Choice among Risky Ventures." Journal of Political Economy, vol 38 (April):144-155. 
Leland, Hayne. 1999. "Beyond Mean-Variance: Performance Measurement in a Nonsymmetrical World.” Financial Analysts Journal, vol. 55, no. 1 (January/ February):27-36.

Liu, Jun, and Francis A. Longstaff. 2000. "Losing Money on Arbitrages: Optimal Dynamic Portfolio Choice in Markets with Arbitrage Opportunities." Working paper, University of California at Los Angeles.

Lo, Andrew W. 1999. “The Three P's of Total Risk Management." Financial Analysts Journal, vol. 55, no. 1 (January/February):13-26.

—. 2001. "Risk Management for Hedge Funds: Introduction and Overview." Financial Analysts Journal, vol. 57, no. 6 (November/December):16-33.

Loewenstein, M., and G.A. Willard. 2000. "Convergence Trades and Liquidity: A Model of Hedge Funds.” Working paper, Massachusetts Institute of Technology.

MacLean, Leonard. C., Michael. E. Foster, and William T. Ziemba. 2002. "Empirical Bayes Estimation of Securities Price Parameters." In Financial Engineering, E-Commerce and Supply Chain. Edited by Panos M. Paradolos and Vassilis K. Tsitsiringos. Boston, MA: Kluwer Academic Publishers:47-57.

MacLean, Leonard, William T. Ziemba, and Yuming Li. 2002. "Time to Wealth Goals in Capital Accumulation and the Optimal Trade-Off of Growth versus Security." Working paper, Dalhousie University.

MacLean, Leonard, Yonggan Zhao, and William T. Ziemba. Forthcoming 2003a. "Wealth Goals Investing." In Applications of Stochastic Programming. Edited by Stein W. Wallace and William T. Ziemba. Philadelphia, PA: SIAM Mathematical Programming Series on Optimization.

—. 2003b. "A Process Control Approach to Investment Risk." Working paper, University of British Columbia.

MacLean, Leonard, Rafael Sanegre, Yonggan Zhao, and William T. Ziemba. Forthcoming 2004. "Capital Growth with Security." Journal of Economic Dynamics and Control, vol. 28, no. 5:937-954.

Markowitz, Harry M. 1952. "Portfolio Selection.” Journal of Finance, vol. 7, no. 8 (March):77-91.

Markowitz, Harry M., and André Perold. 1981. "Portfolio Analysis with Factors and Scenarios.” Journal of Finance, vol. 36, no. 4 (September):871-877.

Maug, Ernst, and Narayan Naik. 1995. "Herding and Delegated Portfolio Management: The Impact of Relative Performance Evaluation on Asset Allocation.” Working paper, London Business School.

Merton, Robert C. 1969. "Lifetime Portfolio Selection under Uncertainty: The Continuous Time Case." Review of Economics and Statistics, vol. 51, no. 3 (August):247-259.

1973. "An Intertemporal Capital Asset Pricing Model." Econometrica, vol. 41, no. 5 (September):867-887. 
1990. Continuous-Time Finance. Cambridge, MA: Blackwell Publishers.

2000a. "Finance and the Role of Financial Engineering in the 21st Century." Keynote speech given at conference at Kyoto University and Nihon Kezai Shinbun, (12-13 December). Available online at www.kier.kyoto-u.ac.jp/ fe/sympo_merton/ merton-e.html\#001.

2000b. "Future Possibilities in Finance Theory and Finance Practice." In Mathematical Finance: Bachelier Congress. Edited by Helyette Geman, Dillip Madan, Stanley R. Pliska, and Ton Vorst. New York: Springer Verlag:47-74.

Michaud, Richard O. 1989. “The Markowitz Optimization Enigma: Is 'Optimized' Optimal?” Financial Analysts Journal, vol. 45, no. 1 (January/February):31-42.

1998. Efficient Asset Management: A Practical Guide to Stock Portfolio Optimization and Asset Allocation. Oxford, U.K.: Oxford University Press.

Miller, Merton. 1996. "The Social Costs of Some Recent Derivatives Disasters." Pacific-Basin Finance Journal, vol. 4, nos. 2-3 (July):113-127.

Mitchell, Olivia S., and Stephen P. Utkus. 2002. "Company Stock and Retirement Plan Diversification.” Technical report, The Wharton School, University of Pennsylvania.

Mulvey, John M. 1996. "Generating Scenarios for the Towers Perrin Investment System.” Interfaces, vol. 26, no. 2 (March/April):1-13.

Mulvey, John M., and A. Eric Thorlacius. 1998. "The Towers Perrin Global Capital Market Scenario Generation System.” In Worldwide Asset and Liability Management. Edited by William T. Ziemba and John M. Mulvey. Cambridge, U.K.: Cambridge University Press:286-312.

Murray, Steven. 1997. "Russell's Individual Asset Liability Planning Model for Bank Federeuen.” Slides for talk at the University of British Columbia.

1998. “An Individual Planning Model in an Italian Context.” Slides for talk at the VIII International Conference on Stochastic Programming, Vancouver (August). Perold, A. 1999. "Long-Term Capital Management, L.P.C.” Harvard Business School case.

Pratt, John W. 1964. "Risk Aversion in the Small and in the Large." Econometrica, vol. 32, nos. 1-2 (January/April):122-136.

Rachev, Svetlozar. 2003. Handbook of Heavy Tailed Distributions in Finance. In Handbooks in Finance Series. Edited by William T. Ziemba. Amsterdam, the Netherlands: North-Holland Press. Available online at www.elsevier.nl/homepage/sae/ hf/menu.htm.

Rockafellar, R. Tyrell, and William T. Ziemba. 2000. "Modified Risk Measures and Acceptance Sets." Mimeo (July), University of Washington.

Lord Rothschild. 1978. Royal Commission on Gambling, Vols. I and II. Presented to Parliament by Command of Her Majesty (July). 
Roseveare, Deborah, Willi Leibfritz, Douglas Fore, and Eckhard Wurzel. 1996. "Ageing Populations, Pension Systems and Government Budgets: Simulation for 20 OECD Countries.” Organization for Economic Cooperation and Development (OECD) Economics Department Working Paper No. 168.

Ross, M.D. 1989. “Modelling a with-Profit Life Office.” Journal of the Institute of Actuaries, vol. 116:691-716.

Ross, Stephen A. 1999. "A Billion Dollars Just Isn't What It Used to Be.” Risk (May):64-66.

Rubinstein, Mark. 1973. "The Fundamental Theorem of Parameter-Preference Security Valuation." Journal of Financial Quantitative Analysis, vol. 8, no. 1 (January):61-69.

Rudolf, Markus, and William T. Ziemba. 2004. "Intertemporal Surplus Management.” Journal of Economic Dynamics and Control, vol. 28, no. 5:975-990.

Samuelson, Paul A. 1969. "Lifetime Portfolio Selection by Dynamic Stochastic Programming." Review of Economics and Statistics, vol. 51, no. 3 (August):239-246.

1970. "The Fundamental Approximation Theorem of Portfolio Analysis in Terms of Means, Variances, and Higher Moments." Review of Economic Studies, vol. 37, no. 4 (October):537-542.

- 1989. "The Judgment of Economic Science on Rational Portfolio Management: Indexing, Timing and Long Horizon Effects." Journal of Portfolio Management, vol. 16 , no. 1 (Fall):4-12.

Schwartz, Sandra L., and William T. Ziemba. 2000. "Predicting Returns on the Tokyo Stock Exchange." In Security Market Imperfections in World Wide Equity Markets. Edited by Donald B. Keim and William T. Ziemba. Cambridge, U.K.: Cambridge University Press:492-511.

Sharpe, William F. 1994. “The Sharpe Ratio.” Journal of Portfolio Management, vol. 21, no. 1 (Fall):49-58.

Shiller, Robert J. 2000. Irrational Exuberance. Princeton, NJ: Princeton University Press.

Shleifer, Andrei. 2000. Inefficient Markets: An Introduction to Behavioral Finance. Oxford, U.K.: Oxford University Press.

Siegel, Jeremy J. 2002. Stocks for the Long Run: The Definitive Guide to Financial Market Returns and Long-Term Investment Strategies. New York: McGraw-Hill Trade.

Smith, Edgar Lawrence. 1924. Common Stocks as Long Term Investments. Kila, MT: Kessinger Publishing Company.

Snyder, Wayne W. 1978. "Horse Racing: Testing the Efficient Markets Model.” Journal of Finance, vol. 33, no. 4:1109-18.

Solnik, Bruno, Cyril Boucrelle, and Yann Le Fur. 1996. "International Market Correlation and Volatility.” Financial Analysts Journal, vol. 52, no. 5 (September/ October):17-34. 
Sornette, Didier, and Wei-Xing Zhou. 2002. "The US 2000-2002 Market Descent: How Much Longer and Deeper?” Quantitative Finance, vol. 2, no. 6 (December):468-481.

Spurgin, Richard B. 2001. "How to Game Your Sharpe Ratio." Journal of Alternative Investments, vol. 4, no. 3 (Winter):38-46.

Stone, Douglas, and William T. Ziemba. 1993. "Land and Stock Prices in Japan." Journal of Economic Perspectives, vol. 7, no. 3 (Summer):149-165.

Stulz, Rene M. 1996. "Rethinking Risk Management." Journal of Applied Corporate Finance, vol. 9, no. 3 (Fall):8-24.

Swensen, David F. 2000. Pioneering Portfolio Management: An Unconventional Approach to Institutional Investments. New York: The Free Press.

Thaler, Richard H., and William T. Ziemba. 1988. "Anomalies: Parimutuel Betting Markets: Racetracks and Lotteries." Journal of Economic Perspectives, vol. 2, no. 2 (Summer):161-174.

Thorp, Edward O. 1962. Beat the Dealer. New York: Random House.

- 1997. "The Kelly Criterion in Blackjack, Sports Betting and the Stock Market." Mimeo. Paper presented at the 10th International Conference on Gambling and Risk Taking, Montreal (June). Available online at www.bjmath.com/bjmath/thorp/ paper.htm

Tobin, James. 1958. "Liquidity Preference as Behavior Towards Risk." Review of Economic Studies, vol. 25, no. 2 (February):65-86.

Tompkins, Robert G., William T. Ziemba, and Stewart Hodges. "The Favorite Longshot Bias in S\&P 500 Futures Options: The Return to Bets and the Cost of Insurance." Working Paper, University of British Columbia.

Turner, Andrew L., and Chris R. Hensel. 1993. "Were the Returns from Stocks and Bonds of Different Countries Really Different in the 1980s?" Management Science, vol. 39, no. 7 (July):835-844.

Viceira, Luis M. 2001. "Optimal Portfolio Choice for Long-Horizon Investors with Nontradable Labor Income.” Journal of Finance, vol. 56, no. 2 (April):433-470.

Warburton, Arthur, and Zhe George Zhang. 2002. "A Computational Model for Analyzing the Properties of Stop-Loss, Take-Profit and Price Breakout Trading Strategies.” Working paper, Simon Fraser University.

Winklevoss, Howard E. 1982. "PLASM: Pension Liability and Asset Simulation Model." Journal of Finance, vol. 37, no. 2:585-594.

Zenios, Stavros A., and William T. Ziemba. 2004. Handbook of Asset-Liability Management. In Handbooks in Finance Series. Edited by William T. Ziemba. Amsterdam, the Netherlands: North-Holland Press (in press).

Ziemba, Rachel E.S. 2003. Importing Monetary Stability: An Analysis of the Dollarization Trilemma. MPhil thesis, St. Antony's College, Oxford University. 
Ziemba, William T. 1974. "Choosing Investment Portfolios When the Returns Have Stable Distributions." In Mathematical Programming in Theory and Practice. Edited by Peter Hammer and Guss Zoutendijk. Amsterdam, the Netherlands: North-Holland Press:443-488.

1994a. "Investing in the Turn of the Year Effect in the Futures Markets." Interfaces, vol. 24, no. 1 (January-February):46-61.

1994b. "Worldwide Security Market Regularities." European Journal of Operational Research, vol. 74, no. 2 (April 28):198-229.

_ 2000. "The Stochastic Programming Approach to Hedge Fund Disaster Protection." Presentation to the Centre for Financial Engineering, National University of Singapore (February).

Ziemba, William T., and Donald B. Hausch. 1986. Betting at the Racetrack. New York: Norris M. Strauss.

- 1987. Beat the Racetrack. 2nd. ed. New York: William Morrow. First published in 1984, San Diego, CA: Harcourt, Brace, Jovanovich.

Ziemba, William T., and J.M. Mulvey. 1998. Worldwide Asset and Liability Modeling. Cambridge, U.K.: Cambridge University Press.

Ziemba, William T., and Sandra L. Schwartz. 1991. Invest Japan. Chicago, IL: Probus Professional Publishing.

1992. Power Japan: How and Why the Japanese Economy Works Chicago, IL: Probus Professional Publishing.

Ziemba, William T. and Raymond G. Vickson. 1975. Stochastic Optimization Models in Finance. San Diego, California: Academic Press.

Ziemba, William T., Abdulkadir Akatay, and Sandra L. Schwartz. 1979. Turkish Flat Waves. Scorpion Publishing, London and Yoruk Carpets and Kilims, Vancouver.

Ziemba, William T., Celik Parkan, and F.J. Brooks-Hill. 1974. "Calculation of Investment Portfolios with Risk Free Borrowing and Lending." Management Science, vol. 21:209-222. 